\title{
TRANSFORMACIONES TERRITORIALES Y ANÁLISIS GEOGRÁFICO EN ÁMBITOS PATAGÓNICOS DE MONTAÑA.
}

\section{La Comarca Andina del Paralelo 42.}

Autor: Lic. y Prof. Conrado Santiago Bondel

Dirección: Dra. Nidia Tadeo

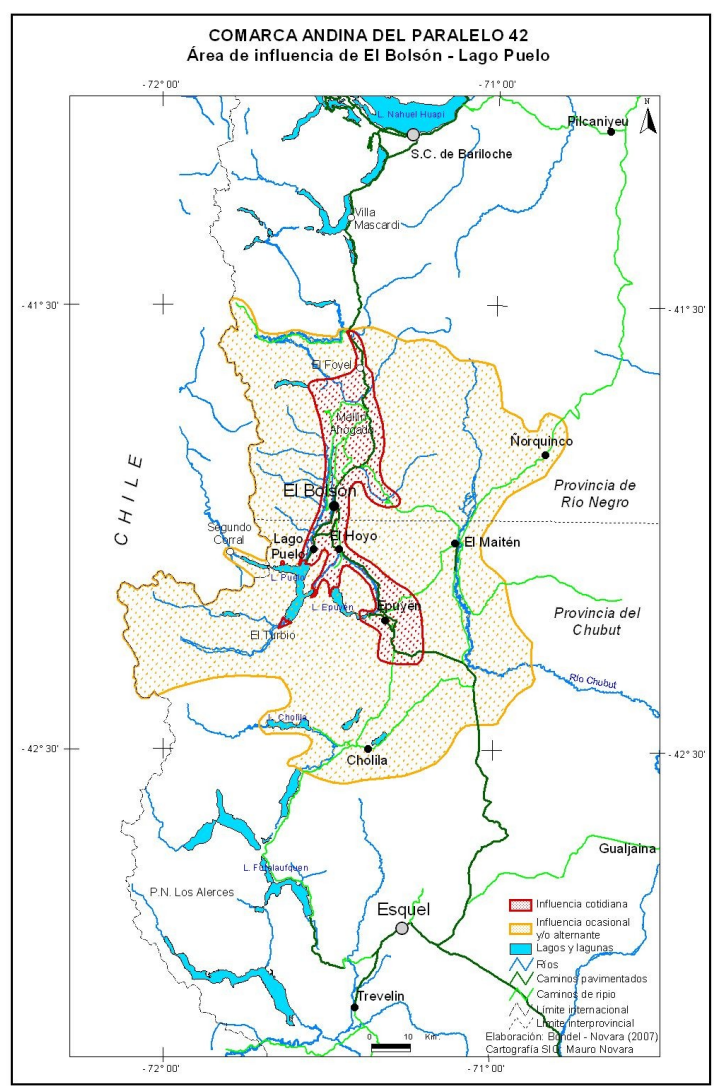

Tesis Doctoral en Geografía

Facultad de Humanidades y Ciencias de la Educación

Universidad Nacional de La Plata

La Plata, Provincia de Buenos Aires. Argentina 
TRANSFORMACIONES TERRITORIALES Y ANÁLISIS GEOGRÁFICO EN ÁMBITOS PATAGÓNICOS DE MONTAÑA ${ }^{1}$. La Comarca Andina del Paralelo 42.

INDICE:

\begin{tabular}{|l|l}
\hline PRÓLOGO Y AGRADECIMIENTOS & 3
\end{tabular}

\begin{tabular}{|l|r|}
\hline INTRODUCCIÓN & 5 \\
\hline
\end{tabular}

PRIMERA PARTE.

I. TEORÍA Y METODOLOGÍA.

I.1. Marco Teórico. Tipo de investigación.

La región en el espacio y el tiempo.

Territorio, paisaje y Geografía Cultural.

Paisaje y estructura.

Competencia territorial y territorios complementarios.

I.2. Metodología.

I.2.1. Antecedentes y contexto problemático.

I.2.2. Objetivos e hipótesis.

I.2.3. Método.

Método y estrategia metodológica.

I.3. Referencias bibliográficas.

SEGUNDA PARTE.

II. ÁREA DE ESTUDIO. LA COMARCA ANDINA DEL PARALELO 42 EN LA PATAGONIA ANDINA 'DE LOS LAGOS’ (ARGENTINA).

II.1. El contexto formal y funcional andino patagónico.

Lo formal.

Lo funcional.

II.2. La Comarca Andina del Paralelo 42. El área de estudio como entidad territorial.

II.2.1. Presentación y funcionalidad básica.

II.2.2. Aspectos bio-físicos relevantes de la geografía zonal.

La Comarca y su fisiografía.

II.2.2.1. El Clima, un 'participante' clave.

II.2.2.2. Indicios para una problemática establecida, el agua.

II.2.3. Aspectos geohistóricos dominantes de la territorialidad andino patagónica.

La perspectiva geohistórica

II.2.3.1. Cortes temporales.

a. 1895-1905, "vía libre"

b. 1930, "el afianzamiento"

c. 1960-70, "nuevas perspectivas.

d. 1985-1995, "un nuevo orden".

II.2.4. Perspectiva geoeconómica. Actividades y algunas cifras orientadoras.

II.2.4.1. Contexto económico general.

Sobre conectividad. La Comarca en el país y el mundo.

Inputs y Outputs de una Comarca bi-provincial.

Il.2.4.2. Principales actividades productivas a modo de inventario comentado.

Il.2.4.3. En definitiva, 'un mosaico colorinche'.

II.3. Referencias bibliográficas.

TERCERA PARTE.

III. EL ENFOQUE GEO-CULTURAL. HACIA INSTANCIAS PROSPECTIVAS.

III.1. Percepciones y comportamientos espaciales.

III.2. Sobre comportamientos y conflictos de esencia territorial.

Tipos sociales.

El poblador rural y sus comportamientos; tipologías.

III.3. Valoración de los impactos territoriales críticos por tipo de poblador, una matriz tentativa con proyección planificadora.

III.4. Referencias bibliográficas.

CUARTA PARTE.

\footnotetext{
${ }^{1}$ Para no generar falsas expectativas y por la propia y lógica imprecisión de los términos geológicos-geomorfológicos de escalas paisajísticamente significativas, se señala que el espacio de estudio general corresponde a la Patagonia Andina Central y Norte, en sus sectores argentinos, excluyendo otros ámbitos montanos de la región. La Comarca Andina del Paralelo 42 es tomada como estudio de caso.
} 


\begin{tabular}{|l|c|}
\hline IV. APORTES AL PLANEAMIENTO TERRITORIAL, HACIA LAS CONCLUSIONES. & 159 \\
\hline $\begin{array}{l}\text { IV.1. Aportes de índole regional-metodológica: la condición de competencia territorial, entre } \\
\text { capacidades y expectativas. Desenvolvimiento espontáneo versus desenvolvimiento consciente. }\end{array}$ & 159 \\
\hline Lago Puelo y la búsqueda de su perfil territorial como caso analítico. & 163 \\
\hline Capacidades y expectativas territoriales de pobladores de Lago Puelo. & 164 \\
\hline $\begin{array}{l}\text { IV.2. Aportes de índole regional-operativa: densificación urbana y territorios } \\
\text { complementarios, alternativas para replanteos en el espacio comarcal. }\end{array}$ & 168 \\
\hline IV.3. CONCLUSIONES Y REFLEXIÓN FINAL. & 174 \\
\hline Alcances & 174 \\
\hline Conclusiones & 175 \\
\hline REFLEXIÓN FINAL & 178 \\
\hline IV.4. Referencias bibliográficas. & 179 \\
\hline V. ÍNDICE DE MAPAS, FIGURAS, TABLAS, CUADROS Y FOTOGRAFÍAS. & 181 \\
\hline VI. APÉNDICES. & 183 \\
\hline
\end{tabular}

\section{PRÓLOGO}

Esta tesis tiene varios antecedentes, pero merece destacarse que comenzó a gestarse con dos proyectos de investigación llevados adelante desde el Departamento de Geografía de la Facultad de Humanidades y Ciencias Sociales de la ciudad de Comodoro Rivadavia entre los años 1999 y 2006. Podría decirse que, a pesar de las grandes distancias patagónicas, el espíritu regional que le es propio a la Universidad Nacional de la Patagonia San Juan Bosco, contribuyó a enfrentarse con un espacio andino de particular proyección socio territorial.

Más atrás en el tiempo con Abelardo de Almeida y entre 1994 y 1996, ya habíamos incursionado en una descripción sistemática comarcal con resultados que, se diría, mostraron una realidad compleja y muchas veces conflictiva. Pero fue a partir de consensuar con Nidia Tadeo en el Departamento de Geografía de la Universidad Nacional de La Plata, en que era oportuno trabajar sobre la Comarca en un contexto teórico riguroso y desde la identificación de sus problemáticas, cuando las transformaciones territoriales actuaron de Norte para ocuparnos del análisis geográfico en su doble faz, teórica y aplicada.

Así, entonces, las hipótesis planteadas lo fueron desde la visión integral de un espacio condicionado y sujeto a una resuelta evolución socio-territorial, donde lo cultural se muestra decisivo a la hora de pretender alcanzar explicaciones y en el que, entendemos, la experiencia personal de compartir 25 años de vida profesional como geógrafo, sumó un ingrediente activo y comprometido con la tarea.

Vale agregar la motivación generada a partir de la singularidad destacada que le cabe a la Comarca para con la geografía de las regiones argentinas. Son territorios de colonización moderna, poco consolidada, en la montaña boscosa templada-fría, de paisajes extraños a las tradicionales modalidades argentinas y que hace ya unos cuarenta años se manifiestan como destino deseado (del imaginario argentino) y buscado por miles de personas. Se trata de territorios en plena gestación identitaria, donde es habitual lo dubitativo y confuso, aún desde perspectivas históricas y literarias, que son en las que normalmente se asientan las raíces regionales.

Simplemente apuntamos a contribuir con una profunda lectura de este medio, a sabiendas que de ser así, la instalación humana regional, incluso en otras comarcas andino patagónicas, tendrá mayores posibilidades de acrecentar el espectro de discusión científica a favor de alcanzar un desarrollo territorial progresivamente armonioso.

El Hoyo, Chubut. 5 de noviembre de 2008

\section{AGRADECIMIENTOS.}


Como es normal que suceda muchas veces, se deja para el final del trabajo este ítem tan importante, es decir cuando tal vez los recuerdos más lejanos estén algo borroneados, en especial cuando, como en este caso, la tesis llevó varios años de elaboración, entremezclándose con un buen número de actividades académicas de variado tipo. Como se entenderá además, el haber trabajado sobre una comunidad, la de la Comarca Andina del Paralelo 42, en toda su complejidad territorial, incluyó consultas y diálogos con un número muy grande de personas, fuera en la formalidad académica y científica tanto como en la informalidad del trato corriente. A todos ellos, familiares, amistades, vecinos y profesionales (algunos de otras zonas argentinas) mi agradecimiento sincero. Sin su aporte, esta geografía no hubiera sido posible.

De todos modos destaco mi máximo reconocimiento a la Doctora Nidia Tadeo, quien además de reunir la suficiente paciencia, se interesó y respaldó, profunda y metódicamente, la evolución de la tesis desde su planteo inicial arrancando el año 2004. También la mayor gratitud para mi compañera Catalina Lew, con quien compartimos observaciones a lo largo y ancho de la Comarca además de ricos debates cuyos alcances han resultado poco menos que estructurales en esta tesis.

Un agradecimiento especial a los colegas de la U.A.T.A., Esquel: María Marta Novella, Gabriela Demarchi, Oscar Alfredo Martínez, Carlos Baroli, Francisco Caravelli, Gabriela Arrieta, Christine Danklmaier y Adriana Kutschker, con quienes hemos trabajado entorno a varias de estas temáticas, no sólo en lo teórico sino también en la práctica territorial concreta. Al amigo y colega Mauro Novara, en particular por su aporte cartográfico; a los colegas y amigos Zuly Lires y Carlos Rojo, por su apoyo manifiesto para sostener la iniciativa; a Fernando Ottone, que permitiera el uso de sus magníficas fotografías; a Hernán Mattioli quien mejoró varias figuras; a Guillermo Scartascini y Mariana Pelissari, con quienes conllevamos múltiples y sumamente ilustrativas instancias de su experiencia productiva rural, y a mi hermana Mónica, quién 'le pasó el rastrillo' al borrador final.

En lo institucional le debo a la Universidad Nacional de la Patagonia San Juan Bosco, y en particular a la Facultad de Humanidades y Ciencias Sociales, su respaldo pleno con la iniciativa; a la Universidad Nacional de La Plata en su Facultad de Humanidades y Ciencias de la Educación, que me ha permitido ser su doctorando y desarrollar mi tarea en clima de excelencia académica; a la Asociación Gremial Docente de la UNPSJB, por sus aportes económicos en materia de viajes y capacitación, y a la Fundación Cooperar de El Bolsón que, presidida hasta hace unos meses por Chapi D'Alotto, permitió el fortalecimiento del lazo entre las investigaciones llevadas adelante y la comunidad comarcal.

\section{INTRODUCCION}


Lejos de ser una elección casual, el estudio de las transformaciones territoriales para con esta parte del país obedece en especial a dos circunstancias, que aunque sin duda emparentadas, son de distinta índole. La primera se vincula con la investigación geográfica y lo que entendemos como su potencial trascendencia teórica y práctica en contextos académicos y profesionales interesados por los ámbitos montañosos y las singularidades en la instalación humana. Es el interés por acompañar intelectualmente a los procesos transformadores de una realidad compleja y atrayente $y$, que por momentos no da respiro a la observación sistemática y planteos científicos. La segunda está ligada a la simple inquietud profesional y, si se quiere, comprometida curiosidad por el devenir del Sur argentino. Inquietud que se corresponde con el desenvolvimiento incierto de las comarcas andino patagónicas frente a incesantes hechos, propuestas y proyectos referentes a aspectos de decisiva impronta regional. Situaciones novedosas involucradas con los usos del territorio, insinuadas desde la década de los años $1960^{2}$ y fuertemente potenciados desde mediados de los ' $90^{3}$.

Estamos ante territorios en plena gestación identitaria, donde lo dubitativo y confuso del desenvolvimiento se presenta a la orden del día, aún desde perspectivas históricas y literarias que son en las que normalmente se asientan las raíces regionales. Un espacio cordillerano estrecho y extenso con casi dos mil kilómetros en sentido meridiano, su vertiente oriental mayormente argentina y la occidental, chilena ${ }^{4}$.Tierras de semblante dicotómico, por un lado misteriosas e inconexas y por el otro con la concreta imagen como reborde montañoso de la lejana y excéntrica Patagonia.

Resulta ilustrativo el comentario de Livon Grosman cuando escribe, "La Patagonia, cualesquiera sean sus límites (...), ha sido desde su primera inscripción en las narrativas de viaje una zona maleable para el imaginario europeo primero y el criollo después" (2003: 9). Andermann (2005) lleva el tema hacia lo político cuando en una entrevista afirma, “... Hay una construcción hacia atrás y hacia adelante, porque la Patagonia siempre se construye como un espacio potencial. (...). "...la Patagonia es una fuente simbólica del poder estatal y de la reproducción y renovación de ese poder" (El subrayado es propio). Y finalmente, hasta la condición montañosa del paisaje, afín en su esencia a cierta visión romántica, aquella de lo sublime, del paisaje

\footnotetext{
${ }^{2}$ Analizados minuciosamente por Wolfgang Eriksen, geógrafo de la Universidad de Bonn, quien orientó su tesis doctoral desde la perspectiva de la kulturgeographishe. Lamentablemente esta tesis y varios artículos importantes permanecen sólo en idioma alemán y con ello bastante alejada de la discusión científica regional (cf.: Eriksen, 1970 y 1979).

${ }^{3}$ Cf. entre otros Bondel y de Almeida, 1996; Abalerón, 1995 y 2006, Esquel-Seas, 2001, Zingoni, et ali, 2006.

${ }^{4}$ Incluso los enfoques históricos y geográficos tradicionales, sostenidos en una visión centrípeta de unificación nacional argentina frente al desprendimiento fronterizo (Daus, 1978: 28-41), se ven hoy cuestionados por otros que destacan la necesidad de rescatar la unidad territorial andinopatagónica (Bandieri (b), 2005), que, por otra parte, también es materia de discusión en materia etnográfica. Ver a modo de ejemplo; Casamiquela, duro con los mapuches que lo "escrachan"; (2005) o en Ricardo Nardi, sobre la funcionalidad cordillerana (1990: 243-273).
} 
vertical con el que no se concilia Ortega y Gassett (1970:172) y que Thomas Mann lleva a lo mágico, promueve una trama analítica contradictoria.

Así, con contados antecedentes que traten en cierto detalle aspectos relacionados con la configuración geográfica prevalente, es decir con la intrincada y dinámica gama de situaciones territoriales vinculadas con la instalación humana, puede afirmarse que los Andes Patagónicos todavía hoy se identifican básicamente por sus rasgos naturales y su condición fronteriza en los confines australes sudamericanos. Incluso, como se verá en la Segunda Parte de esta tesis, la localización y delimitación precisa de esta área singular, no resulta una tarea sencilla. En definitiva, esa figura tenue, de escaso detalle y promotora de malentendidos geográficos, continua siendo destinataria de estrategias específicas de gestión territorial y con ello, cabe preguntarse por sus resultados.

Como recién se afirmó, en los recientes años '90 y en concordancia con los ajustes propios del nuevo orden mundial sostenido en una estructura económica y política de tipo neoliberal y sus convenientes especializaciones o acomodamientos territoriales a escala global $^{5}$, se observan, de modo análogo con otros sectores del país, reacomodamientos locales inscriptos en modalidades que obligan a la revisión profunda ${ }^{6}$. Modalidades post modernas, conformes para nuestro caso con lo que puede identificarse en términos económicos como espacios de consumo y en coincidencia, claro está, con situaciones concurrentes al llamado proceso de globalización y, diríamos, su 'derrame' cultural, económico y geopolítico.

Es justamente la condición cultural la que imprime nuevas valoraciones espaciales. Valoraciones con fuertes proyecciones anímicas enraizadas en lo simbólico y lo estético. De hecho la Patagonia fue un objeto de culto, un símbolo, en los discursos políticos y manifestaciones populares de raíz argentina durante casi todo el Siglo XX. Hoy, sin embargo, la cuestión nacional juega un rol secundario frente a un desenvolvimiento ajustado a circuitos culturales diversos y donde las transformaciones se suceden a partir de una resignificación simbólica de la naturaleza. Reza un logo presentando a El Bolsón: donde lo natural se vuelve mágico. A esto suma lo estético y para valorar su influencia de cambio, nos viene la afirmación de Claval, “... A partir del momento en que el paisaje se convierte en un objeto de contemplación y en que es valorado por motivos estéticos, las relaciones de los grupos con el espacio cambian de naturaleza." (1999:268). También Guibert destaca el contraste con la visión exclusivamente productiva de un espacio agropecuario, afirmando en una entrevista

\footnotetext{
${ }^{5}$ Con rasgos singulares, pero en la generalidad de los procesos, se verá más adelante el significativo desenclave regional andino patagónico (ver la concepción teórica de Desenclave en Labasse, donde afirma: "Se agrupan bajo el título de desenclave los intentos coherentes emprendidos por los poderes públicos para romper el aislamiento material y moral de zonas que quedarían en manos del estacionamiento económico o de la secesión política".(1973: 143).

${ }^{6}$ Sobre el tema en la Argentina se puede ver por ejemplo: en el Litoral a Tadeo et al (2006: 5-9y 199). En el Nororeste, García Lende et a / 2006:87:90).

${ }^{7}$ Ver en Gabriel Bautista que desarrolla el sentido general de los actuales procesos de frontera (2004).
} 
reciente las potencialidades de “...un espacio de descanso, de tranquilidad, de belleza..." (Diario Clarín, Bs. As.. 05/11/2006).

Cabrían aquí las reflexiones que Di Meo toma de Herin y siempre tratando de interpretar las relaciones entre espacio y sociedad, “... las relaciones entre las sociedades y el espacio se establecen en niveles de innegable complejidad, con el espacio como simple soporte material de los hechos sociales, hasta el espacio de las representaciones, los símbolos y el imaginario, pasando por el espacio producido o factor social...". En resumen, sugiere Di Meo, “...ja cada problemática su espacio!...” (1987: 565)

Es desde allí que hacemos planteos hipotéticos en busca de explicaciones, atendiendo principalmente a las valorizaciones que existen para con la Patagonia Andina. Aquellas que implican una preeminencia de los aspectos afectivos y emocionales por sobre los económicos, con el turismo como el vector principal de transformación y a cuyo derredor se entremezclan situaciones conflictivas. Un turismo que, muy lejos de ofrecer un panorama sencillo en espacios como el nuestro, se desenvuelve al modo de un mecanismo de recolonización, alimentado a la vez desde una percepción contradictoria sobre el papel de las condicionantes históricas culturales, políticas y naturales ${ }^{8}$.

Se plantea, entonces, un trabajo que busca esclarecer dudas a partir de la producción de conocimiento geográfico, si se quiere, con sentido 'examinador' de la realidad. Como señalan Chiozza y Carballo rescatando párrafos significativos de Dolfus, Harvey y Santos, “... Es preciso aceptar que no existen recetas establecidas para todo el universo-espacial, sino más bien metodologías y resignificaciones conceptuales que se pueden adaptar a nuestro objetivo central, la comprensión de la realidad social y su expresión en el espacio geográfico (2006: 49).

Fenómenos como los de dispersión, neo-ruralidad y fragmentación espacial, se muestran como los resultados más visibles en materia paisajística y con ello estamos ante un marco problemático, difícil y complejo (cf: en Rovira, 2004, en Tadeo, 2002 y Mikkelsen $(2005)^{9}$. Es mayormente lo que sucede, con diferencias históricas y de escala, en paisajes análogos del 'Viejo Mundo', donde los agrosistemas serranos tradicionales compiten con nuevas pautas de ocupación asociadas a una visión 'romántica' del paisaje (cf.: Ojeda Rivera, 2004).

\footnotetext{
${ }^{8}$ César Dachary, A. y S. Arnaiz Burne ofrecen un interesante y oportuno tratamiento para esta temática (2002). También resulta esclarecedor la proyección de la actividad turística en la Argentina que desarrolla Bertoncello (2002).

${ }^{9}$ Rovira (2004) toma caso trasandino de Puerto Montt, basado en una discusión teórica interesante respecto de una nueva ruralidad y nueva urbanidad y en la que se desarrollan ideas base en la materia de autores como Borja y Castell, 1997; Aguilar 2002; Monclús, 1996; Dematteis, 1996, Ferrás, 2000 y Janoshka, 2002. Tadeo se introduce en el tema percibido en la Argentina como una forma alternativa para mejorar la calidad de vida (contacto con la naturaleza, mayor tranquilidad), sea de manera permanente (residencia rural) o transitoria (turismo rural)... (2002: 33 y 39 ). Ver también los casos de despoblamiento y repoblamiento rural en Mikkelsen, quien tomo como caso de análisis al Partido de General Pueyrredón.
} 
Es éste el rumbo escogido, en que con la sistematización de una significativa cantidad de información involucrada y una fuerte carga empírica proveniente de la convivencia profesional de varios años con la mayor parte de los problemas abordados, se espera generar un aporte al cuerpo teórico de la Geografía preocupada por los ámbitos montanos y otro más significativo, tanto a la explicación geográfica regional como al Planeamiento y la Gestión Territorial.

Podrá parecer elemental, pero reforzando la premisa del párrafo anterior, debe destacarse que es ésta una geografía regional ocupada en particular de aquellos problemas con significación trascendente para la población involucrada en su espacio de acción; cerca de 230.000 habitantes en total. Con ello y en virtud de las manifiestas prevalencias de sesgo cultural, es que se recurrió básicamente al marco conceptual de la geografía cultural. Aquí, en terrenos poco explorados, se trata de llegar a la explicación de las circunstancias del presente, predominando, es cierto, la preocupación por advertir más los cómo que los por qué, que es desde donde entendemos que será posible generar un aporte para el tratamiento integral y multidisciplinario de los aspectos más conflictivos, y por supuesto, sus causas.

Desde nuestra perspectiva, apuntamos a tratar el conjunto territorial con el tamiz propio del análisis geográfico, dado que, como nos indica Hägerstrand, no hay forma de conceptualizar todo nuestro alrededor (ver Díaz Muñoz, 1994: 9). Estaremos conformes si se consigue ofrecer una perspectiva integradora confrontada con escenarios novedosos que, si bien no nos son exclusivos, desde nuestra disciplina pueden abordarse con la posibilidad cierta de orientar una importante cantidad de estudios sectoriales que ya se insinúan con firmeza, en particular por requerimientos políticos.

Finalmente, con la Comarca Andina del Paralelo 42 en el foco del análisis, la tesis se abocó al estudio de la realidad andino patagónica, identificando, sistematizando y valorando las problemáticas de estirpe territorial, en especial las conflictivas, como camino explicativo. Esto, a sabiendas además, que se trata de un ámbito vanguardista en muchos aspectos y con ello potencialmente sugerente en posibles transferencias hacia otros ámbitos de menor dinámica evolutiva ${ }^{10}$.

La Patagonia andina 'de los lagos' (Argentina), localización.

\footnotetext{
${ }^{10}$ La afirmación no es caprichosa. Si bien hoy ha perdido su carácter original y la realidad cotidiana ha desdibujado varias cuestiones, temas como la condición hippie, el municipio no nuclear, la feria regional de artesanos, la producción frutihortícola orgánica, la oposición sistemática a mega emprendimientos y tanto más, estuvieron instalados en la comarca desde hace ya más de 30 años.
} 
La delimitación de La Patagonia Andina 'de los lagos' en su sector argentino es materia de discusión. En realidad no existe un topónimo que agrupe con propiedad a este conjunto territorial en plena conformación. Su configuración geográfica apenas reúne ciertos atributos de cohesión interna; se diría que carece de la contundencia necesaria como para presentarse como un espacio diferenciado en su complejidad. Sin embargo, también es cierto que el común de la gente y por sus propios requerimientos, simplemente acepta la existencia de la Patagonia Andina como aquella parte montañosa y fronteriza del Oeste-Sudoeste nacional.

Con fines prácticos y adaptándonos a la mayor correspondencia formal y funcional posible de evaluar en las circunstancias actuales, tomaremos una delimitación de tipo convencional que se corresponde con una envolvente que agrupa, en un continuo, al límite internacional con Chile de los cuatro departamentos del Sudoeste neuquino, de la provincia de Río Negro y hasta su intersección con el limite sur del departamento Languineo en Chubut; de allí, siguiendo el mismo hasta dar con la demarcatoria del límite Este de la Zona de Frontera en Río Negro y Chubut (Decreto Nacional 887/94), donde se extiende hacia el Norte hasta su intersección con el límite de la provincia de Neuquén en Paso Flores. Completan la envolvente los límites orientales los departamentos neuquinos considerados cerrando con el de Aluminé (inclusive) al Norte. En total suman una superficie de $45.207 \mathrm{~km}^{2}$ y con una población de unos 230.000 habitantes (aproximación a partir de INDEC, 2001) ${ }^{11}$.

El Mapa 1 ofrece, entonces, la delimitación de esta entidad geográfica identificada como Patagonia andina 'de los lagos'; se incorporan también los límites tentativos de la Comarca Andina del Paralelo $42^{12}$.

En la Segunda Parte, desarrollaremos el tema con detalle, incluso involucrando las denominaciones histórico-regionales de peso como Comahue y Araucanía, y presentando además, la delimitación específica de la Comarca Andina del Paralelo 42.

\section{Organización del desarrollo temático (Las Partes).}

La Primera Parte se ocupa del contexto teórico-metodológico exponiendo los criterios teóricos utilizados en la generalidad de la tesis. Aquí, aunque luego se profundizan diferentes aspectos según el tema, es presentado tanto la esencia de las temáticas de estudio, como el estado actual de las cuestiones analíticas inherentes. En un primer anticipo, además, se identifican los problemas operativos clave, así como el grado de

\footnotetext{
11 Valga a modo de simple cotejo y con el absoluto cuidado de destacar el contexto geográfico e histórico 'incomparable', considerar que es ésta una superficie algo superior a los $41.200 \mathrm{~km} 2$ de la Confederación Suiza; donde residen unas 7.500.000 de personas.

12 Nótese que la Comarca en la actualidad, con matices que se desarrollan en el texto (Segunda Parte), involucra un pequeño sector en la República de Chile y una franja fuera de la 'Patagonia Andina de los lagos'.
} 
precisión esperable y las potencialidades en cuanto a la consecución de estudios territoriales.

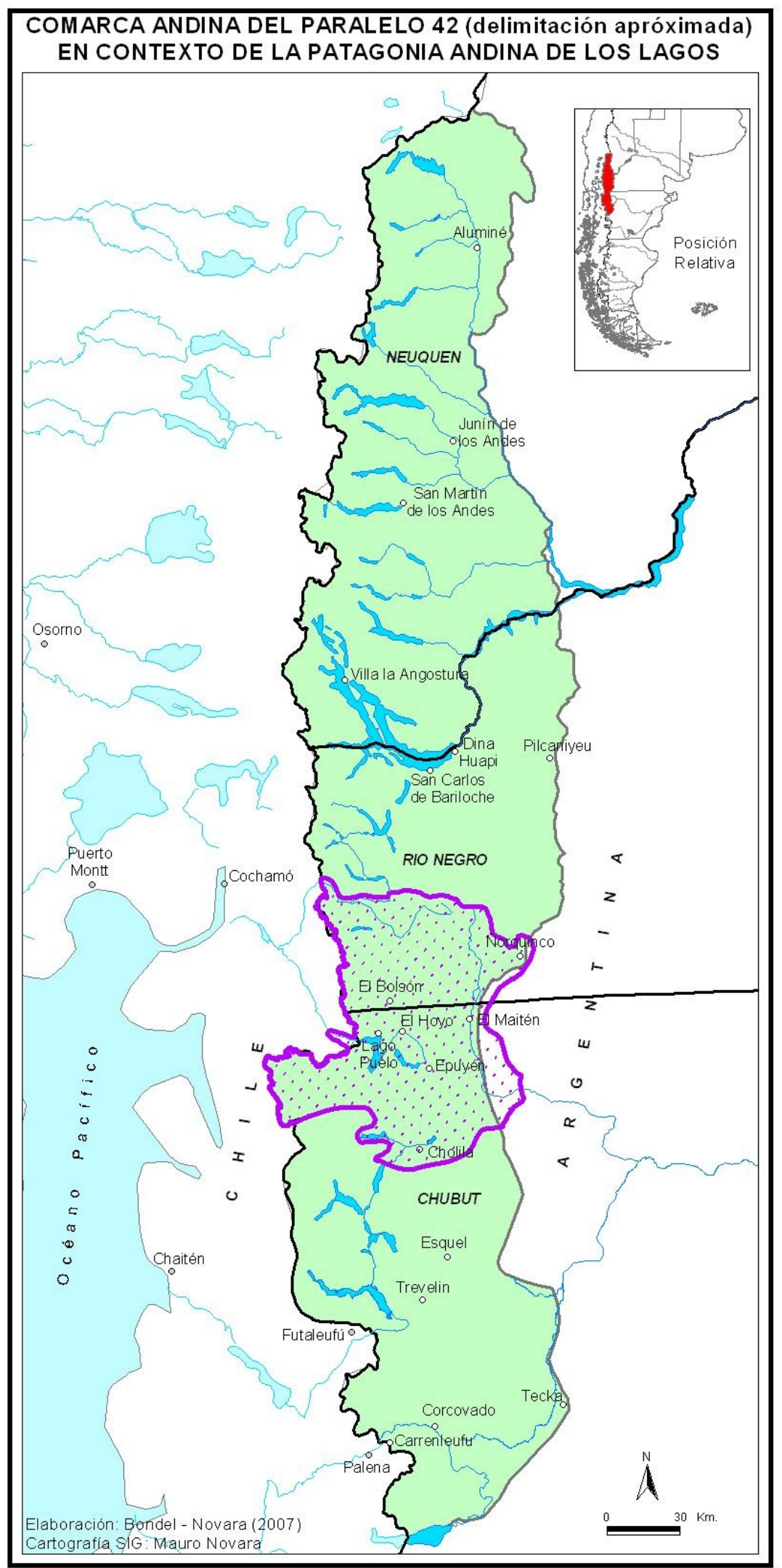

Mapa 1: La Comarca en la Patagonia Andina. Obsérvese que la superficie se extiende hacia el Este en la Patagonia esteparia, así como presenta un pequeño apéndice en territorio chileno. Debe valorarse la movilidad de esta delimitación comarcal basada en aspectos geo-funcionales (ver en II.2.1.). 
La Segunda Parte responde a la presentación sistemática del área de estudio específica, aquella que se toma como unidad de análisis espacial, es decir La comarca andina del Paralelo 42 (en adelante, la Comarca). Se trata del análisis desde una visión problemática, donde, desde su lugar en el imaginario colectivo y sus simples condiciones de sitio y posición, se entremezclan con las circunstancias fundamentales del medio natural, evolución geohistórica y funcionalidad geoeconómica.

Convendrá aclarar que, si bien se presenta una importante información de base, tanto bio-física como socioeconómica y cultural, no será éste un desarrollo que cubra el tipo de expectativas que pudiera suponer una monografía geográfica descriptiva a la usanza tradicional, si bien posiblemente la tesis pueda servir de referente inicial ante la búsqueda de condiciones de detalle de los parajes, con sus pueblos, ríos, montañas, recursos y tanto más. Nuestras inquietudes teóricas, metodológicas y regionales, además de estar orientadas en una demanda social visible y recurrente, hicieron foco primordialmente en las transformaciones territoriales ${ }^{13}$.

En la Tercera Parte privan dos instancias centrales para la tesis, por un lado la aplicación de un enfoque geo-cultural concentrado en las percepciones y comportamientos y por el otro, la proyección metodológica para el trabajo analítico de sesgo prospectivo. Con el paisaje como figura analítica principal, las percepciones y comportamientos trascendentes en el espacio serán las principales cuestiones atendidas, arribando a propuestas de tipo tipológico y matricial con avances en la comprensión de los dinámicos y muchas veces conflictivos usos del suelo.

Previo a las Conclusiones, la Cuarta Parte se introduce en el cruce de capacidades y expectativas, dos cualidades territoriales decisivas a la hora de tratar las situaciones andino patagónicas más críticas y enlazadas con las hipótesis iniciales. Se tratan temas complejos y se los enfrenta a partir del análisis sostenido en conceptos que dimos a llamar competencia territorial y territorios complementarios. En base a ellos, finalmente, se presentan propuestas metodológicas de corte regional como camino de interpretación de la organización espacial en la región y/o ámbitos análogos.

\footnotetext{
${ }^{13}$ Cabe indicar que aún cuando en la región escasean aquellas monografías descriptivas-explicativas que cubren buena parte de nuestro país y que, dicho sea de paso, en ámbitos académicos priva cierto reparo generalizado hacia ellas, seguramente serían de concreta utilidad a la hora de enfrentarse con situaciones en escalas conformes.
} 


\section{PRIMERA PARTE}

\section{TEORÍA Y METODOLOGÍA}

\section{I.1 Marco Teórico.}

Tipo de investigación

Esta tesis es producto de un prolongado proceso de investigación y, como tal, la determinación de su carácter básica o aplicada, permite alguna discusión. Espontáneamente podría asimilarse a los estudios aplicados dado que al referirse a un espacio definido ${ }^{14}$, surge la eventual aplicabilidad de los conocimientos producidos. Pero el proyecto también supone su búsqueda simplemente para resolver, como diría Samaja, enigmas que se le plantean a nuestra conciencia (2004:23) y con ello estaremos originando conocimientos por sí mismos, es decir relacionados con la investigación de tipo básica. Presentado el dilema, nos auxilian Molina de Buono y Furlani de Civit con sus reflexiones metodológicas de sesgo territorial cuando señalan, “... En síntesis, las diferencias entre la investigación básica y la aplicada son mayores en el punto de partida y en el de llegada que en el método...". En el mismo capítulo se esquematiza la distinción entre la investigación básica pura y la básica orientada, y que permite ubicar a nuestro trabajo en el segundo tipo. Podría afirmarse que, el contar con esa característica de 'acomodarse' a fines vinculados con la práctica la engloba en las investigaciones aplicadas (fig. 1). La orientación, entonces estará ligada a las comprobaciones de las hipótesis, hacia el destino preeminente que, en nuestro caso y en un todo, contribuyen a la generación diagnóstica, es decir hacia el caso singular (2005: 51-55).

Es con este soporte y evadiendo poner lo básico y aplicado a modo de contracara, que ubicamos esta tesis en el marco de las investigaciones básicas orientadas, puesto que así como emerge (punto inicial) desde una demanda social contundente y que de nuestros avances se obtendrán diagnósticos territoriales, se aspira también a que éstos tengan diversos tipos de utilizaciones técnicas o prácticas (uno de los principales puntos de llegada).

\footnotetext{
${ }^{14}$ La Patagonia Andina en general y la Comarca Andina del Paralelo 42, en particular.
} 


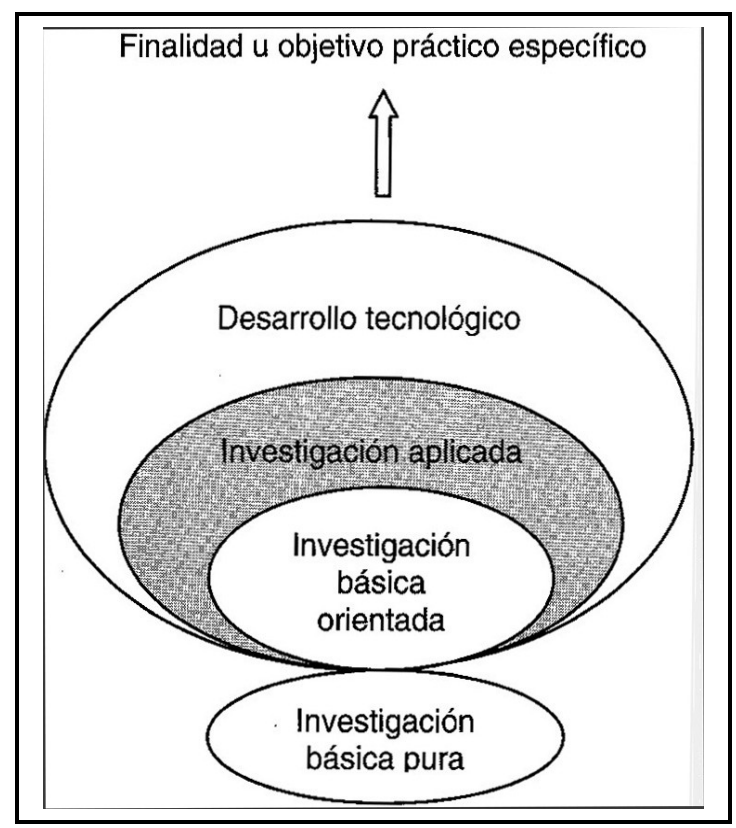

Fig. 1: La investigación aplicada en el conjunto de actividades científicas. Tomado de Molina de Buono (2005: 54) donde cita a Díaz (1997:104)

La región, el espacio y el tiempo.

Pues bien, como podría esperarse en estudios ocupados por las transformaciones territoriales de un espacio definido, será con los enfoques propios de la geografía regional desde donde arraigue su análisis, si se quiere, desde aquella tradición idiográfica que busca en el cuerpo nomotético alcanzar una visión sistemática y sintética del territorio. Es allí, entonces, en la geografía de los lugares y los paisajes, la del espacio geográfico singular, que estará la raíz teórica y metodológica del trabajo. Sin embargo, a la hora de ser precisos, habrá que mostrar cierta prudencia y hacer algunas aclaraciones pertinentes. El hecho de vivir en tiempos de extraordinaria dinámica, de que no haya sorpresas si se habla de cualquier mudanza, del Planeta Nómada (Knafou, R., 1997), de la era de los nómades y las tribus (Maffesoli, 2005) o de la virtualidad del ciberespacio (Buzai, 2003), nos obliga a ser cautos para no caer en planteos inconducentes. Es que en cierta forma ocuparse de la geografía regional resulta paradójico, puesto que vivimos en circunstancias propias de aquello que podríamos denominar, tiempos y espacios de incertidumbre y cuando el mismo concepto sostenedor de la rama disciplinar, la región, está en medio de un debate importante (cf: Ortega Cantero, 1988: 69-73; Santos, 1996: cap. 4; Rentería Vargas, 2001; Buzai, 2000) ${ }^{15}$.

La región, aquella unidad de análisis de difícil precisión conceptual, pero de tanto arraigo en el devenir territorial de los pueblos y que con Hartshorne alcanzara entidad

\footnotetext{
${ }^{15}$ No nos referimos a la discusión sobre el uso específico del término región y su adecuada aplicación en el análisis geográfico sino, en especial a las posibilidades que tienen las estructuras espaciales de sostenerse diferencialmente en el tiempo (Santos, 1996:45-48; Albet, 2001).
} 
científica para incorporarse con fortaleza en el análisis geográfico, nuevamente hoy y sin dejar de ser una rama disciplinar obligada a la hora de considerar espacios concretos, su término definitorio devino en el terreno de la duda, el de la vacilación analítica. Ocurre que la realidad contemporánea impone condiciones de agitación restrictivas en la búsqueda de certezas, en el delimitar a cada espacio o encontrar esencias territoriales identitarias. El trabajo científico, aquel que se debe a procesos metódicos para arrimarse al conocimiento verídico, actualmente se encuentra en terrenos novedosos. Interrogado Hägerstrand sobre una satisfactoria definición para el concepto de región nos dice, “... En algunos casos es muy clara, por supuesto. Particularmente en Geografía Física, (...). Pero tan pronto como entramos en el mundo humano de hoy, las interacciones son tan difusas que no se puede regionalizar excepto de una manera puramente convencional...". Y afirma luego, contrastando con las enormes diferencias de movilidad en tiempos en que “... las ideas de Vidal de la Blache, como la de Género de Vida, le permitieron llegar a unas bellas regionalizaciones...". Este reconocido geógrafo sueco, propulsor inicial de las investigaciones de relación espacio-tiempo-comportamientos, sostiene que la geografía regional puede plantearse desde otra perspectiva, con el Tiempo como partícipe fundamental y con las áreas locales (micro-entidades) como punto de partida en la búsqueda de analogías y diferenciaciones ${ }^{16}{ }_{-17}$. Sus dioramas con representaciones espacio-temporales no sólo localizan, sino que ayudan a explicar, a “...aprender como funciona (un área) introduciéndose en terrenos propios de los comportamientos, teniendo presente como condicionante a la realidad física y biológica y con la tecnología como contacto entre nuestras mentes y el mundo físico. (Díaz Muñoz, 1994:7-15) ${ }^{18}$.

Santos es aún más contundente y, en su análisis crítico afirma, “...Los cambios que el territorio experimenta en sus formas de organización, terminan por invalidar los conceptos heredados del pasado y obligan a renovar las categorías de análisis". Rematando enseguida “...Pero, mientras los procesos modernos de producción se extienden por todo el planeta, la producción se especializa regionalmente. (...) Cualquier parte del globo adquiere una nueva connotación cada vez más abierta, más vulnerable a las influencias exógenas. Las crecientes relaciones con áreas cada vez

\footnotetext{
${ }^{16}$ Resultan ilustrativas las consideraciones que Hartshorne rescata de Platt ante la discusión sobre la validez de los estudios micro-geográficos. La geografía microscópica (...) se desarrolló como actitud racional y oportuna contra las limitaciones de la compilación de sillón de información promiscua (...). Para lograr estos propósitos los geógrafos fueron al terreno y en el terreno todos los geógrafos son microscópicos. Concluyendo "...generalizaciones precisas para regiones mayores requieren de un examen del complejo total fundamental de rasgos interrelacionados que puede ser examinado en detalle sólo en áreas pequeñas". (1984: 212-213). En nuestro medio Analía Conte (1981), retoma con una estancia bonaerense y desde la geografía histórica, una de las unidades de análisis originales de Platt.

${ }^{17}$ David Robinson desde su especialidad en geografía histórica latinoamericana, plantea dudas sobre las bondades de la especialización profesional en lo micro. (Ver en Revista Meridiano, 1996)

${ }^{18} \mathrm{Al}$ respecto ver el ilustrativo y consistente artículo que desarrolla Díaz Muñoz (1992: 15-44).
} 
más alejada suprimen las veleidades de la autonomía. No se puede, pues, considerar la región como autónoma...." (1996: 45-6).

Para evitar confusiones innecesarias a las que nos puede llevar utilizar el término región, para el caso lo evitamos, aún con su validez, ya que no nos estaríamos refiriendo strico sensu a una región geográfica sino de un territorio diferenciado y complejo dentro de un ámbito regional; lo que Cóccaro llama 'recorte territorial' (2002: 194).

Esta falta de integridad espacial también se observa si acudimos a la concepción regional genérica, es decir eludiendo el conjunto geográfico como tal. Sirva de ejemplo la que asume Arnaiz Burne para el turismo, para quien en un contexto espacial relativista y a partir de la lectura de un mundo que se contrae permanentemente, la región turística sugiere un territorio sin fronteras, tomándolas como nuevos sistemas abiertos cuya centralidad es un destino turístico (2006).

A todo esto, se debe insistir en el rol ineludible que juega el tiempo en el análisis regional, en particular con sentido dinámico, aquel que permite remontar y proyectar procesos $\operatorname{concretos}^{19}$. La sujeción dinámica (en el sentido de devenir) imprime entonces a la propia definición espacial, una condicionante temporal que, así como la hace más cercana a la realidad, también puede caer en una veloz obsolescencia. Claro que también de esa visón dinámica obtendremos los 'datos' de lo estable, de lo que permanece, activo muchas veces y otras en estado de latencia, tal vez hasta en la memoria 'residual' de los pueblos. Como ignorar, por fin, que el recorrido temporal y la precisión de la definición de unidades espaciales (zona, región, etc.) puede flaquear en el mismo momento de definirse.

Como se sabe, el tema del tiempo espacial, al decir de Chiozza y Carballo, es uno de los grandes contenidos de la Geografía, más aún cuando se lo lleva al plano de la geografía regional (2006: 85-89), al ideográfico, donde simplemente resulta estructural, aún en términos de la heterogeneidad de tendencias geográficas (Bozzano, 2004:20). Nos dice Cóccaro tomando el sur cordobés como caso tipo, "... Así, si el recorte territorial contextualizado, al que dirigimos nuestra preocupación de análisis y comprensión de sus problemas territoriales actuales para la búsqueda de respuestas (...), el apelar al ejercicio de la memoria territorial nos involucraría en la detección de los ejes históricos directrices de las tendencias de valorización espacial (...), y nos obligaría a seleccionar ciertas secuencias de su 'producción histórica', alimentadas por una representación del proceso de su organización definida por la reconstrucción del

\footnotetext{
${ }^{19}$ Sin avanzar en un debate sobre la condición de universales y necesarios que Kant le asignaba al tiempo y el espacio como posibilitadores de la percepción, creemos que resulta muy convincente su interdependencia en materia geográfica (al respecto, ver la interesante discusión en Lecturas de Kant en Freud y Bretano. Acerca del tiempo y el espacio (Acuña, C.: 2005: 159-167). Ver también en Pickenhayn (1994: 24)
} 
pasado en base a las necesidades del presente y descubrir tendencia (2002: 195). También en ese sentido resume Randle, “... En rigor no se trata de la abstracción tiempo, sino más bien de la forma que éste tiene de encarnarse en la realidad espacial, como movimiento, o bajo la forma del cambio, que con sus fases sucesivas teje una suerte de historia" (1978: 77). Es el soporte geo-temporal que, a modo de 'riel guía', acompaña el análisis, llevándonos muchas veces y en función del presente a la proyección, hacia la prospectiva. Vale la advertencia de Gaignard, “...podemos asegurar que todo hecho geográfico está cargado de pasado, pero mucho más de porvenir." (1968: 215).

Territorio, paisaje y Geografía cultural

Nos dice Sassone, luego de puntualizar referencias de Claval sobre contrastes culturales en el espacio geográfico, "...En la medida en que el recuerdo de las acciones colectivas se enlaza con los caprichos de la topografía, con las arquitecturas, o con los monumentos creados para sostener la memoria de todos, el espacio se convierte en territorio y entonces el espacio es vida" (2001). Con ese sentido general y en la complejidad de sus transformaciones, es que hemos tomamos al territorio en cuestión, la Patagonia Andina, como el objeto de análisis.

Atendiendo como estructurales a los conceptos de territorio y paisaje en nuestra explicación, cabrá acordar algunos significados conceptuales y habituales que confluyen en el espacio geográfico. Se señala que a partir de la revisión de una extensa producción científica que debate el peso conceptual de lo territorial y el paisaje en geografía ${ }^{20}$, evitando una discusión que nos desviaría de nuestros propósitos analíticos, en esta tesis se han adoptado los significados que se muestran en el recuadro que sigue.

\section{Términos clave y sus significados adoptados}

\footnotetext{
${ }^{20}$ Valgan algunos títulos que pueden orientar frente a una larga lista de trabajos en que estos conceptos son tratados en particular:

Bozzano (2004), que desarrolla con detalle la discusión conceptual y epistemológica centralizado en especial en la proyección espacio y territorio (capítulos 1, 2 y 3). En Chiozza y Carballo (2006), puede seguirse una síntesis sobre las concepciones relacionados con el espacio geográfico, donde se recatan en especial conceptos de Dolfus, Harvey y Santos (1996: 45-54). Claval (1999) dedica un especial ítem al tema lecturas de los paisajes (266-270). Santos (1996) dedica particular atención a la dupla paisaje y espacio (cap. 5). Haggett (1988) en su Síntesis, trata al paisaje desde el análisis de las regiones culturales (272-277); dedica varios ítems al concepto de territorio, básicamente desde una visión conflictiva asociado a temáticas de soberanía y fronteras. (477-497) y también aporta precisiones sobre la tríada espacio-localización-lugar (4-7). Tadeo et al (2006), proponen su enfoque desde la interrelación territorio, lugar y cultura (cap.1). Sassone (2001) acude al enfoque teórico-metodológico cultural en relación a las migraciones. Roccatagliata (1982) sistematiza conceptos espaciales desde la óptica del ordenamiento territorial. Pickenhayn (1994), contrasta planteos teóricos espaciales básicos (24-27).
} 
Espacio (a secas): análogo a área, con un rol de sustrato para con el desenvolvimiento humano.

Sitio: menor espacio homogéneo en una configuración espacial compleja; de carácter neutro.

Lugar. análogo a sitio, pero sujeto a instancias de pertenencia y acción ${ }^{21}$.

Territorio: Espacio social diferenciado ${ }^{22}$ que requiere de estas cualidades genéricas:

- Pertenencia comunitaria

- Ocupación (actividad)

- Trascendencia generacional

El territorio involucra al lugar (el continente) en el tiempo (lo vivencial).

- Visión tradicional: como espacio socialmente construido y apropiado.

- Visión posmoderna: de incertidumbre, sitios e imágenes superpuestas (en avalancha).

Paisaje: representación geográfica del lugar como espacio habitado ${ }^{23}$ (vivido).

Espacio geográfico: aquel involucrado en el análisis abordado desde la Geografía, ya como objeto mismo o cuando en su condición compleja es partícipe necesario.

En virtud, entonces, de ya saber que tratamos, no sólo con la complejidad de lo territorial sino que también con los procesos de construcción social en plena metamorfosis, es que el enfoque cultural en Geografía se presenta como una alternativa de análisis promisoria. Es cierto también que debe ponerse el acento en el carácter provisional de muchos de los alcances logrados, necesitados de una visión multidisciplinar a la hora de arribar a conclusiones más profundas. Como se dijo, el imaginario colectivo sobre la Patagonia sostiene dilemas donde lo geográfico alcanza un significativo peso; pero abundan aquellos operativamente imprecisos (mágicamaldita, virgen-postergada, pródigo-estéril, promisoria-desértica, etc.), de modo que mayormente el recorrido metodológico implicó encaminarse a través de percepciones, conductas y resultados para alcanzar una sistematización mayormente esquemática.

Entonces, repitiéndonos, uno de nuestros principales objetivos fue acudir a planteos propios del enfoque cultural, respondiendo con especificidad a la valorización de los comportamientos sociales vinculados con situaciones territoriales críticas y acudiendo a la noción de paisaje como representación geográfica de síntesis o, como diría García Ballesteros, como la expresión tangible del espacio geográfico (1992: 58).

Es decir, nos ocupamos de examinar y sistematizar los aspectos cruciales referidos a una ocupación territorial activa, conflictiva y compleja a la vez. En su aporte geocultural crítico Chivallon propone re-conceptualizar la significación de lo territorial y, al tratar la dupla espacio-tiempos, rescata de Soja su apelación a la relación "trialéctica" entre historicidad, espacialidad y socialidad (1999: 133). Así, en la inseparabilidad de

\footnotetext{
${ }^{21}$ Albet sintetiza con rigor la temática y sus implicancias idiomáticas como parte de su profunda reconsideración de lo regional para la Geografía Postmoderna (2001).

22 De una complejidad social mínima; superadora de instancias solamente individuales/familiares

23 En su Diccionario de Geografía, Pierre George toma al paisaje como sinónimo de entorno, en el proceso de percepción de paisaje y advierte, "...Se confunde entonces con 'espacio habitado' (2004: 438).
} 
la acción y los objetos, el paisaje se muestra como un recurso descriptivo-explicativo válido. Al respecto cita Santos a Hägerstrand, "una acción es una acción en un paisaje y es el paisaje que da forma a la acción" (2001: 75-6).

Debe advertirse que este avance sobre lo cultural no supone un enfoque sociológico, por el contrario, tratamos de mantener el que sugiere Claval cuando afirma, "......La cultura es un campo común al conjunto de las Ciencias Humanas. Cada disciplina aborda este inmenso dominio según puntos de vista diferentes. La mirada del geógrafo no disocia entre los grupos y los territorios que estos han ordenado o donde viven. La estructura y la extensión de los espacios de intercomunicación, la forma en que los grupos sortean el obstáculo de la distancia y a veces lo refuerzan están en el centro mismo de la discusión..." (1999: 17). Es decir que más bien son las modalidades de interactuar en el espacio y sus consecuencias territoriales las que nos orientan para tener la posibilidad de sistematizar las problemáticas territoriales andino patagónicas. Entendemos, así, que el concepto de paisaje visto con la mirada del geógrafo como nos indica Claval, se acomoda perfectamente a la visión cultural del territorio.

Será una constante referirnos al paisaje (landscape, pays, landschaft) en su sentido más caro a la Geografía; aquel del espacio habitado, que involucra estructuralmente a la percepción en la complejidad de lo medio ambiental; percepción donde lo formal y funcional del medio geográfico no excluye lo estético. Aquí, en una integración analítica, la brecha entre la naturaleza-hombre es una realidad factible de análisis (cf; Silvestri, G. y F. Aliata, 2001: 9-26; ver también en Nogué i Font 1992: 85). Es cierto que la noción de paisaje quedó prácticamente desposeída de reconocimiento científico por sus intrínsecas cualidades subjetivas o como destaca Bonnemaison cuando trae a colasión la mirada sostenida por numerosos críticos, "...el paisaje no es un fin, tan sólo es un medio...", o que "...no se puede fundar una ciencia sobre un concepto vago que reposa en descripciones y apariencias..." (2000: 60-61). Pero justamente, las apariencias con sus formas, con su propensión a ser percibidas y con ello, determinando acciones de la más diversa índole en la promoción o no de intervenciones en el espacio, forman hoy en día parte trascendente de lo territorial. El mismo autor destaca el redescubrimiento en las Humanidades del concepto científico de paisaje y en su relación con la sociedad los categoriza definiendo sus modos o aspectos:

- el paisaje-marco de vida; el entorno de la vida cotidiana que reacciona como un elemento de la personalidad.

- el paisaje-patrimonio; elemento de la memoria colectiva. 
- el paisaje-recurso; se vende bien, la belleza es el mejor capital de los vendedores de sueños.

○ el paisaje-identidad; identificación socio-cultural.

Reforzando este acudir al paisaje, tenemos aquí que el actual proceso de transformación territorial hace poco menos que imposible valernos de las categorías tradicionales de las organizaciones espaciales y los usos del espacio. Podemos afirmar que las regionalizaciones formales y funcionales sostenidas sólo en variables naturales y económicas quedan truncas desde el inicio. Aqui es necesario incorporar en el análisis a los comportamientos sociales e individuales en su rol de lo que podríamos llamar formadores territoriales, y con atención además, a la movilidad o dinamismo sobre la que volvemos recurrentemente. Para ello se trabaja sobre el paisaje, aquel que muestra la posibilidad concreta de incorporar de forma ordenada y sistemática las intencionalidades, gustos, miedos, negaciones, prohibiciones y demás. En buena medida se trata de aquello que Di Meo en su discusión sobre el territorio como fenómeno psicológico o representación social, destaca sobre la territorialidad de cada persona y donde además advierte que el impacto de algunas comunidades sobre la realidad territorial no se reduce a un solo motivo, destacando tres tipos de causas diferentes:

- los condicionamientos provenientes de la posición social que ocupan las personas,

- los condicionamientos que pertenecen a la esfera cultural en las que ellas se desenvuelven

- y los resultantes de un "efecto del lugar", que son más estrictamente geográficos que las representaciones y que las prácticas (1998: 65).

\section{Paisaje y estructura}

Pues bien, con la valoración que se le da a la transversalidad del tiempo en la explicación de las problemáticas, se buscaron las estructuras en el paisaje, lo sustancial de los elementos y procesos del territorio. Aquello que nos permite sostener con argumentos consistentes unidades y divisiones, analogías y diferencias. Como ya se dijo, lo que no se explica ni como sumatoria del todo, ni como una desagregación caprichosa. Sin caer en un estructuralismo rígido e impenetrable, le asignamos a esta condición estructural, superadora de cuestiones meramente distributivas, la valía de permitirnos ver desde lo territorial la complejidad de innumerables formas y relaciones atendiendo solamente a aquello que no puede dejar de estar; lo necesario para que la entidad analizada sea lo que es. 
Nos reforzamos con Difrieri, quien en su artículo sobre la noción de estructura y la geografía regional, advierte la marginación de la Geografía frente al paradigma positivista y su validación científica en dirección al orden de complejidad creciente y generalidad decreciente. Se afirma en esta condición necesaria de dirigirse hacia una progresiva integración que en su análisis debe culminar en la concepción regionalizante. $\mathrm{Y}$ es así entonces que la teoría de la estructura permite ocuparse de la naturaleza heterogénea del espacio geográfico (...). La idea de estructura se corresponde con la totalidad y comprende además la idea de las relaciones entre las diversas partes de esa totalidad y la totalidad misma (1984:329.336). Por supuesto que se deberá estar atentos con el riesgo de que la estructura se transforme en caja, en esqueleto y con ello tienda a prevalecer el continente sobre el contenido, o en correspondencia con el concepto de región, que se instale esa condición de neutralidad bien advertida críticamente por Rentería Vargas (2001:18-19).

Por otra parte, en el proyecto original y a falta de claridad en las formas estructurales organizadoras del espacio, recurrimos a plantearnos la identificación tipológica de los usos del territorio como recurso inicial de análisis. Sin embargo como ya se anticipó, la realidad fluctuante de hoy ya no responde al mero traspaso de las tipologías corrientes con funcionalidades en general precisas y definidas históricamente desde la geografía y la economía ${ }^{24}$. Fue así que lo coyuntural (migrantes, ocupantes, modas, crisis económicas y políticas, contingencias naturales, etc.) se incorpora al análisis en analogía con aquello, también de Difrieri, cuando indica que “...la noción regional debe abandonar toda idea de permanencia y equilibrio estable, y asumir, en cambio, junto con la idea de estructura, la de variación coyuntural" (1984:333) ${ }^{25}$.

En tal sentido sirva el planteo de Steck, quien al contrastar la geografía económica tradicional con la actual, destaca el carácter volátil de la producción en diferentes escalas y prefiere aferrarse más a la noción funcional del espacio que a la de territorio. En la misma conferencia concluye Le Morvan sobre los espacios productivos en Francia, “... Intentar una tipología es difícil, la síntesis cartográfica imposible.” (2001). También en Brasil Seemann (2001) destaca la extraordinaria dinámica en las transformaciones espaciales de las últimas décadas, tomando por caso el de Campinas (1970: 90), donde los usos del suelo cambiaron en más de un $40 \%$ de su superficie.

\footnotetext{
${ }^{24}$ Por supuesto que no se trata de una desvalorización de las clásicas diferenciaciones tipológicas; por el contrario, éstas son en extremo sugerentes. Trabajos magistrales como la Geographie Humaine de Brunhes (1947), resultan categóricos al poner énfasis en la fisonomía de la instalación humana y los tipos geográficos para el análisis geográfico de todo el planeta; o también de Stamp, quien generó un marco referencial para el planeamiento territorial británico de posguerra que aún hoy 'no tiene desperdicio' (1981, 4ta. edición; 1960 edición original).

${ }^{25}$ En su artículo sobre La Geografía Activa, desarrollado en La Geografía en la República Argentina, Romain Gagnaird destaca la contingencia de ciertas leyes explicativas fundadas en tipologias comparativas, generadas, ya por entonces, en un mundo de cambios acelerados. (1968: 214-216).
} 
En definitiva, para la identificación del paisaje y dándole énfasis a la tipología de la instalación humana se estará en un recorrido continuo:

\section{estructura $\longrightarrow$ coyuntura $\longrightarrow$ estructura}

Como muestra el esquema, asumir el dinamismo de lo coyuntural significa ver su impacto sobre la estructura, a riesgo de no perderse en una avalancha de sucesos sin eslabonamiento posible. Conceptualmente Labasse nos afirma en la idea cuando sostiene, "...la constante referencia a los paisajes es el antídoto más seguro para no dejarse obnubilar por lo accidental..." (1973:28).

En el planteo original señalamos que acercarnos a la identificación tipológica de usos sería primario para alcanzar un mejor entendimiento de la configuración geográfica. Por lo recién expuesto y si bien se avanzó en esa dirección, en especial para el ejido de Lago Puelo y en relación a una tarea multidisciplinar con varios colegas ${ }^{26}$, hubo que asumir que no sería posible atender la enorme complejidad, de revisar, identificar y especialmente localizar todo el conjunto tipológico aggiornado en materia de usos. De este modo, se profundizó el análisis desde la óptica de los comportamientos, pero dejando la sistematización tipológica en un marco más acotado, como indicador de los tipos de población más trascendentes en relación al territorio y sus modalidades características. La tesis recorre a través de relaciones múltiples, lugares, imaginarios, problemas territoriales y comportamientos, un terreno donde la percepción y la descripción se muestran como el camino de rigor para llegar a las explicaciones ${ }^{27}$.

Es decir que, con la base de información bio-física geográfica, en general disponible, además de la interpretación geohistórica, estructural a la hora de comprender el devenir local y regional y de la funcionalidad geoeconómica, regida por las actividades y su rol espacial, nos introducimos en el campo del enfoque fenomenológico, del espacio vivido, el que involucra a los comportamientos cuyos principales motores exhiben un ostensible solapamiento entre diferentes situaciones de raíz afectiva, emocional e identitaria (García Ballesteros, 1992; Nogué i Font, 1992; Sassone, $2001)^{28}$.

\footnotetext{
${ }^{26}$ Martínez, et al. Estudio sobre: "Directrices para el desarrollo territorial y zonificación básica de Lago Puelo". Convenio municipalidad de Lago Puelo - Unidad de asistencia en temas ambientales (U.A.T.A.), sede Esquel de la Universidad Nacional de la Patagonia San Juan Bosco. Esquel, 2007.

${ }^{27}$ Resulta muy ilustrativo y útil a la hora de ver los enfoques iniciales en estas temáticas, el capítulo Percepción y descripción con artículos de J. Wright, D. Lowenthal y C. Darby en la Segunda Parte de Teoría de la Geografía (Randle, P. (ed.), 1984: 165-251)

28 En nuestro medio, siguiendo lo que Downs llamó la revolución del comportamiento (behavioural revolution) de los años '60, señalaba Daus, "El anterior esquema simplista de explicación de las diferencias regionales de la realidad terrestre: tierra-hombre, se enriquece en esta otra fórmula: medio natural - hombre - percepción del medio - decisión comportamiento espacial. Si bien cabría ver si se trata de una secuencia como la así presentada, cabe destacar el peso que cuatro décadas atrás ya adquiría el rol de lo anímico como elemento significativo, si no crucial en geografía (Daus, 1976: 7-11).
} 


\section{Competencia territorial y territorios complementarios}

Así entonces, con un paisaje de fuerte sesgo 'natural' montañoso, a todas luces presente en el desenvolvimiento social, tanto fáctico como simbólico, se consideró prudente darle un énfasis singular al condicionamiento del medio bio-físico, a aquel de las respuestas ecológicas, en analogía con el sentido de receptividad para con la instalación humana que da Reboratti cuando desarrolla índices para subregiones de la Patagonia Norte $^{29}$. Es clave aquí el condicionamiento físico propio de sistemas montañosos jóvenes donde se imponen confinamientos y asimetrías morfológicas propios de un modelado quebrado ubicado en latitudes medias; a ello se le agrega, además, el carácter ecotonal Oeste-Este que se suma en un todo de fisiografía heterogénea.

Con esa antesala podrá entenderse la necesidad de ingresar en visiones relacionadas en conceptos de aptitudes, expectativas, umbrales, límites, tolerancia, capacidad, sustentabilidad y otros $^{30}$. Se trata de terrenos muchas veces transitados con cierta liviandad y donde también con cierta inconsistencia se llegan a sugerir cómodas cuando no delicadas posiciones concluyentes. Aún así debe destacarse que también, desde estos ámbitos de discusión, se han abierto ocupaciones y preocupaciones geográficas que normalmente estuvieron circunscriptas a esferas exclusivas de escasa proyección social y que hoy ocupan agendas de un amplio espectro profesional y político. Como señala Wilbanks (1994), desde los años '60 y con más fuerza con la Conferencia de Estocolmo de 1972 y la publicación de The Limits to Growth de Meadows, se instalaron globalmente las discusiones sobre desarrollo, conservación de la naturaleza y crecimiento demográfico.

Para el caso, nos referimos en especial a las compatibilidades de las acciones humanas con los sistemas ecológicos intervinientes. Así, algo 'corridos' de conceptos como los de capacidad de carga o límites del crecimiento ${ }^{31}$, que en determinados casos se muestran reduccionistas respecto del complejo significado de lo cultural en los lugares; se trabajó con una base conceptual que denominamos competencia territorial de una zona o comarca. Competencia que, en términos de ser capaz, especifica la relación entre las actividades desarrolladas por una comunidad y sus expectativas de acción, con la respuesta física del medio natural a las intervenciones ${ }^{32}$. En términos sencillos, se diría que estamos ante una imagen dinámica de capacidad o

\footnotetext{
${ }^{29}$ En la Síntesis de Peter Haggett, puede verse un importante seguimiento temático con un sentido geográfico 'unitario' (1988: 145-251).

${ }^{30}$ A respecto, ver ejemplos relacionados con el turismo y la sustentabilidad en César Dachary, A. y Arnaiz Burne, 2002: Cap. V y Vl; o en casos más acotados, cercanos y entre muchos a: Alvarado y Palma, 1999: CONAF 2000; Rush 2002.

${ }^{31}$ Esta temática en sí requeriría un desarrollo tal que desborda las posibilidades de este trabajo. Las escalas pueden ser tan abarcativas que permiten pasar desde planteos Maltushianos o los de Shumacher y su 'small y beautiful', hasta figuras como el Modelo Mundial Latinoamericano de la Fundación Bariloche (Herrera et al, 1977) o limitarse a planes de manejo sectoriales acotados a tal parque, reserva y demás. Ver indicadores en este sentido y en relación al turismo en Ivars Baidal, J. et al (2001: 27-31).
} 
soporte, ya que cuentan formas y magnitudes, pero al que ineludiblemente van adheridas las expectativas sociales (desde locales, prima facie, hasta globales).

Frente a ello y tan sólo a modo de planteo regional andino patagónico que restaría verificar en su complejidad, arribamos conceptualmente a la figura territorios complementarios, cuyo significado no va más allá que lo que indica ese calificativo.

Tal vez los planteos espaciales complementarios se presentan como de cierta obviedad en cuestiones de problemáticas geográficas de la sociedad vistas en conjunto. Sin embargo, para las visiones ecosistémicas y geoeconómicas su tratamiento espacial es más riguroso y, en buena medida, de su análisis surgen conceptos clave en materia de flujos, jerarquías y redes espaciales, tal como puede desprenderse, por ejemplo, a partir del modelo de Ullman (Cf.: Haggett, 1988: 459-463). También es considerada en la visión del paisaje como totalidad y, basta pensar en las tradiciones nómadas y trashumantes como para su valorización geográfica ${ }^{33}$. En ellas la complementariedad espacial y estacional actúan directamente como móviles de lo que Vidal de la Blache llamó género de vida y su conocimiento estricto resulta crucial.

Se diría, entonces, que en cuestiones del territorio, el significado de la complementariedad es moneda corriente en términos geográficos, y tal vez por ello poco se habla de su entidad conceptual. De hecho, cualquier zonificación de cierta complejidad, urbana, rural, productiva, social, etc., normalmente refleja situaciones complementarias, algunas veces deseadas o no y otras existentes con mayor o menor ponderación. Aún así, la condición montañosa y atendiendo a su diversidad inherente, imprime singularidades que requieren mayor atención ${ }^{34}$.

Pues bien, el trabajo en su conjunto sugiere la óptica regional por sobre la políticaadministrativa, tratando de resaltar las potencialidades y limitaciones en un marco territorial coherente, donde la competencia pasa por la acepción del término en el sentido que recién le dimos (ser capaz de) y no por una lucha de exclusión interna con superposición competitiva de actividades y servicios.

En nuestro caso específico de estudio, La Comarca Andina del Paralelo 42, y como se verá con algún detalle, se desenvuelve en un mosaico de jurisdicciones, de modo que aún cuando hay fuertes signos de cohesión interna de carácter espontáneo, en la proyección política de cada provincia y municipios, todavía no se ve planteado esta

\footnotetext{
${ }^{32}$ En la Cuarta Parte de la tesis se describe el concepto capacidad territorial aplicado por el equipo de la U.A.T.A. de la Sede Esquel (UNPSJB), donde también se lo relaciona respecto de las tecnologías de producción, consumo y conservación, considerando además las expectativas que de ellas se plantean. (cf: informe Martínez, et al (UATA), 2007). Bozzano, por otra parte, introduce la competitividad territorial, como una cualidad analítica que consideramos fácilmente incorporable al rol de competencia que le puede caber a un determinado lugar (2004:77).

${ }^{33}$ Ver el cercano caso neuquino en Bendini et al; en particular el ítem Los trashumantes, el trabajo y la naturaleza (1994: 17-27).

${ }^{34}$ Ver en Mountain Geography: a review, el desarrollo del ítem Human Geography en Funnell y Price; 2003: 183-90
} 
alternativa territorial; con ello, las expectativas sociales, se potencian como un tema a indagar.

Finalmente, cabe agregar que así como este marco teórico responde a una visón regional totalizadora, con el paisaje como vehículo para ello y desde una perspectiva de investigación básica orientada, serán las posibles proyecciones en trabajos geográficos más acotados a los problemas territoriales en sí, hacia donde y en definitiva, va dirigida esta tesis.

\section{I.2. Metodología.}

\section{I.2.1. Antecedentes y contexto problemático.}

Como referencia más directa, esta tesis cuenta con los alcances logrados con los proyectos "Uso humano del territorio y aspectos ambientales críticos en Patagonia Andina" y "Uso del espacio y transformaciones territoriales en la Patagonia Andina de Chubut y Río Negro". Ejecución: 2002-2005 ${ }^{35}$, donde se avanzó sustancialmente en la generación de información de base y de planteos problemáticos, en particular en materia físico ambiental, histórica, catastral, socio-territorial y geoeconómica. También ha sido a partir de los mismos y de las instancias de coordinación con la Dra. Nidia Tadeo en su rol de directora de tesis, que se sustanció la propuesta de trabajo.

Aunque tal vez podría soslayarse y como lo hemos anticipado en el Prólogo Introducción, valoramos como significativa la experiencia personal. Entendimos que, aún cuando no es necesariamente una garantía, el contar con 25 años de residencia y trabajo profesional en el ámbito de la montaña patagónica, nos permite presuponer una condición de baquía importante a la hora de la valorización de antecedentes. Vendría al caso el comentario de Hägerstrand que, consultado sobre las raíces respecto de sus líneas de investigación, señala “...la manera de empezar es con los estudios locales en el área de residencia del investigador..." (Díaz Muñoz, 1994: 9).

El punteo que sigue resume la situación diagnóstica y cada enunciado responde a modo de indicador de base para el abordaje problemático, si bien, como se verá a lo largo de esta obra, el tratamiento ha sido diferente según fuera su influencia en relación con los objetivos e hipótesis planteadas.

\section{Principales situaciones conflictivas de carácter geográfico detectadas en la Comarca Andina del Paralelo 42 ${ }^{36}$ :}

\section{1.- Excentricidad geográfica.}

\footnotetext{
35 PI 279/98, 1999-2001 y PI 429/01, 2002-2005 de la Universidad Nacional de la Patagonia San Juan Bosco. Informes Finales 2002 y 2006 respectivamente.

${ }^{36}$ Ver avances al respecto en Bondel, Novara y Carabelli, 2006.
} 
De fuerte influencia en el marco de las decisiones políticas y económicas. Rawson y Viedma (capitales provinciales), no sólo se encuentran alejadas en kilómetros (800 y 1100 respectivamente), sino que también la Comarca se emplaza en extremos de subsistemas de gestión territorial interiores (Esquel y Bariloche) enlazados con Buenos Aires. Servirá de ejemplo el hecho que no existe vínculo directo en materia de transporte público entre El Bolsón y Viedma (con suerte, los $900 \mathrm{~km}$ se sortean en no menos de 20 horas). Con Rawson, los vínculos en materia de transporte son más ágiles, si bien las 14-15 horas de traslado no supera al par de frecuencias diarias y con trasbordos necesarios. En ambos casos tampoco existen vínculos aéreos públicos y el ferrocarril que une San Carlos de Bariloche con Viedma, con sus dos frecuencias semanales, no resulta una alternativa operativa.

2.- Superposición funcional de dependencias y responsabilidades jurisdiccionales en materia de conservación ecológica, recursos energéticos y administración política y territorial (nacionales, provinciales, municipales). Situación agravada por la escasa autonomía de gestión de las delegaciones de los organismos. Con ello abundan casos de gestión fallida de distinto costo social y ecológico ${ }^{37}$.

También es cierto que esta situación, a su vez, supondría la existencia de una suerte de 'amortiguador' para evitar apresuramientos en decisiones trascendentes sometidas a las presiones de los 'tiempos políticos', así como además puede resultar favorable a la hora de acceder a eventuales condiciones de financiación de diferente origen. Valga por caso para el primer caso las decisiones respecto del aprovechamiento hidro-energético y para el segundo, la obtención de financiamiento en sectores ambientalmente protegidos (provincias, Parques Nacionales, ministerios nacionales, municipios).

\section{3.- Incumplimiento y/o incertidumbre en los comportamientos políticos, sociales y económicos hacia amplios sectores de trascendencia territorial.}

En particular en ámbitos valorizados escénicamente. Riberas de ríos, lagos y lagunas, cabeceras de cuenca, humedales, faldeos abruptos, bosques y arbustales de protección, escurrimientos esporádicos y remanentes glaciarios, son objeto de recurrentes situaciones conflictivas. Si bien existen reglamentaciones sobre su uso y/o conservación, en general sobresale la indiferencia o el abuso. El manejo del agua en escorrentías y lagos, así como los usos y accesibilidad, sobresalen por sus aspectos imprecisos en el comportamiento social ${ }^{38}$.

\section{4.- Expansión urbana espontánea, de muy baja densidad, 'confusa' y muchas veces antisocial ${ }^{39}$.}

\footnotetext{
${ }^{37}$ Es ilustrativa la generación de un Consejo para el desarrollo de la Comarca Andina del Paralelo 42 -CODECAP, sostenido en la integración de las comunidades involucradas de ambas provincias. El tema se explica en la Segunda Parte. Ver también en Madariaga (2007).

${ }^{38}$ Este tema ha tenido una re-significación social y se demuestra en una profusa serie de intervenciones que la justicia viene sobrellevando en los últimos años. Son recurrentes en los medios regionales y locales, en especial en problemas relacionados con los cursos de agua y lagos. Ver por ejemplo y sin entrar a considerar las múltiples instancias andino patagónicas en general, los casos en la Comarca río Azul, río Epuyén, Arroyo Golondrinas, La Catarata, Lago Espejo - Lago Escondido. Cf: en los buscadores de diarios: www.rionegro.com.ar ; www.elcordillerano.com.ar www.elchubut.com.ar www.eloeste.com.ar www.elciudadanobche.com.ar www.noticiasdelbolson.com.ar y www.adnrionegro.com.ar .

${ }^{39}$ El carácter de antisocial puede desprenderse de la creciente pérdida de tierras de buena potencialidad agroecológica y escénica (turística) y el sostenimiento de servicios públicos para pobladores dispersos no incorporados a
} 
Crecimiento poblacional acompañado de presión sobre áreas rurales y/o de protección y, arrinconamiento urbano de carácter marginal ${ }^{40}$. Ver antecedentes teóricos y aplicados a la expansión física de Bariloche en Hernández y Mochkofsky 1974; o por ejemplo los casos actuales de San Martín de los Andes en Zingoni et al, 2006; de El Bolsón, 1997-8 en su Plan estratégico (Foglia et al, 1998) o en las bases del Plan estratégico de Esquel SEAS, 2001.

\section{5.- Parcelamiento y tenencias de la tierra condicionadas por procesos de inversión y especulación inmobiliaria (orgánica y voluntaria).}

De alcance local nacional e internacional, ya advertida por Eriksen en 1970. Potenciada a partir de la desregulación de la tenencia de la tierra en áreas de frontera y acorde con la moda en materia de gustos sobre la 'calidad' estética del paisaje.

Este escenario genera dos situaciones "umbral" en materia de sustentabilidad:

- Sobre-parcelamiento rural-boscoso y situaciones forzosas de stress ambiental (eliminación de franjas de protección de fauna y flora, presión sobre el grado de estabilidad de faldeos y vertientes, demanda de agua, 'aclarado' residencial y turístico). (Ver Novara, 2005 y Novara-Bondel, 2006).

- Sobre-dimensionamiento rural-boscoso, situaciones de riesgo geográfico por extensiones privadas que involucran ecosistemas completos (en toda la Patagonia Andina, incluso la chilena). Aceptada la fragilidad ecológica del ámbito montañés, resultaría incompatible la 'gran' propiedad, incluso ante una coyuntural actitud conservacionista frente a una estructural situación de falta de control comunitario.

\section{6.- Perfil cultural-socioeconómico heterogéneo de proyección territorial conflictiva.}

Mapuches y paisanos, migrantes urbanos y rurales argentinos, migrantes chilenos, colonos tradicionales y no tradicionales, se asocian con pautas de uso y pertenencia diferentes. Patrones culturales de una sociedad que, además, involucra desde sectores sociales excluidos hasta poseedores de fortunas de rango mundial, generan trastornos socio-territoriales graves. (cf.: González, Myriam S., 2004) Distintas modalidades por delimitaciones, usos (urbanos estructurales o no, rurales y neorrurales) y herencias, se suman a una heterogénea y muchas veces contradictoria lectura colectiva del paisaje, con abundantes representaciones y subjetividades provenientes del imaginario social (la Patagonia generosa y abundante versus la Patagonia maldita y postergada; ver en Bondel 2002, Livon-Grosman, 2003).

\section{7.- Crecimiento geo-demográfico y confinamiento físico.}

$\mathrm{Si}$ bien el grado de compatibilidad en la convivencia sociedad-medio natural no es de exclusividad montana y obedece a la relación, cultura - tecnologías - medio natural, en la montaña se destaca por la potenciación de sus condicionamientos. Implicancias directas en la

\footnotetext{
instancias productivas.

40 Un reciente artículo demuestra plausiblemente el rol de impulsores del crecimiento poblacional y económico en sectores cercanos y/o vinculados a las áreas protegidas, en particular en ámbitos latinoamericanos y africanos. De hecho, el planteo surge a partir de la contradicción que supone promover inversiones en favor de la conservación de la naturaleza en áreas protegidas, si estas inversiones motorizan la presión geo-demogáfica sobre las mismas. (George Wittemeyer et al, 2008).
} 
superposición competitiva de un medio natural físicamente restrictivo para las modalidades tradicionales argentinas en los usos del espacio (las de las planicies) y en particular frente a expansión residencial y a obras de alto impacto (caminos, represas, urbanizaciones, canteras, residuos, etc.).

Como se entenderá, este fraccionamiento temático surge tan sólo como un recurso metodológico en favor de la profundización del análisis. Pero, como es lógico que ocurra, hay temas que se adosan naturalmente y podrían reunirse en diversas situaciones conflictivas. Así, la excentricidad geográfica se relaciona fácilmente con la superposición en materia y jurisdiccional o la incertidumbre en los comportamientos con el perfil cultural-socioeconómico y la expansión urbana con los parcelamientos, el crecimiento geo-demográfico y el confinamiento físico. 


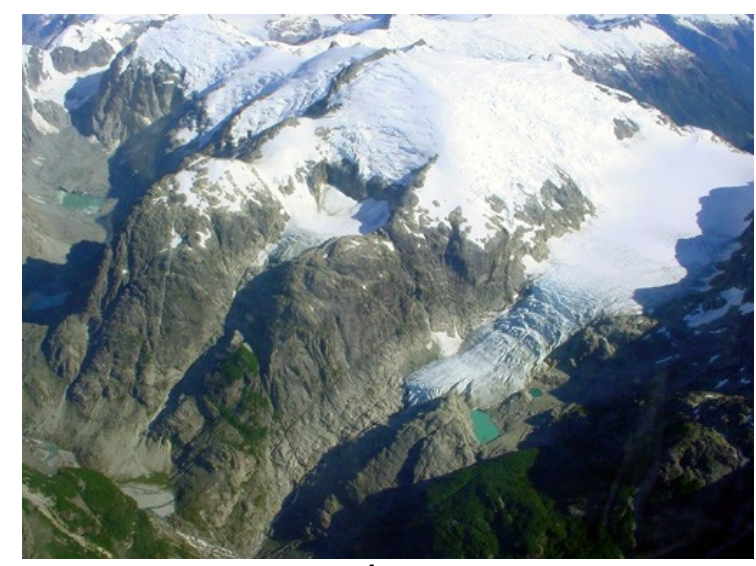

1

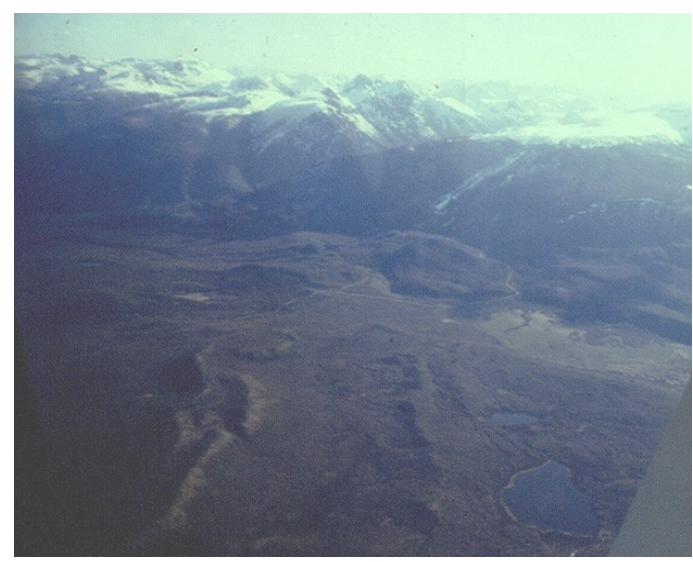

2

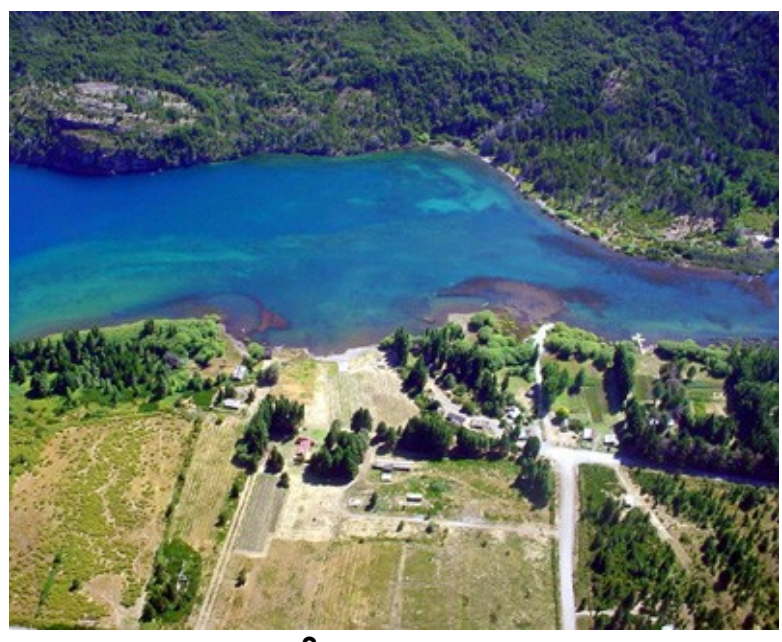

3

Foto 1,2 y 3: Sectores conflictivos y de escasa claridad en materia de gestión territorial:

1. Altos del Turbio: cabeceras de cuencas, de difícil gestión por accesibilidad restringida, tanto por razones naturales como por 'cerramientos' de los ganaderos. Foto: F. Ottone, 2004.

2. Pampas de Mallín Ahogado y Cerro Perito Moreno: ocupaciones ganaderas tradicionales (pastajes) y concesiones fiscales para deportes invernales y refugio de montaña. Ambos usos de gestión provincial, sometidos a nuevas perspectivas inmobiliarias y en conflicto con intereses locales. Foto del autor, 1999.

3. Lago Epuyén: de uso intenso estival por turismo local y externo. Caso prototípico de incertidumbre en materia de acceso al lago, uso de playas, tenencia de la tierra, manejo de escorrentía, bosque fiscal, etc.. Foto: F. Ottone, 2004.
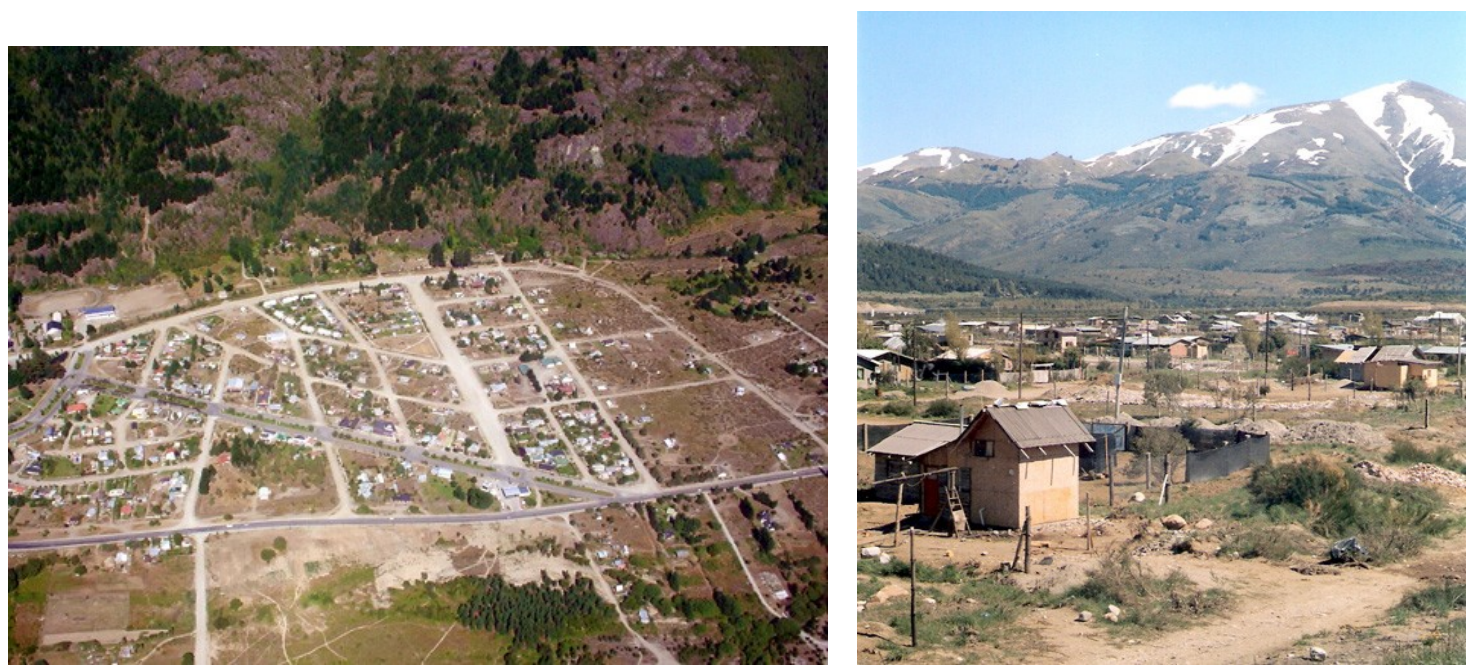
Fotos: 4 y 5.

4: Casco urbano central de Lago Puelo: las bajas densidades son una constante del paisaje urbano comarcal. Foto: F. Ottone, 2004.

5: Barrio Alto (S. C. de Bariloche): sub-urbanización marginal en sectores ambientalmente agresivos. Foto del autor, 2006.

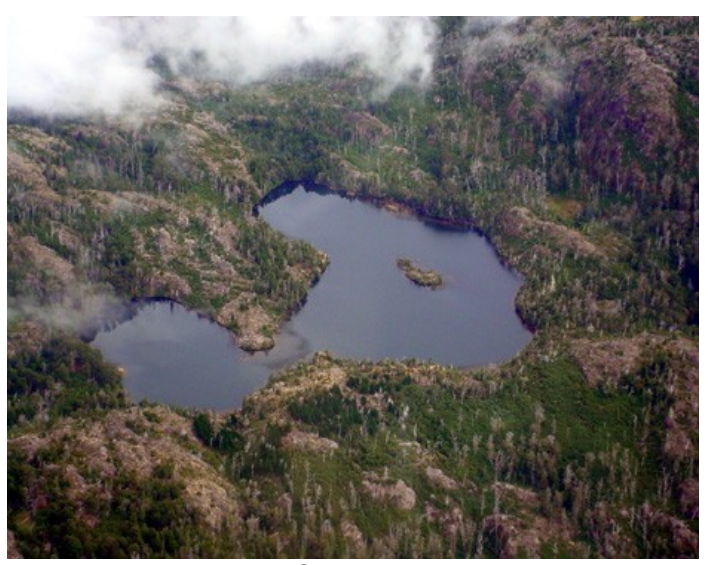

6

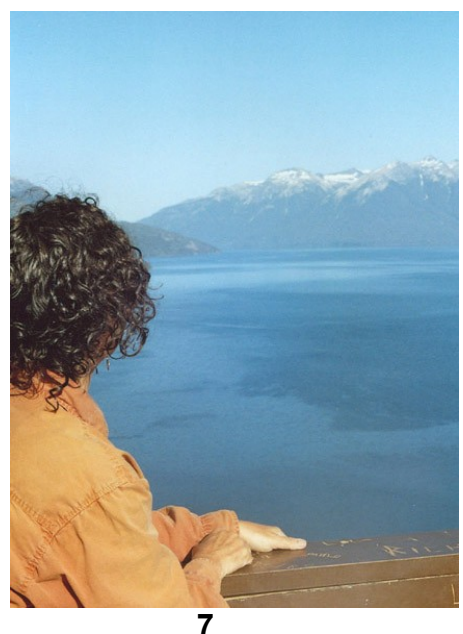

7

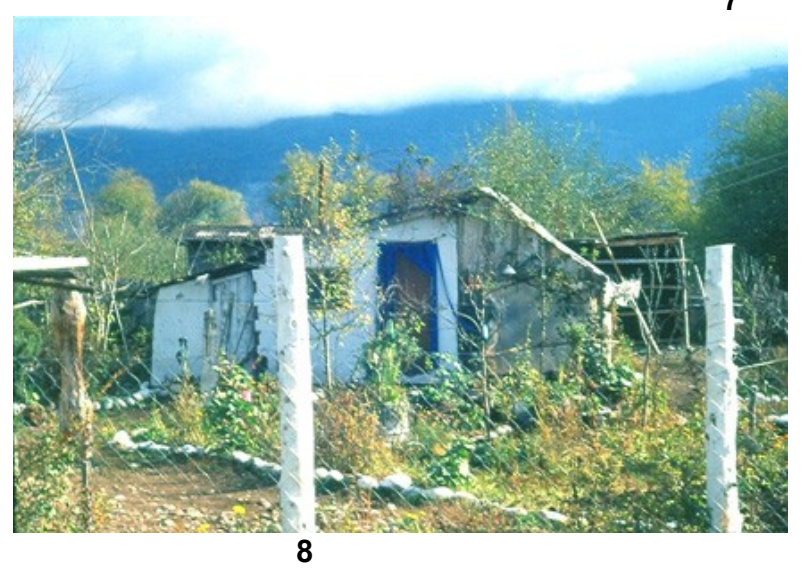

Fotos: 6,7 y 8.

6: Laguna Alerce (sobre 'umbral' Lagos Epuyén y Puelo): sitio valorado por los paisanos jóvenes como de recreación espontánea, de difícil acceso y sin controles, y como recurso turístico y de conservación para la gestión territorial ordinaria. Foto: F. Ottone, 2004.

7 y 8: Escenario panorámico vs. espacio vivido. Se trata de compatibilidades complejas (mirador en Lago Traful, y vivienda de tipo 'espontánea' en barrio popular en El Bolsón. Fotos del autor, 2005. 


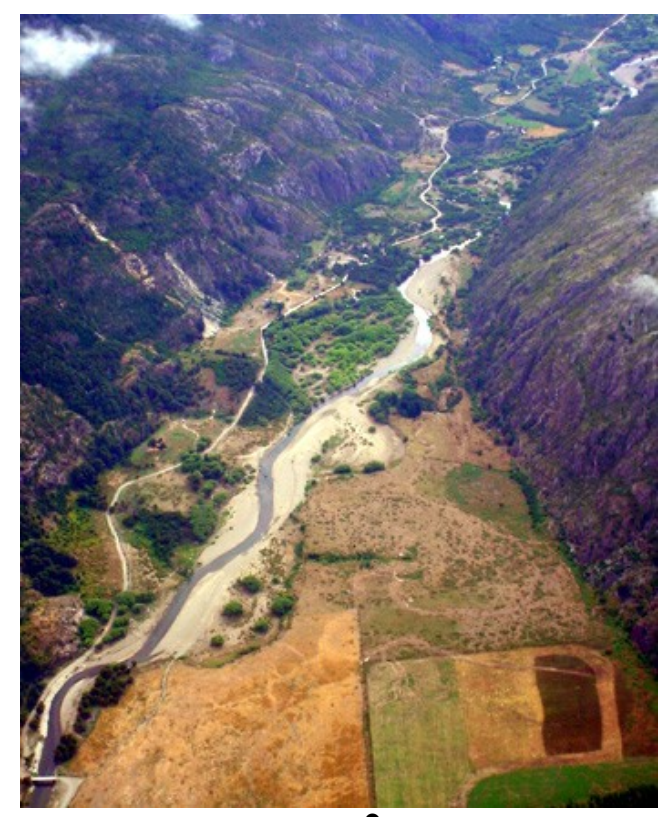

9

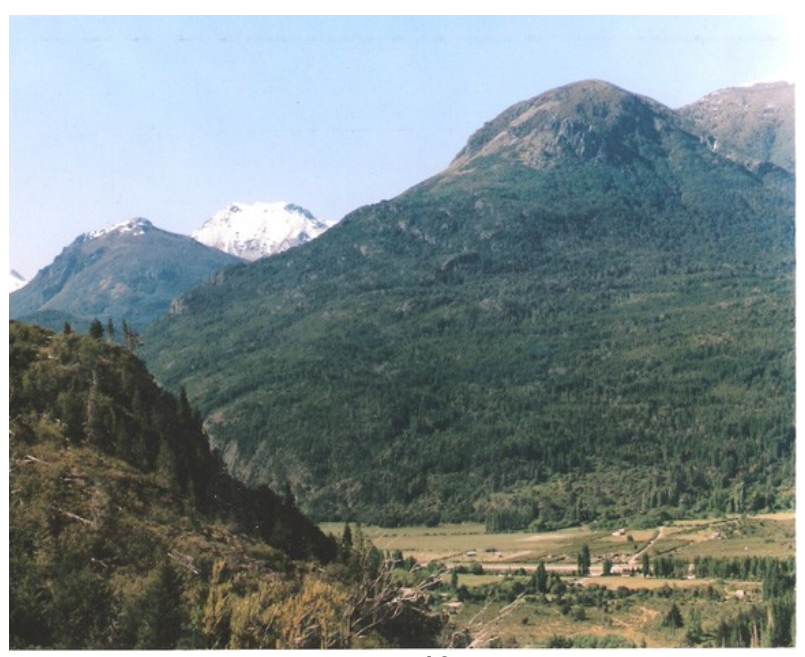

10

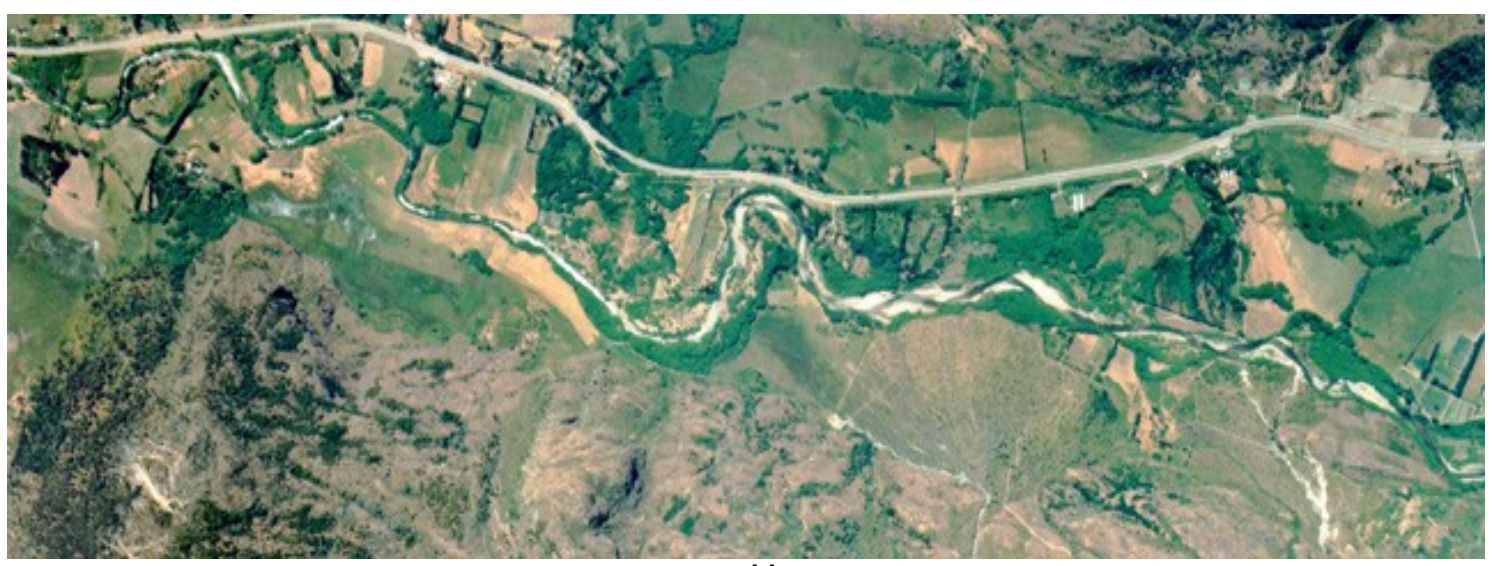

11

Fotos: 9,10 y 11. Fondo de valle del Río Epuyén.

Curso inferior 9 y medio 10 y 11: plano, con inundaciones y anegamientos sectoriales. Edáficamente heterogéneos y faldeos abruptos con usos forestales-ganaderos rudimentarios y extensivos. Existe una valoración creciente de aspectos escénicos. Fotos: 9: F. Ottone, 2004; 10: del autor, 2005 y 11: Dirección Provincial de Bosques, Chubut - CFI, 1999.

\section{I.2.2. Objetivos e hipótesis.}

Teniendo ya como referentes al marco teórico y el contexto problemático territorial, y antes de desarrollar las instancias metodológicas seguidas, enunciaremos, con alguna modificación menor, los objetivos originales del proyecto (junio de 2004) que justamente son los que motorizaron la investigación. Cabe destacar que el último de los objetivos se agrega posteriormente a la presentación del proyecto original y cobró especial relevancia por su posibilidad de trascendencia. 


\section{Objetivo general:}

Desarrollar un análisis geográfico de la Comarca de El Bolsón que permita una interpretación profunda de la actual organización territorial en el contexto de la montaña patagónica.

Esta ha sido la meta fundamental para acompañar desde la geografía a las profundas transformaciones territoriales contemporáneas ocurrentes. Creemos que los alcances de la tesis están en consonancia con ella. Cabe la salvedad de haber reemplazado el nombre de la Comarca de El Bolsón, inicialmente vista desde una perspectiva histórica y geo-funcional, por el de Comarca Andina del Paralelo 42, hoy en día casi una 'marca registrada' impuesta por la necesidad de contar con un nombre aglutinante ${ }^{41}$.

\section{Objetivos específicos:}

1. Establecer las tipologías de uso del territorio rural y rururbano sostenidas en su configuración económica y cultural a fin de alcanzar una visión sintética y sistemática del conjunto territorial.

Hemos desarrollado más arriba, el por qué de la adaptación de este objetivo a una visión más ajustada con una realidad tan versátil, donde los 'tipos' de usos están fuera del alcance sectorial de alguna disciplina y necesitarían de un tratamiento multidisciplinario. Fue entonces un objetivo, determinar los 'tipo de pobladores' en relación con el territorio y trabajar sobre ello. En este sentido y por cuestiones de magnitud y complejidad, se excluyó el análisis intra-urbano, dado que son justamente los espacios extra-urbanos los más involucrados en la temática central de la tesis.

2. Identificar las claves explicativas esenciales del sistema económico comarcal (input-output de flujos, sistema urbano y usos económico del suelo) para ayudar a comprender el contexto relacional en la materia y explicar el grado de autonomíadependencia existente.

3. Profundizar el análisis de los conflictos socio territoriales más importantes a escala comarcal.

Para así, por un lado contribuir con el objetivo general sin desviar el análisis en cuestiones menores y por el otro, atender a situaciones muchas veces cercanas a lo urgente.

4. Consolidar enfoques integrales (básicamente ambiental, geohistórico y socioeconómico) para el análisis territorial, en consonancia con la tendencia de abordaje multidisciplinario existente en materia territorial.

\footnotetext{
${ }^{41}$ Resulta curioso que aparentemente es una denominación poco menos que defenestrada por la visión del marketing turístico; véase CFI - Grupo Estratégico de Negocios A. Wilensky en materia turística (2001).
} 
5. Generar una obra que sirva como orientadora a futuras actividades $y$ asentamientos humanos con un criterio de racionalidad cultural, ambiental $y$ económica.

Objetivo incorporado con posterioridad a la presentación de Proyecto de Tesis:

6. Contribuir a la generación de un marco teórico relacionado con la instalación humana en áreas montañosas, en particular de la Patagonia Andina, para que, principalmente, sirva de insumo ante las evidentes situaciones de expansión, ocupación y transformación espacial ocurrentes.

Valga la aclaración que este marco teórico evita entrar en el terreno de la valoración condenatoria o elogiadora per se en materia de la realidad existente, la organización del espacio y el cierto orden territorial que se describe, lo es a los fines explicativos. Son oportunas las palabras de Andrada, cuando en su tesis sociológica de la Patagonia Austral se plantea dónde reside la utilidad de su propuesta teórica y dice "...debido a la necesidad de considerar el origen de las prácticas y su manifestación actual, no con la intención de justificarlas ni de juzgarlas sino con el objetivo básico de comprenderlas" (2005: 50)

Seguidamente se ofrecen los planteos hipotéticos y sobre los cuales se harán referencias específicas que, entendemos, servirán para comprender mejor las instancias metodológicas dadas, así como también el desarrollo de cada uno de los capítulos.

Hipótesis general:

- En el contexto general de la globalización y su afán expansivo en materia turística y cultural, la Patagonia Andina es valorizada como un lugar paradigmático en materia ecológica, demográfica y paisajística; con ello, se denota una preeminencia singular de los aspectos afectivos-emocionales por sobre los económicos en el desenvolvimiento de las temáticas territoriales más dinámicas de la Comarca (inmobiliarias, turísticas, de producción agropecuaria-silvícola, de conservación ambiental).

Esta hipótesis ha actuado como eje fundamental; el planteo se profundizó en su verificación como así también se buscaron posibles fisuras a considerar. Se generaliza respecto del desenvolvimiento de las temáticas territoriales más dinámicas, involucrando a aquellos sectores, grupos o simplemente actores sociales 
posicionados favorablemente en la motorización de los cambios y transformaciones en el territorio ${ }^{42}$.

Como se ha visto, es central la idea sobre el rol decisivo de lo aspectos afectivosemocionales a la hora de explicar el orden territorial existente en la región. Explicación que no responde simplemente a los habituales enfoques regionales basados en el cruzamiento de las condicionantes naturales, las pautas económico-productivas y los modos propios de una economía de aglomeración, que si bien son imprescindibles a la hora de la compresión, actúan básicamente como complementos.

Algo similar sucede con otros escenarios territoriales conflictivos, como la problemática del parcelamiento-acaparamiento de tierras, la accesibilidad a cursos de agua y costas de lago, la expansión urbana 'confusa' o la contradictoria lectura colectiva del paisaje, donde a los intereses económicos se le agregan con contundencia una larga lista de aspectos a considerar y que tienen en la economía tan sólo una componente más. Por supuesto que también, y en términos generales, se deben considerar determinados umbrales de sustento, donde las respuestas estarán más atadas a la lógica de raíz económica que otras, si bien para el caso, esas por ahora se ven como situaciones singulares, de coyuntura.

\section{Variables de análisis:}

- aspectos afectivos-emocionales en materia ecológica, demográfica y paisajística.

- aspectos económicos (productivos, comerciales y financieros)

- configuraciones geográficas (forma y función)

\section{Indicadores:}

- discursos inmobiliarios, periodísticos y políticos, lectura ambiental, cambios en los usos del suelo, patrones culturales (herencia, costumbres de uso), actividades y lugar de residencia.

- productividad, empleo, estacionalidad comercial y productiva, valor monetario de la tierra y sustentabilidad económica, valor de la tierra y especulación inmobiliaria, divisiones y dimensiones de los campos, tenencia de la tierra ${ }^{43}$.

- dinámica demográfica, estructura de la administración territorial, tradiciones de uso del territorio, discurso inmobiliario y periodístico, cambios en los usos históricos del suelo.

\footnotetext{
42 Es por ello que temas de profunda significación socioeconómica con sus visibles inequidades y desequilibrios, sólo son tomadas contextualmente. A sabiendas, además, que existen investigadores y equipos ocupados en ello. Véase a modo de ejemplo en un Informe del Ministerio de Trabajo de la Nación sobre el empleo en San Carlos de Bariloche (2006), una importante lista de grupos de investigación e investigadores ocupados en materia socio-económica regional. Otro tanto y con una gran diversidad temática, se puede encontrar en diversas fuentes científicas y de gestión política, nacionales y provinciales (UNPSJB; UNC; UNPA; INTA, Patagonia; CENPAT-CONICET; CADICCONICET; Secretarías y Direcciones provinciales, etc.).

${ }^{43}$ Un indicador inicialmente buscado y desechado por no tener acceso a la información fue el macro-movimiento bancario; se trata de un registro de segura utilidad para futuras investigaciones.
} 
Hipótesis derivadas:

- En general, para la toma de decisiones de trascendencia espacial (planificadas como espontáneas), existe una percepción contradictoria sobre el papel de las condicionantes históricas (culturales, políticas y económicas).

La hipótesis se demuestra en particular en base al desarrollo de los aspectos dilemáticos en la consideración de la Patagonia Andina y el imaginario (¿malos entendidos?). Además, por su condición temporal, ha sido transversal al desarrollo general del trabajo ya que hay una recurrencia obligada para el esclarecimiento de los procesos históricos locales.

Variables de análisis:

- El rol de las condicionantes históricas en el desenvolvimiento territorial de la región.

Indicadores:

- nomadismo de los pueblos originarios.

- ocupación pre-colonizadora de carácter violento.

- aislamiento geográfico y excentricidad económica nacional e internacional.

- frontera internacional de potencialidad conflictiva.

- capacidad productiva con excedentes agropecuarios y forestales de escala zonal.

- mosaico migratorio.

- Respecto de los usos del territorio, la región ofrece condiciones naturales que son consideradas 'contradictorias' y muchas veces competitivas unas con otras (entre la sobrevaloración y la infravaloración).

En este caso y respaldada en la verificación de las anteriores, fue necesario presentar las condiciones naturales en su rol territorial así como en el contexto económico y la confrontación con los comportamientos, en particular respecto de los usos del espacio (¿malos entendidos?). Es así que el medio natural se analiza en su papel condicionante, de capacidad territorial, en particular ante las restricciones que imponen los ámbitos montanos, con el agravante además, de tratarse de un medio reconocido como frágil (cf: Rappoport, E., 1990: 46-47).

Variable de análisis:

- las condicionantes naturales percibidas como 'contradictorias'.

Indicadores:

- condicionamiento geomorfológico (valles, faldeos, cumbres, etc.)

- condiciones climáticas (temperatura, viento, precipitaciones, sequías, nubosidad etc.)

- condicionamiento hídrico (escorrentías, lagos, glaciares, etc.).

- condicionamiento biogeográfico (flora y fauna) 
- La urbanización de muy baja densidad y proyección territorial imprecisa de los ámbitos rurales es, en materia paisajística, el resultado más visible de la configuración espacial andino patagónico (en términos regionales: barilochización).

Si bien la problemática intra-urbana apenas si se frecuenta, sí lo son los procesos de expansión urbana y sus consecuencias territoriales. Neo-ruralidad, dispersión, marginación y fraccionamientos, entre varios, son términos corrientes en la explicación de las transformaciones territoriales.

Variable de análisis:

- configuración espacial

Indicadores:

- red caminera y sistema urbano regional,

- estructura productiva rural,

- densidades rurales y rururbanas (demográfica, parcelaria y productiva),

- $\quad$ equipamiento de servicios (salud, educación, seguridad y comunicaciones), e

- $\quad$ infraestructura energética.

\section{I.2.3. Método}

Presentaremos aquí los procedimientos y técnicas para el conjunto de la investigación. Debe tenerse en cuenta que muchas veces fue necesario alternar en materia de escalas incluso, y como suele suceder en el análisis geográfico regional, ir desde lo macro a lo micro, incluyendo, además, perspectivas que contemplen la opinión de muchos actores involucrados.

Como pudo verse en el marco teórico, el planteo de los estudios regionales está condicionado por un amplio espectro de visiones posibles, incluso, a veces con aristas difíciles de sortear ${ }^{44}$. Resulta interesante notar, sin embargo, que una vez orientada una investigación, con singularidades mayormente ligadas al territorio y su complejidad intrínseca, y las generalidades provenientes de las temáticas involucradas, el método científico se instala de forma relativamente espontánea. Son oportunas las palabras de Pech y Regnauld que ceñidamente nos señalan un camino, “... Para prever debemos recolectar la información (tarea de inventario y de campo), jerarquizar los factores (tarea de clasificación) y proponer una alternativa a la sociedad. Es ella quien

\footnotetext{
${ }^{44}$ Aunque no será un tema de análisis en este trabajo de tesis, entendemos importante dejar mención sobre la fractura que existe en nuestro país en materia de estudios geográficos regionales; enfoques y métodos parecen ir por carriles sin contacto. Se trata de una fractura no sólo actual sino visiblemente arrastrada desde las sucesivas crisis institucionales desde 1966 a esta parte, y su consecuente ruptura político-ideológica entre posturas conservadoras de distinto tenor y progresistas también diversas. Es de destacar que en los ámbitos académicos se viene trabajando en la materia por décadas y, aunque las diferencias subsisten, habría que evaluar si hoy en día la brecha es tan profunda o, en realidad existen solapamientos teóricos y metodológicos con dejos viciosos.
} 
determinará su verdad." (1997: 14-17). De todas formas, no resulta sencillo acomodarse a circunstancias que coexisten con una 'mundialización' que es sincrónica con continuos y veloces cambios de patrones tiempo-espacio ${ }^{45}$.

Desde un principio y a fin de ubicarnos nosotros mismos en un contexto metodológico general, tomamos de Molina de Buono la diferenciación en cuanto a enfoques metodológicos, donde presenta cuatro esquemas de base para el análisis territorial: inductivo/deductivo, hipotético/deductivo, a priori/deductivo y anárquico (2005: 58-61). Con ello vemos que con un estudio de caso (la Patagonia Andina), su valorización y explicación problemática, nos acomodamos en los dos primeros esquemas. Así se llega a un escenario analítico cargado de apreciaciones y comportamientos de raíz subjetiva, habiendo sido antes meticulosos respecto al reconocimiento esencial del área como entidad territorial.

Ha preponderado el método analógico propio de la geografía, alternando entre diferenciaciones y asociaciones areales, atravesadas tanto por la perspectiva geohistórica como por el rol condicionante del medio natural y la funcionalidad geoeconómica, indagando y ponderando la consistencia de la estructura comarcal. Es decir que, operativamente, se ha recurrido a modos tradicionales de la geografía regional, fructíferos a la hora de tratar con diversidades intra-regionales que no pueden contentarse con sólo atender algunos principios generales (cf: Labasse, 599 y Ortega Cantero: 30-35). Incluso y cuando fue necesario, recurriendo al lenguaje metafórico, aquel lenguaje que, como señala Ortega Cantero acudiendo a Berdulay, permite que el conocimiento geográfico no sea una lectura impersonal sino un saber ver con la activa participación del sujeto (p. 66)

En cierta forma nos referimos a metodologías un tanto 'devaluadas' en la modernidad tardía, básicamente por aquella imposibilidad frecuente de no poder superar instancias descriptivas o de haber quedado fuera de la órbita modelística en las esferas de análisis y decisión económica en la segunda mitad del Siglo XX (cf.: Krugman 1997:37). Pero utilizando términos del mismo autor, para la actualidad es posible hablar de una geografía perdida y encontrada (cap. 2), seguramente no sólo por la recuperación de la espacialidad económica, sino y en especial, por la arraigada visión holística de los procesos territoriales por parte de los geógrafos. Hoy, aquella base científica disciplinar regional, corológica, impulsada entre tantos por Reclus, Vidal, Brunhes, Hettner o Sorre y consolidada en su cuerpo teórico por Hartshorne ya con su

\footnotetext{
${ }^{45}$ Una discución interesante en este sentido gira entre quienes se orientan por la necesidad de conducirse hacia una teoría de los territorios (ver en Bozzano 2004: 13) y aquellos que no esquivan el llevar al rol del geógrafo directamente al ámbito de la comprobación empírica y espacialmente concreta (Pech y Regnauld, 1997: 15-19).

${ }^{46}$ Aún así resulta válida la observación de Hollman, que recalca la necesidad de no abusar de las metáforas en su análisis sobre el concepto de frontera y como parte de la "...ausencia de conceptos satisfactorios para aprehender la realidad contemporánea" (2003).
} 
primera edición de The Nature of Geography (1939), parece haber hallado una senda activa importante. Por ejemplo y sólo retomando la cuestión del tiempo en este contexto de métodos tradicionales, los 'cortes temporales' (a modo de instantánea) y la visión evolutiva (proceso geohistórico) son actualmente referentes obligados. Carl Sauer escribe el siguiente párrafo en 1925 y que además de completar el enfoque de lo temporal, mantiene su vigencia “... Los objetos que existen juntos en el paisaje, existen en interrelación. Estamos seguros de que ellos constituyen una realidad, como un total que no se expresa en la consideración de las partes constitutivas separadamente; que el área tiene forma, estructura y función y, que por lo tanto, posición en un sistema que está sujeto a desarrollo, cambio y completamiento. Sin esta visión de la realidad y de la relación areal, existen sólo disciplinas especiales, no geografía como generalmente se entiende. La situación es análoga con la historia, que puede ser dividida entre la economía, el gobierno, la sociología, etc.; pero cuando esto se hace el resultado ya no es historia" (En Randle, 1978:93-94) (7. $^{47}$

Hay que añadir que este redescubrir va de la mano de los recursos tecnológicos de última generación. Claro está que será bueno evitar los riesgos de 'avalancha' en la materia y que con la evolución de técnicas, las alternativas deben tener su tiempo de 'digestión'. Pero es innegable el potencial que encierran ciertos recursos; tanto es así que la simple digitalización de fotografías sugiere ya un recurso clave y manipulable a la hora de las continuas síntesis con las que se trabaja el territorio ${ }^{48}$. Qué decir entonces del uso de imágenes satelitales, Sistemas de Información Territorial y docenas de programas (soft) de enorme potencia, (cf:, Hägerstrand, entrevistado por Díaz Muñoz, 1994:11; Buzai, 1999 y 2000). Pasar del espacio real a un modelo digital, significa llevar elementos y relaciones concretas a una composición donde los elementos y relaciones signifiquen una representación; o mejor, de un modelo conceptual de la realidad a otro digital, comprensible para el ordenador y con ello con capacidad de generar un 'universo' de posibilidades para el ejercicio geográfico, antes limitado tanto por simples razones operativas, como por no tener la monumental 'oferta' de visiones espaciales (Durán y Buzai, 1996: 84-85; Buzai, 2000).

Al respecto, además, creemos que será saludable mantener una dirección disciplinar que propenda hacia instancias metodológicas transdisciplinares (ver en Bozzano, 2004: $17-18)^{49}$, a sabiendas, claro, que no podrían sostenerse sin, en nuestro caso, una geografía fortalecida y bien posicionada como potencial multiplicador.

\footnotetext{
${ }^{47}$ Ver también en Randle, Las etapas del método científico y la Geografía (1978: cuadro anexo)

48 Jean Brunhes demostraba hace más de medio siglo las posibilidades fantásticas de las fotografías en las síntesis geográficas. Su agudeza, difícil de superar, la muestra en la Table des photographies hors-texte de su Géographie Humaine con 117 fotografías (1947),

49 No viene al caso entrar en vericuetos semánticos respecto de las interacciones científicas; de hecho, entendemos que serán los propios problemas que lleven a lo inter, multi y/o transdisciplinario.
} 
Esquemas conceptuales de referencia:

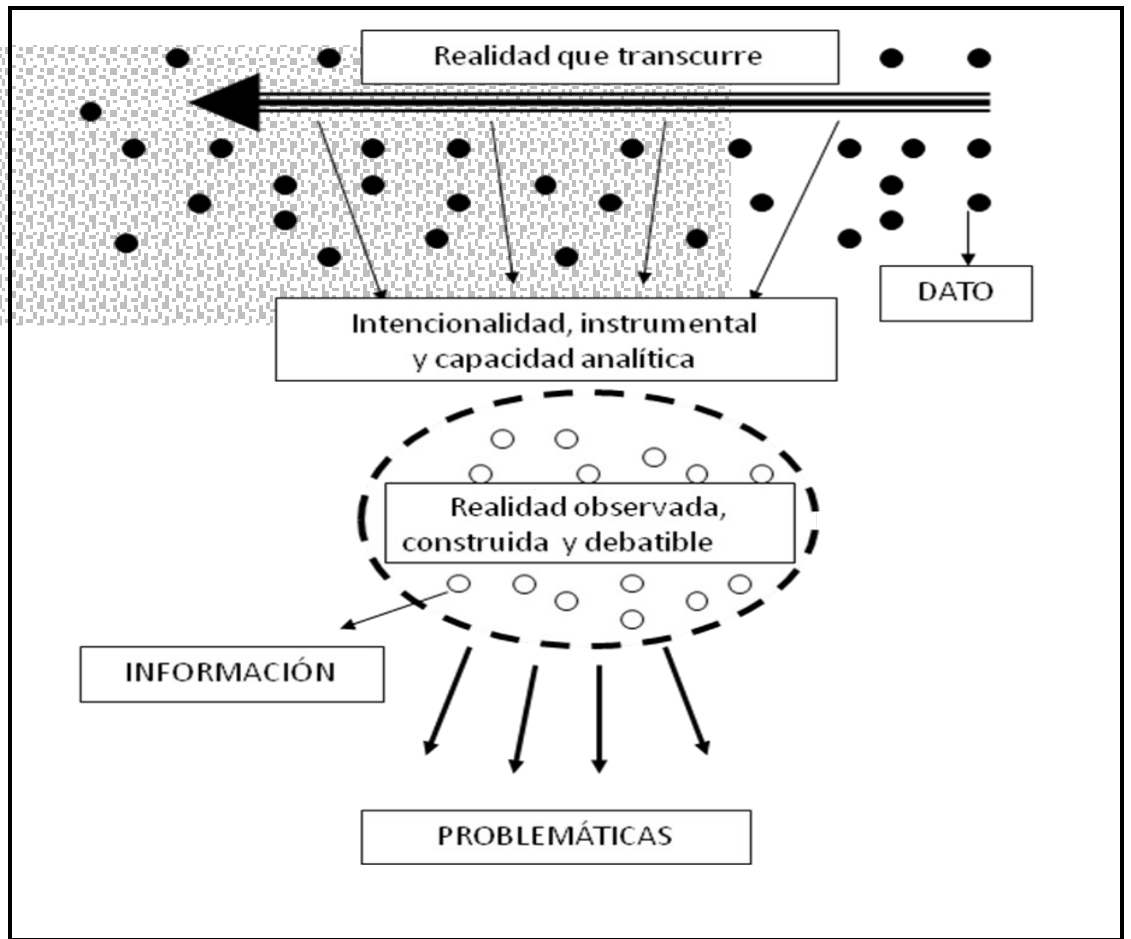

Fig.: 2. Esquema complementario para arribar al marco problemático; es desde allí que parte Bozzano para posicionarnos teórica y metodológicamente (2004: 62-63). Ver además el esquema desarrollado en IV.1., (Fig. 19) donde se avanza sobre la competencia territorial de los territorios. Fuente: elaboración propia.

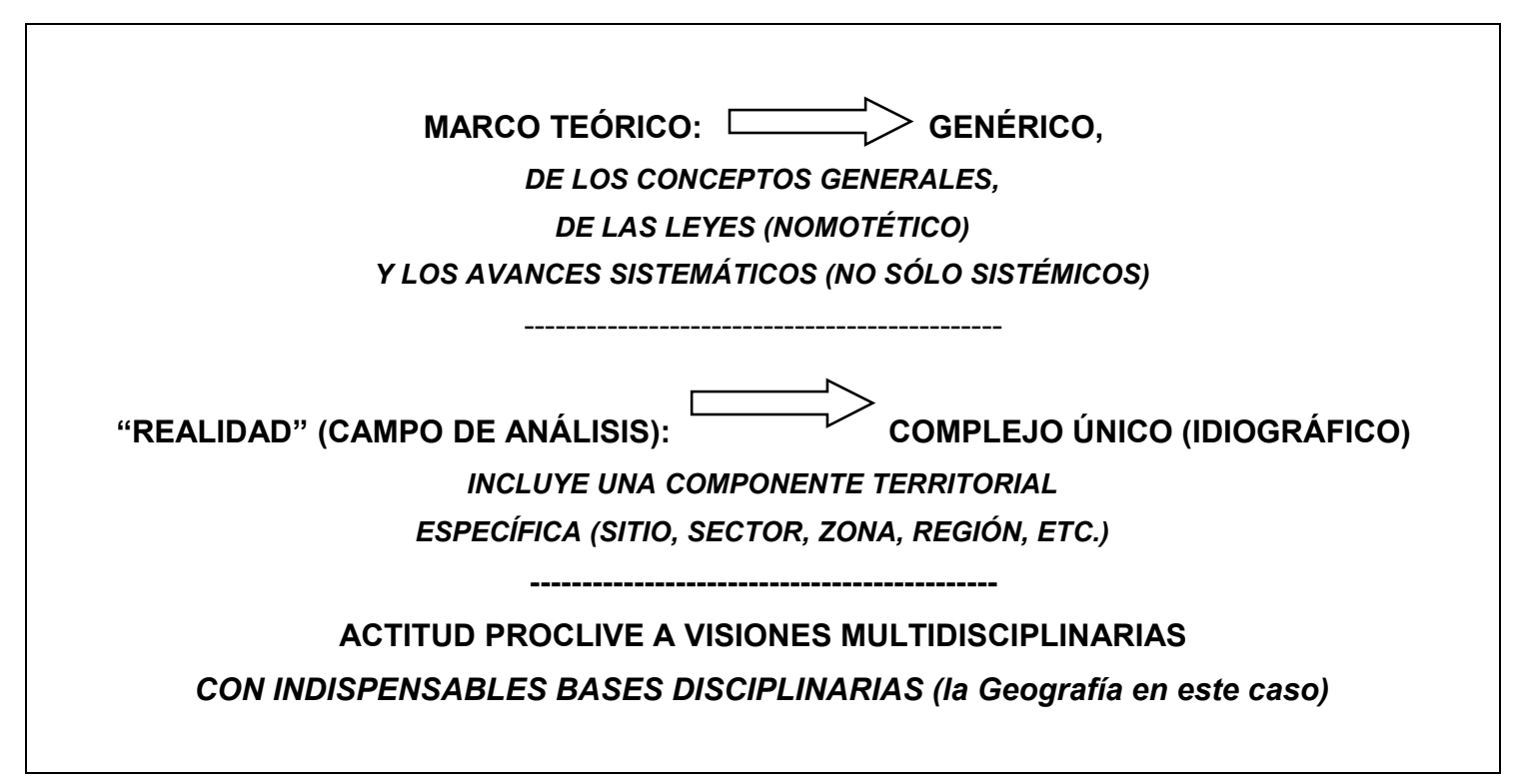

Fig.: 3. 


\section{Método y estrategia metodológica.}

La Primera Parte se sostiene en enfoques de corte teórico-analítico acordes a la realidad considerada. 'Realidad' que actuara como base de la investigación y que debió ser planteada a partir de la constatación de problemáticas socioterritoriales reveladoras, muchas veces exploradas 'a campo', que permitieran llegar a describir y explicar a las configuraciones geográficas básicas.

La indagación bibliográfica ha sido fundamental para poder llevar lo observado a un plano de abordaje teórico, siendo la dispersión que sugieren las cuestiones regionales el principal escollo a la hora de tomar posturas o direccionar la investigación. Incluso, la complejidad propia del ejercicio necesitó de constantes cotejos o 'controles' de tipo transdisciplinar, atentos a las necesidades en ese sentido que con acierto nos recuerda Bozzano cuando se introduce en terrenos de la territorialidad y la sustentabilidad $(53)^{50}$.

Se trabajó también con entrevistas propias y de colegas ${ }^{51}$, inicialmente generales y semiestructuradas, para luego hacerlo sobre las hipótesis por medio de entrevistas informales profundas.

Es de hacer notar que ya desde esta Primera Parte se acude a figuras, fotografías y esquemas, convencidos tanto sobre el potencial de su despliegue básicamente integrador como de su significación muchas veces tridimensional con posibilidades concretas de proyección en el espacio.

\section{Acciones en la Primera Parte:}

- relevamientos de campo intercalados,

- análisis documental-bibliográfico,

- confrontación bibliográfica con situaciones análogas,

- relevamientos fotográficos intercalados,

- entrevistas generales, específicas (sectoriales, pobladores y profesionales) y casos clave de tipo 'profunda' (pobladores),

- participación en múltiples talleres o instancias con implicancias territoriales,

- pre-confección de mapa descriptivo y mapas temáticos,

- elaboración de esquemas para la identificación de las principales problemáticas territoriales.

\footnotetext{
${ }^{50}$ Como puede rescatarse de la bibliografía, fuentes y apéndices, han sido múltiples las instancias de participación en materia científica, técnica y de gestión territorial (talleres, seminarios, reuniones sectoriales, congresos, etc.), que, aún con un muy diferente grado de rigor y contexto, permitieron consolidar, rectificar y proyectar con más certeza las ideas centrales.

${ }^{51}$ En especial producto de la participación en el Proyecto de Investigación (Bondel et al 2002) y en la Unidad de Asistencia en Temáticas Ambientales (U.A.T.A.) de la U.N.P.S.J.B. desde 1999.
} 
En la Segunda Parte se trabaja sobre el contexto regional en general y el área de estudio en particular. Sustentados en los principios básicos de localización y causalidad, siguieron los pasos analógicos-comparativos propios de los estudios regionales, tratando de alcanzar, en escala adecuada, una visión estructural convincente de la Comarca, con una interpretación corológica y la consecuente lectura de localizaciones, distribuciones y disposición general de las entidades geográficas distintivas. El planteo, llamémosle problematizador; se apoyó en terrenos descriptivos ya recorridos (Bondel y de Almeida, 1996; Bondel et al 2002; Bondel et al, 2006) y con pocas dudas sobre lo dificultoso de abordar la explicación geográfica regional sin ser cautos a la hora de subrayar los problemas preponderantes y trascendentes en la organización de un espacio que sería considerado como abierto de acuerdo con la dicotomía abiertos - concluidos (ver en Labasse, $2^{\circ}$ Parte; cap. $\mathrm{X}$ y $\mathrm{XI}$ ). De todos modos, ya desde nuestra propia hipótesis sobre el mayor peso de las cuestiones anímicas-afectivas por sobre las económicas, inhibieron un tratamiento analítico análogo a los frentes pioneros tradicionales. Aquí, más bien primó la certeza de estar ante una figura antropogeográfica de ingredientes novedosos y que, desde el análisis geográfico se podría avanzar en su entendimiento.

Podría decirse que es la presentación-descripción de los objetos que le dan unidad al territorio y sobre los cuales ocurren procesos que nos interesan. Es decir, tan sólo se desarrollaron aquellas partes de ambos conjuntos geográficos que se involucran en la transformación territorial contemporáneos. Tanto es así que faltarán innumerables datos concretos que hacen a la geografía local y regional. Pero, como se anticipara, no será éste el texto donde puedan encontrarse datos específicos de los sitios, salvo que efectivamente participen en alguna de las problemáticas a las que nos abocamos. En definitiva, se puso énfasis en la relación lugar - imaginario - acción (actividad), para con ello identificar situaciones transformadoras de carácter geográfico y trabajar sobre ellas, tratando de llegar a la explicación, sobre todo en sus aspectos más conflictivos.

\section{Acciones en la Segunda Parte:}

- relevamientos de campo intercalados,

- análisis documental-bibliográfico,

- entrevistas semiestructuradas a informantes 'clave', pobladores y/o profesionales,

- relevamientos fotográficos intercalados,

- participación en múltiples talleres o instancias con implicancias territoriales,

- confección de mapas temáticos y esquemas explicativos. 
La Tercera Parte, responde al tema central de la tesis, es decir las transformaciones territoriales, con sus las modalidades, causas y efectos con un sentido básicamente prospectivo. Aquí, con el sustento de investigaciones zonales antecedentes (González, M. 2004; Bondel, 2000), acudimos a las perspectivas fenomenológicas, centralizando la investigación en percepciones y comportamientos para su posterior clasificación (percepción, actitudes y conductas) ${ }^{52}$.

En este campo, propio de la geografía cultural, variadas entrevistas, la participación en talleres vinculantes y hasta el desarrollo de una importante encuesta dirigida a 316 pobladores (hogares) en Lago Puelo (Martínez, O. U.A.T.A., UNPSJB, 2007), se sumaron a los antecedentes y la indagación teórica, para ver el modo en que las percepciones y comportamientos reflejan su proyección territorial, particularmente a través de las actividades de la población. Se buscaron resultados concretos que pudieran reflejarse espacialmente, donde la generación de mapas, esquemas y matrices permitieran alcanzar una significación analítica y operativa importante. Se persiguió con ello enriquecer las configuraciones que proponen los indicadores sociales y económicos clásicos, atendiendo a Antoine Bailly cuando deja en claro respecto de ellos, "... No es la calidad de estas medidas lo que se pone en duda, sino más bien la ambigüedad de la relación entre indicadores y sociedad, lo cual privilegia determinadas propiedades materiales". (1998:45).

Aún sin haber llegado a concretar mapas mentales y/o representaciones espaciotiempo prototípicos (los dioramas de Hägerstrand), creemos que se generaron las condiciones teóricas para que ello pudiera trabajarse desde un base conceptual sólida. Cabe destacar el desarrollo cartográfico que aún en su sencillez en general, se ha dispuesto sustentado en la versatilidad de los sistemas de información geográfica de modo que permite su proyección para futuras investigaciones y actividades conexas donde se requiera una escala de análisis superior.

Acciones en la Tercera Parte:

- relevamientos de campo intercalados,

- entrevistas generales y específicas semiestructuradas (sectoriales) a pobladores y profesionales,

- entrevistas de tipo informal, en casos 'clave' de tipo 'profunda' (pobladores y profesionales),

- encuesta dirigida (en colaboración),

- relevamientos fotográficos intercalados,

- participación en múltiples talleres o instancias con implicancias territoriales;

- confección de mapas temáticos, esquemas explicativos y matriz poblador/impacto.

\footnotetext{
52 Enfoques fenomenológicos (García Ballesteros, A. et al, 1992; García Ballesteros, A. (Coord.), 1998) y geohistóricos tradicionales.
} 
La Cuarta Parte ya en el plano de las conclusiones, desarrolla planteos originados en las comprobaciones de las hipótesis iniciales, presentándose como marco dos situaciones contextuales trascendentes, la competencia territorial y alternativas para replanteos en el espacio comarcal, en particular respecto de los patrones de ocupación del espacio e materia de distribuciones. Su tratamiento propone, además, alcances de índole metodológico para el primer caso y de índole operativa en el otro.

En su desarrollo, la primer situación ponderara y propone sobre tres condiciones categóricas en la geografía andino patagónica, el tipo de poblador en relación al territorio, sus expectativas y la competencia territorial del área. Mientras que en el segundo caso se analiza primariamente la relación sustentabilidad - territorios complementarios. En ambos casos, si bien iniciales, se presentan propuestas metodológicas de sesgo regional como camino de interpretación de la organización espacial en la región y/o ámbitos análogos.

El último apartado corresponde a las conclusiones alcanzadas.

\section{Acciones en la Cuarta Parte:}

- entrevistas y específicas semi-estructuradas (sectoriales) a pobladores y profesionales,

- entrevistas de tipo informal, en casos 'clave' de tipo 'profunda' (gestores políticos locales y regionales, profesionales),

- relevamientos fotográficos intercalados,

- participación en múltiples talleres o instancias con implicancias territoriales,

- confección de mapas temáticos, esquemas explicativos y de gestión y 2 matrices cualitativas (tipo de poblador-impacto territorial y tipo de poblador-sustentabilidad). 


\section{I.3. Referencias bibliográficas.}

- Abalerón, Carlos A.. Marginal urban space and unsatisfied basic needs: the case of San Carlos de Bariloche, Argentina. Environment and Urbanization, vol. 7 number 1, 1995. (pp. 97-116).

- Abalerón, Carlos A.. Los efectos de la caída del Plan de Convertibilidad sobre el turismo, la movilidad poblacional y las desigualdades en San Carlos de Bariloche, Argentina. IX Seminario Internacional de la Red de Investigadores en Globalización y Territorio. Universidad nacional del Sur, Bahía Blanca, 2006. Versión digital; 44 p.

- Acuña, Cynthia. Lecturas de Kant en Freud y Bretano. Acerca del tiempo y el espacio. En Cosentino, Juan Carlos y otros. El problema económico. Yo - ello - súper yo síntoma. Ed. Imago Mundi, Buenos Aires. 2005.

- Albet i Mas, Abel. ¿Regiones singulares y regiones sin lugares?. Reconsiderando el estudio de lo regional y lo local en el contexto de la Geografía Postmoderna. Boletín de la A. G. E. N 32. 2001 (pp. 35-52).

- Alvarado, Ramón y José A. Palma. Cálculo de la Capacidad de Carga Turística del Río Chagres. Plan de Manejo APSL, C.E.P.S.A.. versión digital 1999.

- Andrada, Larry. Sociología de la desertificación. Los productores ovinos extensivos de la patagonia austral. Universidad Nacional de la Patagonia Austral. Miño y Dávila Editores (Madrid). Buenos Aires, 2005. (287 p.)...

- Andermann, Jens. La construcción de un mapa de símbolos en la Patagonia. Entrevista de Gerardo Burton, Suplemento Debates del Diario Río Negro. General Roca. 20/03/2005.

- Arnaiz Burne, Stella M.. El espacio y el territorio en el turismo. Ponencia presentada en el Simposio Geografía y Turismo. IX Encuentro Internacional Humboldt. Juiz de Fora, Brasil. Setiembre de 2006.

- Bailly, Antoine. Los indicadores sociales: medidas objetivas de las ciencias duras en las evaluaciones subjetivas de las ciencias blandas. En García Ballesteros, A..(Coord.). Métodos y técnicas cualitativas en Geografía Social. Barcelona, Oikos-tau. 1998. (pp. 45-52)

- Bandieri, Susana. (a) Historia de la Patagonia. Editorial Sudamericana. Buenos Aires 2005. (445 p.).

- Bautista, Gabriel. Frontera y alienación: El caso argentino en el sistema mundial. Ponencia en el Vo Encuentro Internacional Humboldt. Merlo, San Luis. Argentina, 2004.

- Bendini, Mónica, Pedro Tsakoumagkos y Beatriz Destéfano. Campesinado y ganadería trashumante en Neuquén. Grupo de Estudios Sociales Agrarios, Universidad Nacional del Comahue. Editorial La Colmena. Buenos Aires. 1994. (225 p.)

- Bertoncello, Rodolfo. Turismo, mercado de trabajo y territorio. Una revisión de sus vinculaciones a partir de la experiencia argentina. En Reflexiones Geográficas. 
Agrupación de Docentes Interuniversitarios de Geografía. Río Cuarto, Argentina. 2002 (pp. 167-178).

- Bondel, C. S.; Novara, M.; Novella, M.M. y Raimondo, A. M.. Uso del espacio y transformaciones territoriales en la Patagonia Andina de Chubut y Río Negro .Proyecto de Investigación №23. Departamento de Geografía, Facultad de Ciencias Sociales, Sede Comodoro Rivadavia, Universidad Nacional de la Patagonia San Juan Bosco. 2006.

- Bondel, C. Santiago; Mauro Novara y Francisco Carabelli. Problemáticas socioterritoriales en las comarcas andino patagónica de Argentina. Fundación Cooperar, Serie de Divulgación Científica №1. El Bolsón. 2006 (18p.).

- Bondel, C. Santiago: "La Patagonia y el imaginario geográfico, ¿tan sólo una cuestión de mapas?". Conferencia inaugural de las "IV Jornadas de Geografía de la Patagonia". Comodoro Rivadavia, octubre de 2002.

- Bondel, C. S.; A. M. Raimondo; M. M. Novella; M. Novara y C. Augustaci. Uso del espacio y transformaciones territoriales en la Patagonia Andina de Chubut y Río Negro. Proyecto de Investigación № 479. Departamento de Geografía, Facultad de Ciencias Sociales, Sede Comodoro Rivadavia, Universidad Nacional de la Patagonia San Juan Bosco. Informe final. 2002.

- Bondel, C. Santiago. Tipologías de uso y 'lectura ambiental' en la explicación de situaciones territoriales comprometidas. La Patagonia Andina como caso paradigmático. Ponencia, 50 Congreso internacional de Americanistas. Warszawa, Polonia. Julio, 2000. (21p.).

- Bondel, C. Santiago y Abelardo de Almeida. "El Bolsón en la cuenca del lago Puelo. Descripción inicial de la relación hombre-medio ambiente". Anales XX, Sociedad Argentina de Estudios Geográficos. Buenos Aires, 1996. (pp.43-70).

- Bonnemaison, Joël. La géographie culturelle. Cours de l'université. Paris IV Sorbone. 1994-1997. Éditions du C.T.H.S.. Paris. 2000. (75 p.).

- Bozzano, Horacio. Territorios reales, pensados y posibles. Aportes para una Teoría Territorial del Ambiente. Editorial Espacio, $1^{\circ}$ reimpresión; Buenos Aires, 2004. (263 p.)

- Brunhes, La Géographie Humaine. Édition Abrégée, Presses Universitaires de France. París. 1947. (355 p.).

- Buzai, Gustavo. "Evolución del concepto de región ante la emergencia del ciberespacio. Elementos para un debate actual". Centro de Estudios Avanzados-UBA. Presentación en el II Encuentro Humboldt. Mar del Plata, 2000.

- Buzai, Gustavo. Geografía Glob@l. El paradigma geotecnológico y el espacio interdisciplinario en la interpretación del mundo XXI. Lugar editorial S.A.. Buenos Aires. 1999. 
- Buzai, Gustavo. "Nuevas tecnologías y cultura de la libre circulación den el ciberespacio". En "Ensayo 2001", Concurso Nacional de Ensayo "Arturo Jauretche" 2001. Ediciones Corregidor. Buenos Aires, 2003.

- Casamiquela, Rodolfo. Entrevista: Casamiquela, duro con los mapuches que lo "escrachan". Diario El Chubut, 7 de setiembre de 2005.

- Claval, Paul. “La Geografía Cultural”. EUDEBA, Buenos Aires, 1999. (377p.).

- Chiozza, Elena y Cristina Carballo. Introducción a la Geografía. Bernal: Universidad Nacional de Quilmes Editorial. 2006. (160p.).

- Chivallon, Chirstine. Fin des territoires ou necessite d'une conceptualisation autre?. Géographie et Cultures, n 31, 1999.

- Cóccaro, José M.. La voz del territorio: el desafío de escucharla. En Reflexiones Geográficas. Agrupación de Docentes Interuniversitarios de Geografía. Río Cuarto, Argentina. 2002. (pp. 193-198).

- CONAF, Corporación Nacional Forestal (Chile). Metodología para determinar intensidad de uso público en áreas silvestres protegidas. Manual de aplicación. Versión digital, 2000. (73 p.).

- Conte, Analía. Pirovano. 50 años después. Geografía histórica de una estancia. Oikos, Buenos Aires. 1981. (54 p.).

- Consejo Federal de Inversiones (CFI), Grupo Estratégico de Negocios Alberto Wilensky. Plan de Marketing turístico de El Bolsón. Informe Final. Buenos Aires, 2001.

- César Dachary, Alfredo y Arnaiz Burne, Stella Maris. "Globalización, Turismo y Sustentabilidad". Universidad de Guadalajara, Puerto Vallarta - Jalisco. México, 2002. (245 p.).

- Daus, Federico A.. Geografía y Unidad Argentina. El Ateneo, $2^{\circ}$ ed., Buenos Aires. 1978. (191 p.).

- Daus, Federico. "Desarrollo y comportamiento". Buenos Aires. Ed. El Ateneo. 1976. (224 p)..

- Di Meo, Guy. Objectivation et représentation des formations socio-espatiales: de I 'acteur au territorie. Annales Géographie, nº 537. Paris, 1987. (pp. 564-593).

- Díaz Muñoz, María de los Ángeles. Sociedad, Tecnología y Naturaleza: una entrevista con el profesor Torsten Hägerstrand. Estudios Geográficos, Tomo LV n 214. Valencia. 1994 (pp. 5-31).

- Díaz Muñoz, María de los Ángeles. Espacio y tiempo en la actividad cotidiana de la población. En Bosque Sendra et al. Prácticas de geografía de la percepción y de la actividad cotidiana. Barcelona, Oikos-tau, 1992.

- Difrieri, Horacio. La noción de estructura y la Geografía Regional". En Randle, P. (Editor) "Teoría de la Geografía". Segunda Parte. Sociedad Argentina de Estudios Geográficos, GAEA. Buenos Aires, 1984. 
- Durán, Diana y Gustavo Buzai. El impacto de las nuevas tecnologías en la educación geográfica. En Durán, Diana. Geografía y transformación curricular. Lugar Editorial. Buenos Aires, 1996. (pp. 76-93).

- Eriksen, Wolfgang. Kolonisation und Tourismus in Ostenpatagonien. Bonner geographische Abhandlungen. Ferd. Dummlers Verlag. Bonn, 1970. (289 p.).

- Esquel SEAS, Plan Participativo de Desarrollo Local, Junta Promotora y Municipalidad de Esquel, 2000 (Prediagnóstico) y 2001. Informe Final.

- Foglia, María Elena, Mónica E. Sánchez, Carlos A. Gómez y Liliana Argüello. El Bolsón. Provincia de Río Negro. República Argentina. Bases para la elaboración de un plan estratégico. Facultad de Arquitectura, Urbanismo y Diseño. Universidad Nacional de Córdoba. Córdoba. 1998. (57p.).

- Funnell, Don and Martin Price. Mountain geography: a review. Geographical Journal, 169 №3. September 2003.

- García Ballesteros, A. Las aportaciones de la Geografía Humanística. En García Ballesteros, A.(Ed.). Geografía y Humanismo, Barcelona, Oikos-tau, 1992 (114 p.).

- García Ballesteros, A..(Coord.). Métodos y técnicas cualitativas en Geografía Social. Barcelona, Oikos-tau. 1998. (239 p.).

- García Lende, Sebastián, Guillermo Velázquez y Jorge O. Morina. Reestructuración productiva, exportaciones provinciales y desempleo en el Noroeste Argentino (1991-2000). En Jorge O. Morina (Director), Neoliberalismo y Problemáticas Regionales en Argentina. Interpretaciones geográficas. Edición J. O. Morina. Buenos Aires, 2006.

- George, Pierre. Diccionario Akal de Geografía. Ediciones Akal. Madrid. 2004 (Primera Edición Akal, 1991).

- Gaignard, Romain. La Geografía Activa. En Zamorano, M. et al. La Geografía en la Republica Argentina. Problemática y enseñanza. Editorial Paidós. Buenos Aires. 1968.

- González, Myriam Susana. (2004). Una aproximación al paisaje vivencial de los habitantes de una comarca cordillerana. El caso de El Bolsón en la Patagonia Andina. Revista Geográfica. Instituto Panamericano de Geografía e Historia, № 133. México.

- Guibert, Martine. Entrevista: La gente ha perdido sus raíces, pero se esfuerza por recrearlas. Por C. Martyniuk, Diario Clarín, Buenos Aires, 5 de noviembre de 2006.

- Haggett, Peter. Geografía. Una síntesis moderna. Ed. Omega, Madrid, 1988. (669p.).

- Hartshorne, Richard. The Nature of Geography. Lancaster, Pensilvania. 1939.

- Hartshorne, Richard. ¿Qué clase de ciencia es la Geografía?. El carácter de la Geografía Regional. En Randle, P. (Editor) "Teoría de la Geografía”. Primera Parte. Sociedad Argentina de Estudios Geográficos, GAEA. Buenos Aires, 1984. 
- Hernández, Raúl Augusto y Mochkofsky. Notas sobre un ejercicio de simulación del uso del Medio Ambiente. El caso de Bariloche. Departamento de Sociología. Fundación Bariloche. San Carlos de Bariloche. 1974. (123 p.).

- Herrera, Amílcar et al. Catástrofe o nueva sociedad. Modelo Mundial Latinoamericano. Fundación Bariloche. Bogotá. 1977. (125 p.).

- Hollman, Verónica. Fronteras: objeto, concepto y metáfora en discusión. Quinto Encuentro Internacional Humboldt. Neuquén.2003.

- Ivars Baidal, Josep (redactor). Planificación y gestión del desarrollo turístico sostenible: propuestas para la creación de un sistema de indicadores. Instituto Universitario de Geografía. Universidad de Alicante. № 1 , 2001. (75p.).

- Knafou, Rémy. La planète nomade. Belín, Paris. 1997.

- Krugman, Paul. Desarrollo, Geografía y Teoría Económica. Antoni Bosh, editor. Barcelona. 1997. (113 p.).

- Labasse, Jean. La organización del espacio. Ed. Ariel, Barcelona, 1973. (739p.).

- Livon Grosman, Ernesto (2003:9). "Geografías imaginarias. El relato de viaje y la construcción del espacio patagónico". Ediciones Beatriz Viterbo. Rosario (202p.).

- Madariaga, Marta, "Interacción entre ambiente y población en San Carlos de Bariloche”, INTA, Bariloche. 2007. Versión digital.

- Maffesoli, Michael. Estamos en la era de los nómades y las tribus. Entrevista de Luisa Corradini. Diario La Nación, Buenos Aires, 31/08/2005.

- Martínez, Oscar A., Bondel, C. Santiago, Demarchi, Gabriela. y Danklmaier, Christine. Directrices de ordenación para el desarrollo territorial de Lago Puelo. Municipalidad de Lago Puelo - Unidad de asistencia en temas ambientales (UATA) de la Universidad Nacional de la Patagonia San Juan Bosco, sede Esquel. 2007.

- Mikkelsen, Claudia A.. Despoblamiento y neoruralidad. Viejos y nuevos procesos de poblamiento analizados en el Partido de General Pueyrredón. Anais do X Encontro de Geógrafos da América Latina. Universidade de São Paulo. 2005.

- Molina de Buono, Gladys. Metodología de investigación para el análisis y el diagnóstico territorial (51-85). En Molina de Buono, Gladys y María Estela Furlani de Civit (coordinadoras). Teoría, Método, Práctica. Proceso metodológico para la toma de decisiones en un territorio local. INCIHUSA, CRICYT. Zeta Editores. Mendoza. 2005. (356 p.)

- Nardi, Ricardo. La araucanización de la Patagonia (síntesis general). En Culturas indígenas de la Patagonia. Edición a cargo de J. Roberto Brácenas. Sociedad Estatal Quinto Centenario. Producción Turner Libros S. A.. Madrid. 1990. 
- Nogué i Font, Joan. El paisaje existencial de cinco grupos de experiencia ambiental. Ensayo metodológico en García Ballesteros, A. (Ed.). Geografía y Humanismo, Barcelona, Oikos-tau. 1992. (pp. 87-96).

- Novara M., Bondel C. S. (2006). Análisis Geográfico y Aplicación SIG a los parcelamientos rurales de la Patagonia Andina Argentina. En: Revista Internacional de Ciencia y Tecnología de la Información Geográfica - GeoFocus (www.geo-focus.org), Num. 6, Año 2006.

- Ojeda Rivera, J. F.. El paisaje como patrimonio- factor de desarrollo de las áreas de montaña. Universidad Pablo de Olavide, Sevilla. Boletín de la AEG, 2004, nº 38.

- Ortega Cantero, Nicolás. Geografía y cultura. Alianza Universidad Editorial. Madrid. 1988. (123 p.).

- Ortega y Gassett. El espectador. Textos escogidos. Ed. Salvat. Buenos Aires 1970.

- Pech, Pierre y Hervé Regnauld. Geografía Física. Editorial Hernandarias, Buenos Aires. 1997. (403 p.)

- Pickenhayn, Jorge. Epistemología y Geografía. Editorial Plus Ultra. Buenos Aires. 1994 (160 p.).

- Randle, Patricio. El método de la Geografía. Cuestiones epistemológicas. Ed. Oikos, Buenos Aires, 1978. (261 p.).

- Rappoport, E. 1990. La primera guerra mundial de las especies. Entrevista Rev. Ciencia Hoy. Vol.1, №6.

- Rentería Vargas, Javier. Una aproximación teórica y práctica al concepto de región. En GEOCALLI, Cuadernos de Geografía, Año 2, № 4. Universidad de Guadalajara, México, 2001. (pp. 15 a 36).

- Robinson, David. Espacio y Tiempo es un continuo. Entrevista de Omar Gejo en Revista Meridiano. Centro de Estudios A. von Humboldt. Buenos Aires. №3. 1996. (pp. 32-43)

- Roccatagliata, Juan A.. El espacio desde la óptica geográfica. Sociedad Argentina de Estudios Geográficos GAEA. serie: Aportes al pensamiento geográfico $N^{\circ} 1$. Buenos Aires. 1982.

- Rovira, Adriano. Nueva ruralidad y nueva urbanidad. El caso de Puerto Montt, Chile. Instituto de Geociencias. Universidad Austral de Chile. Valdivia, Chile. Ponencia en el VI Encuentro Internacional A. Von Humboldt. Centro de Estudios Alexander Von Humboldt de Buenos Aires. Carlos Paz, Córdoba (Argentina) en 2004.

- Rush, Verónica. Estado de situación de las áreas protegidas de la porción argentina de la ecoregión Valdiviana. Fundación Vida Silvestre y WWF. Versión digital, 2002. (99p.).

- Samaja, Juan. Epistemología y metodología. Elementos para una teoría de la investigación científica. EUDEBA, $3^{\circ}$ edición. Buenos Aires, 2004. 
- Santos, Milton. Metamorfosis del espacio habitado. Ed. Oikos-tau. Barcelona. 1996. (118p.).

- Santos, Milton. A Natureza do espaço. Técnica e tempo; razao e emoçao. $3^{a}$ ediçao. Editora Hucitec, San Pablo. 2001.

- Sassone, Susana. El enfoque cultural en geografía. Nueva aproximación teóricometodológica para el estudio de las migraciones internacionales. Informe inédito, DIGEO-IMHICIHU; CONICET. Buenos Aires, 2001. (20 p.).

- Seemann, Jörn. Land use dynamics in a Latin American city: The example of Campinas / Brazil. Revista Geográfica No 129. Enero-Junio, 2001. Instituto Panamericano de Geografía e Historia.

- Silvestri, Graciela y Fernando Aliata. El paisaje como cifra de armonía. Ediciones Nueva Visión, Buenos Aires, 2001.

- Stamp, Dudley. Geografía Aplicada. EUDEBA, Buenos Aires. 1981.

- Steck, Benjamin; Le Morvan, Jacqueline. En Síntesis de la Conferencia universitaria del 11 de abril de 2001. El Havre, Francia. www.ac-rouen.fr . Fuente: Noticias del CeHu 626/03 Centro Humboldt, Bs. As..

- Tadeo, Nidia. La reconceptualización de lo rural en la Argentina. Un tema para el debate. En Tadeo, Nidia (coord.), Procesos de cambio en las áreas rurales argentinas. Hacia la construcción de un nuevo concepto de ruralidad. Estudio Qubbus. La Plata. 2002. (p. 33 a 48)

- Tadeo, Nidia (coord.), Paula Palacios y Fernanda Torres. Agroindustria y empleo. Complejo Agroindustrial Citrícola del Noreste Entrerriano. Editorial La Colmena. Buenos Aires. 2006. (220p.).

- Wilbanks, Thomas. 'Sustainable Development' in Geographic Perspective. Oak Ridge National Laboratory. Annals of the Association of American Geographers. 1994.

- Zingoni, J. M., S. M. Martínez, y E. Quartucci. Causas y efectos de la valorización del suelo urbano en destinos turísticos de la cordillera andino patagónica; el caso de la localidad de San Martín de los Andes. Informe inédito. Bahía Blanca, 2006. 


\section{SEGUNDA PARTE}

\section{II. Área de estudio. La Comarca Andina del Paralelo 42 en la Patagonia Andina 'de los lagos' (Argentina).}

\section{II.1. El contexto formal y funcional andino patagónico.}

En la Introducción se destacó un apartado sobre un tema bastante más complejo de lo que habitualmente se estima: la delimitación del territorio considerado en la investigación. Para nuestro caso son dos las escalas a considerar. Desde una perspectiva amplia trataremos aquella que involucra a la Patagonia Andina 'de los lagos', en su sector argentino y, ya como área de estudio específica, a la Comarca.

\section{Lo formal}

Frente a este planteo y en toda su extensión, la Patagonia Andina, desde su extremo Norte en el Centro Oeste de Neuquén hasta el Centro Oeste de Chubut, se presenta como espacio típicamente formal, esto es, donde hay coincidencia, o mejor, correspondencia en las formas; conformidad en su configuración geográfica. Aquí las diversas morfologías, tanto bio-físicas como socio-culturales se manifiestan con un cierto orden espacial unificado ${ }^{53}$.

\footnotetext{
${ }^{53}$ Como comentario adicional y descriptivo para nuestros fines, merece destacarse cierto reconocimiento generalizado como lugar 'fabuloso y perdido' y que, aún sin precisión espacial ni centros de gestión de jerarquía suficiente (Bariloche
} 
Ciñendo una visión de conjunto, vemos que se trata de una conformidad propia de ámbitos coincidentes en las ofertas y demandas naturales así como en las expectativas territoriales de sus pobladores, que, con cierto orgullo, se presentan como cordilleranos. De un modo $u$ otro, los Andes y sus estribaciones le dan conformidad al espacio, esto aún en amplios sectores orientales menos 'andinos' y casi sin bosques, pero en los que se han desarrollado modalidades distintivas del resto de la Patagonia extra-andina; es decir respecto de aquella de la aridez y los horizontes escalonados. De cualquier modo, a fuer de ser realistas, y más aún donde los ingredientes históricos en el paisaje son relativamente recientes, la realidad no es tan sencilla y hacia el Este se presentan componentes socio-culturales y económicos indefinidos.

Como antídoto ante las dudas, valdrá el hecho que, como se desprende de cualquier conversación, así como de los discursos políticos y mediáticos, en particular para chubutenses o rionegrinos, a los pueblos y parajes esteparios que habitualmente se vinculan con Esquel, El Bolsón, Bariloche o la frontera internacional, se les llama cordilleranos. De hecho, en cada provincia, los respectivos sistemas educativos, de salud y seguridad, responden orgánicamente y según el caso, a la figura de zona cordillerana o andina.

\section{Lo funcional}

Es de hacer notar que, en términos funcionales, aún para la Patagonia toda y tal como sucede en varias zonas de la periferia argentina, la estructura funcional no es coincidente con esa conformidad a la que hacíamos mención. Aquí, deficiencias en materia de autonomía de gestión económica (muchas de ellas lógicas en términos mercantiles) e importantes restricciones naturales, le hacen el juego a una debilidad característica. A la concentración económica y política en Buenos Aires y que es propia del país, se le suma una tutoría que, hasta hoy, invalida cualquier proyección funcional unificada de la Patagonia. Hecho, este último, potenciado por el alto grado de fragmentación regional interna, donde, el Alto Valle del río Negro, con NeuquénCipoletti-General Roca como centro, el conjunto Trelew-Rawson-Puerto Madryn y Comodoro Rivadavia con su entorno, se presentan como organizadores secundarios de la totalidad patagónica ${ }^{54}$.

\footnotetext{
parece desentendida), la Patagonia Andina aparece mencionada, sin más, en cuestiones resonantes. Ya con hechos concretos como el proyecto atómico de Huemul o ser refugio de jerarcas nazis o ser, también, la meca hippie argentina, y, en supuestos, como aquello de la Andinia Argentina junto con otras especulaciones que pueden remontarse al Siglo XVII cuando Mascardi buscaba la Ciudad de los Césares (Furlong 1995: 29-40).

${ }^{54}$ En realidad la fragmentación es tal, que en muchos aspectos, Río Gallegos, Ushuaia, Viedma y San Carlos de Bariloche, también juegan ese rol secundario y espacialmente importante. Son válidas las consideraciones de Roccatagliata y Capitanelli, quienes para el conjunto regional destacaban la existencia de focos pioneros de ocupación. (1988:434 y 687 respectivamente)
} 
En la franja andina en particular, la tipología funcional obedece a las lógicas provinciales y cada una de ellas ha sectorizado su gestión territorial en concordancia con la existencia de un sector occidental cordillerano ${ }^{55}$. Resultarán entendibles las consecuencias de una conformación territorial de estas provincias patagónicas en sentido transversal a la cordillera, que mucho han ayudado para que prevalezca la lógica y a veces 'saludable' prioridad de coherencia interna de cada una de ellas, por sobre las demandas sectoriales interprovinciales. Es así que temas clave, como el manejo de agua, los sistemas educativos, de salud y hasta de transporte, por mencionar algunos, permanecen en compartimientos estancos unos de otros.

Con todo, son innegables los indicios concretos que propenden el enlace territorial por encima de las divisiones políticas. En este sentido el turismo se muestra como la actividad más activa, siguiéndole también la conservación ecológica, el comercio y telecomunicaciones, la energía, ciertos roles militares y otras iniciativas más acotadas como la investigación científico-tecnológica. Como se entenderá, dado el contexto político contemporáneo, estas tendencias obedecen en unos casos a las propias de políticas nacionales, mientras que en otros, a la demanda de reacomodamiento que impone prioridades desde un nuevo orden internacional 'globalizante'56.

La Patagonia Andina 'de los lagos' (Argentina), (ver Mapa 1).

Como se ha visto en la Introducción, unos 230.000 habitantes ocupan una franja relativamente estrecha de entre 45 y $115 \mathrm{~km}$. y que se extiende de Norte a Sur entre los aproximadamente $39^{\circ}$ y $44^{\circ}$ Sur (unos $560 \mathrm{~km}$ ). Se trata de unos $45200 \mathrm{~km}^{2}$ recostados sobre el límite con Chile y que agrupa a los cuatro departamentos del Sudoeste neuquino, al Oeste rionegrino y al extremo Noreste chubutense ${ }^{57}$ (para mayor detalle, ver apéndice 3).

\section{II.2. La Comarca Andina del Paralelo 42. El área de estudio como entidad territorial.}

\footnotetext{
${ }^{55}$ Resultarán entendibles las consecuencias de una conformación territorial de estas provincias patagónicas en sentido transversal a la cordillera, que mucho han ayudado para que prevalezca la lógica y a veces 'saludable', prioridad de coherencia interna de cada una de ellas, por sobre las demandas sectoriales interprovinciales. Con todo, temas clave, como el manejo de agua, los sistemas educativos, de salud y hasta de transporte, por mencionar algunos, permanecen en compartimientos estancos unos de otros.

${ }^{56}$ Temas tradicionalmente 'quisquillosos' como el funcionamiento de las aduanas, las normativas de áreas zonas de frontera, aeropuertos, hotelería y tenencia de la tierra y demás, son tratados hoy en día desde una posición 'aperturista'.

${ }^{57}$ Por el hecho de corresponder este límite en Río Negro y Chubut con la traza de la Ruta Nacional 40 (al año 1994) y de que en algunos parajes y pueblos el camino atraviesa literalmente tramas pobladas, hemos desplazado ligeramente la delimitación hasta donde, por conocimiento propio de los sitios, resultara razonable. Se buscó evitar un efecto de 'corte' espacial, donde justamente, el camino es factor de enlace. Por otra parte, en términos de superficies involucradas y dadas las dimensiones generales, estas pequeñas modificaciones son casi insignificantes. Los lugares más significativos son, de Norte a Sur, Pilcaniyeu, Las Bayas, Ñorquinco, Leleque, Nahuel Pan y Tecka.
} 


\section{II.2.1. Presentación y funcionalidad básica.}

"...hay en la región austral argentina comarcas muy precisamente delimitadas que contienen factores considerables de productividad, (...). Los valles cordilleranos habitables tienen prioridad en la enumeración laudatoria de lugares propicios para la instalación del hombre en equilibrio con la Naturaleza. (...) El más notable de estos valles es El Bolsón..." (Federico Daus. 1976:171).

Recurriendo a tradicionales definiciones geográficas, conceptualizamos como Comarca, a aquella unidad territorial en las que dos o más poblaciones linderas, tienen elementos y/o factores que se vinculan ineludiblemente; esto último, aún frente a divisiones administrativas excluyentes.

Aunque resulte extraño, esta entidad geográfica, reconocida como tal desde fines de la década de 1980 y que abarca una amplia zona repartida entre las provincias de Río Negro y Chubut, no reúne claridad en cuanto a su verdadera jurisdicción definida. Sin embargo la figura comarcal, varias veces ya mencionada hasta ahora, resulta aceptada e incluso utilizada, a modo de carta de presentación. Es el nombre aglutinador de un conjunto de condiciones que le dan la particularidad de espacio diferenciado. En otros términos y como lo utilizamos con Abelardo de Almeida (1996), podría decirse que se trata del área de influencia de El Bolsón; si bien dada la evolución sectorial del último decenio, más acertado sería referirse al área de influencia de El Bolsón-Lago Puelo ${ }^{58}$.

La Comarca involucra netamente a los ejidos administrativos de las localidades de El Bolsón, Lago Puelo, El Hoyo y Epuyén, y, además con menor especificidad por su solapamiento con el área de influencia de la ciudad de Esquel, a los de El Maitén y Cholila. También en la estepa rionegrina el pueblo de Ñorquinco mantiene vínculos visibles con la Comarca compartidos con San Carlos de Bariloche. Son unos 7.550 $\mathrm{km}^{2}$ de los cuales $3.000 \mathrm{~km}^{2}$ se corresponden con la cuenca del Lago Puelo y donde se distribuyen en total unos 35.000 habitantes (un tercio en el sector chubutense) ${ }^{59}$. El Bolsón se encuentra a $120 \mathrm{Km}$. al sur de San Carlos de Bariloche y $180 \mathrm{Km}$. al Norte de Esquel. A escala nacional, es una ciudad pequeña (aprox. 22.000 hab.), regionalmente de tercer rango ${ }^{60}$.

\footnotetext{
${ }^{58}$ Aunque es lógica una aceptación conceptual respecto que el área de influencia implica una gravitación con doble sentido, entendemos que la relativización progresiva de la centralidad y sus roles territoriales jerárquicos, nos habilita a rescatar el 'binomio' influencia-afluencia, en el sentido de destacar una mirada más amplia de las relaciones centroperiferia, al menos en escalas locales y sistemas urbanos apenas incipientes.

${ }^{59}$ Se trata de estimaciones generales que deben profundizarse en caso de requerir precisiones; se obtiene a partir de valores censales 2001 y un ajuste tentativo con la confrontación de los padrones censales y la evolución de las conexiones eléctricas domiciliarías (EDERSA, 2007).

${ }^{60} \mathrm{Sin}$ entrar en un debate jerárquico en materia urbana, parece aceptable que regionalmente un centro de tercer rango actúa tan sólo como un distribuidor económico comarcal pero carente de autonomía funcional (escasas delegaciones administrativas de dependencia directa con la cabecera provincial, complejidad hospitalaria intermedia-baja (sin terapia intensiva), carencia de: aeropuerto, sede universitaria, bancos netamente privados, shoppings, etc.). A título comparativo, un segundo rango, que es hacia donde todo indicaría que se dirige El Bolsón, implica la presencia de instituciones o entidades, en especial de servicios, que reúnan cierta autonomía operativa por diversidad y complejidad (salud, comercio y finanzas, educación, comunicaciones, seguridad, etc.), pero que de todos modos se hallan articulados desde un centro regional de mayor jerarquía (San Carlos de Bariloche, Viedma, Trelew-Rawson y Neuquén).
} 


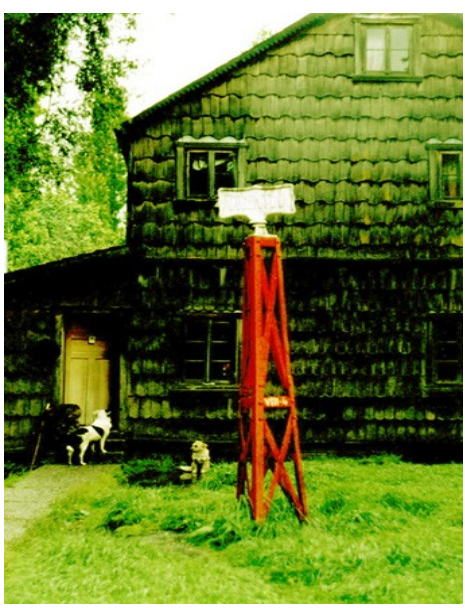

12

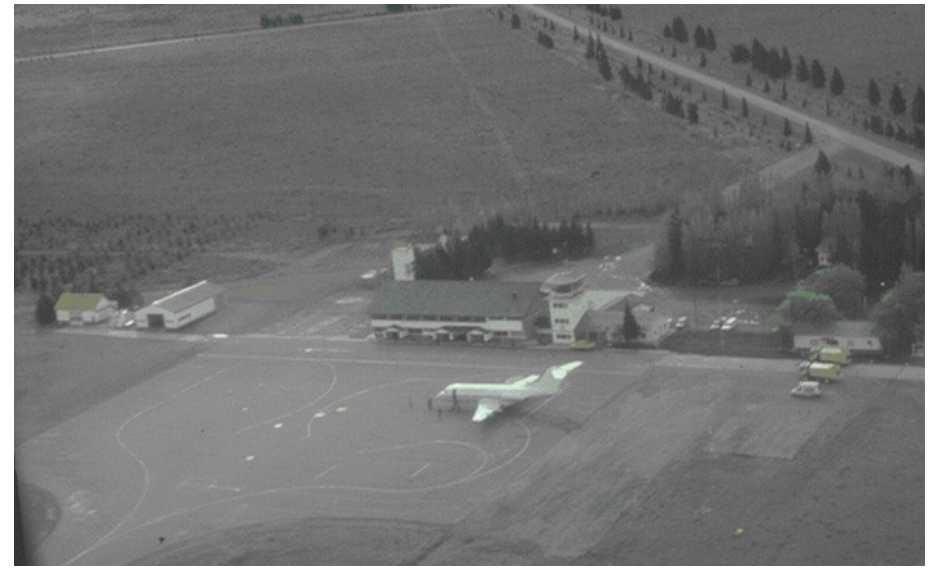

13

Fotos: 12 y 13. Elementos estructurales.

12: Fronteras jóvenes; hito fronterizo (complementario) Argentino-Chileno en el patio de una familia rural; El Manso. Foto del autor, 2004.

13: Aeropuertos regionales, nacidos como enlaces nacionales, hoy casi desactivados y en busca de circuitos internacionales; aeropuerto Esquel. Foto el autor, 2005.

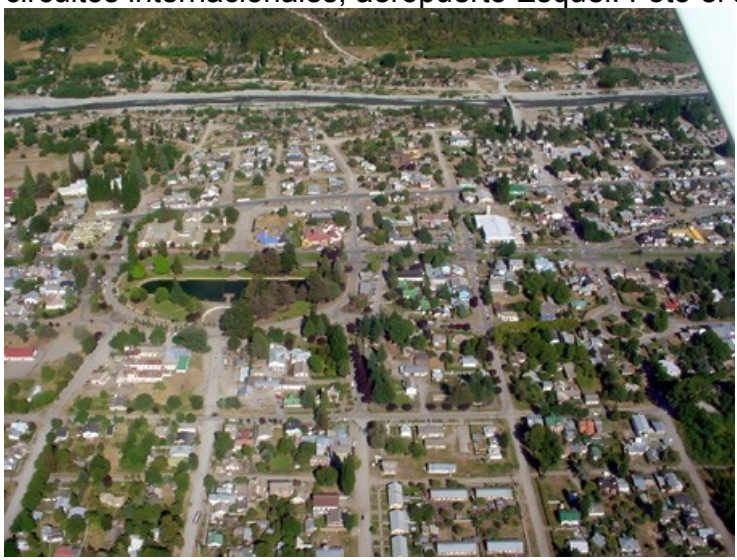

14

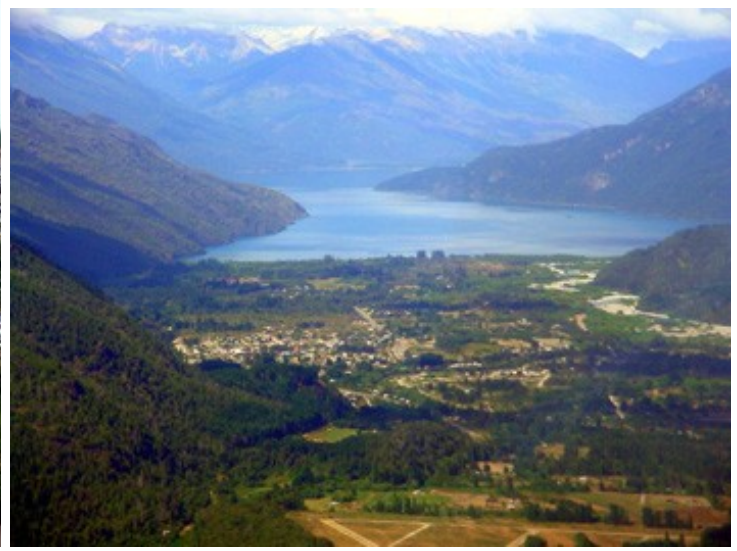

15

Fotos: 14 y 15: Ciudad y pueblos en la organización espacial de los valles. 14.: área central de El Bolsón. 15: localidad de Lago Puelo y al centro y fondo, el lago en el Parque Nacional homónimo. Fotos: F. Ottone, 2004.

El topónimo Valle Nuevo es quizás el antecedente más aceptado en cuanto a la necesidad popular de atribuirle a este espacio una denominación espacial abarcadora de estos valles y montañas. De hecho existe cierto consenso histórico regional en el que aparece como aglutinador del área, al Norte y Sur del Paralelo $42^{\circ} \mathrm{S}$. (Méndes, J. M.:comunicación Personal), si bien en casos se le atribuye su exclusividad al valle del Río Azul (Cf: Catania y Sales 2001: 78-79). Aún así, debe rescatarse que frente a las jurisdicciones establecidas, se mantuvo la búsqueda de una identificación unitaria y ha sido la de Valle Nuevo la más recurrente en las citas que tratan al conjunto territorial ${ }^{61}$.

\footnotetext{
${ }^{61}$ Aunque haya sido en el entorno de las bromas, resulta de alguna significación aquella anécdota de 1912 sobre la creación de la República de El Bolsón, seguramente inspirada en el aislamiento de estos valles y su desconexión con el resto del país (Roselli, 2000).
} 
Finalmente, con la consolidación de los circuitos administrativos provinciales de Río Negro y Chubut el topónimo cayó en desuso, cobrando entidad el paralelo limítrofe interprovincial que atraviesa al valle (la cuenca del río Azul-Quemquemtreu) ${ }^{62}$.

Tal ha sido el peso de esta división política, que aún los equipos técnicos del CONADE y otros (1966-67), hicieron caso omiso de eventuales integraciones locales de carácter lógicas y espontáneas, delimitando la propuesta regional Comahue y Patagonia con el Paralelo 42 (Decreto Nacional 1.097/67) ${ }^{63}$. Por supuesto que incumbencias nacionales exigieron ciertos tratamientos conjuntos, en particular en materia forestal, vial y militar, pero el peso de las estructuras provinciales fue decisivo, incluso en tiempos previos a las provincializaciones de los años 50 . Viedma en un principio y Rawson luego, fueron y son fuertemente centrípetos en materia de salud, educación, seguridad y administración.

Durante las últimas décadas El Bolsón, como cabecera 'natural', ha crecido en proporción significativa, tanto por su población como por su jerarquía geográfica, manifestando un ostensible rol funcional respecto del ámbito rural y las localidades chubutenses involucradas. Es más, la vinculación, básicamente espontánea entre ambos lados del Paralelo 42 es tan obvia, que rompe cotidianamente con las ya mencionadas políticas centrípetas provinciales. La Feria Regional de El Bolsón, con unos 300 sitios de venta, las ocupaciones a uno y otro lado del Paralelo, las decenas de alumnos y docentes que diariamente 'cambian' de provincia para la rutina escolar, etc., son demostrativos de una realidad compleja y territorialmente integradora.

Es interesante destacar que así como esta condición bi-provincial de la Comarca trae inconvenientes importantes, en especial a los fines del Planeamiento, también se proyecta favorablemente en ciertas situaciones críticas. Para el caso, siendo dos los estados provinciales, las posibilidades de gestión son mayores y hasta existe alguna complementariedad, se diría espontánea, en materia de empleo, salud, educación, medio ambiente, comercio, recreación y otros aspectos de la vida comunitaria.

Por otra parte, vista desde una perspectiva funcional regional, la Comarca se sitúa en el extremo de un eje territorial de carácter nacional; extremo no vinculante, es decir prácticamente sin proyección sobre otras áreas dinámicas más alejadas. Esta situación se ajusta al carácter periférico del centro-oeste patagónico y al escaso desarrollo económico-demográfico del territorio chileno en estas latitudes. El eje Buenos Aires-Neuquén-Bariloche, tiene en El Bolsón-Puelo su extremo sur más

\footnotetext{
${ }^{62}$ Resultará ilustrativa la trascendencia de este tipo de división administrativa. Por ejemplo, el Paralelo 42 adquirió cierta fama en tiempos de Frondizi (1957-63); fue entonces que entre varios productos, los vehículos que se compraban al Sur de su misma línea, gozaban de amplias exenciones impositivas. Temática que, por cierto no afectó al sector andino, carente por entonces de condiciones de mercado y caminos como para hacer valer la ventaja.

${ }^{63}$ Véase una interesante crítica a esas instancias del Planeamiento territorial en Daus (1976: 169-175).
} 
alejado $^{64}$ y compite con aquel menos significativo en la zona que articula Buenos Aires-Bahía Blanca-Trelew-Esquel.

La funcionalidad interna, obedece básicamente al área de influencia de El Bolsón, con salvedades propias de una Comarca bi-provincial, donde Lago Puelo, El Hoyo y Epuyén concentran sus propios servicios institucionales y algunos comerciales ${ }^{65}$.

\footnotetext{
${ }^{64}$ Hasta la pavimentación de la Ruta Nacional 40 (ex 258) en 1996, un cul de sac.

${ }^{65}$ En cuanto a El Maitén y Cholila, se valora su condición periférica respecto de la Comarca y con ello se debe analizar desde una perspectiva que involucre también a la ciudad de Esquel.
} 


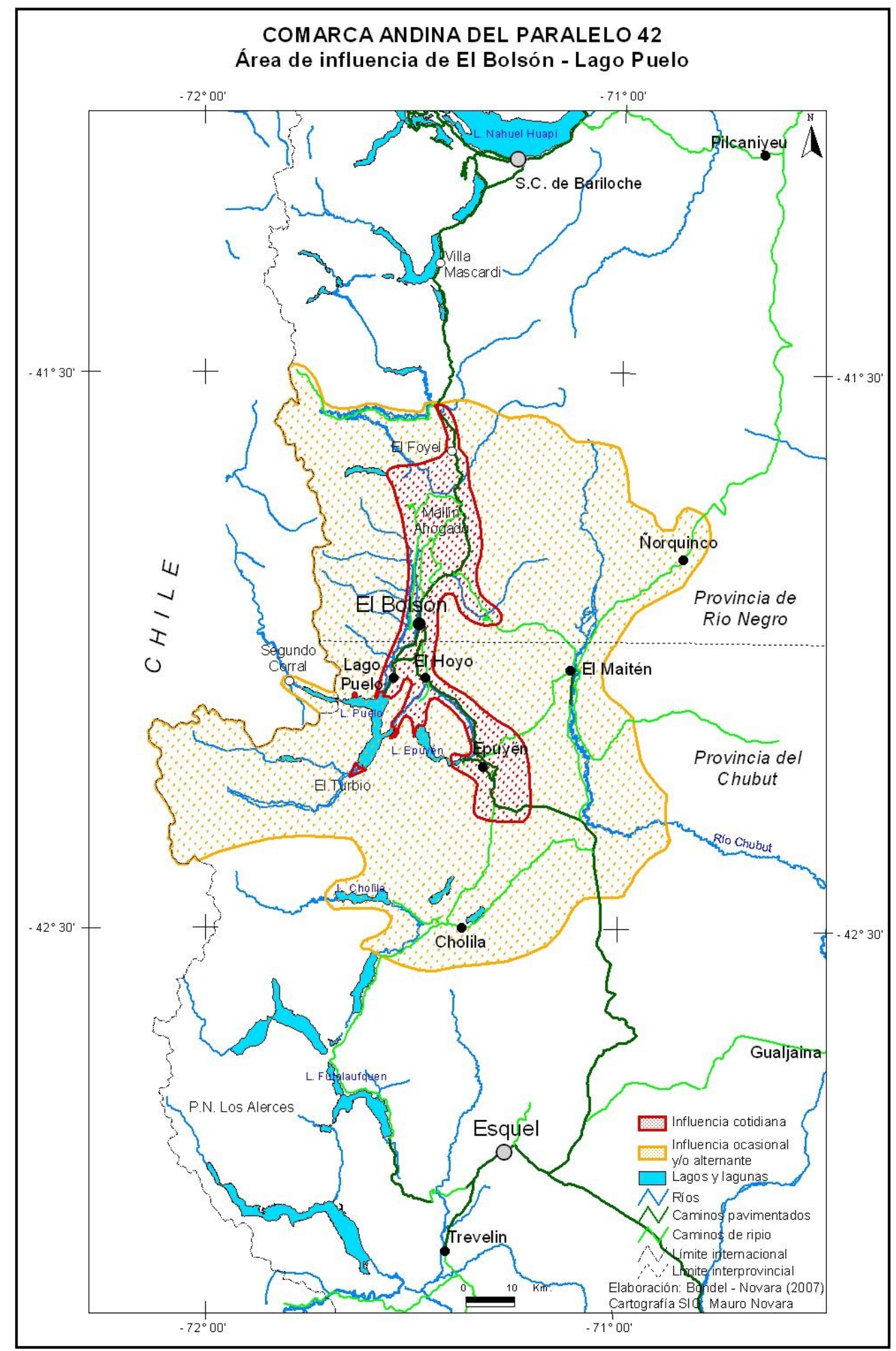

Mapa: 2: Áreas de influencia comarcal. Debe valorarse la relación directa entre una topografía montañosa, el recorrido de la ruta pavimentada que la atraviesa de Norte a Sur y la forma 'caprichosa' de área de influencia cotidiana. Con cambios reiterados por el diferente paso relativo del poder de atracción, el área de influencia ocasional se comparte con S. C. de Bariloche y Esquel. El caso de Segundo Corral en Chile es apenas circunstancia; día a día se estrecha el vínculo con su centro regional en Puerto Montt. Desarrollado a partir de: ejidos municipales, destino de los mensajes sociales de las radios locales, informantes clave respecto de: domicilios de feriantes, reparto de materiales de construcción y transporte automotor; también, por cierto, de la experiencia a campo. 


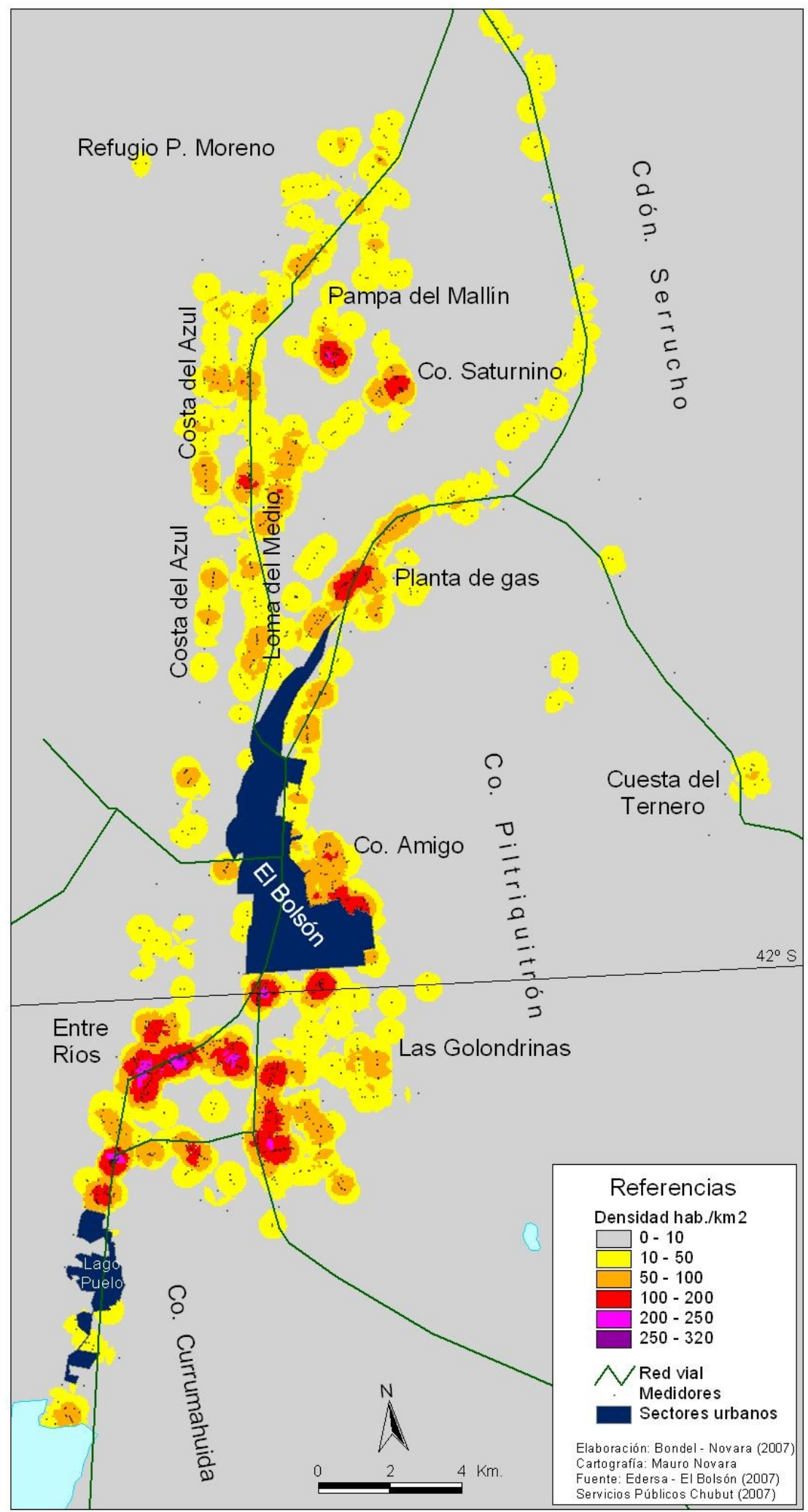

Mapa: 3. Densidad de población rural. Estimaciones a partir de medidores eléctricos residenciales. Nótese además de los altos valores relativos, la tendencia concentradora en sectores (parajes), en particular adyacentes a los corredores viales. La densidad de población fue calculada por celda (de 50 metros de lado), a partir de la sumatoria del valor de población (4 hab. por punto) dividido por el área del círculo en las unidades de área (300 metros). El resultado es la cantidad de habitantes $/ \mathrm{km} 2$. Fuente: elaboración propia en base a información suministrada por la Empresa Edersa, El Bolsón y Servicios Públicos de Chubut (Lago Puelo). 
Localidades cantidad de habitantes

\begin{tabular}{|l|c|c|c|c|c|}
\hline \multicolumn{4}{|c|}{ Habitantes según censos } \\
\hline \multicolumn{1}{|c|}{ Localidad $^{|c|}$} & $\mathbf{1 9 6 0}$ & $\mathbf{1 9 7 0}$ & $\mathbf{1 9 8 0}$ & $\mathbf{1 9 9 1}$ & $\mathbf{2 0 0 1}$ \\
\hline El Bolsón urbanos ${ }^{66}$ & $\mathbf{2 6 0 7}$ & $\mathbf{2 6 7 8}$ & $\mathbf{5 0 0 1}$ & $\mathbf{1 0 0 0 4}$ & $\mathbf{1 3 . 5 6 0}$ \\
\hline El Bolsón rural & $\mathbf{1 9 9 9}$ & s/d & s/d & $\mathbf{2 6 9 6}$ & 1977 \\
\hline Lago Puelo (agrupada y dispersa) & - & $\mathbf{5 4 1}$ & $\mathbf{1 9 6 0}$ & $\mathbf{2 4 6 3}$ & $\mathbf{4 0 4 6}$ \\
\hline El Hoyo (agrupada y dispersa) & - & $\mathbf{7 0 7}$ & $\mathbf{1 0 8 3}$ & $\mathbf{1 5 9 9}$ & $\mathbf{2 1 6 2}$ \\
\hline Epuyén (agrupada y dispersa) & s/d & s/d & $\mathbf{7 9 5}$ & $\mathbf{1 1 9 6}$ & 1498 \\
\hline El Maitén (agrupada y dispersa) & 202 & 278 & 285 & 3085 & 3782 \\
\hline Cholila (agrupada y dispersa) & 7 & 0 & 2 & & \\
\hline Ñorquinco (agrupada) & $s / d$ & 822 & 133 & 1557 & 1981 \\
\hline Segundo Corral, Chile (tentativa) & - & - & - & - & 230 \\
\hline
\end{tabular}

Tabla 1. Población; en 'negrita' las localidades del área de influencia cotidiana del El Bolsón-Lago Puelo. En cursiva las localidades en el área de influencia comarcal ocasional o alternante compartida con S. C. de Bariloche (Ñorquinco), Esquel (El Maitén y Cholila) y Puelo-Puerto Montt (Segundo Corral).

Fuentes: elaboración propia en base a datos de los Censos Nacionales INDEC) de 1960, 1970, 1980, 1991 y 2001 e información turística complementaria (Chile). Ver consideraciones generales en pág. 53.

Merece destacarse, que la configuración geográfica comarcal, tanto por sus condicionamientos naturales (topografía y red hidrográfica, en particular) como por el diseño de sus asentamientos y trama caminera, consolida la condición central de El Bolsón y potencia la especialización territorial de las diferentes localidades y parajes. Tanto es así que, aún cuando se observan situaciones de superposiciones un tanto recurrentes, en especial en materia administrativa y aunque todavía no lleguen a complementarse, cada localidad se orienta hacia un perfil no muy competitivo entre si, en particular en materia cultural-educativa.

En definitiva, además de los usos vinculados al turismo, que lideran la vocación territorial en la generalidad del territorio, existen sectores más asociados a:

- la producción ganadera-agrícola en Mallín Ahogado, El Maitén, Cholila, Epuyén y Rincón de Lobos- Currumahuida - El Desemboque;

- la fruticultura y la residencia rur-urbana en El Hoyo, Las Golondrinas, Los Nogales y Entre Ríos;

- la actividad silvícola y silvo-pastoril en Los Repollos, Cuesta del Ternero, Rinconada de Nahuelpán, El Pedregoso, El Turbio y Cerro Radal;

\footnotetext{
${ }^{66}$ Del análisis demográfico de Miatello (1970: 184), se deprende que en 1960 la población rural representaba para el entorno rionegrino de El Bolsón el $43 \%$ del total y con ello se obtenía una densidad rural patagónica relativamente significativa de $1,1 \mathrm{~h} / \mathrm{km}^{2}$ esto, claro está, si se aprecia la cifra en un contexto del paisaje sumamente quebrado y boscoso (1795 km² departamentales al Sur del P.N. Nahuel Huapí).
} 
- la conservación 'plena', en el Parque Nacional Puelo y la conservación 'orientada', en INTA Las Golondrinas, INTA Loma del Medio y en varias reservas provinciales y municipales ${ }^{67}$;

- los servicios especiales de comercio y recreación, en El Bolsón y los demás núcleos más o menos urbanizados.

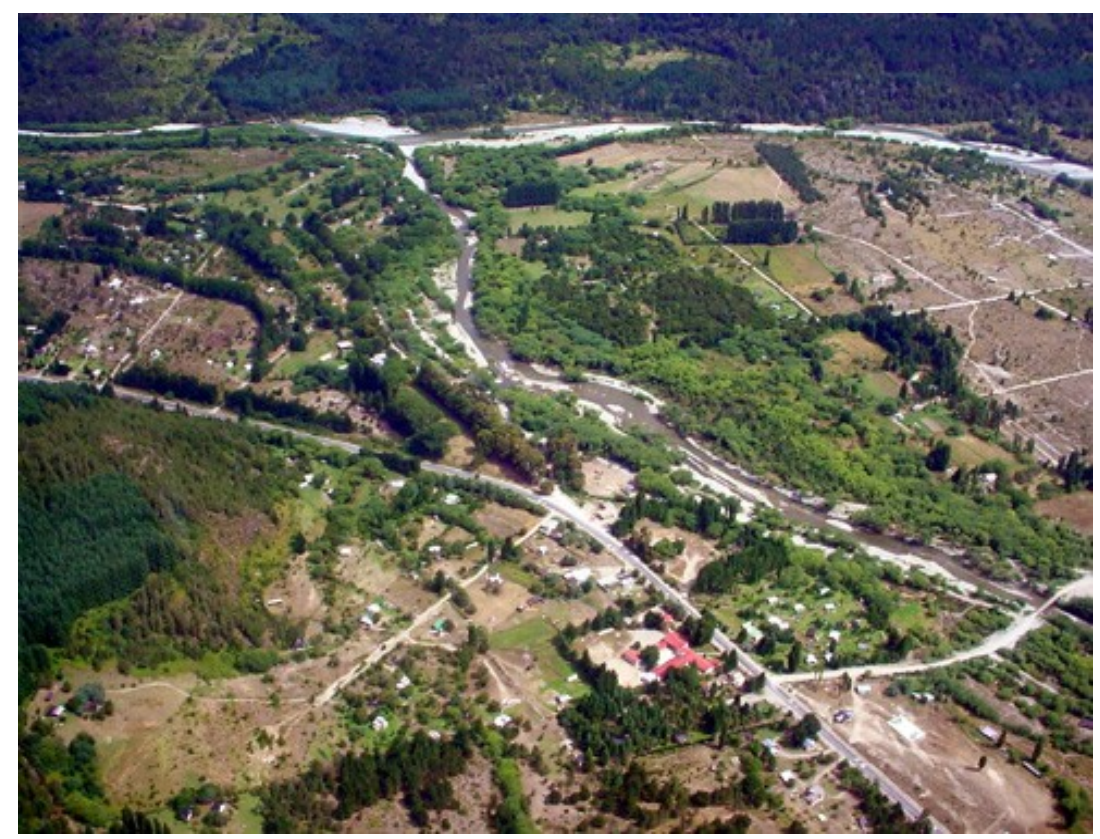

16

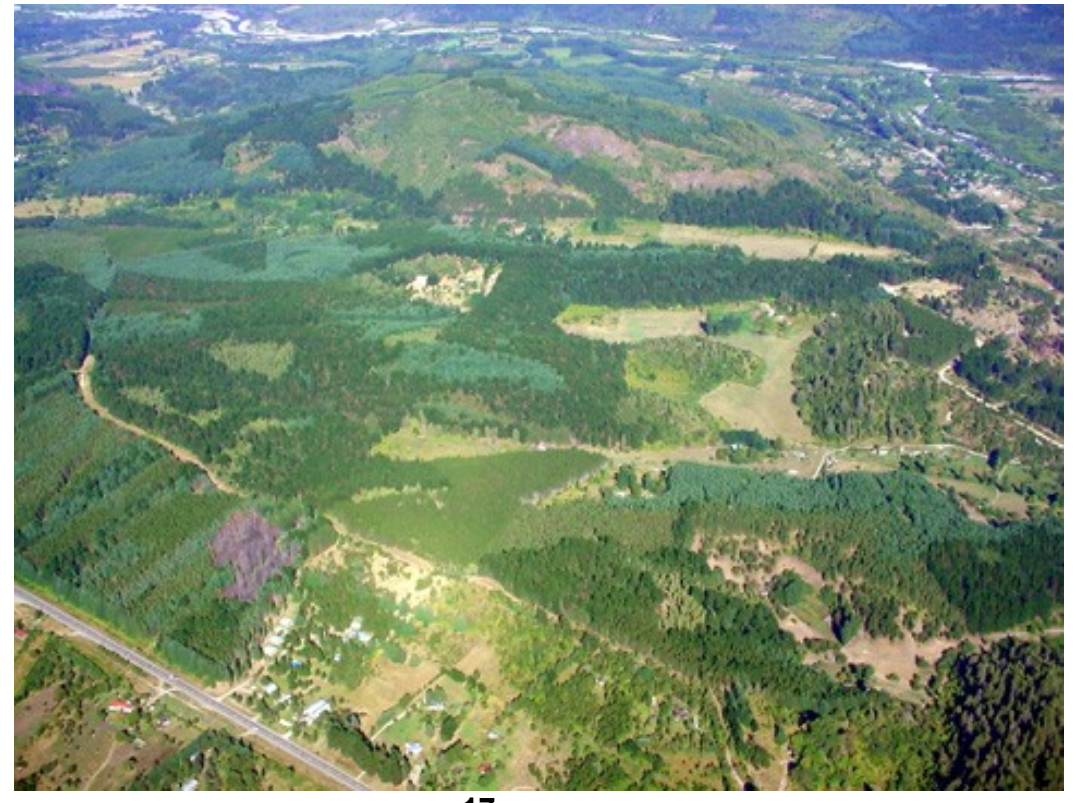

17

Fotos: 16 y 17. Una constante en el paisaje es la diversidad de usos. Fotos: F. Ottone, 2004.

\footnotetext{
${ }^{67}$ Como será tratado más adelante, los casos provinciales y municipales revelan una gran heterogeneidad en sus verdaderos alcances, siendo los casos de la reserva Río Azul- Lago Escondido (ANPRALE) y Cerro Pirque-Lago Epuyén, casos paradigmáticos en cuanto a reunión de conflictos prototípicos (usos, tenencia de la tierra, actividades, deslindes, incumbencias).
} 
16: Sector: Confluencia del los ríos Quemquemtreu y Azul (Entre Ríos). Notese la importante cantidad de edificaciones donde hasta no mucho más allá de 15 años solamente reunía unas cuantas chacras dispersas.

17: Sector Cerro Radal con la Ruta Nacional 40 en el ángulo izquierdo-abajo. Mayormente se observan plantaciones de pinos sometidos a un plan de manejo que, dado los portes convenientes, implica una saca importante y con ello una constante modificación de los espacios cubiertos.

\section{La gestión territorial y la Comarca, una entidad imprecisa.}

Siguen abajo tres apreciaciones que muestran una realidad formalizada, pero, de momento, sin capacidad ejecutiva y con confusiones en cuanto a su conformación espacial (los subrayados son propios).

Nos dicen Lemoine y Sarabia (2001) en su análisis sobre micro regiones y desarrollo sustentable en Argentina, "... producto de un tratado interprovincial, el CODECAP (Consejo de Desarrollo de la Comarca Andina del Paralelo 42). Esta micro región está integrada por los municipios de Cholila, Epuyén, Lago Puelo, El Maitén y El Hoyo (Chubut) y por el municipio de El Bolsón y la Comuna Rural El Manso (Río Negro). Este tratado, firmado el 17 de septiembre de 1998, fue suscripto por los gobernadores de las provincias mencionadas, rubricado por el Ministro del Interior y ratificado por las respectivas legislaturas".

Adriana N. Martínez (2006) en su interesante análisis sobre regionalidad y espacio político en Argentina, incorpora localidades y agrega datos, "... la Microrregión de la comarca andina del Paralelo 42, está constituida por los municipios de Cholila, Lago Puelo, El Maitén, El Hoyo, Epuyén, El Bolsón y la Comuna rural El Manso, creada en el marco de la firma de un tratado interprovincial entre Río Negro y Chubut, previa promoción y acompañamiento de parte de la Conadepa (órgano del gobierno federal que puso en marcha un programa de microregiones patagónicas), que expresamente consigna en sus documentos el concepto que adopta de microregión: "Entendemos por microregión a la unidad de análisis territorial, contenida especialmente por la región -la unidad mayor- y constituye un sistema homogéneo y diferenciado-". En dicho ámbito se interrelacionan el estado nacional, las citadas provincias, los municipios y comunas, contando con el apoyo de la cooperación española.(...). En una superficie territorial de $8.500 \mathrm{~km} 2$ y con sólo 33.000 habitantes involucrados, estos pequeños municipios patagónicos concretan un trascendente paso institucional, modelo cuya reproducción en el resto del país, atendiendo a las particulares situaciones y circunstancias de cada caso, es más que deseable."

La gestión provincial rionegrina, en cambio, reconoce la figura de una comarca interprovincial, pero sin involucrar a las localidades de Cholila y El Maitén. En su programa de gestión territorial (Río Negro-CFI, 2007: 290) se indica, "... La UTG Andina Sur comprende El Bolsón y El Foyel, debemos marcar que estas localidades están comprendidas, por su interrelación entre sí y con otros lugares cercanos, en la comarca andina del paralelo 42, la cual tiene una superficie de $4.369 \mathrm{~km} 2$. La conformación geográfica que abarca el valle de El Bolsón se concibe como una sola estructura que va desde El Manso, El Foyel, los Repollos, Lago Puelo, El Hoyo y Epuyén, como un mismo sistema. Y luego se sostiene "...En la comarca andina del paralelo 42 todas las actividades desarrolladas en las localidades están interrelacionadas, lo que dificulta la recuperación de información aislada de la localidad de El Bolsón, aún más cuando tres de las localidades pertenecen a la provincia del Chubut con una legislación diferente a la de Río Negro. La Comarca Andina se sitúa a grandes rasgos entre los paralelos $41^{\circ} 30^{\prime}$ y $44^{\circ} 55^{\prime}$ de Latitud Sur y los meridianos $71^{\circ} 20^{\prime}$ a $71^{\circ} 42^{\prime}$ de Longitud Oeste. Los límites son: al sur el Parque Nacional Los Alerces, al oeste la República de Chile, al este coinciden con los del ejido municipal de El Maitén y al norte con el paraje de El Manso".

Para completar un contexto impreciso, la gestión política del Chubut instala en estos años la figura de Comarca de los Andes, en atención a las iniciativas, en particular, de su Ministerio de la Producción, involucrando en ella, tanto a la llamada Comarca de los 
Alerces (Esquel-Trevelín- Parque Nacional Los Alerces), como al sector chubutense de la Comarca, excluyendo, sin más, al sector rionegrino. Con lo cual resultará claro, que territorialmente las definiciones son de esencia precaria.

Con todo, la figura de la Comarca Andina del Paralelo 42 está en el 'embretado' de existir en los papeles. El intento para darle organicidad política y superar el escollo de las jurisdicciones provinciales y municipales, no ha podido sostenerse y, el proyecto: Consejo para el desarrollo de la Comarca Andina del Paralelo 42 (CODECAP - 1999) sostenido por entonces desde la CONADEPA (Comisión Nacional para el Desarrollo de la Patagonia - Ministerio del Interior), permanece en stand $b y^{68}$.

Como anticipamos, al encontrarnos con territorios en proceso de gestación, pocas serán las chances de permanecer mínimamente ajenos a circunstancias extraregionales. Como ya dijimos, estos son los espacios que Labasse presenta como abiertos en contraposición de los concluidos; es donde las tramas se están armando, $\mathrm{y}$, así como se produjo un proceso de desenclave comarcal a partir de unas pocas e importantes obras de infraestructura (pavimentación de la Ruta Nacional 40 (ex 258)), construcción del gasoducto cordillerano y aplicación de innovaciones en materia de telecomunicaciones ${ }^{69}$, otras obras, podrían derivar en consecuencias territoriales también importantes ${ }^{70}$.

\section{II.2.2. Aspectos bio-físicos relevantes.}

Como se entenderá, dado el sesgo problemático que venimos sosteniendo, será ésta una breve introducción al medio natural en su rol participante de la instalación humana. Participante en el sentido cabal del término, es decir involucrado en el desenvolvimiento social, ya como limitante o restrictivo, ya como incentivante o motivador y también, por qué no, como simple acompañante silencioso del devenir de los habitantes ${ }^{71}$. Estará claro que estos adjetivos deben tener cierta elasticidad en sus significados, dependiendo en mucho de la trama histórica local, con su carga culturaltecnológica, el escenario económico-político y el propio comportamiento de los

\footnotetext{
68 A pesar de esta situación, de un informe de sesgo multidisciplinario, se pueden rescatar distintas visiones significativas relacionadas con las instancias de gestión para el desarrollo y la concertación pública-privada en la Comarca. (CODECAP, diciembre, 1999)

69 Labasse conceptualiza al desenclave y su trascendencia geográfica progresiva promediando la segunda mitad del Siglo XX (143-47); resulta evidente que hoy habrá que adaptarse a nuevas y vertiginosas 'conexiones', aún así, cabe destacar su validez conceptual.

${ }^{70}$ Es destacable el grado de sensibilidad social que existe en estas temáticas. Ejemplos que están en 'el tapete' y que significarian importantes reacomodamientos espaciales: apertura para automotores de los pasos a Chile en EI Manso y el Paso Puelo, construcción de un aeropuerto en El Maitén o La Burrada, ampliación de la capacidad energética, endicamiento del río Puelo en Chile, pavimentación de la ex ruta 40 entre Pilcaniyeu y El Maitén, consolidación de los Centros de esquí en Mallín Ahogado y/o en El Maitén, desafectación del aeródromo de El Bolsón y su re-significación urbana.

71 Es necesario en relativizar las condiciones del medio físico y dejamos abierta la eventual ponderación de otros factores incentivantes para la instalación humana. De hecho, es reconocida la zona como no contaminada, de gran belleza escénica y con baja presión demográfica, ¡Aspectos nada despreciables en nuestros días!.
} 
elementos naturales. Costumbres, tecnologías y aspiraciones involucran al medio natural, y así como habrá potenciales óptimos de convivencia sociedad-medio natural, también deberá haber posibles umbrales de tolerancia para esta relación. Nos vienen las reflexiones de Pech y Regnauld en la introducción a su Geografía física, "debemos confesar realmente que no tenemos la seguridad de las leyes del espacio. En el espacio, en verdadera dimensión, la validez de un razonamiento geográfico no proviene de su exactitud teórica, sino de la eficacia para resolver el problema social (planteado por la sociedad)" (1997: 15)

Como se anunció en el Marco Teórico, es importante destacar que no será éste un espacio donde se profundice en los rasgos bio-físicos del área de estudio, tan sólo se toman aspectos indudablemente enlazados con las cuestiones territoriales de los habitantes. Así, quedarán sin examinar temas que podrían sugerir un interés mayúsculo como ser faunísticos, geológicos, glaciológicos, hidrológicos o florísticos, pero nuestra selección temática se apoyó en los problemas y con ello, lo que aquí se trae es con el fin de reinsertarlo en las dos últimas partes de esta tesis.

\section{La Comarca y su fisiografía.}

"...El geólogo y visionario Bailley Willis, fiel reflejo de una mentalidad que sin interfaces comulgaba con el paradigma del 'progreso' y sostenido en una visión esencialmente cientificista del desarrollo de los territorios, en 1914 describió con sencillez rigurosa muchas de las condiciones del paisaje bolsonés. Por entonces resaltaba, para el llamado Valle Nuevo y zona, singularidades especiales respecto de la generalidad de nuestros valles andino-patagónicos. Refiriéndose a El Bolsón, que "...ha adquirido gran fama como el mejor distrito de los Andes Meridionales..." (En Bondel-de Almeida, 1995:2).

La Comarca se corresponde espacialmente con la sumatoria de (considerando sólo territorio argentino) la totalidad de la cuenca hidrográfica del lago Puelo, la vertiente Sur de la cuenca del río Manso, el entorno de Cholila con el lago Rivadavia como colector y un sector acotado de la alta cuenca del río Chubut, éste ya en la pendiente atlántica $^{72}$. Los valles son de orientación dominante Norte-Sur, aunque por sus dimensiones y consecuentes efectos en la circulación de los vientos, deben destacarse los valles transversales del brazo Norte del lago Puelo-lago Puelo Inferior (Chile), del lago Cholila, del río Manso y Los Repollos-El Boquete y otros menores.

Por otra parte, ya el epígrafe nos inscribe propiamente en la Comarca, donde las características naturales obedecen a los mismos patrones regionales y su acomodamiento lógico a cuestiones morfológicas propias, en particular altitud, relieve y posición respecto del gradiente ecotonal.

\footnotetext{
72 Salvo el caso del río Chubut, el resto drena hacia el Océano Pacífico; valórese entonces su cercanía relativa y con ello lo activa y poderosa de su torrencialidad potencial. Las pendientes de ladera, del orden del $24 \%-25$, explican la consideración de muy alta (MA) a la erosión hídrica potencial de los ríos Puelo y Futaleufú (ver Carabelli et al, 2000: 11-12).
} 
No será éste el espacio para tratar aspectos excepcionales, pero como nos advierte la reciente erupción del volcán Chaitén (mayo de 2008), debe valorarse en particular la situación cordillerana de la Comarca y con ello, tanto la caída-depósito de cenizas volcánicas, con una recurrencia relativamente importante y como la sismicidad, aunque de relativo bajo riesgo en esta parte de la Cordillera de los Andes, estarán entre los 'eventuales' de gran impacto potencial. El gran terremoto que afectó especialmente al sur chileno en 1960, o los signos activos de los varios volcanes relativamente cercanos hacia el Oeste, son una advertencia innegable (Volcanes Osorno, Hornopirén, Calbuco, Michamahuida, Chaitén, etc.).

Entonces en lo general, sin duda, la diferencia sustancial respecto del conjunto andino patagónico está en la baja altura relativa de los valles más poblados y su consecuente mitigación de las bajas temperaturas regionales; suma a ello el hecho de tener importantes sectores 'protegidos' respecto de los intensos vientos característicos en estas latitudes. Con ello, podría decirse que resulta una combinación ecológica más ajustada al poblamiento, ya que reúne las condiciones templadas de los bajos valles del Sur chileno, con aquellas considerablemente más benévolas en materia de precipitaciones, humedad y nubosidad, propias del sotavento cordillerano ${ }^{73}$.

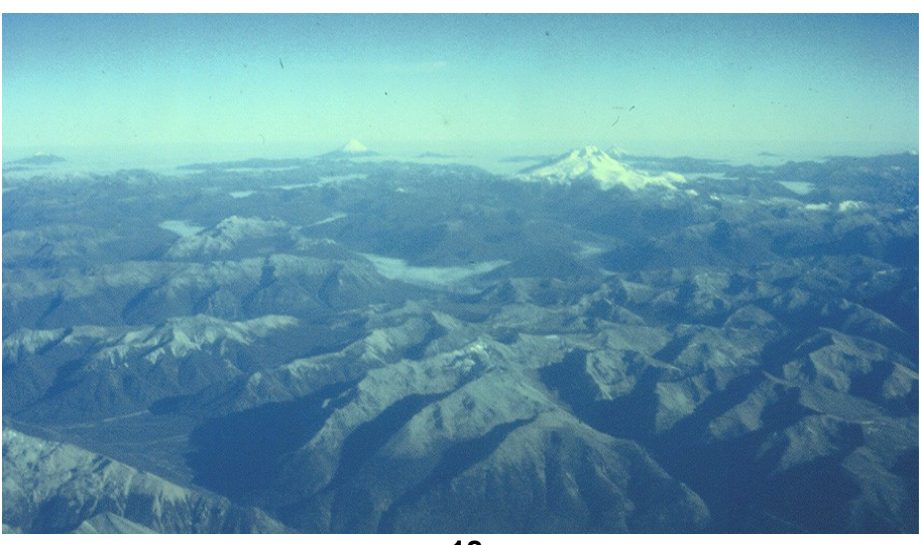

18

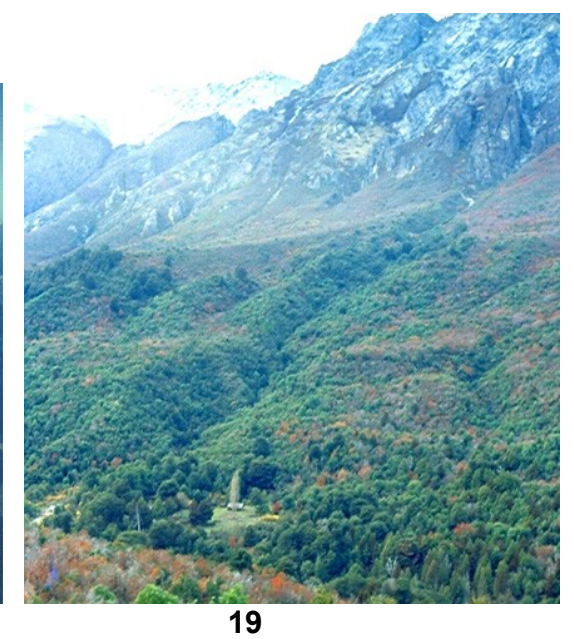

19

Fotos: 18 y 19. Fotos del autor.

18: Toma en altura del ámbito cordillerano a la latitud del Monte Tronador (volcán de 3460m); corresponde al comienzo del otoño y nótese que en la altura predominante (entre 1900 y 2100 msnm), apenas se insinúan nieves permanentes. Al fondo el volcán Osorno en Chile. Foto tomada de ESE-NNW.

19: Posición geográfica, altitud y formas del modelado que concluyen en un mosaico florístico con intervención humana 'débil'. Cordón Serrucho Norte.

\footnotetext{
${ }^{73}$ Condiciones que, en términos de humedad atmosférica, rápidamente se tornan semiáridas a propósito del efecto tipo foehn (zonda) y con ello la intensificación del ritmo de evapotranspiración. De todas formas, cabe observar que este efecto, si bien es decisivo por su resultado ecológico, alcanza los valores extremos comparativamente mitigados, dada la relativa baja altura de esta sección de los Andes, su importante fracturación transversal y las alturas considerables de las mesetas y serranías orientales, (ver Eriksen, 1975 y Bran et al, 1998).
} 


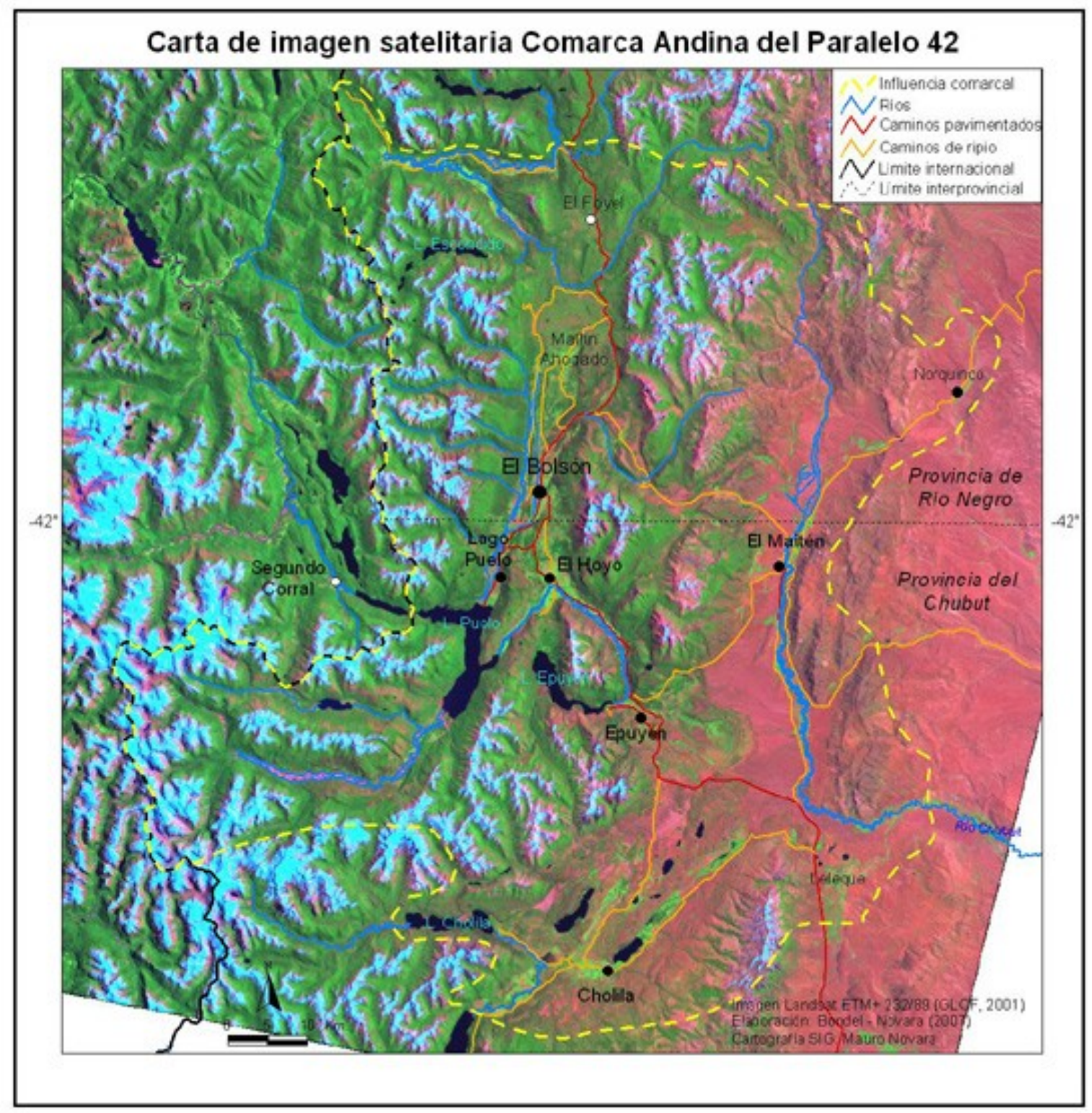

Mapa 4: Contexto topográfico. Si bien a la escala de impresión resulta algo impreciso, puede rescatarse lo quebrado del relieve, donde para el caso, las nieves cubren a partir de los $1600 \mathrm{msnm}$ con máximas alturas en los $2400 \mathrm{msnm}$ y el lago Puelo a solo $200 \mathrm{msnm}$. El verde representa sectores boscosos y las tonalidades rojizas a la estepa arbustiva y de pastizales, afloramientos rocosos y pedreros.

Aquí el modelado obedece, básicamente, a la disposición de los sistemas montañosos y su conjunción con las características climáticas zonales; valga entonces la valoración de los sistemas de erosión, potenciados en estas escalas con alturas entre los $1.800 \mathrm{y}$ 2.400 metros y relieves locales importantes; la mayor de las veces, con menos de una decena de kilómetros en sus secciones transversales y donde las pendientes se constituyen entre las principales condicionantes para la instalación humana ${ }^{74}$.

${ }^{74}$ Como dato ilustrativo, para el caso de toda la cuenca del río Puelo (Arg.-Chile), se establecen los rangos de restricción para el uso forestal en función de las pendientes, quedando apenas un $15 \%$ del territorio con restricciones 
Perfil Topográfico - Cuenca del Lago Puelo-Paralelo $42^{\circ}$

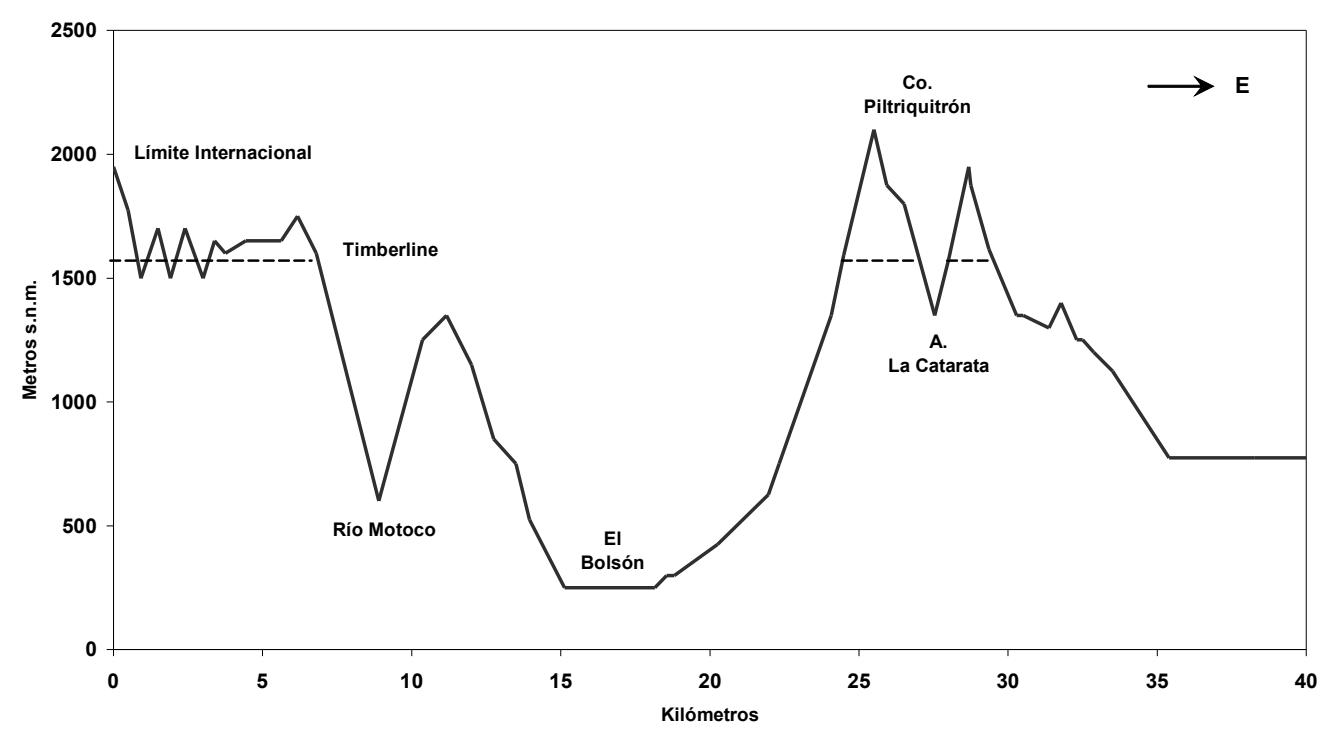

PERFIL TOPOGRAFICO LOMA ATRAVESADA-LAGO PUELO

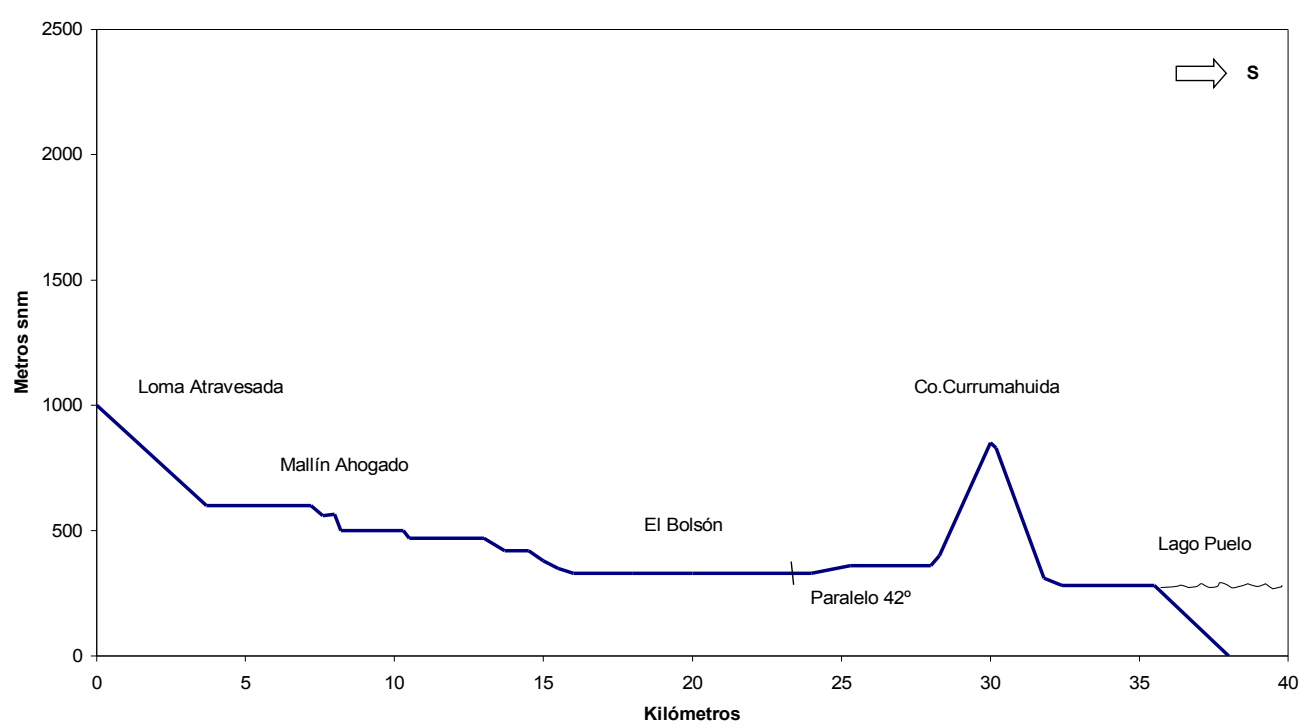

Fig. 4. Perfiles: transversal W-E y longitudinal N-S. Nótese la igualdad de escalas. Fuente: Bondel, C. S. y A. de Almeida (1996).

La geomorfología refleja, entre los afloramientos estructurales de las montañas, la componente glaciar de su pasado geológico inmediato; con geoformas recurrentes de valles en auge, circos glaciares (incluso con remanentes englazados de consideración), aterrazamientos fluvioglaciares y glacilacustres, depósitos glaciarios en general (imponentes morenas terminales hacia el Este) y depósitos turbosos. En la 
actualidad, desfiladeros, abanicos, terrazas de origen aluvial, deslizamientos y tantas otras formas, muestran en pleno desarrollo a los sistemas de erosión fluvial ${ }^{75}$.

Además, y a pesar de lo profundo de los valles, los relieves aterrazados pedemontanos y los fondo de valle de escasa pendiente son comparativamente importantes en superficie. Entre los primeros se destacan Mallín Ahogado, las terrazas boscosas de El Foyel y Los Repollos ${ }^{76}$, y las grandes pampas en las márgenes del río Chubut, extendidas desde algo más al Norte de El Maitén hasta Cholila. Entre los fondo de valle, sobresalen por su trascendencia antrópica, los valles del Quemquemtreu-Azul, Epuyén, Manso, Carrileufú y El Turbio. Por supuesto, prolifera un sinnúmero de valles menores, propios del la morfología andino patagónica.

Como será de esperar, entonces, otro tanto sucede con la variedad y compleja distribución de los suelos (ver Fig.: 5 ) $^{77}$. En materia edafológica, los sitios proponen una gran heterogeneidad en el orden general de los andisoles (similar andosoles de la clasificación FAO-ONU, 1988). Suelos de baja evolución y condicionados por el material originario, con un alto contenido en materiales amorfos o de baja cristalinidad. Casi siempre generados a partir de materiales volcánicos piroclásticos y con frecuencia con horizontes superficiales melánicos.

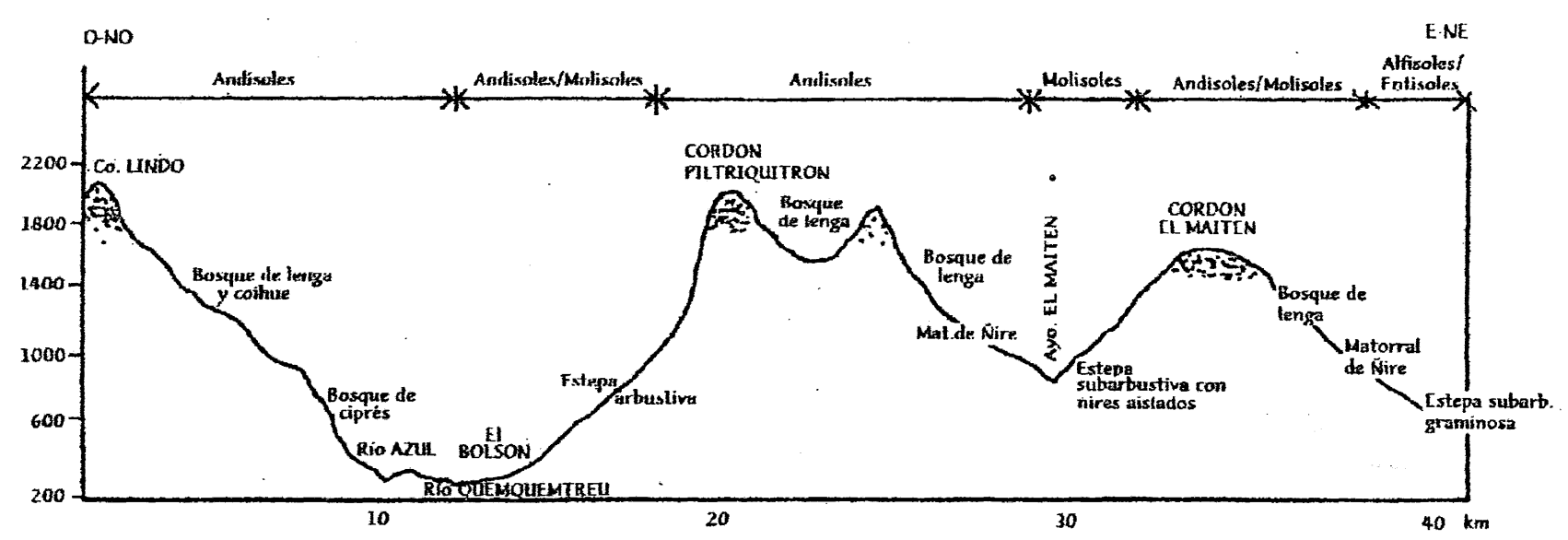

Fig.5: La condición ecotonal, ilustrada por Lanciotti y Cremona (1999) con la transecta W-E transversal a la Comarca.

Respecto del grado de aptitud en materia de suelos y a pesar de generalizaciones apresuradamente favorables, visto en su conjunto, no es arriesgado afirmar que predominan los terrenos con dispersos y escasos buenos suelos ${ }^{78}$. Dijimos,

\footnotetext{
${ }_{75}$ Ver Bosquejo Geomorfológico, Césari, O y Martínez, en Bondel, C. S. y A. de Almeida (1995).

${ }^{76}$ Daus inscribe a estos parajes en el Valle Longitudinal Bariloche - El Bolsón- El Hoyo. (1970)

${ }^{77}$ En Lanciotti y Cremona, se analizan las distintas condiciones de sitio siguiendo un ordenamiento transversal a los sistemas montañosos que "... permitió visualizar los perfiles en una climo-topo-secuencia que va desde los 1700 msnm al oeste, con bosque de lenga, hasta los 700/800 msnm al este, ya en los pastizales de la estepa, pasando por situaciones intermedia...", (1999: 9).

${ }^{78}$ El comentario viene a cuenta por la tan difundida imagen de los pródigos valles cordilleranos y su connotación perceptiva que volverá a tratarse en las dos últimas partes de esta tesis.
} 
refiriéndonos en particular al uso agrícola "... según se desprende de la mayor parte de los estudios al respecto, lo usual es una gran alternancia de terrazas aluviales pedregosas, con mallines y con afloramientos rocosos y faldeos de gran pendiente casi sin suelos; asimismo, claro está, con 'manchones', libres o no de la espesura del bosque autóctono, con buena aptitud para el asentamiento agrícola". (Bondel-de Almeida, 1996: 49). Pero, en un contexto silvícola-ganadero, y aunque es materia de discusión científico-ambiental, en principio, deben valorarse las condiciones más competitivas y relativamente homogéneas que se observa en amplios sectores de la comarca $^{79}$.

A todo esto rescatamos dos señalamientos clave. El primero de Etchevehere, al considerar las condiciones edafogénicas de la región andino patagónica, refiriéndose en especial a los rellenos pedemontanos, coluvios y abanicos, "...Debe prestarse especial atención al hecho de que el relieve relativamente abrupto, no facilita la formación de suelos zonales en gran escala; los procesos pedogénicos son posibles sólo en ciertos sectores del paisaje...". (1972:85). En segundo lugar y de un trabajo acotado al Oeste rionegrino, se concluye que alrededor del $40 \%$ del terreno es básicamente apto respecto del grado de aptitud de suelos para las forestaciones (Mendía e Irisarri,1986).

Finalmente y frente a tantas restricciones, desde el punto de vista agrícola, se cuenta con sectores más favorecidos, destacándose la franja pedemontana inmediatamente adyacente al casco urbano de El Bolsón hacia el Norte y que se extiende por unos 7 $\mathrm{km}$ con un ancho variable de entre 1 y $2 \mathrm{~km}$, conocido como el sector del Camino de los nogales.

Se ha tomado el texto que sigue como ilustrativo de los rasgos fisiográficos respecto de identificar aptitudes de los parajes El Hoyo y Las Golondrinas, ambos prototípicos en materia agrícola zonal:

Podemos decir que las dos subzonas se diferencian notablemente entre si.

Área El Hoyo: se trata de un sector angosto del valle del río Epuyén, que comienza a ensancharse poco antes de la desembocadura en el mismo del arroyo Pedregoso. Se caracteriza por terrazas fluviales, una reciente en donde el río divaga actualmente y otra alta que es donde se desarrolla la actividad agrícola. El mencionado arroyo Pedregoso vuelca su derrame hacia ambas márgenes provocando un abanico (se evidencian rasgos de haber variado su cauce). El resultado es un sector con suelos coluviales en donde dominan rodados gruesos. En el sector medio del área estudiada se presenta un área mallinosa que reduce la

\footnotetext{
${ }^{79}$ Tal vez y aunque en un contexto de discusión diferente, la afirmación que sigue más abajo, podría explicar una percepción que luego se verificó en los hechos. Decía Daus en 1970, "... Como espacio de asentamiento el Valle Longitudinal tiene también un valor especial, pues algunos de sus ensanchamientos forman pampas muy apropiadas para la ganadería y para el aprovechamiento forestal" (45).
} 
terraza alta a formas alargadas contra la terraza baja (albardones). Siguiendo hacia el norte, nos encontramos con que el río dobla hacia el oeste dejando hacia el norte un mallín extenso (Pastos Comunes) y hacia el sur un corto valle que se va cerrando. En el sector norte, el arroyo Cataratas produjo un abanico amplio que llega hasta la zona de los mallines, y que tiene una presencia de rodados importante.

Área Las Golondrinas: ocupa un pequeño valle dentro de la falda del cordón oriental del Piltriquitrón. Se caracteriza por presentar un cañadón central con cauce excavado, extendiéndose a ambos lados planicies con suelos de buena calidad, que al ir alejándose van subiendo y acentuando su pendiente hasta llegar al límite de la zona con rasgos serranos (presencia de grandes rocas).

En otra parte del estudio, se concluye:

"... sólo un $8,1 \%$ corresponde a las tierras de mayor aptitud (Clase 1). Si tomamos las 3 mejores clases (1,2 y 3), el porcentaje alcanza un 47,1\%. Puede apreciarse también que Las Golondrinas, en aptitud de las tierras para riego, aventaja a El Hoyo, ya que tiene un 63,3\%, de tierras aptas, a las que se suman un $20,5 \%$ de tierras moderadamente aptas, alcanzando así un $83,8 \%$ de tierras cultivables bajo riego. (Pero) En superficie absoluta, El Hoyo alcanza entre las tres primeras clases las 1.050 ha, mientras que Las Golondrinas sólo 311 ha. ..."

Fuente: Ongaro, 1999.

Es la flora, seguramente, la instancia más demostrativa del medio bio-físico en su rol 'receptivo' para con la sociedad. Sin embargo aquí, es cierto, apenas llegaremos a un estado 'insinuador' de la temática, toda vez que se destaca una prolífica producción científica que demuestra un interés particular y la trascendencia ambiental que sugiere, en particular, el bosque como la componente culminante del paisaje cordillerano $^{80}$.

Se trata del Bosque andino patagónico, bosque subantártico que encuentra su estado clímax hacia el Oeste, en territorio chileno, donde, como indica Dimitri, a la mayor pujanza de la flora, por condiciones ambientales más favorables, se le suma una más amplia variabilidad específica. A modo de ejemplo, el número de especies del género Nothofagus, agrupa en el sector argentino, sólo seis de los once tipos que se desarrollan en Chile (Dimitri, 1982:15-17). De estos seis y por efecto latitudinal también decreciente en diversidad, sólo tres se extienden en la CAP 42; los Nothofagus: antartica (Ñire), dombeyi (Coihue) y pumilio (Lenga) $)^{81}$.

\footnotetext{
${ }^{80}$ Entre un gran número de trabajos regionales, es decir sin contar la notable lista de 'sectoriales', cabe destacar los 'básicos' de Dimitri (1972 y 1974); Boelcke-Burgos-Roig (1984); Correa, M. N. (1964-1984); Donoso Z., (1994(a) y 1994 (b)).

${ }^{81}$ Sin embargo, se reconoce al entorno inmediato del lago Puelo y buena parte de la cuenca del río Turbio, como zona de ingresión desde Chile del bosque ('selva') Valdiviano.
} 
Plantas leñosas observables en distintos parajes de la cuenca del lago Puelo:

Ciprés (Austrocedrus chilensis), Ñire (Nothofagus antarctica), Coihue (Nothofagus dombeyi), Lenga (Nothofagus pumilio), Maqui (Aristotelia maqui), Calafate y Michay (Berberis sp.), Espino negro (Colletia spinosissima), Chacay (Chacaya trinervis y Discarria serratifolia), Colihue (Chusquea culeou), Retama (Diostea juncea), Notro (Embothrium coccineum), Mutilla (Empetrum rubrum), Palo Piche (Fabiana imbricata), Chaura (Pernettya mucronata y Gaultheria phyllireaefolia), Avellano (Guevina avellana), Radal (Lomatia hirsuta), Maitén (Maytenus boaria), Patagua o Pitra (Myrceugenia exsucca), Arrayán (Myrceugenella apiculata), Chapel (Escallonia virgata), Canelo (Drimys winteri), Maniu macho (Podocarpus nubigena) y Maniu hembra (Saxegothaea conspicua), Pañil (Buddleja globosa).

Como es de esperar, la complejidad también disminuye según la altitud, desarrollando pisos de vegetación con la singularidad recurrente en esta zona de carecer del llamado prado alpino. A modo de ejemplo y contribuyendo a no caer en falsas analogías, valga la aclaración que ya nos advertía Ferruglio. Dice respecto de la importante diferencia de nivel existente entre el límite de las nieves y el de los bosques de los Andes Patagónicos y los Alpes (unos 250 metros), “... La zona intermedia, de los prados alpinos, se reduce por lo general a una franja muy angosta y a menudo falta por completo; circunstancia que contrasta vivamente con lo que se observa en los Alpes y constituye, además, para los Andes Patagónicos, una condición desfavorable desde el punto de vista económico, o sea, para el pastoreo". (1957: 64)

De cualquier modo y en términos relativos, se debe resaltar que, aún no siendo muy abundante la cantidad de especies arbóreas propias del bosque regional, no por ello debe suponerse una distribución sencilla y homogénea de las unidades de vegetación (cf. Seibert, P. 1981).

El siguiente comentario de Milán Dimitri, sintetiza al ambiente fitogeográfico regional desde Neuquén hasta Tierra del Fuego, cuando refiriéndose a los Parques Nacionales señala, "...Alrededor de 365 géneros de plantas vasculares componen la flora de los bosques andino patagónicos (...). Alrededor de 20 géneros corresponden a plantas arbóreas; los géneros restantes incluyen arbustos, subarbustos, enredaderas, lianas, plantas herbáceas, epífitas, hemiparásitas, saprófitas, etc.. Pero no obstante ello, puede asegurarse que el $90 \%$ de la masa boscosa, tiene como especies casi exclusivas en el estrato arbóreo a los distintos Nothofagus, salvo los sectores muy aislados donde dominan el Ciprés o el Alerce..." (1974:3).

Aún así, es el Austrocedrus chilensis (ciprés) la especie dominante en la Comarca, en particular en las partes medulares desde el punto de vista de la instalación humana.

Resulta sugerente que el ámbito natural propio del ciprés es el que mejor se corresponde con aquellos elegidos por la población, al menos a partir de la 
colonización agro-ganadera y sus parámetros para el asentamiento. Al menos, esto puede afirmarse luego de la lucha y desplazamiento de los pueblos nativos en la octava década del siglo $\mathrm{XIX}^{82}$.

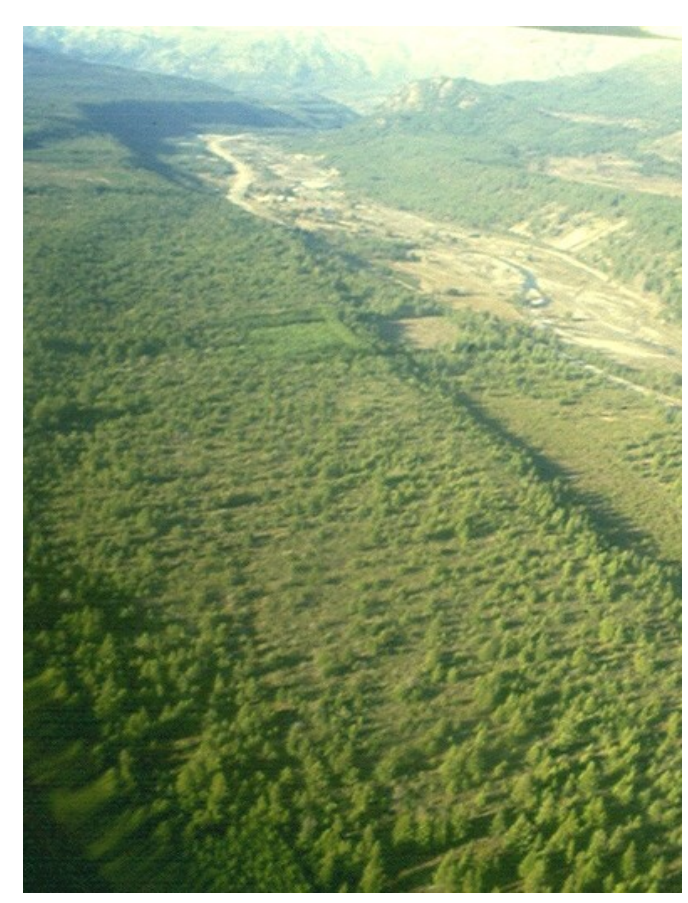

Foto 20: Cipresal en terraza de la margen derecha del río Quemquemtreu. Foto del autor, 1997.

Un tratamiento aparte merecería la temática de la flora introducida, aquella que implantada culturalmente, con los matices propios que sugieren los procesos de intercambio histórico. Por supuesto que la condición de excentricidad ecuménica por siglos habrá mitigado, incluso minimizado, impactos invasivos en materia florística hasta la llamada colonización moderna (argentina y chilena). De todos modos, sin tener el éxito extraordinario de los animales domésticos europeos, se verifican en la zona puntuales y exitosos arraigos, en particular con los manzanos, al punto que la tierra Pehuenche era llamada también El país de las manzanas ya en el siglo XVIII. Quedará claro, sin embargo, que con los pueblos y ciudades, chacras y estancias, las circunstancias han sido relativamente análogas a lo ocurrido en el resto del continente. Nos aclara Dimitri "Es un hecho bien comprobado que las especies exóticas encuentran en casi toda la región (...), un ambiente muy favorable para su implantación y desarrollo, en especial en todas las áreas modificadas. Es así que es muy frecuente hallar amplias superficies ocupadas por plantas del Viejo Mundo, que

\footnotetext{
82 Lejos de caer en un determinismo 'estrecho', los esfuerzos por sistematizar las relaciones entre aspectos del medio natural y el devenir del desarrollo histórico de los pueblos, seguramente constituyan una base preventiva y proyectiva de gran valor. Sobre nuestra región ver interesantes enfoques en Veblen y Lorenz (1988), de Lasa (1998), Rey Balmaceda (1985) y Martinic B (1985). Como se verá luego, la Comarca en general se condice con esa característica y, desde los impresionantes incendios que acompañaron a la colonización (principalmente 1890-1940), o la instalación de aserraderos, pueblos o ciudades, hasta la convivencia, aún hoy, con una ganadería extensiva peculiar, han dado una interesante gama de situaciones.
} 
por su lozanía y abundancia, parecieran pertenecer al elenco de la flora indígena". (1974: 5) (el subrayado es propio) ${ }^{83}$.

\section{II.2.2.1. El Clima, un 'participante' clave.}

En lo climático y con el sentido interviniente que le damos al marco natural, esto es desde su rol tanto como condicionante y recurso como perceptivo, es imprescindible insistir con la valoración rigurosa del contexto físico dado por:

ola condición topográfica y su consecuente variabilidad acorde a la morfología y, ola marcada condición ecotonal W-E

El clima local se identifica con el templado-frío de montaña con abundantes lluvias. invernales.

Siguiendo los criterios de Unidades Climáticas de Capitanelli (1988: 99-107), tendremos a la zona en la Región del aire heterogéneo del Pacífico, con precipitaciones de invierno, de la Patagonia y Andes Áridos. Se corresponde con la Unidad 15: sin verano térmico, con abundantes precipitaciones nivales y pluviales.

Para la clasificación de Köppen correspondería al tipo: Cfb; esto es, mesotermal húmedo de verano cálido. Sin embargo debe considerarse la posición limítrofe que le cabe por corresponder a una estrecha franja longitudinal N-S montañosa.

Para Defina y Ravello y en su regionalización fitogeográfica, estaremos dentro de los rangos de los climas del bosque subantártico; caracterizado por moderados $\Delta \mathrm{T}$, extremas considerables (entre $-25^{\circ} \mathrm{C}$ y $35^{\circ} \mathrm{C}$ ) y de régimen mediterráneo.

Sobresalen entonces:

a)- la frescura generalizada del verano andino patagónico,

b)- la frecuente irregularidad estacional climática (oscilación estacional),

c)- la prevalencia plena de los vientos occidentales $y$

d)- la singular incomodidad de las condiciones invernales.

a)- Frescura generalizada del verano: si bien con valores térmicos más elevados respecto del resto de la Patagonia Andina $^{84}$ (más alta y/o más austral, según los casos), compone una limitante singular en lo agrícola, con los beneficios, por otra parte, de dejar casi completamente ausente al granizo ${ }^{85}$.

\footnotetext{
83 Al respecto ver entrevista a Eduardo Rappoport (Revista Ciencia Hoy, 1990). También resulta orientador las consideraciones sobre la modificación del paisaje patagónico de Rey Balmaceda (en 1976: 241-46 y 1984: 98-99)

${ }^{84}$ Afirmamos con de Almeida, Aquí madura el cereal y prospera el lúpulo (...); el verano es suficientemente templado, aún con la frescura de sus noches, por otra parte saludables para el desarrollo de plantas frutales criófilas (1996: 50).

${ }^{85}$ Es interesante ver que, en términos generales, el verano argentino no se condice con los valores potenciales por latitud (Cf.: De Fina y Ravello: 295).
} 
En la relación temperatura - tipo climático, tendremos el Templado-Frío (Bruniard, 1992), con:

- ningún mes cálido (por encima de $18^{\circ} \mathrm{C}$ y libre de heladas)

- de 8 a 9 meses entre $6^{\circ}$ y $18^{\circ} \mathrm{C}$

- de 3 a 4 meses fríos ( $\mathrm{T}$ media debajo de $6^{\circ} \mathrm{C}$; de reposo)

En materia silvícola, a los valores térmicos relativamente restrictivos se le suma la estación seca estival y con ello una menor potencialidad productiva. Aún así, cabe apreciar que la escasez de tormentas eléctricas asociadas a las condiciones térmicas y de inestabilidad atmosférica; con ello y a diferencia de otros ámbitos similares del hemisferio Norte, los incendios de campo por causas naturales son mínimos.

Por otra parte, vista la temática desde implicancias relacionadas con la confortabilidad para su población, sirva de muestra que la región en su conjunto apenas deja entre tres y ningún mes de bienestar térmico, según la localidad que se trate. Para los rangos utilizados ya por Brazol en su clasificación bioclimática y aceptando consideraciones locales, El Bolsón y San Carlos de Bariloche obtienen los siguientes valores medios respectivos de: 9 y 10 meses entre fresco y frío, 3 y 2 meses de bienestar y ningún mes de calor fuerte; esto sin considerar el viento (!) (1954).

\begin{tabular}{|c|c|c|c|c|c|c|c|}
\hline \multicolumn{8}{|c|}{ TEMPERATURAS. Conti -INTA } \\
\hline & & AÑO & & & ero & & Julio \\
\hline $\begin{array}{l}\text { Series } \\
1958-94\end{array}$ & $\begin{array}{c}\text { Ta. } \\
\text { media }\end{array}$ & $\begin{array}{c}\text { Ta. máx. } \\
\text { media }\end{array}$ & $\begin{array}{c}\text { Ta. mín. } \\
\text { media }\end{array}$ & $\begin{array}{c}\text { Ta. } \\
\text { media }\end{array}$ & $\begin{array}{l}\text { Ta. máx. } \\
\text { absoluta }\end{array}$ & $\begin{array}{c}\text { Ta. } \\
\text { media }\end{array}$ & $\begin{array}{c}\text { Ta. mín. } \\
\text { absoluta }^{86}\end{array}$ \\
\hline El Bolsón & 9.8 & 16.6 & 2.9 & 15.5 & 35.2 & 3.9 & -10.5 \\
\hline Bariloche & 8.1 & $\begin{array}{c}1 \\
4.1\end{array}$ & 2.1 & 14.0 & 33.7 & 2.4 & -15.0 \\
\hline
\end{tabular}

En la clasificación bioclimática de Hoffmann-Nuñez (1981), nuestros valles se identifican como $4 * 11$ (con referente clasificatorio en S. C. de Bariloche, aprox. 800 msnm), índice para los climas de veranos templado-frescos e inviernos fríos. El asterisco indica que al ponderar el viento se pasa a la categoría inmediata inferior. Valga entonces la consideración de lugares como El Bolsón, donde el viento es un condicionante menor. La misma clasificación refiere un índice 2/FG a casi 2000 metros de altura (Co. Catedral, $1955 \mathrm{msnm}$ ), que significa, veranos con tiempo frío durante el día, noches muy frías y frío glacial durante todo el día en invierno ${ }^{87}$.

\footnotetext{
${ }^{86}$ En el invierno del 2007 en ambas localidades se habría superado la mínima absoluta, con $-12^{\circ} \mid \mathrm{C}$ en El Bolsón y $-16^{\circ} \mathrm{C}$ en San Carlos de Bariloche

${ }^{87}$ Mountain Bioclimatology denomina Roger Barry a un importante capítulo, donde profundiza sobre el particular en forma genérica. (1992: 344-57).
} 
Es destacable que en la Comarca y en alturas del orden de los 200-500 msnm las temperaturas medias son decididamente más altas que en el resto de la región. Bailey Willis ya advertía en la segunda década del Siglo XX, "...Las tierras labrantías de este distrito pueden dividirse, según la altitud y la exposición, en las que son adecuadas para el cultivo de legumbres y frutas, y las que pueden dar avena o yerba. Las primeras están libres de heladas en el verano, pero no así las últimas. En general, aquellas están situadas a menos de 500 metros sobre el nivel del mar ..." (1988: 253). Debe destacarse, sin embargo, que las heladas estivales son 'esperables' en toda la región, aún en los valles más bajos, si bien allí su recurrencia es de baja probabilidad $^{88}$.

Con el fin de relativizar y con ello avanzar comparativamente, se muestran una serie de figuras que entendemos, son explicativas a nuestros fines de contexto.

El Bolsón - Lat.41 $51^{\circ}$ S. Long $71^{\circ} 37^{\prime} \mathrm{W}$ de G Elevación $310 \mathrm{msm}$

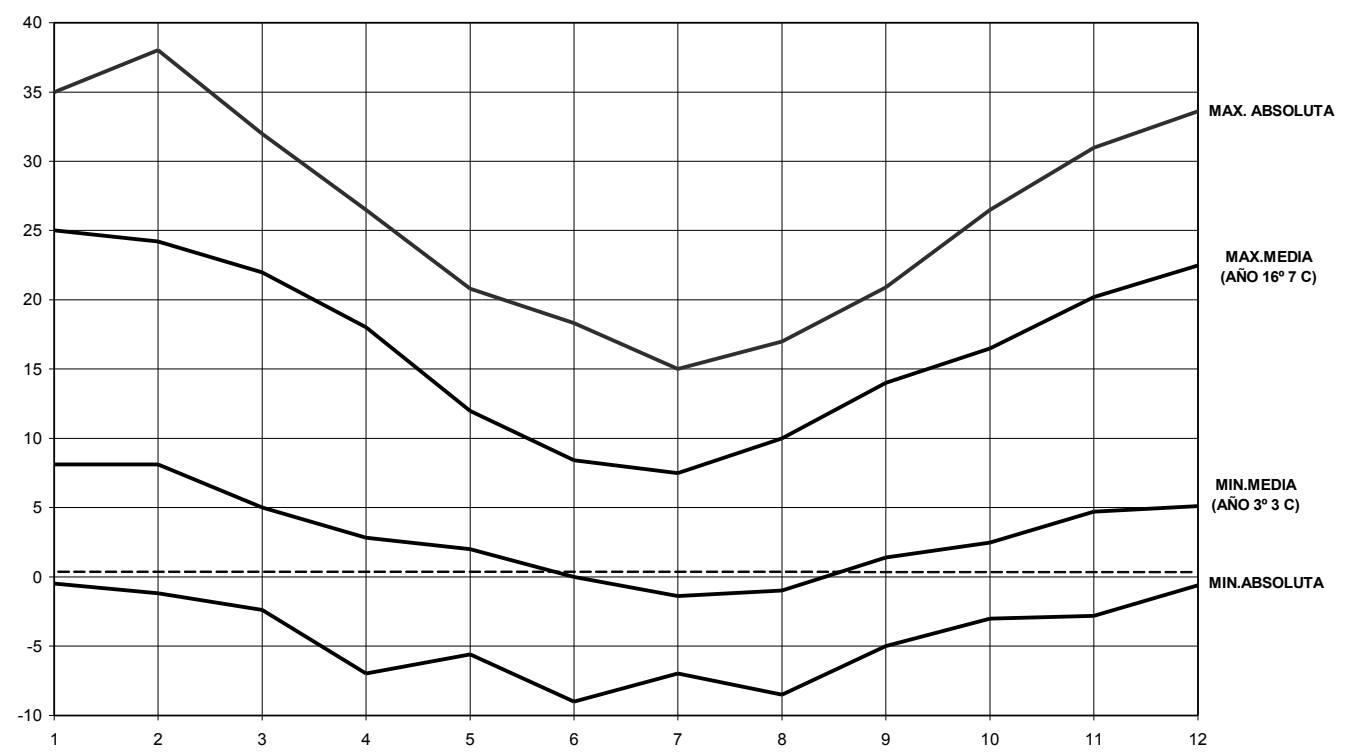

Fig. 6. Temperaturas, valores extremos medios y absolutos. Fuente: Dimitri, M. (1982); serie: 1961-70

\footnotetext{
${ }^{88}$ Cabe destacar que B. Willys, observador prodigioso, desarrolla sus impecables informes en 1914, con lo cual las series de datos meteorológicos apenas reunía unos lustros. En El Bolsón (1952-60), por ejemplo, tendremos Nov. 2, Dic. 0.9, Ene. 0.1, Feb. 0.8 y Mar. 2.
} 
Temperaturas Medias

Bs.As.-C.Rivadavia-EL BOLSON-Bariloche

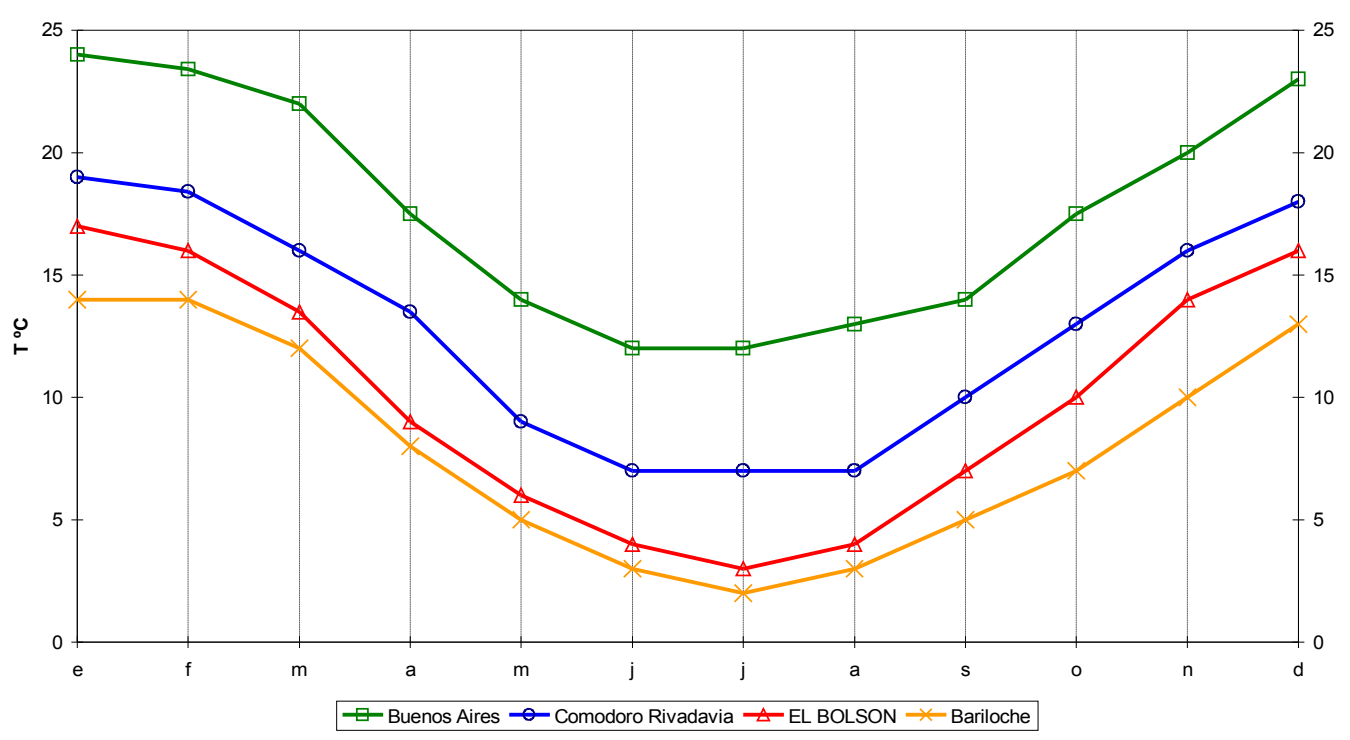

Fig. 7. Temperaturas, curvas comparativas. Fuente: S.M.N. Series 1961-70 y 1981-90

b)- Irregularidad estacional climática (inestabilidad estacional): aquí, con frecuencia, otoños y primaveras invaden los inviernos y veranos; en lo agrícola, con consecuencias mayormente negativas (heladas tardías y/o tempranas; vernalización incompleta, etc.), como así también resulta cada vez más visible el impacto de estas condiciones sobre la actividad turística (rachas de frío y/o lluvias estivales, deshielos prematuros o falta de nieve, etc.). En realidad es esta una característica usual de los climas argentinos (cf.: De Fina y Ravello, 1979: 297), pero aquí se destaca por tratarse de situaciones más agresivas para los asentamientos humanos ${ }^{89}$.

Esta cualidad puede resultar decisiva a la hora de la valoración de los sitios según las distintas expectativas que provoque. Se diría que para cada condición meteorológica, habrá un escenario microclimático que se adapte mejor o peor. Como ya dijimos con de Almeida, "... Habrá lugares más o menos heladores, soleados o húmedos. La altura, la exposición de los faldeos, la cercanía a los lagos (Puelo y Epuyén), así como el tipo de sustrato, las formas locales del relieve y la distribución de la vegetación, adquieren entonces, un valor singular" (1996: 51).

c)- Prevalencia plena de los vientos occidentales: condición de fundamental trascendencia meteorológica y climática, gobernada, en especial, por la disposición hemisférica del Anticiclón del Pacífico Sur. Los regímenes de temperatura y precipitaciones tienen en esta característica su clave explicativa; precisa Villalba, "... La precipitación está concentrada durante los meses de invierno en momentos en que

89 Ver consideraciones sobre eventos anuales o multianuales con anomalías climáticas, en particular para la región Patagónica en Villalba (2003), Veblen y Lorenz (1988) y Donoso, (1994) (a). 
la celda de alta presión alcanza su posición más próxima al Ecuador, lo que facilita el ingreso de los vientos del oeste. Los veranos son secos y cálidos como consecuencia de una intensificación del anticiclón del sudeste del Pacífico, su migración a más altas latitudes, y el bloqueo de las masas de aire húmeda provenientes del Pacífico..." 90. También es destacable su intensidad para la mayor parte de los Andes Patagónicos ('moderados-fuertes'), acentuada en general en primavera-verano. Aún así, la Comarca ofrece sitios y parajes definidos en que, tanto la intensidad como la regularidad de los vientos en superficie, es sustancialmente menor que en el resto de la región ${ }^{91}$. Es posible especular con la disposición de los cordones occidentales como 'protectores' del flujo superficial. De hecho, ya en altura o sobre los valles dispuestos con sentido dominante W-E, el viento suele ser intenso y en realidad, basta salir de algunos sitios y parajes 'protegidos', para ver que el viento no da tregua al poblador de la vertiente oriental de los Andes Patagónicos.

UIENTOS (aeropuertos)

Velocidades medias (1971-89). F: S.M.N.

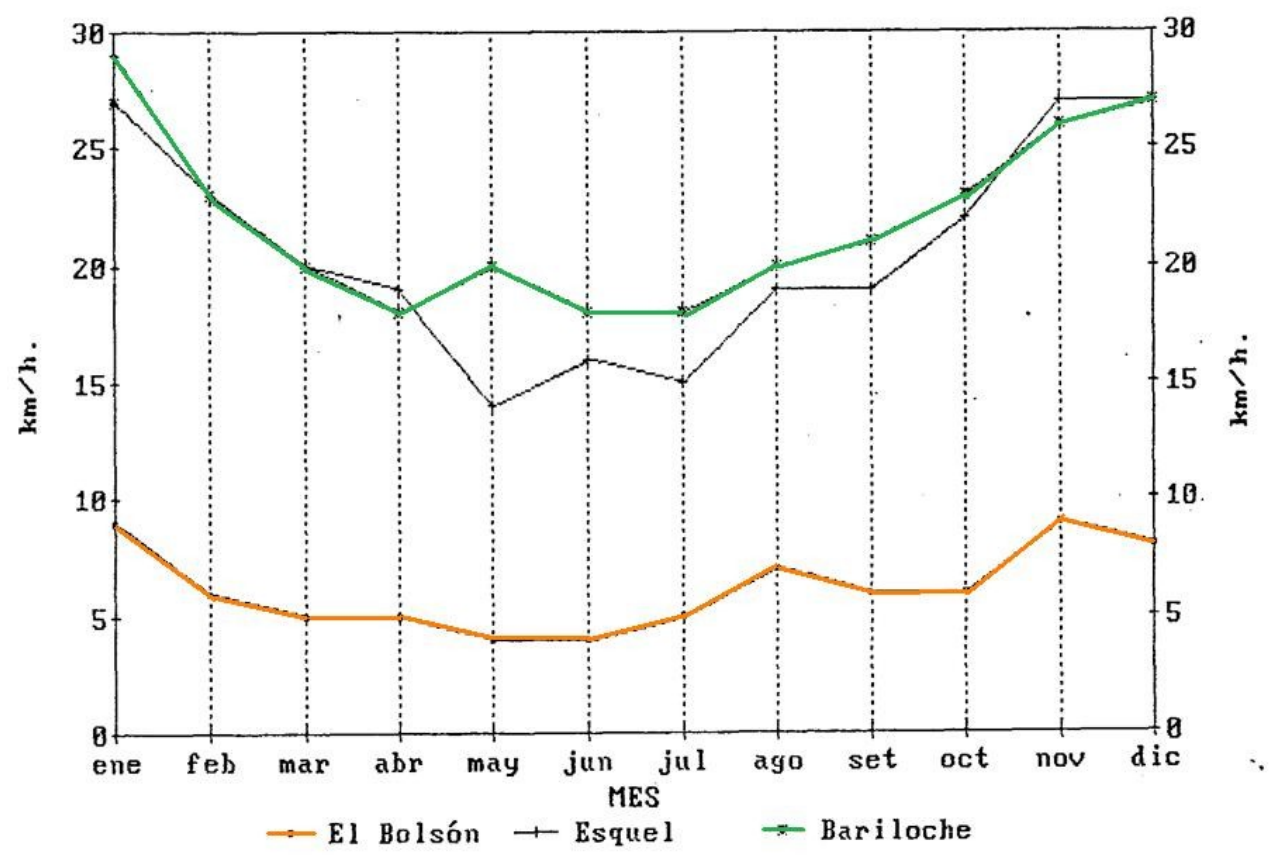

Fig. 8. Vientos. Velocidades medias mensuales comparativas..

Como contracara a la intensidad y frecuencia de los vientos patagónicos, aunque sin dejar de formar parte del marco atmosférico regional, aquí, en particular en los fondos de valle, es dable la calma, asociada muchas veces a procesos de inversión térmica.

\footnotetext{
90 Aunque con un desarrollo concentrado en latitudes más altas $\left(51^{\circ} \mathrm{S}\right)$, es interesante ver la temática en Burgos en relación al 'peso' regional de la Antártida (1984:14).

91 Son varios los sitios y parajes de la Comarca donde se advierte el menor 'peso específico' del viento (El Bolsón urbano, Las Golondrinas y Cerro Radal, El Hoyo Norte, etc.); se puede corroborar con El Bolsón (aero) con calmas de un orden de 620 / 1000 y una velocidad media anual que fluctúa entre 7 y $12 \mathrm{~km} / \mathrm{h}$ según las series. Está visto también, que en sitios favorables a la condición de venturi, los valores pueden llegar a los 15 a $20 \mathrm{~km} / \mathrm{h}$ en las medias mensuales y con rachas máximas relativamente altas (entre 40 y 90 km/h); registros propios, estación Barlovento 1997-2003 (El Hoyo).
} 
Proceso de trascendencia agronómica, en general, benefactora, así como de potenciales consecuencias negativas en materia de contaminación del aire en sectores poblados o retención de heladas por baja nubosidad ${ }^{92}$.

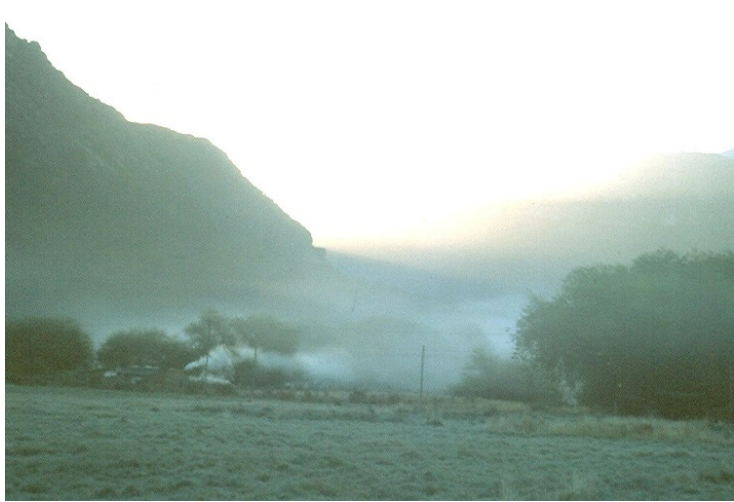

21

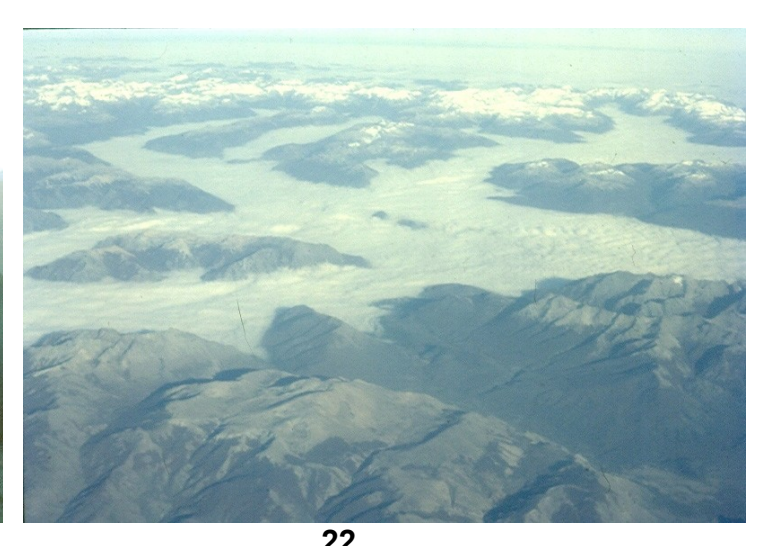

22

Fotos: 21 y 22. Las inversiones térmicas, situaciones recurrentes. Fotos del autor.

21: Ejemplo de retención, lo visible es humo. También son situaciones recurrentes en atardeceres apacibles de verano, donde el material en suspensión es el polvo levantado por los automotores. Amanecer invernal en Rincón de Lobos.

22: Nubes bajas 'ancladas' por inversión térmica en los valles de El Bolsón, Epuyén, Puelo y Turbio. A modo de isla el cerro Pirque (1890 m.). Toma de otoño.

d)- Singular incomodidad de las condiciones invernales: aspecto asociado a la confortabilidad y acentuado por coincidir la estación fría con el período de las mayores precipitaciones $^{93}$. En El Bolsón, con unos $830 \mathrm{~mm}$ anuales, el 75\% del total cae en el semestre de los meses fríos con sus consecuentes efectos en las condiciones de humedad y nubosidad ${ }^{94}$. Valórese que, promediando los valores anuales igualmente el Índice de aridez es de 42 (muy húmedo, casi al límite con el húmedo que es 40) (cf.: Bruniard, 1992). Aquí la altura juega un rol categórico, predominando las lluvias invernales por debajo de los 600-700 metros de altura y las nevadas por sobre esas cotas, con las lógicas diferencias entre temporada y temporada ${ }^{95}$.

Debe destacarse que en los valles más 'privilegiados' por la baja altura relativa, el invierno suele tornarse decididamente incómodo, en particular cuando, de no llover regularmente, ocurren largas rachas donde se combinan el encajonamiento de masas de aire frío y húmedo con altos valores de nubosidad ${ }^{96}$. Entre abril y septiembre

\footnotetext{
92 Bolsones de frío o lagos de frío. Sobre procesos de inversión térmica asociados con la región ver en Dentoni y Cerne(1999:59-63) y Donoso Z. 1994 (a) (73-76).

93 Es una cualidad propia del régimen de precipitaciones regional; por ejemplo San Martín de los Andes recibe en verano entre 100 y 200 mm., mientras que en invierno caen de 700 a 900 mm.. Para mayores detalles ver: Cordon, V.; Forquera, J. y Gastiazoro, J., 1993.

94 En otro aspecto, también debe destacarse que esta distribución es inversa a los requerimientos de cultivos y pasturas, por lo que el riego se convierte en una necesidad indiscutible.

${ }^{95}$ Mientras en Bariloche ( $800 \mathrm{msnm}$ ) son esperables unas 30 nevadas anuales (Conti) y con la salvedad del importante gradiente descendente Oeste-Este, en las partes bajas de la Comarca apenas si llegan a 5 por término medio.

${ }^{96}$ Para completar el cuadro en ámbitos poblados, repetimos de R. Barry "..es irónico que comienzos de este Siglo (XX) los sanatorios estuvieran localizados en zonas alpinas por la pureza del aire de montaña" (357, traducción propia); la ironía va de la mano con el hecho que el conjunto de las emisiones se concentran en los fondos durante las inversiones de valle nocturnas, muy persistentes en invierno.
} 
inclusive, puede esperarse una media entre 70 y 80 días con precipitaciones y sólo entre 25 y 30 días con cielo claro ${ }^{97}$.

Cabe consignar que, fundamentalmente, aunque no con exclusividad, en invierno son esperables secuencias diarias de precipitación de varias semanas ${ }^{98}$.

\begin{tabular}{|l|l|l|l|l|l|l|l|l|l|l|l|l|l|}
\hline \multicolumn{10}{|c|}{ PRECIPITACIONES; Series 1958-94. Conti -INTA } \\
\hline & E & F & M & A & M & J & J & A & S & O & N & D & A \\
\hline El Bolsón & $\mathbf{2 7 . 7}$ & 28.9 & 26.9 & 60.1 & $\mathbf{1 6 1 . 8}$ & 157.1 & 129.9 & 68.6 & 41.6 & 43.8 & 31.3 & 46.6 & $\mathbf{8 2 4 . 3 ^ { 9 9 }}$ \\
\hline Bariloche & 22.6 & $\mathbf{2 1 . 4}$ & 29.0 & 54.4 & 131.1 & $\mathbf{1 4 1 . 8}$ & 129.7 & 113.6 & 57.9 & 39.9 & 24.5 & 30.7 & $\mathbf{7 9 6 . 6}$ \\
\hline
\end{tabular}

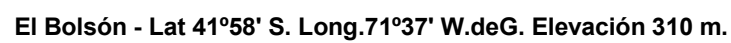

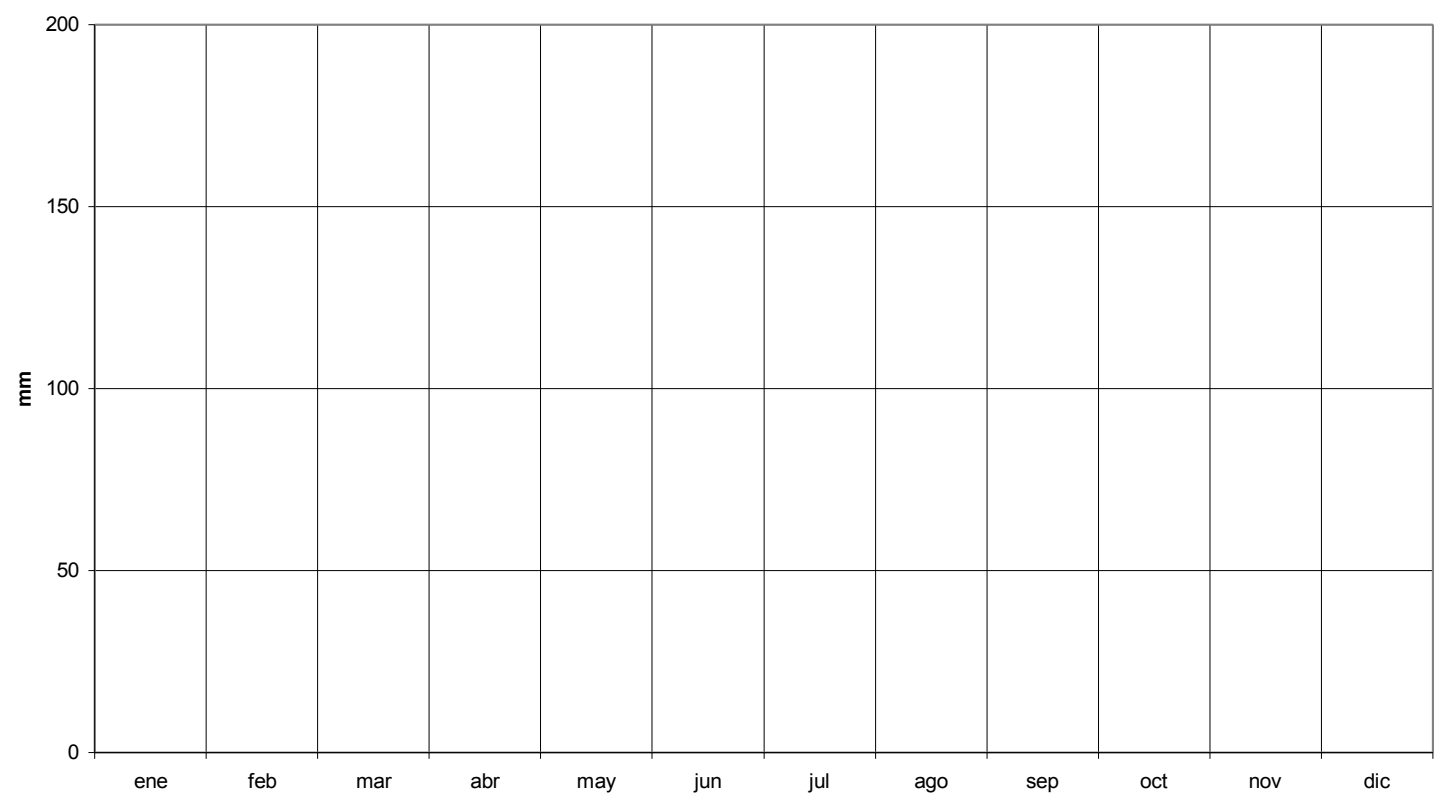

Fig. 9: Precipitaciones medias mensuales. Fuente: Dimitri, 1982 (serie:1961-70).

\footnotetext{
${ }^{97}$ Servicio Meteorológico Nacional, series $1941-50$ y 1971-78.

98 En junio de 2006 hubo 26 días con algún registro de precipitación; datos propios en El Hoyo.

${ }^{99}$ Serie 1941-50: $814 \mathrm{~mm}$ y serie 1971-78: 974mm. S.MN..
} 


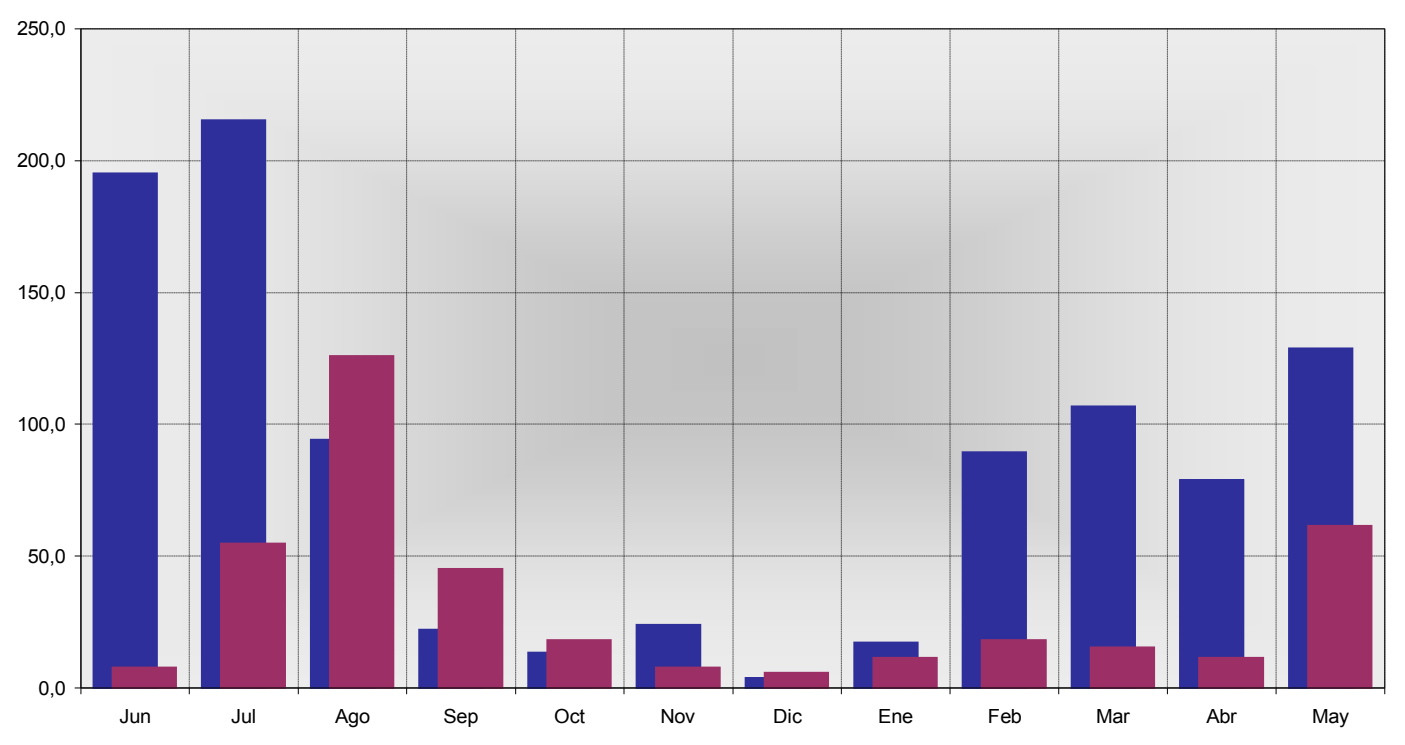

口2001 —1998

Fig. 10: Irregularidad en los totales pluviométricos. Con cierta frecuencia ocurren anomalías; véanse los valores alejados de las medias mensuales en ambas series (datos propios).

\section{Balance Hídrico El Bolsón (1941-60)}

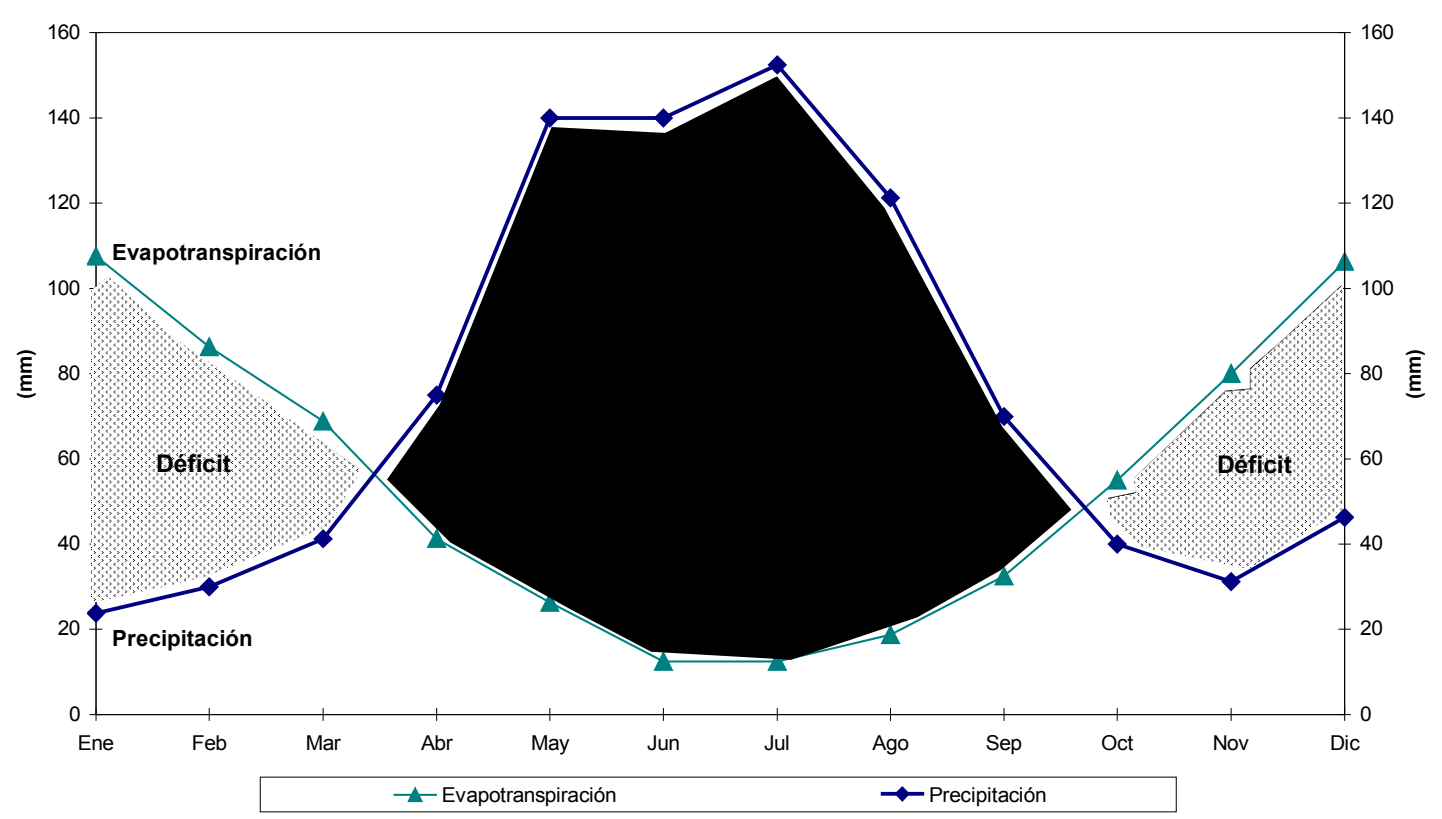

Fig. 11: Balance hídrico. Si bien faltan señalar el corrimiento por los períodos de recuperación (marzo-abril) y 'retardo' (setiembre-octubre); las variables muestran el marcado peso estacional. Elaboración propia. Fuente: S.M.N..

Reiterándonos, todas estas características, que según las circunstancias merecerían ser llevado a un plano de minuciosidad que claramente nos desborda ${ }^{100}$, están asociadas con el tiempo y clima de montaña, de modo que por lo menos, y siempre de

\footnotetext{
${ }^{100}$ Duración de las heladas, intensidad de las precipitaciones, balance hídrico, dirección de los vientos superficiales,
} asoleamiento sectorial y así, según la problemática a tratar 
acuerdo con las condiciones regionales, tres tipos de situaciones serán decisivas: cimas, faldeos y fondos de valle; asociados además con consideraciones sobre: pendientes, orientaciones, particularidades topográficas y micro-relieves ${ }^{101}$.

\section{II.2.2.2. Indicios para una problemática establecida, el agua.}

El enunciado se realiza solamente por tener la certeza de ser un camino necesario para quien quiera profundizar en materia del contexto biofísico para la geografía local, se rescata la figura hidrográfica como sostenedora de buena parte de las problemáticas socio-territoriales en la región. La condición multiestructural que le cabe al agua a nivel general, se potencia en zonas como ésta donde consumo residencial, riego (sistemático y espontáneo), recreación, conservación, industria-artesanías y, en algunos casos hasta comunicación, muestran un perfil donde el agua no puede faltar, con ello y al decir de Labasse, la dominante hidráulica preside la organización del espacio. Pero como también destaca, "Pocas veces el agua es solamente inútil: si no es útil se transforma en perjudicial" (44). Es decir la preocupación deberá pasar por cuestiones referidas al agua, su manejo (también su des-manejo) ${ }^{102}$.

Por sus características más dramáticas las inundaciones y aún los torrentes, son fenómenos esperables y de participación creciente en el desenvolvimiento de los valles; máxime cuando la ocupación de sectores de riesgo, con diferente intensidad, existe en una gran diversidad de modalidades, desde el marginal-espontáneo, las neorrurales o hasta barrios planificados.

Es una constante la ocupación progresiva de terrazas de inundación de los ríos y sectores de escorrentía hoy en día abandonados, especialmente incorporándolas a las tramas urbanas. De hecho, evacuados y destrucción de bienes, hablan por sí sola de una 'lectura' poco convincente de la problemática hídrica-hidráulica (apéndice 4).

Dijimos hace algo más de un decenio, "La disposición y funcionamiento hidrológico todavía obedecen casi con exclusividad a las condiciones naturales; sólo algunas canalizaciones menores, rectificaciones y el desarrollo, hoy casi espontáneo de sauzales ribereños, se destacan como modificaciones significativas. De todos modos, las necesidades han llevado a que se conformen sistemas distributivos de agua para

\footnotetext{
${ }^{101}$ Respecto del clima montañés en general y su tratamiento profundo, se puede consultar Barry; por ejemplo ver, en especial, la síntesis que desarrolla en el ítem The study of mountain weather and climate (Cap. 1: 9-13), el Cap. 2 y el ítem Mountain and valley winds (Cap. 3: 167-182). Por otra parte, en esta obra se puede comprobar que nuestro ámbito recibe proporcionalmente escasa atención científica (1992).

102 Tomamos de un informe especializado. Se utiliza el agua para riego en muy pequeña escala, pero el uso turístico y recreativo de los lagos es importante. El régimen de los cursos es torrencial y debido a la ausencia de normas que regulen la ocupación territorial y el uso de la tierra, se generan daños por inundación en diversos asentamientos urbanos y rurales (Chubut, PROSAP, 2001).
} 
riego y consumo. Claro que estos, por ahora, apenas superan lo artesanal y sólo involucran a varias decenas de chacras en producción...” (1996: 56).

Hoy el panorama es más complejo, al crecimiento demográfico y la expansión física de la ocupación espacial, se sumaron a efectos devastadores de las inundaciones de 1997, 2002 y 2004, para que las intervenciones ribereñas en las cuencas AzulQuemquemtreu (todavía en obra) y Epuyén, fueran 'radicales', generando modificaciones importantes tanto en el trazado como en sus márgenes y cauces. Se ha optado por una opción a modo de canalización ${ }^{103}$ a fin de facilitar el rápido escurrimiento, evitando anegamientos, en el caso del río Epuyén, menos torrencial por contar con su cabecera lacustre, y/o el arrase, muy significativo en el caso del Quemquemtreu, con su cuenca imbrífera hacia el Este en altura y sin lagos, lagunas ni mallines que atenúen el flujo.

Los aproximadamente $7.550 \mathrm{~km} 2$ que abarca la Comarca implican la totalidad de la cuenca hidrográfica del lago Puelo, la vertiente Sur de la cuenca del río Manso, el entorno de Cholila con el lago Rivadavia como colector y un sector acotado de la alta cuenca del río Chubut. En términos generales, el régimen hídrico obedece a los aportes por precipitaciones, que conllevan picos de máximas con las crecientes de otoño-invierno y primavera y un marcado estiaje hacia fin de verano. Se debe tener presente que los faldeos boscosos actúan como moderadores de los efectos por torrencialidad; huelga señalar entonces, las diferentes situaciones provocadas por el grado de cobertura de las laderas en función de sus condiciones naturales como por el efecto de degradación por incendios, pastoreo y quita de árboles.

A todo esto y por una suma de razones climáticas y geomorfológicas, pasaremos de vertientes más maduras y caudalosas al poniente, a caudales menores pero de torrencialidad más acentuada al oriente (ver I.O.V.I.F.,1971; Gomis,H.,1976; Daus F.,1975). Cabe consignar, por fin, que la menor entidad de los ríos respecto de algunos sistemas hidrográficos vecinos (Nahuel-Huapi; Manso, Futaleufú y Chubut).

Respecto a los espejos de agua en la Comarca, además de los cuatro principales lagos, Puelo, Epuyén, Cholila y Escondido, cabe mencionar otros menores como el Lezana y Carlos Pellegrini, a la vez que es posible identificar innumerables lagunas y lagunitas, muchas de ellas valoradas como recurso escénico e incorporándose a la discusión social en materia de manejo y tenencia.

Tabla 4. Hidrografía, Algunos datos ilustrativos.

\footnotetext{
${ }^{103}$ Metodología controvertida por su condición unitaria respecto de las inundaciones. Por una parte, los cambios en los niveles de base con la profundización de los cauces supondría una dinámica de desecamiento potencial de varios sectores; hecho por cierto buscado por algunos pero de trascendencia micro ecológica, al menos, debatible. Por otra, la intervención por la urgencia generó modificaciones básicamente inconsultas sobre el uso de los ríos en materia de recreación y contemplación, y por ahora se diría que han perdido potencialidad al respecto.
} 


\begin{tabular}{|l|c|c|c|}
\hline \multicolumn{4}{|c|}{ Caudales medios demostrativos (m3/seg.) } \\
\hline Río & $\begin{array}{c}\text { medio } \\
\text { anual }\end{array}$ & $\begin{array}{c}\text { máximo medio } \\
\text { mensual }\end{array}$ & $\begin{array}{c}\text { mínimo medio } \\
\text { mensual }\end{array}$ \\
\hline Quemquemtreu (confluencia Repollos) & 11 & 17 (nov.) & 8 (mar) \\
\hline Azul (Hermosilla) & 21 & 29 (nov.) & 12 (mar.) \\
\hline Epuyén (Angostura) & 15 & 24 (ago.) & 6 (mar.) \\
\hline Puelo (Paso internacional) & 110 & & \\
\hline Turbio & 27 & & \\
\hline
\end{tabular}

\begin{tabular}{|l|c|}
\hline $\begin{array}{l}\text { Otros ríos vinculados con la } \\
\text { Comarca }\end{array}$ & Caudales medios (m3/seg.) \\
\hline Manso (lago Steffen) & 66 \\
\hline Manso (Paso internacional) & 145 \\
\hline Foyel & 32 \\
\hline Carrileufú (Cholila) & 50 \\
\hline Futaleufú (Garzón) & 220 \\
\hline Chubut (El Maitén) & 96 \\
\hline
\end{tabular}

\begin{tabular}{|l|c|l|c|c|c|c|}
\hline Lago & $\begin{array}{l}\text { Cota } \\
\text { m.s.n.m. }\end{array}$ & $\begin{array}{l}\text { Superficie } \\
\mathrm{km} 2\end{array}$ & $\begin{array}{l}\text { Profundidad } \\
\text { máxima }(\mathrm{m})\end{array}$ & $\begin{array}{l}\text { Profundidad } \\
\text { media }(\mathrm{m})\end{array}$ & $\begin{array}{l}\text { Longitud de } \\
\text { la costa }(\mathrm{Km})\end{array}$ & $\begin{array}{l}\text { Área } \\
\text { cuenca } \\
(\mathrm{km} 2)\end{array}$ \\
\hline Puelo & $\mathbf{1 9 9}$ & $\mathbf{4 5}$ & $\mathbf{1 8 0}$ & $\mathbf{1 1 1 , 4}$ & $\mathbf{5 7}$ & $\mathbf{3 . 0 4 0}$ \\
\hline Epuyén & $\mathbf{3 0 0}$ & $\mathbf{1 7 , 5}$ & $\mathbf{1 4 8}$ & $\mathbf{9 2 , 4}$ & $\mathbf{3 3}$ & $\mathbf{5 0 6}$ \\
\hline Cholila & $\mathbf{5 6 0}$ & $\mathbf{1 7 , 5}$ & $\mathbf{1 0 8}$ & $\mathbf{4 8 , 5}$ & $\mathbf{3 1}$ & $\mathbf{1 0 9}$ \\
\hline Escondido & $\mathbf{7 5 0}$ & $\mathbf{9 , 8}$ & $\mathbf{s} / \mathbf{d}$ & $\mathbf{s} / \mathbf{d}$ & $\mathbf{s} / \mathbf{d}$ & $\mathrm{s} / \mathrm{d}$ \\
\hline
\end{tabular}

Fuentes: www.hidricosargentina.gov.ar/75 ; www.mineria.gov.ar/ambiente/estudios/irn/chubut/ y Urzúa Vergara, J. (1992: 77-91).

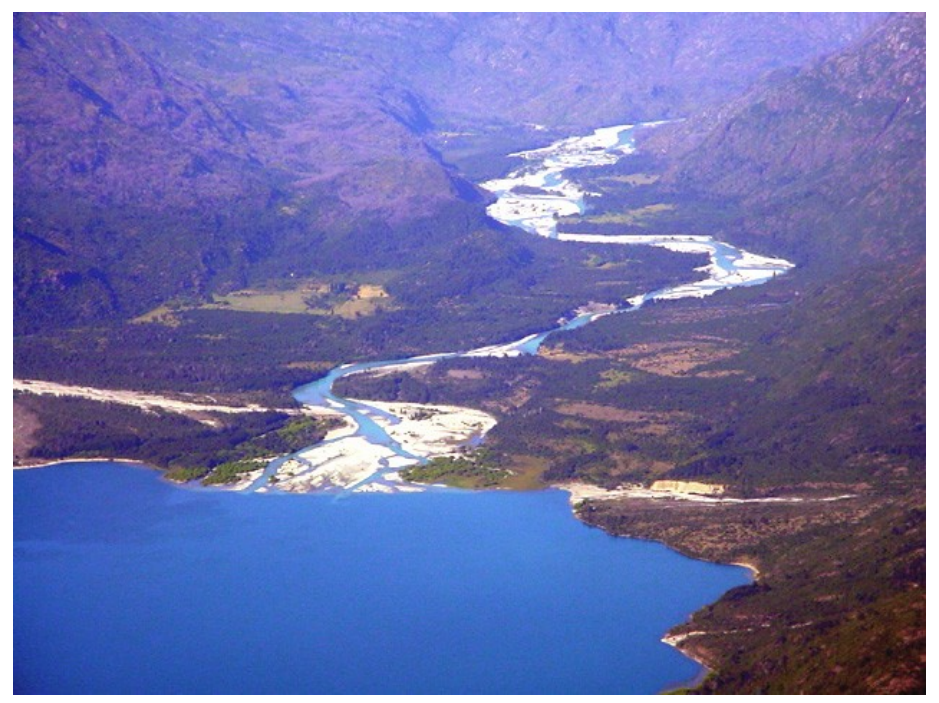

23

Foto 23: Desembocadura del río Turbio en el lago Puelo, Parque Nacional Lago Puelo. Nótese la amplitud relativa de lecho de inundación periódica ocupado por material de arrastre (Foto de F. Ottone, 2004).

Por otra parte, aunque con una tendencia ascendente en materia de usos y complejidad en materia de riego ${ }^{104}$, entendemos que mantiene validez aquello que expresamos en su oportunidad, "Pero, aún así, acequias, pequeñas piletas y esclusas, conforman una parte inseparable de la infraestructura básica para la producción agropecuaria. Sin ella, sus posibilidades son mínimas y, a decir verdad y en lo

104 Algunos datos dispersos: superficie empadronada en El Bolsón-Mallín Ahogado es de 1.072 ha con 402 regantes (2006). Fuente: www.hidricosargentina.gov.ar/75

En El Hoyo hay un potencial para riego de 1.050 ha, mientras que Las Golondrinas 311 ha. Fuente: Ongaro 1999. 
agropecuario, el aprovechamiento global no parece estar alejado del mínimo". (1996: $56)$.

Cabe por fin, destacar la sensibilidad social que existe en materia del aprovechamiento hidroeléctrico de magnitud, así como en los primeros años de la década de 1980-90 hubo una actitud de rechazo frente a la posible concreción del complejo hidroeléctrico Epuyén-Puelo, hoy en día, en un contexto más habituado a enfrentarse a situaciones del estilo, también se objeta desde varios sectores sociales, la realización de importantes embalses, aguas abajo del Puelo-Manso, en territorio chileno.

La existencia de obras menores como la de Loma Atravesada, que involucra una captura, el riego potencial de unas 2000 hectáreas y la generación de $2.0 \mathrm{MW}$, indicarían una dirección más moderada, que se condice con otros proyectos de riego y energéticos, sin que todavía se aprecie mayor claridad en el tema.

Para cerrar este capítulo el cuadro que sigue propone una visión conjunta y orientadora inicial a la hora de trabajar en la Comarca en términos tentativos de capacidades territoriales, como se verá más adelante en la Tercera y Cuarta Parte.

Cuadro 1. El medio natural en su rol de condicionante, aproximaciones.

\begin{tabular}{|l|l|}
\multicolumn{1}{|c|}{ Condicionante } & \multicolumn{1}{c|}{ Trascendencia en los usos } \\
\hline Falta de verano térmico (fresco). $\rightarrow$ & - desarrollo agrícola y turístico condicionado. \\
\hline $\begin{array}{l}\text { Vientos (potentes, fríos, secos y } \\
\text { frecuentes). } \rightarrow\end{array}$ & $\begin{array}{l}\text { - desecante en lo agropecuario; de riesgo en turismo } \\
\text { (incendios); incomodidad; potencialidad energética. }\end{array}$ \\
\hline Heladas tempranas y tardías. $\rightarrow$ & - limitante en lo agro-frutícola. \\
\hline $\begin{array}{l}\text { Inviernos rigurosos aunque } \\
\text { irregulares (discontinuidades). } \rightarrow\end{array}$ & $\begin{array}{l}\text { - potencialidad turística; aislamiento físico; costos de } \\
\text { calefacción. }\end{array}$ \\
\hline $\begin{array}{l}\text { Alternancia de frecuentes } \\
\text { inundaciones y sequías. } \rightarrow\end{array}$ & $\begin{array}{l}\text { - limitaciones agropecuaria, frutícola y a la expansión } \\
\text { física; aislamiento físico y situaciones de riesgo. }\end{array}$ \\
\hline $\begin{array}{l}\text { Condiciones microclimáticas } \\
\text { relativas favorables para el } \\
\text { asentamiento tradicional. } \rightarrow\end{array}$ & $\begin{array}{l}\text { - capacidad productiva primaria; posibilidades de } \\
\text { excepción a nivel nacional (lúpulo, berries, etc.). }\end{array}$ \\
\hline $\begin{array}{l}\text { Topografía y relieves de montaña } \\
\text { (faldeos abruptos, terrazas, bajos } \\
\text { mallinosos, etc.). } \rightarrow\end{array}$ & $\begin{array}{l}\text { - limitante de la expansión física; potencialidad escénica; } \\
\text { 'archipiélago' de sitios por aptitud; situaciones periódicas } \\
\text { de riesgo ambiental (inversión térmica, inundaciones, } \\
\text { etc.). }\end{array}$ \\
\hline $\begin{array}{l}\text { Ríos y lagos de montaña. } \rightarrow \\
\text { Paisaje natural valorado como } \\
\text { atractivo y estimulante. } \rightarrow\end{array}$ & - condicionantes entre el estímulo y las limitaciones. \\
\hline $\begin{array}{l}\text { Ambiente natural de relativa escasa } \\
\text { intervención y contaminación } \rightarrow\end{array}$ & - potencialidad económica 'disparadora'105. \\
\hline $\begin{array}{l}\text { Fuente: elaboración propia, en base al análisis bibliográfico-documental y relevamientos. Bondel et al } \\
\text { (Proyectos de investigación, } 2002 \text { y 2006). }\end{array}$ \\
\hline
\end{tabular}

\section{II.2.3. Aspectos geohistóricos dominantes de la territorialidad andino patagónica.}

\footnotetext{
105 Ver por lo indicativo, el artículo de Wittemeyer et al, donde enumera atractores relacionados con la cercanía a las áreas naturales protegidas en general. (2008).
} 
Seguramente la presencia del término transformaciones en el título de esta tesis dejará pocas dudas sobre la singular valoración que se le da a la componente temporal, que, de hecho, está insertada, por así decir, en el tronco general de su desarrollo. Aún así se estimó conveniente desplegar en un capítulo aparte el contexto histórico de sucesos y procesos de relevancia espacial, toda vez que su relativa brevedad debe observarse a partir de la necesidad de mantener el hilo problemático de trabajo en su conjunto y no por la falta de complejidad y matices, que abundan y son cada vez más abordados desde la historiografía local, regional y nacional ${ }^{106}$.

Como se ha visto, además, la historia regional ya ha tenido protagonismo en este segmento del trabajo preocupado por presentar al área de estudio. Pero, retomando apreciaciones de Chiozza y Carballo en cuanto al tiempo espacial, las permanencias y cambios (2006: 85-89) y el rumbo explicativo buscado, se hace necesario ahondar un tanto en varios aspectos estructurales. Así, desde lo territorial, nos ocuparemos del tiempo histórico, aquel propio de las generaciones, de los decenios y centurias, aquel de las proyecciones espaciales que prevalecen aún cuando hayan perdido vigencia funcional y hasta puedan haber desaparecido sus componentes materiales ${ }^{107}$.

A la hora, entonces, de adentrarnos en la dimensión temporal, optamos por recurrir como camino interpretativo a la visión resultante de dos enfoques; uno a partir de una síntesis asociada a la perspectiva espacialmente integradora que sugiere Claval con la caracterización de lógicas territoriales (1999:244-51) y el otro de la mano de la esquematización de cuatro cortes temporales.

En suma, como ya se enunciara en el marco teórico, se trata de identificar cortes reveladores a través de improntas territoriales propias de circunstancias decisivas en el desarrollo histórico y aludiendo a interpretaciones historiográficas básicamente consumadas, si bien, claro está, no por ello alejadas de polémicas. La 'lupa' estuvo puesta en el tiempo-espacio regional y por el 'zoom-tamiz' han pasado, desde simples objetos hasta entreveradas decisiones políticas. En definitiva, nuestra búsqueda apuntó, con el complemento clave que sugiere el pasado, hacia una dirección explicativa de las cuestiones de hoy, de los problemas actuales.

\section{La perspectiva geohistórica}

\footnotetext{
${ }^{106}$ Respecto de la Patagonia en general y la Patagonia Andina en particular, es una constante que surjan y resurjan consideraciones históricas en la raíz territorial problemática; para su verificación, por ejemplo, basta consultar las temáticas de los múltiples Congresos, Seminarios, Jornadas y Simposios regionales realizados tanto en nuestro país como en el extranjero.

${ }^{107}$ Vale advertir que el otro tiempo, el de la contemporaneidad, de lo cotidiano, como los modelizados por Hägerstrand con dioramas, será significativo en los dos últimos capítulos
} 
El área de estudio, es decir la actual Comarca, sugiere raíces unitarias relativamente distantes en el tiempo, con el aislamiento geográfico como una constante condición. Aislamiento propio de la lejanía y de su fisiografía de montañas y bosques a la vera del 'desierto' patagónico ${ }^{108}$.

Sin embargo, todavía hoy son válidas las dudas respecto de las modalidades de ocupación original, tanto por su origen como por su antigüedad. En términos de traspaso estructural en el paisaje contemporáneo, las mayores precisiones surgen de pinturas rupestres y algún hallazgo arqueológico puntual; claro que se puede intuir que con un poblamiento regional cercano a los 10 milenios, el legado territorial podría haber sido importante, pero es una materia que nos desborda ${ }^{109}$.

Más certeza se tiene sobre la débil presión demográfica característica, aún en tiempos posteriores a la ocupación por los españoles de la Gran Isla de Chiloé y su entorno continental en el siglo XVII; es decir cuando los Poya o Chûwach a Kûnna (Tehuelches septentrionales, gente del borde -precordilleranos-) tenían en estas tierras de la vertiente oriental de los Andes, sus confines y zonas de contacto con los Tehuelches meridionales hacia el Sur, los Huiliches al Oeste, Pehuenches al Norte y al Este con los Gununa Kunna (también Tehuelches septentrionales pero de menos contacto con el piedemonte cordillerano oriental $)^{110}$. Las incursiones españolas al saliente cordillerano, tanto en materia exploradora y misionera, como en la búsqueda de indios esclavos, dejaron señales, aunque imprecisas, sobre un espacio de escaso poblamiento y con sus habitantes en condición de continuo movimiento ${ }^{111}$.

Con una mirada tal vez algo audaz, cabe especular con que las tierras que ocupan el centro de la Comarca y visto desde una perspectiva pre-colonizadora, se emplaza en un sitio desventajoso. Estos valles profundos han tenido a sus flancos Este y Oeste, dos ámbitos más 'amables' en términos ambientales asociados a las tecnologías propias de cazadores y cazadores-recolectores. La oferta alimenticia (proteica) del mar y la estepa fueron seguramente superiores a aquella más circunstancial de bosques y lagos.

\footnotetext{
108 La postura revisionista (¿neo-revisionista?) destaca con firmeza el uso peyorativo del término desierto como sinónimo de vacio como estrategia de expansión territorial en la Patagonia. (ver por ejemplo en Bandieri (a), 2005:13-16 o en Novella, 2006) Sin dejar de coincidir en la esencia de la crítica; cabe considerar que también el término lleva, y suponemos, ha llevado, una connotación natural asociado, además de con la bajísima densidad demográfica de los ámbitos esteparios (a excepción de Tierra del Fuego), la aridez generalizada, la falta de agua, aspecto recurrente en cuanta fuente documental se consulte. (cf por ejemplo en Denis, 1987:178). En realidad, puede afirmarse que la sentencia de Alberdi, "nuestro peor enemigo es el desierto", fue tan paradigmática como de fácil reinterpretación, según el contexto de las diferentes circunstancias (ver por ejemplo en la obra de Sarobe donde se retoma constantemente el mandato 'civilizatorio' (1943).

109 (ver, por ejemplo, la síntesis que desarrollan, Albornoz, Hajjduk y Lezcano.2002).

${ }^{110}$ Novella, María M.. Comunicación personal.

111 Una reciente obra de Rodolfo Casamiquela, escrito a modo de Vademécum étnico en especial para servir de apoyo a quienes están en la gestión pública y para los profesionales del Derecho, reúne información clave para ilustrarse respecto de la complejidad étnica y espacial de los pueblos indígenas de la Patagonia (2006). En este contexto y entre un importante número de autores, servirán de guía segura para ahondar en la temática desde enfoques geográficos e históricos, Luis de Lasa (1998: 619-30) y María T. Luiz (2006:63-67).
} 
Por un lado, y aún con el rigor de las lluvias y el frío del Oeste, estuvo el mar como proveedor de alimentos 'seguros', entre fiordos profundos, abrigados y boscosos. Por el otro, hacia el Este, la estepa patagónica, rica en recurso de caza y donde, en especial con la incorporación del caballo, temas críticos para los grupos nómades, como la escasez de agua, el abrigo y traslado de petates, se simplificaron notablemente. Se diría que el bosque fue para ellos, lugar de excursión o tal vez de eventual intercambio (Musters, Cap. IV).

En todo caso y para nuestros requerimientos al respecto, resulta ilustrativo y demostrativo de ser ésta una temática que sólo puede extrapolarse a los espacios de hoy de un modo apenas tentativo. Navarro Floria y Nacach, confirmarían esta insinuación cuando afirman en su introducción al libro del viajero Guillermo Cox, "...Otro misionero, el franciscano Francisco Menéndez, pasó varias veces en los últimos años del siglo XVIII, reconociendo los alrededores del Nahuel Huapi y describiendo un panorama humano de una impactante diversidad y movilidad. (...); .... los únicos dueños de los pasos eran los pehuenches y los huilliches cordilleranos, intermediarios y participantes en el circuito ganadero que unía las estancias del campo bonaerense con los mercados del sur chileno a lo largo de los grandes ríos del norte de la Patagonia y a través del Neuquén, en una compleja red de relaciones nunca bien conocida ni controlada por los centros de poder coloniales (2006:VIII); el subrayado es propio. Valga nuevamente la consideración, que todo indicaría que la Comarca que nos ocupa estuvo fuera de esos circuitos, en su periferia aislada. Serían, éstas, tierras de los Poya (grupo Tehuelche septentrional) (cf.: Casamiquela, 2006: 22) sometidas a diferentes pulsos de contactos culturales (evangelizadores) y guerreros (esclavistas) durante algo más de dos siglos (1660-1880) desde la Chiloé española ${ }^{112}$ y también, más tardíamente, Mapuche. A la vez, también es válido considerar a estos valles como de circunstancial caza bagualera de otros grupos Tehuelche (Meridionales).

Se presentan, entonces, las bases del poblamiento regional moderno, aquel que responde al devenir histórico del sur argentino, con un espacio estructurado a partir de la conquista territorial y el establecimiento de una colonización acorde a los principios y objetivos de la llamada Generación del ' $80{ }^{113}$.

Los asentamientos se rigieron según la oferta de recursos naturales, limitada por la accesibilidad y las posibilidades de realizar intercambios de bienes económicos desde

\footnotetext{
$\overline{112}$ Ver en Furlong (1995:29-32); Willis, (199-201).

113 Además de la Ley de colonización o ley Avellaneda (817 de 1876), las dos normas de aplicación más importantes para la zona fueron en materia espacial, la Ley 1501 de 1884 o "Ley del Hogar" por las que se entregaban hasta 625 ha. para explotación agropastoril (ej: Cushamen) y la Ley 4167 de 1903 o "nueva ley de tierras" que preveía la venta de superficies de hasta 2500 ha. para pastoreo y 100 para agricultura y el arrendamiento de hasta 20000 ha. con opción a compra de la mitad de la superficie al finalizar el contrato. Se aplicó con los ocupantes que se instalaban y solicitaban el arrendamiento. Implicaba pagar pastaje y otras obligaciones. Además hubo 51 leyes especiales y 7 decretos. Dentro de estas leyes especiales entraría por ej. la Colonia 16 de octubre (Novella, comunicación personal).
} 
y hacia los diferentes mercados (Carabelli et al, 2000). Así, entre 1885 y 1915-20, con un retroceso del bosque en casi un $50 \%$ durante las primeras décadas del proceso en la región nordpatagónica cordillerana argentino-chilena ${ }^{114}$ y con el establecimiento de pueblos, chacras, estancias y caminos, se consolidaron los núcleos de población definitiva.

Un nuevo paisaje se instaló y la estructura agro-silvo-pastoril fue su rasgo socioeconómico característico inicial, aunque sólo perdurable en los valles bajos de El Bolsón y adyacencias y en la Colonia Valle 16 de Octubre y no así en valles y parajes más altos como los de San Carlos de Bariloche o la Vega Maipú (San Martín de los Andes), donde al condicionamiento físico que impusieron las heladas tardías y tempranas, el viento y la sequedad del verano, se le sumó el agotamiento temprano de los suelos y la pequeñez del mercado; opciones que orientaron hacia el predominio de la producción primaria ganadera y forestal ${ }^{115}$. Eriksen añade a esta sumatoria el desánimo ante intentos frustrados o situaciones productivas y comerciales vacilantes, aspecto que, diríamos, se traslada con el tiempo y que se retomará en los últimos capítulos de esta tesis (1979).

Nos señala Abalerón refiriéndose a las iniciales formas de ocupación del ámbito cordillerano cisandino hacia finales del Siglo XIX, "... Crónicas de la época hablan que al norte del lago Nahuel Huapí, las tierras de las Pampas Occidentales y de las estribaciones orientales de los Andes hasta la desembocadura de los Lagos, fueron ocupadas por ganaderos argentinos. En cambio, al sur (...) la colonización ha venido principalmente de Chile, ..." y continúa tomado como referencia las actividades comerciales de un activo colono de origen alemán, "...Antes de fin de siglo las actividades de Don Carlos Wiederhold, principalmente, habian permitido despachar hacia Chile 300.000 kgrs. de lana, e ingresar 93.000 kgr. de carga general, ..." ( 1992: 2 y 4$)$.

Convendrá insistir con el aislamiento físico comarcal, esta suerte de encierro que pudo igualmente sostener a las pequeñas comunidades ya instaladas. Los comentarios que siguen corresponden a la década de los años 1950, pero sirva de ilustración sobre los temas de espacio-tiempo y accesibilidad, de los cuales se podría abundar (el dato de época que tomamos de la zona de Carrenleufú):

"...El rendimiento de marcha en el camino Corcovado - Puente Carrenleufú (25km), es el siguiente:

\footnotetext{
${ }^{114}$ De sumo interés es la consulta de Veblen y Lorenz (1988), así como los mapas topográficos levantados a principios del S. XX por Bailley Willis y su equipo, donde se identifican las enormes superficies con quemazones de los bosques (1988).

${ }^{115}$ En este sentido resultan de sumo interés las detalladas observaciones que hace Wolfgang Eriksen respecto del uso agrícola y que dan por tierra con la imagen agrícola exitosa andino patagónica (1970:58-62; traducción inédita de Muriel Sauzet; gentileza de Susana Lara)
} 
- Catango, 48 horas.

- Jinetes, 3 horas.

- A pie, 1 jornada.

- Automóvil, 40 minutos.

Si bien se trata de un paraje extra-comarca, sus condiciones físicas y culturales pueden considerarse análogas (Clifton Goldney, 1964:26-7):

Otro ejemplo revelador es el que rescata Félix Vidoz, cuando relata que en los años '40, el primero de los guardaparques de lo que se llamó Anexo Puelo del Parque Nacional Los Alerces, iba a cobrar sus sueldos desde Lago Puelo a Villa Futalaufquen a caballo, tardando tres días en ir y volver, recorriendo unos $140 \mathrm{~km}$ desde Lago Puelo(1998).

Fue con la demorada llegada del ferrocarril a San Carlos de Bariloche (1934) ${ }^{116}$, que, podría decirse, la administración política del país encontró una nueva forma de participar del desarrollo del Oeste patagónico. La fundamental reducción de la distancia-tiempo no sólo significó la readecuación de la economía doméstica, sino que también motorizó múltiples instancias decisivas apoyadas en la condición paisajísticasimbólica (la Suiza argentina) y fronteriza, en términos de potencial disputa.

Gran parte de la clase dirigente 'visible' con sus vínculos terratenientes y proclive a la visión europeizante del destino nacional, tuvieron en estas montañas patagónicas su propio lugar de encanto, de excelencia. La conservación tuvo el guiño político aristocrático y los Parques Nacionales fueron una vía interesante en términos territoriales. El turismo, inicialmente, seguía esquemas europeos y la infraestructura acompañó esta tendencia básicamente clasista. Los grandes hoteles, financiados por el Estado, embarcaciones, puentes y caminos, abrieron paisajes majestuosos e imprimieron una nueva organización regional del espacio.

A todo esto la Comarca, con su aislamiento e impronta de sustentabilidad básica, apenas pudo participar muy tangencialmente en empresas de magnitud, en todo caso, sí se pudo apreciar un re-direccionamiento económico que progresivamente nutrió los flujos hacia y desde Bariloche. Se necesitarían décadas para consolidar la tendencia, pero cabría arriesgar que ese autismo territorial característico tampoco habrá sido un gran generador de necesidades. Debe contemplarse, para el caso, que los valles chilenos linderos, permanecieron por décadas en estado de mayor aislamiento aún, de

\footnotetext{
${ }^{116}$ Resulta sumamente indicativa la lectura de Pierre Denis (1920) y su obra sobre la Argentina en la segunda década del S XX. Por entonces, con la seguridad de la rápida llegada de las obras ferroviarias a todo los valles andinos y las posibilidades de contar con energía hidroeléctrica, la figura del poblamiento y la colonización se mantenía como indiscutible. Cita Denis a B. Willis "... La hulla blanca hará (...) una gran región industrial e implantará la vida urbana...". Siendo que B. Willis proyectó con detalles una ciudad industrial de 40.000 habitantes en el extremo oriental del lago Nahuel Huapí (1987:183-186).
} 
modo que su mínimo peso geopolítico seguramente habrá incidido para sostener este cuadro de situación ${ }^{117}$.

El esquema que sigue en seguida (fig. 13.), reproduce una síntesis evolutiva que trata de reflejar la secuenciación del orden territorial a través de los años, poniendo énfasis en los cruces temporo-espaciales más trascendentes y que en general continúan reflejándose en las actuales modalidades de la instalación humana comarcal.

Con estos antecedentes a la actualidad, fueron cuatro los cortes temporales que, en materia de usos, se tomaron como relevantes de los aspectos esenciales que hicieron y hacen a la organización espacial comarcal. Estos son: 1895-1905, 1930-40, 1960-70 y 1985-95. Se trata de décadas que podrían denominarse culminantes y a la vez 'bisagras', de tendencias de ocupación y explotación de los asentamientos, y, con ello, indicadores estructurales del territorio ${ }^{118}$.

\section{LA COMARCA EN EL ESPACIO-TIEMPO}

${ }^{117}$ Distinto fue en otros ámbitos limítrofes más favorables para la colonización agro-ganadera; por ejemplo, en los años '40-'50, el caso de litigio "Palena - río Encuentro", 300km más al Sur de la Comarca, evidenciaba la mejor condición de enclave militar de Esquel.

118 Los diez años de rango significan tan sólo un lapso prudencial para que esta condición de culminación y readecuación de modalidades pudieran concretarse y no una demanda metodológica. 


\section{SECUENCIACIÓN ESTRUCTURAL \\ Las lógicas territoriales (en base a Claval 1999: 244-51)}

- Pre 1884: territorios indígenas, espacios de lógicas de producción primaria periférica; caza, recolección y tránsito-intercambio hacia el barlovento andino inicialmente Poya (cf.: Casamiquela, 2006: 22). Pulsos diferentes durante algo más de dos siglos (1660-1880) en función de la expansión española (Chiloé) y Mapuche.

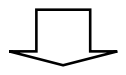

- 1885-6: comienza el $1^{\circ}$ arribo (espontáneo); de lógica pionera, del derrame posterior a la conquista militar de la región. Tiempos de la 'frontera libre' (cf.: Bandieri (b), 2005: 8-9) ${ }^{119}$. De las exploraciones, demarcaciones y ocupaciones de sitios; de la marginación socio-territorial de los indígenas y de las bases de proyectos colonizadores.

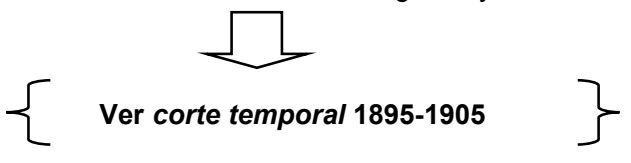

- 1902: comienza la 'argentinización' de los valles (des-chilenización) y se perfila la condición de enclave con la frontera internacional como reborde y para la vigilancia; predominancia de la lógica de la producción primaria agroganadera de base autosuficiente, desprendida de la estructura pampeana agro-exportadora dominante (excluida de la 'gran estancia'); aparece Ingeniero Jacobacci (Huahuel Niyeo) como concentrador del movimiento mercantil desde la 'vertiente' argentina ${ }^{120}$

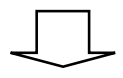

- 1930/2 comienza el $2^{\circ}$ arribo (dirigido-orgánico) y la consolidación de la estructura agropecuaria y socio-cultural local; lógica de zonas fronterizas en esquemas nacionales 'centrípetos' y con la soberanía territorial como eje cardinal; incluidos los Parques Nacionales.

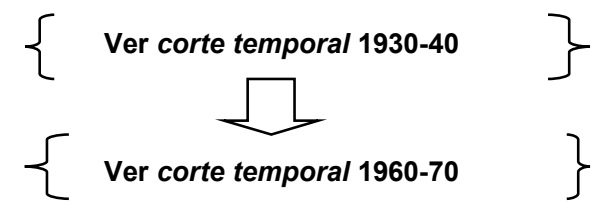

- 1970 comienza el $3^{\circ}$ arribo (espontáneo); hacia el desenclave; El Bolsón y zona como destino paradigmático en la 'vuelta al campo' o la 'fuga' de las grandes ciudades y receptor de la migración de población rural empobrecida desde la meseta patagónica aledaña ${ }^{121}$. Destino reconocido inicialmente como hippie. Lógica de la producción primaria con el desenvolvimiento estatal y los servicios. Primeros quiebres regulares al aislamiento: camino enripiado y con obras de arte clave, con la radio (A.M.) y las telecomunicaciones. Desde 1983-86 replanteo contextual de la condición fronteriza.

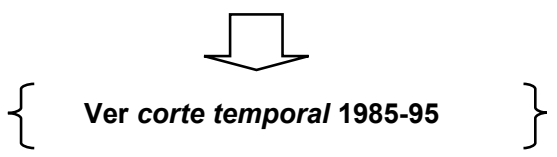

- Post 1995, continua el $3^{\circ}$ arribo pero se posiciona como primordial la lógica de la contemplación; donde de tener a la explotación de recursos naturales como objetivo a sostener se pasa a valorar las modalidades del poblamiento como prioritarias ${ }^{122}$. Se corresponde con el desenclave físico y virtual, y la estructura de corredores turísticos; con los cambios funcionales y estratégicos de la frontera internacional ${ }^{123}$; la especialización sectorial del territorio, el despegue turístico, la marginalidad 'oculta' y la expansión físico-territorial (¿geofagia?) de sesgo geográfico básicamente, aunque no en exclusividad, conflictivo.

Fig. 12. Secuenciación temporo-espacial.

\footnotetext{
${ }_{119}$ A comienzos del S XX, desde San Carlos de Bariloche llegó a existir, con una frecuencia semanal, un servicio regular de transporte a Chile por el Paso Pérez Rosales (Laría, 1970: 95)

${ }^{120}$ Ver interesantes aportes al respecto y su diagrama ilustrativo en Mendes y Blanco (2004: 6-9)

${ }^{121}$ En este sentido ya resultaban categóricos los índices negativos (expulsores) de los Departamentos Pilcaniyeu (-21.7) y Ñorquinco (-22.5), 1947-60; ver en Miatello, 1970:148-50, donde, además hace un nutrido análisis de variables demográficas a nivel departamental de Bariloche (Río Negro) y Los Lagos (Neuquén), además de provinciales patagónicos.

${ }^{122}$ Nos sentimos tentados de adoptar los criterios de Ojeda Rivera en su visión crítica del desarrollo de las áreas de montaña (2004:273-75. El autor enfatiza el paso del modelo colonial de explotación de recursos al modelo colonial de poblamiento, pero preferimos evadir la analogía, en vista de las diferencias importantes en materia de la geohistórica del poblamiento de las montañas patagónicas con otros ámbitos mundiales con raíces mucho más profundas en el tiempo. Es, claro está, sin dejar de valorar las numerosas coincidencias en materia del proceso contemporáneo.

${ }^{123}$ Como titulan Lopez Trigal y Guichard una sección de su libro para el caso de la frontera luso-hispana "La frontera, espacio repulsivo y nuevo espacio de atracción..." (2000).
} 


\section{II.2.3.1. Cortes temporales.}

\section{a. 1895-1905, "vía libre".}

Con el Siglo XIX en marcha y los Poyas desaparecidos como grupo individualizable, ya por directa eliminación física y/o 'asimilación' étnica española o mapuche, se mantuvo en el territorio, y con fuertes indicios de coherencia funcional, esa condición, diríamos 'bifacial', que impuso la cordillera y que tuvo con los grupos tehuelches y mapuches-pehuenches como dominantes territoriales hasta la llamada Conquista del Desierto. Igual condición se mantuvo durante el devenir de las nuevas corrientes pobladoras, en particular para con la onda expansiva de la colonización germanochilena de la segunda mitad del S XIX. Es éste el cuadro territorial de referencia previa a una lenta pero progresiva consolidación de la dependencia política hacia el gobierno rioplatense.

Este carácter de antecedente ${ }^{124}$ que le cabe a toda el área, es seguramente una condición identitaria, que, aún en la discusión entre posturas más o menos flexibles entre 'unicistas' o 'bipartistas' del ámbito cordillerano, se acepta una funcionalidad basado en el reconocimiento e interdependencia ancestral (Cf por ejemplo en: Bandieri 2005 (b); Casamiquela, 1990 o en, Albornoz et al 2002: 10 ).

Fue después de convenir con Chile en materia limítrofe (1902) que a la colonización agro-ganadera y sus modalidades de ocupación espacial, se le sumaba una decisiva tendencia centrípeta hacia la integración con el resto del país (administración, derechos de importación, militarización fronteriza, ferrocarriles, escuelas, Parques Nacionales, etc.); hecho lógicamente también perseguido, en su sentido inverso, desde Santiago de Chile y que sentó, con diferente éxito, las bases espaciales organizativas que perdurarán por décadas (Cf: Novella, 2006).

Fueron, entonces, el direccionamiento hacia la colonización mixta agro-pastoril, la defensa nacional y, más tarde la conservación de áreas naturales, las figuras comunes que mostraban la dirección a la que se dirigía con modalidades casi idénticas el Sudoeste argentino. En sentido inverso, estas tendencias crecientes convivieron con aquellas que se desenvolvían en retroceso, en lo que podría denominarse la geografía espontánea llevada adelante por distintos grupos y pobladores que no respondían directamente al modelo pretendido (indígenas, comerciantes independientes mercachifles ${ }^{125}$ y bolicheros- chilenos no integrados a la colonización trasandina, mineros y demás).

\footnotetext{
${ }^{124}$ Nos referimos al contexto fronterizo con el sentido que desarrollan Prescott 1978: 31 y 32 y en Haggett, 1988:488).

${ }^{125}$ Personajes fundamentales a la hora de sostener la vida aislada, sin intercambios regulares posibles, de cuanto poblador dedicara sus esfuerzos a buscar su sustento en estas 'nuevas' tierras.
} 


\section{Modalidades en de forma de adquisición de tierras en la zona \\ Extractado de Novella (2006)}

Según los términos de la ley Avellaneda, en 1889, el Estado había otorgado una concesión de 298 leguas (unas 750.000 has.) en los territorios de Chubut y Río Negro a una compañía colonizadora de capitales ingleses, la Argentine Southern Land Cia. con el objetivo manifiesto de ésta de "subdividir la tierra en chacras para colonos, y ofrecer incentivos a los inmigrantes para que se establezcan en sus tierras". No obstante este objetivo nunca se cumplió, contando la Compañía con la buena disposición de las autoridades argentinas en favorecer sus intereses mediante la sanción de la Ley $N^{\circ} 2875$, en 1891, por la que se anulaba la obligación de colonizar, otorgando la plena y libre propiedad de la tierra con la devolución del $25 \%$ de las tierras concedidas, y, dedicando el saldo al otro objetivo que planteaba en sus prospectos: "formar una estancia para ganado mayor, ovejas, etc.". Se constituye así la mayor unidad productiva de la zona que estamos examinando (...): la estancia de la Compañía dividida en varias secciones de 16 leguas cuadradas (20.000 has.) cada una y dedicada a la cría de ganado bovino y ovino con casco y centros administrativos en El Maitén y Leleque. El 25\% de la Cía. devuelve según los términos de la Ley de 1891 corresponden a la zona de Cholila, presumiblemente por las dificultades que le podría acarrear ya que no estaba resuelto todavía a esa fecha el diferendo limítrofe y era un área reclamada por Chile. Acogiéndose a los términos de la Ley del Hogar varios pobladores del valle de Cholila solicitan al gobierno un cuarto de legua cada uno en mayo de 1902. Estos pobladores, que llegaban casi a la veintena eran argentinos, chilenos, norteamericanos (entre ellos Santiago Ryan, el famoso Butch Cassidy) y algún europeo. Formaban parte de un proceso de poblamiento espontáneo que llevaba ya varios años y en el que se iban constituyendo pequeñas y medianas unidades productivas familiares dedicadas en su mayoría a la ganadería. ...".

Tal vez, y respecto exclusivamente al área que nos ocupa, esta convivencia explique en algo los magros resultados iniciales de la colonización, para los valles que ya se identificaban como de los mejores, sino los mejores de la Patagonia Andina, en sus condiciones agro-ecológicas. Habrá que esperar varias décadas del Siglo XX para que la cuenca del Puelo, con El Bolsón como referente zonal, tuviera una conexión rutinaria con su entorno argentino. La endeble conexión de las tierras intermontanas al sur del Nahuel Huapí, tuvieron en montañas, ríos, mallines-pantanos y bosques, escollos sólo salvables con importantes obras de ingeniería.

Fueron las localidades de la 'antesala' andina (Ñorquincó, El Maitén y Epuyén) los pequeños y vitales enclaves que actuaron de nexo necesario. Un inspector de Escuelas, como el mejor explorador, describía a partir de su raid las vías de acceso a El Bolsón en 1911, "...y sólo puede penetrarse por dos estrechas entradas: por el boquete del Maitén, al noroeste, entre las cadenas Piltriquitrón y del Serrucho y por el boquete del Pirque. Los pobladores llaman a la primera, "Puerta del Cielo" y la segunda "Puerta del Infierno"..." (Martínez, 1913). Cabe decir que la segunda entrada imponía al menos ocho cruces (vadeos) al río Epuyén. 
Con este cuadro y ante las nuevas instancias territoriales de una ganadería que penetraba en cuanta tierra ofreciera posibilidades, con el acompañamiento de una cultura de raíz europea y criolla-mapuche de tradición agrícola, y con ello sedentarios, los valles se abrieron a formas de ocupación inicialmente espontánea. Formas de ocupación que, en cierto modo, y tal como anticipamos al tratar las condiciones agroecológicas distintivas de la Comarca, devinieron casi en autónomas, al generar una economía doméstica de autoconsumo con instancias esporádicas de intercambio en materia agro-ganadera-silvícola y alguna actividad artesanal vinculada con la madera (ver en Bondel-de Almeida 1996:58-60).

\section{Estructura espacial $1895-1905$}

- Espacio 'marginal' en términos de apropiación inmediata pos-conquista; como resultado de su onda expansiva y carente de alguna capacidad autónoma de gestión territorial (sin localidades organizadoras del espacio).

- Condición de aislamiento zonal potenciado por una geografía física fuertemente condicionante y con una 'red' caminera apenas insinuante (sendas), penetrante desde el Este y sin obras de arte oficiales.

- Espacio jurídicamente 'despejado' para las nuevas pautas de ocupación (colonización) de decidida tendencia centrípeta argentina frente a la concluyente mayoría de población de origen chileno (cf: Novella y Finkestein, 2005) ${ }^{126}$.

- Concreción de mensuras o acuerdos de mensuras clave; límite internacional, de los Territorios (Novella, 2006).

- Control cívico-militar de baja, aunque de fuerte trascendencia social.

- Expansión física al modo pionero sobre los valles y terrazas; con la ganadería vacuna como 'punta de lanza', la agricultura como instancia de arraigo y los bosques en su doble condición de obstáculo y recurso (carpintería, leña y obras básicas). Ganadería extensiva de crianceros 'ocupantes' con tendencia al aprovechamiento agrícola de sectores aptos (desmonte o rozado).

- Ganadería extensiva vacuna en estancias latifundistas en la periferia, con acceso al bosque y orientadas al comercio con Chile.

- Enorme impacto por incendios sobre la masa forestal asociado a titánicos esfuerzos en la culturización del paisaje natural en función del arraigo (incendios de campo, desmontes, destoconamientos para el laboreo primario $)^{127}$.

- Economía de base familiar de autoconsumo y cierta sustentabilidad básica, con orientación hacia la incorporación tecnológica para la producción a escalas artesanales de intercambios.

- Visible y vital presencia del comercio informal. Gradual caída del comercio mercachifle con Chile y progresivo reemplazo hacia el Atlántico y Neuquén (europeos y sirio-libaneses).

\footnotetext{
${ }^{126}$ Las autoras, así como demuestran la actitud gubernamental y de sus 'acompañantes' particulares, hondamente celosa hacia los chilenos, plantean también otra alternativa seguida por los migrantes trasandinos en la Argentina, en función de lo inaccesible de los valles del Sur chileno desde su propio territorio , "... una vez ingresados (...) a Neuquén, donde la presencia estatal argentina, si bien débil, era al menos evidente (...); la decisión de moverse hacia el sur haya estado guiada, por la intención de ubicarse nuevamente en espacio chileno pero con mayores posibilidades de acceso a la propiedad de la tierra que en sus lugares de origen". (2005:40). Al respecto, ver también los breves pero, como lo es toda su obra, rigurosos comentarios de Pierre Denis (1987:176-178)

${ }^{127}$ Cultus, del latín, cultivo hacer fundamental del hombre que garantiza la subsistencia y la continuidad, con todo lo que para ello hace falta (Garreta y Bellelli, 1999, en Novella, Informe inédito 2006.
} 
- Asentamientos de consolidación precaria de los ciudadanos chilenos y/o regreso a Chile sobre valles no colonizados del Sur ${ }^{128}$.

- Consolidación de tenencias con el perfil 'deseado'; acorde con los objetivos nacionales.

- Gestación de un caserío pre-urbano en El Bolsón y Ñorquinco, y de los parajes Epuyén, El Hoyo de Epuyén, Leleque, El Maitén, Las Golondrinas, Cholila, Cuesta del Ternero y Mallín Ahogado.

- Aparición esporádica, aunque jurídicamente relevante, de inspecciones de Tierras y Colonias.

- Radicación de argentinos y/o europeos en instancias de gestión educativa, seguridad y, en menor medida, de salud.

\section{b. 1930-40, "el afianzamiento".}

En el contexto regional Nordpatagónico, por una parte, centralizado en el Alto Valle del Río Negro, donde la obra pública y la sistematización de las tierras labrantías generaron una verdadera avanzada socioeconómica y cultural de la expansión colonizadora argentina y por la otra, con San Carlos de Bariloche, que finalmente y luego de largos años de intentos frustrados, se direcciona firmemente hacia el turismo y la conservación de la Naturaleza, los valles de El Bolsón y zona acaban consolidando un perfil productivo sostenido en un orden espacial de singular autonomía económica.

La colonización mixta agro-ganadera, generadora de los pueblos y parajes, se concentró en espacios de relativa bondad receptiva; en cambio, los sitios menos propicios para el afincamiento, se mantuvieron como fiscales y la gran estancia (al estilo pampeano), fue el modo de ocupación prevalente para los ámbitos de condiciones intermedias, con excepciones ciertamente arbitrarias ${ }^{129}$.

\footnotetext{
${ }^{128}$ En Finkesltein et al, se desarrolla la temática y ejemplifican varios casos (16-27)

${ }^{129}$ En especial por el otorgamiento, apresurado e incongruente con los propósitos de la colonización, de extensiones de hasta 20.000 ha. en terrenos subandinos. Estas grandes extensiones, como la de la Compañía de Tierras, se entregaron por la ley de colonización o ley Avellaneda (817 de 1876) con el propósito de colonizar, cosa que nunca se cumplió y cuyas obligaciones se anularon con la Ley de "Liquidación" de 1891 (Com. personal M.M. Novella; también ver en Dumrauf, Cap. 16, y de Lasa, L., 670-1
} 


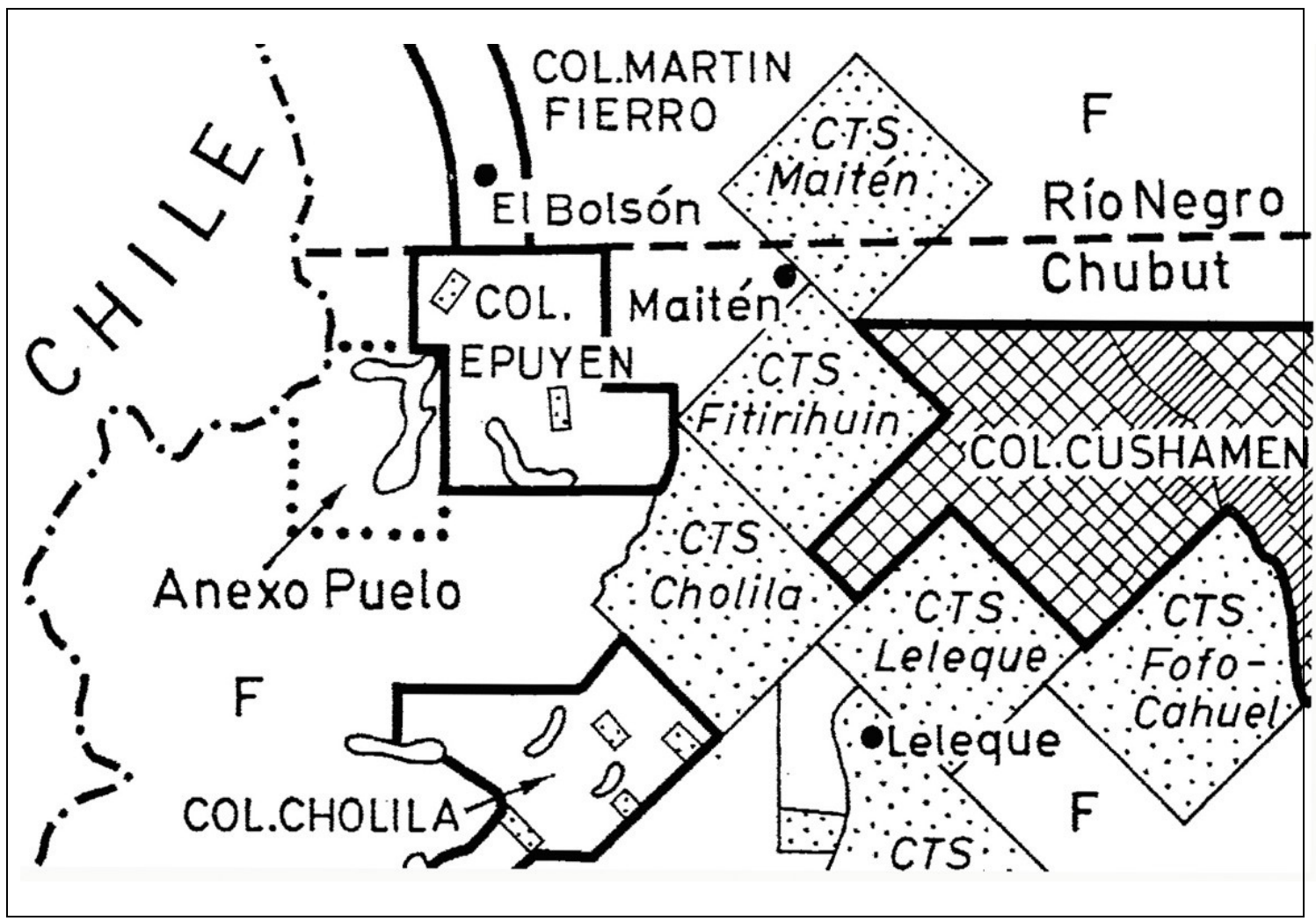

Mapa 5:. Estructura básica de las tenencias colonias, grandes estancias, tierras fiscales y Parques Nacionales. Zoom al mapa general del NW chubutense y extremo SW rionegrino de W. Eriksen (1970: 78). Ref.: Col.: colonias; F: tierras fiscales; CTS: Compañía de Tierras de Sur (estancias con 20.000 ha. de extensión).

En el sector comarcal rionegrino (Territorio Nacional de Río Negro), y a pesar de estar ocupado desde fines del Siglo XIX, y tal como lo atestiguan las inspecciones de Tierras, recién en 1920 se subdividen en chacras los terrenos hasta entonces fiscales, sin perfilarse aún el núcleo urbano de El Bolsón, surgido como caserío espontáneo a la vera del río Quemquemtreu y en una posición central respecto de los valles más promisorios en materia agrícola. Otro tanto ocurre en el sector chubutense, donde en las décadas de los años treinta-cuarenta se establecen formalmente las colonias mixtas Epuyén y Cholila, quedando asentadas las bases catastrales aún vigentes de los valles y en ambas provincias se normalizan muchas adjudicaciones en propiedad de las chacras. (en Eriksen 1970: IV.3., Schlüter, R. et al. (1996: 152-57) y en Daus, 1970: 51).

Por medio siglo a partir de la conquista militar de los territorios patagónicos, ninguna localidad andina estuvo vinculada a la red ferroviaria nacional. Y, a decir verdad, tan sólo San Carlos de Bariloche, y tardía y cortamente, El Maitén y Esquel pudieron concretar el propósito. Aún así, si pudieron haber dudas respecto de la consolidación efectiva de la ocupación argentina de estos valles de vertiente pacífica, el corte temporal muestra una estructura geográfica, en especial en materia jurídico- 
institucional, aduanera, educativa y militar, que no admitía otra dirección que la tomada.

Esto no obstó para que el tema limítrofe y sus vaivenes políticos estuvieran presentes, tanto en los medios de prensa como en alguna bibliografía ocupada del tema ${ }^{130}$. Fuera la integración y potenciales estrategias de intercambio y planteos comerciales bioceánicos ${ }^{131}$, así como también de disputas y planteamientos de conflicto. De cualquier forma, los casos más dramáticos como los del río Encuentro ${ }^{132}$, los de las islas Sudorientales del archipiélago fueguino o de Laguna del Desierto y los Hielos Continentales, ocurren tardíamente y como resultados de imprecisiones espaciales específicas, no ya como instancias de poblamiento general.

La década de 1930-40 muestra, entonces, un espacio con usos agro-ganaderos y silvícola extractivo ya definidos; las innovaciones vendrán de la mano del Estado, donde las reservas para usos públicos comienzan a materializarse, así como se establecen el definitivo espacio para el Parque Nacional Lago Puelo (1937) ${ }^{133}$.

\section{Estructura espacial $1930-1940$.}

- Consolidación de la lógica territorial de la producción primaria en planteos concretos de colonización (Chubut y Río Negro) de base agropecuaria-familiar.

- Aislamiento generalizado, mitigado en parte desde el Este. Llegada del ferrocarril a Jacobacci (1915), Pilcaniyeu (1925) y San Carlos de Bariloche (1934). Jacobacci es desplazado por S. C. de Bariloche y El Maitén en su rol de proveedor relativamente regular de El Bolsón y zona ${ }^{134}$.

- Desvinculación física prácticamente total con Chile (Novella y Finkesltein, 2005:42), si bien la población chilena y argentinos hijos de chilenos son mayoría absoluta (ver Vapnarsky 1982:117-9) ${ }^{135}$.

- Regularización inicial de las tenencias a colonos nacionales o extranjeros 'no-limítrofes', acordes a los planteos de base chacarera (producción primaria familiar).

- Ocupación plena de los fondos de valle y terrazas intermontanas de mejor aptitud agroecológica.

- Agricultura cerealera comercial de pequeña escala y horticultura doméstica en fondos de valle y algunas terrazas de buena aptitud.

\footnotetext{
${ }^{130}$ Hennessy en su sintético y ágil análisis histórico de la frontera en América Latina, destaca la hipersensibilidad fronteriza chilena-argentina, como un feroz imperativo territorial (1978:108).

${ }^{131}$ Ver una síntesis orientadora en Bandieri (b) (2005)

${ }^{132}$ Lo sucedido respecto de la llamada cuestión del Río Encuentro (1955-66), a unos 300 km al Sur de la Comarca, y la recurrencia al arbitraje británico, resulta ilustrativo de situaciones puntuales propias para una cordillera boscosa y escasamente habitada. Ver interesantes datos y antecedentes, incluso en materia de poblamiento, en Clifton Goldney (1964).

${ }^{133}$ Es un buen ejemplo de lo afirmado con anterioridad respecto del decisivo peso de la administración nacional. Este Parque, como los otros, se establecen por sobre explotaciones agropecuarias y madereras asentados con anterioridad, en algunos casos de hasta 50 años y que dará pié a situaciones irritantes que todavía hoy están en discusión. Ver ejemplos específicos en Vidoz, (1998)

${ }^{134}$ En una primera instancia el vínculo caminero con San Carlos de Bariloche fue a través de un rodeo fuera de la cordillera por Ñorquinco-Las Bayas-Nirihuau (en Daus 1970: 49);

${ }^{135}$ Ver casos demostrativos de la exclusión de chilenos reinsertados a su país, en Blanco et al (1999).
} 
- Ganadería mixta bovina-ovina de escalas reducidas atendiendo al mercado zonal, excepto las estancias de la periferia semiárida involucradas en la producción lanar patagónica para la exportación o el mercado nacional.

- Creación de los Parques Nacionales y gran impulso a la obra pública en el Parque Nacional Nahuel Huapí

- Afianzamiento de la presencia militar en la zona Andina (Bariloche y Esquel como enclaves) $)^{136}$

- Consolidación del equipamiento básico en los parajes escuelas, policía, hospital y correo.

- Instancias concretas de urbanización de El Bolsón; estructura catastral urbana y Centro Cívico.

- Afirmación del Turismo 'aristocrático' como actividad económica en San Carlos de Bariloche (FFCC y Llao-llao y otros) (cf: Abalerón, 1992:10-13; Vapnarsky,105-116)

\section{c. 1960-70, "nuevas perspectivas"}

Este corte refleja el paulatino final de más de medio siglo de modalidades territoriales adquiridas y consolidadas (gestadas ya en el primer corte temporal elegido); es cuando, tanto la estructura local productiva y comercial, como el perfil socio-cultural de la zona, comienzan a compartir 'espacios' con otras nuevas modalidades, muchas de ellas propias de la evolución regional en general.

La estructura agraria mantuvo y consolidó la distribución de chacras en los fondos de valle, las estancias y campos ganaderos-silvícolas, en faldeos, terrazas y valles altos. Chacras de dimensiones suficientes para sostener una diversidad productiva interesante en escala familiar-artesanal, donde convivieron la producción hortícola, cerealera, de frutas y animales de granja, y, en sintonía con los cambios que se perfilaban, con la incorporación del lúpulo y frutas finas, como señaladoras de una dirección productiva que, con altibajos, se ha mantenido y fortalecido.

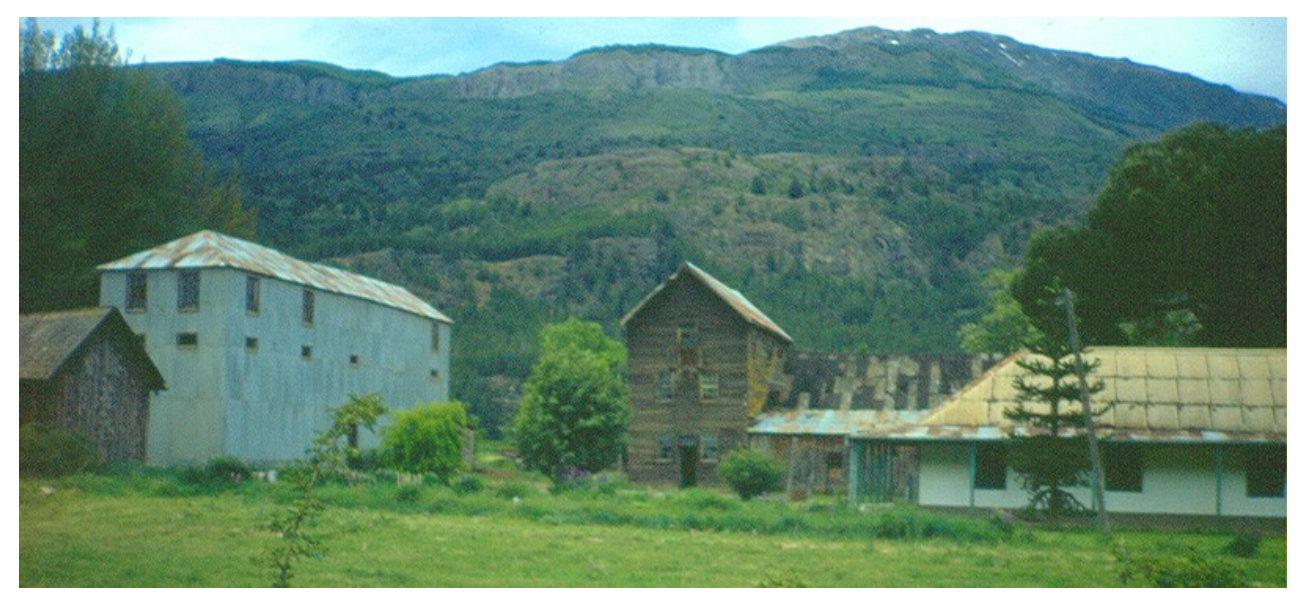

\footnotetext{
${ }^{136}$ Es posible especular que El Bolsón y zona de influencia, y a pesar de la definitiva prevalencia de habitantes de raigambre chilena, no fue un bastión prioritario visto desde la estrategia militar en los Andes Patagónicos. San Martín de los Andes-Junín de los Andes y San Carlos de Bariloche, así como Las Lajas y Chos Malal más al Norte, en cambio, habrán tenido en el peso demográfico-económico trasandino un condicionante primario.
} 
Foto 24: Chacra andina tradicional ya consolidada. Al fondo, faldeo Noroeste del cerro Piltriquitrón. Foto del autor, 1989.

El turismo, ya multifacético en el Parque Nacional Nahuel Huapí, apenas si sólo asomaba en el plano intencional y a finales de la década contaba con una capacidad hotelera para 100 turistas (Daus, 1971:51)

El pueblo de El Bolsón cumplía una centralidad funcional con parte de la actual Comarca, que hoy por hoy se ha fortalecido; pero, aún así, su falta de jerarquía administrativa la posicionó sólo como centro menor de intercambios. Incluso, las poblaciones más alejadas como El Maitén, Epuyén y Cholila, prescindieron de El Bolsón y directamente operaron en caso de necesidad con San Carlos de Bariloche o Esquel.

Debe subrayarse que por entonces se trataba de localidades pequeñas, con servicios eléctricos de horarios acotados, sin pavimento en sus calles y, salvo El Bolsón y El Maitén, hasta carecían de escuela media. Es San Carlos de Bariloche la localidad que actúa de decidido centro comercial y de servicios zonales, así como su principal mercado comprador de madera, hortalizas y pasturas. Para darnos una idea comparable en tipos y magnitudes, tomamos de Civit y Velasco, su visón temática en 1969-70 refiriéndose a San Carlos de Bariloche "...Como en el ejido el cultivo de verduras se hace difícil, ya sea por problemas climáticos o de suelo, la zona hortícola hay que buscarla en las fértiles vagas cordilleranas como El Bolsón, Epuyén y Esquel. Los campos de las dos primeras proveen de papa, especialmente El Bolsón que destina la mitad de su producción, estimadas en 1.000 .000 de kg.., para la ciudad de San Carlos." (1970: 256).

Con ello, se establece un servicio de transporte colectivo diario y, aunque todavía sujeto a las condiciones del tiempo y el estado de un camino de montaña sumamente complicado, el flujo Comarca-Bariloche-Comarca señala una dirección que se mantiene en crecimiento hasta hoy.

También, aunque en menor medida, es posible advertir 'coletazos' de la evolución de la actividad petrolera en el Golfo San Jorge, y el habitante comodorense, a pesar de las distancias y calidad de los caminos, se perfila desde entonces como un visitante progresivamente asiduo que busca contrapesar la particular aridez del litoral chubutense $^{137}$.

En realidad se tata de años depositarios de políticas expansivas respecto de la Patagonia, luego de posicionarse la región como fundamental respecto del petróleo y el gas, la obtención de energía hidroeléctrica, en particular de la cuenca del Limay, se

\footnotetext{
137 Esta afirmación, que comprobable simplemente por cuestiones de vecindad y vínculos personales, merecería profundizarse en planteos hipotéticos, que verifiquen el grado de trascendencia local que reviste la presencia de pobladores de la costa, especialmente chubutense, con una progresiva gama de intereses económicos y familiares.
} 
transformaron en metas nacionales. De hecho, el golpe de estado que generó la llamada Revolución Argentina (1966), toma a la dupla energía-caminos como vitales, manteniendo y consolidando la condición de país abanico característico de nuestro país ${ }^{138}$ y fortaleciendo a modo de vector, sectores andino patagónicos. La condición de área fronteriza, nuevamente toma vigor y marchar a las fronteras es una política de estado (ver en Liberali, 1998: 6-9) ${ }^{139}$.

A todo esto, en los últimos años del corte (luego del mayo francés) se fortalecieron nuevos paradigmas culturales, que entre otras motivaciones sustanciales, especialmente en la juventud, tuvo una de sus banderas en el retorno a lo natural. La Comarca, así, fue una 'oferta' que sustentada en el aislamiento (no contaminación) y la belleza escénica. Con un Bariloche pujante a modo de 'punta de riel' o enclave, comenzó un flujo de pobladores dispuestos al re-planteo cultural que recién se manifestará en los años ochenta; fueron los hippies argentinos los más visibles, toda vez que el flujo sería ampliamente variado y de la más diversa trascendencia (ver González, M.; 2004 y 2007) $)^{140}$.

Ya por entonces, el Parque Nacional Nahuel Huapi es destinatario consolidado de políticas de turismo social, particularmente de raíz gremial en confrontación con el de sesgo aristocrático prevalente hasta entonces promovido desde la Administración de Parques Nacionales. Con ello se produce la gestación de grupos empresariales locales con actitudes ambivalentes ante nuevas instancias de negocios y especulación, especialmente inmobiliarias, relacionadas con el Turismo, los nuevos paradigmas socio-culturales y la capacidad de ahorro de la clase media acomodada nacional (Eriksen, 1970); aunque en la Comarca estas situaciones apenas re-orientan en algo su producción primaria, duramente condicionada por la calidad de los caminos y las dificultades estacionales.

\footnotetext{
${ }^{138}$ Ver la importante síntesis que desarrolla Bandieri (a) respecto de muchas de las circunstancias territoriales asociadas a la secuencia Frondizi - llia - Onganía (a 2005: 351-55)

${ }^{139}$ En orden a tener referentes cuantitativos de época, se puede ver en Miatello consideraciones especiales para con el Paso Pérez Rosales (220-1).

${ }^{140}$ Debe atenderse también que, como todos o casi todos los pueblos 'chicos' El Bolsón y la zona, también ofrecían un panorama propio de los movimientos contemporáneos campo- ciudad y tanto Buenos Aires, como Comodoro Rivadavia y seguramente el Alto Valle y San Carlos de Bariloche fueron receptores de migrantes comarcales, especialmente laborales y estudiantiles (cf.: Daus, 1970: 52).
} 


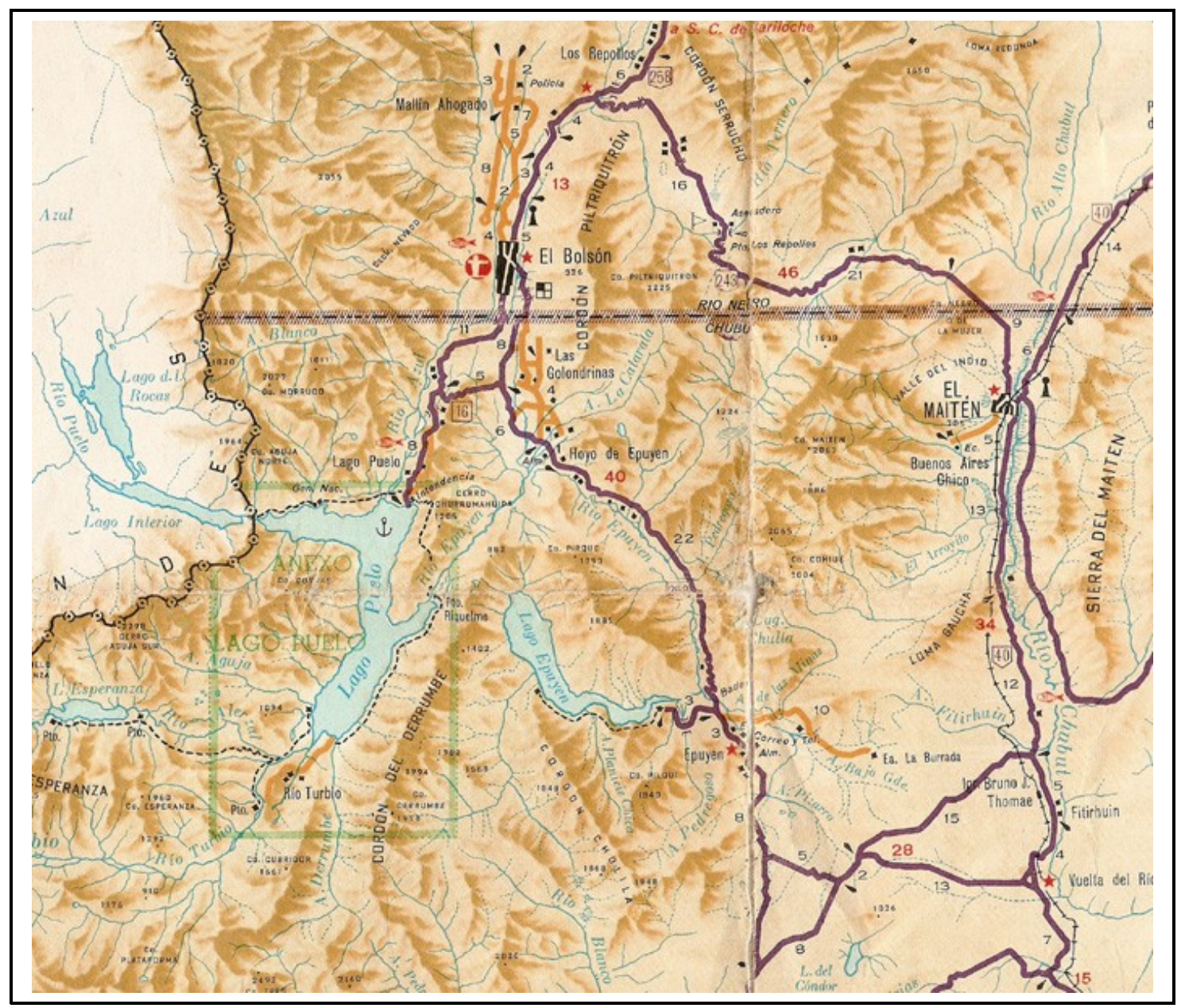

Mapa 6: Extracto de mapa del Automóvil Club Argentino editado en 1967. Nótese que las dos únicas localidades que constan como tales son las de El Maitén (la de mayor jerarquía entonces) y la de $\mathrm{El}$ Bolsón, mientras que los actuales pueblos son sólo parajes. También se destaca la inexistencia de caminos pavimentados.

Una reflexión que merecería rescatarse proviene de la cartografía contemporánea al corte; es entonces que, así como ya se percibe nítidamente la tendencia creciente del transporte vial por sobre el ferroviario, se hacen visibles los límites de la expansión ferroviaria que se habían proyectado a partir del lanzamiento de la Argentina moderna, con sus bases en los ideales de la Generación del ochenta y en las que casi no quedaba espacio nacional sin atender. La realidad interpuesta dejó a la Patagonia con apéndices ferroviarios de escasa entidad ${ }^{141}$ y a la Patagonia Andina como destino caminero $^{142}$.

\footnotetext{
${ }^{141}$ Tal vez, dadas sus frecuencias y capacidad portante, la línea Buenos Aires - Neuquén - Zapala haya sido una excepción.

${ }^{142}$ Localmente, resulta de sumo interés contrastar la cartografía de B. Willis, con las cartas actuales (de excelente factura son las del Automóvil Club Argentino). Se puede profundizar sobre el tema y para todo el ámbito nacional en Roccatagliata (1988). También en Randle (1981), puede visualizarse fácilmente la evolución temporal del ámbito nacional en materia de infraestructura.
} 


\section{Estructura espacial $1960-1970$.}

- Decidido impulso oficial y privado en materia turística.

- Mantenimiento del status-quo fronterizo, con un rol restrictivo respecto de la integración física con Chile, si bien se habilita el paso Internacional Puyehue que desplaza al Paso lacustre-vial de Pérez Rosales. ${ }^{143}$

- Condiciones de aislamiento zonal sólo mitigados por la progresiva irrupción del automóvil y mejoramiento caminero y pavimentación de rutas troncales Bs. As. - Neuquén - Zapala Bariloche y consolidación de la rutas S.C. de Bariloche - El Bolsón y El Bolsón - Esquel.

- Surgimiento de la fruticultura artesanal-comercial (dulcería) y del lúpulo.

- Consolidación del aporte maderero de El Bolsón y zona de influencia hacia San Carlos de Bariloche (en especial de ciprés).

- Avenimiento de S. C. de Bariloche como mercado de consumo de productos primarios estacionales de la Comarca (hortalizas, pasturas, frutas finas y hortalizas, papas en especial), en particular por el reemplazo en el entorno del Nahuel Huapí, de las actividades productivas primarias por otras relacionadas en especial por el fraccionamiento de la tierra con fines turísticos-inmobiliarios ${ }^{144}$.

- Fortalecimiento de la presencia estatal en temas forestales (IFONA); investigación y experimentación; importantes forestaciones con especies introducidas en múltiples sectores comarcales.

- Continuidad de los incendios forestales como principal problemática de carácter geoambiental (ver por ejemplo en Grondona, 1970:86-87).

- Se instalan decididamente desde el Estado los lemas 'Hay que poblar la Patagonia' y el de 'Marchemos a las fronteras'.

- Incipientes condiciones de superposición funcional de dependencias y responsabilidades de las distintas jurisdiccionales provinciales.

\section{d. 1985-1995, "un nuevo orden".}

Son éstos años en los que las bases territoriales del presente van consolidándose, años en que junto con el turismo, se instauran las modalidades productivas y administrativas observadas en el corte anterior con casi la única resistencia generada por la lógica inercia que pudiera haber existido respecto de conservar el orden territorial silvo-pastoril de zona de frontera con bastas extensiones de tierras fiscales.

Es en este corte cuando toma decidida forma la tendencia al replanteo territorial de la zona. El Bolsón ya se proyectaba como lugar alternativo para el imaginario social argentino setentista, de modo que, y seguramente alentado con la progresiva descompresión política surgida de la caída del régimen militar en 1983, a mediados de

\footnotetext{
${ }^{143}$ Hubo importantes intentos en sentido contrario, en particular merced de la política de Unión Económica entre Chile y Argentina segundo gobierno peronista. Ver en Bandieri (a), 2005: 350). Pero no será hasta la década de los años '90 en que realmente se concretaran acciones en sentido inverso. De hecho, las localidades trasandinas de Segundo Corral y Llanada Grande, pobladas por chilenos pero desde la Argentina y con vínculos familiares en la Comarca, vivieron largas décadas de total aislamiento dadas las restricciones que impuso (y aún impone) naturalmente el medio físico para vincularse con el resto de Chile y la mutua política de 'cerrojo' fronterizo.

${ }^{144}$ Ver la reproducción detallada de los fraccionamientos de S. C. de Bariloche y su contexto urbanístico en Abalerón 1992. También se trata el tema en Kaufmann, 1970: 111 y 120.
} 
la década tomó cuerpo el flujo migratorio espontáneo y con él, el replanteo territorial que todavía hoy está en plena construcción.

Fue entonces, como ya se afirmó, que la Comarca comienza a perfilarse como entidad geográfica en sincronía con las divisiones provinciales y municipales involucradas. Lago Puelo y El Hoyo transitan en esos años de caserío al pueblo, la sección Lago Puelo del Parque Nacional Los Alerces se convierte en Parque Nacional propiamente dicho, se consolidan las delegaciones provinciales e instituciones educativas y sanitarias a ambos lados del paralelo $42^{\circ} \mathrm{S}$., así como el proceso inmigratorio se mantiene ascendente, con distinto 'anclaje', y con ello crece la presión sobre la tierra y se desenvuelven infinidad de iniciativas particulares ${ }^{145}$.

Por otra parte, a sido aquí y entonces, en que se concretan los primeros pasos hacia la neo-ruralidad y El Bolsón llega a trascender, incluso internacionalmente como un lugar elegible para sostener los nuevos paradigmas de base ecológica en ámbitos de montaña ${ }^{146}$. El esquema que sigue no es más que una aproximación espacial a 'la movida' que aún perdura (intensificándose).

\footnotetext{
145 Con de Almeida (1996: 64) señalábamos para El Bolsón, "Un continuo cambio y 'recambio' de rubros es observable casi a simple vista; como reflejo de esta situación los pedidos de altas y bajas en habilitaciones comerciales pueden ser ilustrativas:$$
\begin{array}{lccccl} 
& 1990 & 1991 & 1992 & 1993 & 1994 \\
\cline { 2 - 6 } \text { ALTAS } & 130 & 137 & 228 & 210 & 144 \\
\text { BAJAS } & 50 & 75 & 30 & 50 & 93
\end{array}
$$

${ }^{146}$ Fenómeno por cierto que no nos es exclusivo. Sirva de ejemplo como en su tesina en turismo, sobre Migrantes de amenidad, Mariela Marchissio cita, entre varios, títulos como estos: Sustainable Mountain Communities y Global Phenomenon and Strategic Paradigm For Sustaining Mountain (2007).
} 


\section{ESQUEMA FIGURADO DE LOS FLUJOS POBLACIONALES DOMINANTES}

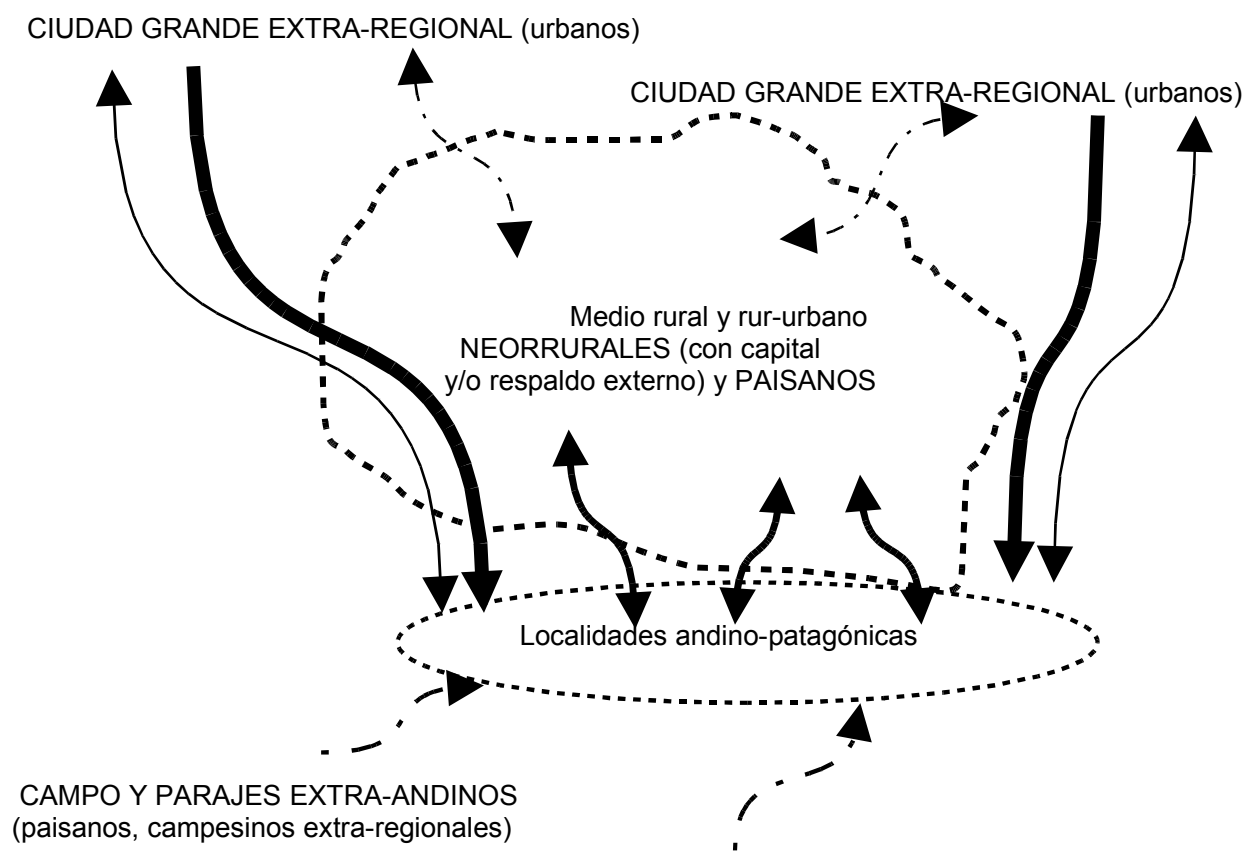

(paisanos, campesinos extra-regionales)

PUEBLOS Y CIUDADES PEQUEÑAS EXTRA-ANDINOS

(paisanos y urbanos)

Ref.: flujos continuos, discontinuos e intensidad figurada.

Fig. 13. Esquema de los flujos poblacionales dominantes. Patagonia Andina (1985 y continúa).

Fuente: elaboración propia de base esencialmente empírica y como corolario de las conclusiones de entrevistas agentes inmobiliarios y otros informantes clave (PI Bondel et al 2002 en especial entrevistas de Ana Raimondo, M. González, Guillermo Scartascini y Carla Augustaci, así como de la participación varios encuentros y talleres relacionados con temáticas territoriales, en especial el Plan Estratégico de Trevelín, UATA y Municipalidad de Trevelín (2006) y de la participación en el Esquel, SEAS (2001).

Con todo, el aislamiento vial (ruta/s afaltadas) con el resto de la región no ofrecía mayores variantes respecto del corte anterior, aunque sin duda debe valorarse especialmente el cambio estructural que significó la pavimentación intra-comarca (1980-85) de la Ruta Nacional 258 (actual R. N. 40), resultado de las políticas camineras nacionales de decidido sesgo geopolítico y que representó la consolidación de un eje troncal alrededor del cual el espacio sentó sus bases actuales.

Con unos $50 \mathrm{~km}$ lineales asfaltados entre Epuyén y la periferia Norte de El Bolsón, la dinámica interna fue acomodándose a nuevas pautas de accesibilidad, aún cuando todavía se necesitaban 4 a 5 horas para hacer el tramo de $130 \mathrm{~km}$ a San Carlos de Bariloche y otro tanto a Esquel (180km).

Es en estos años cuando la Feria Regional se establece con regularidad semanal para ir constituyéndose en uno de los ámbitos más dinámicos y económicamente significativos de la Comarca. Cabe entonces atribuirle su origen y desarrollo inicial, no sólo al nuevo perfil demográfico-cultural propio de la inmigración creciente, sino también a las nuevas condiciones de movilidad interna. 
Precisamente es sobre el final del corte cuando se concreta el asfalto de los tortuosos $75 \mathrm{~km}$. restantes hacia el Norte, vinculándose así la Comarca con la red caminera nacional pavimentada y con ello hacia 1995-6 puede hablarse, sin margen de dudas y, como se verá en el capítulo siguiente, que se concreta el desenclave zonal.
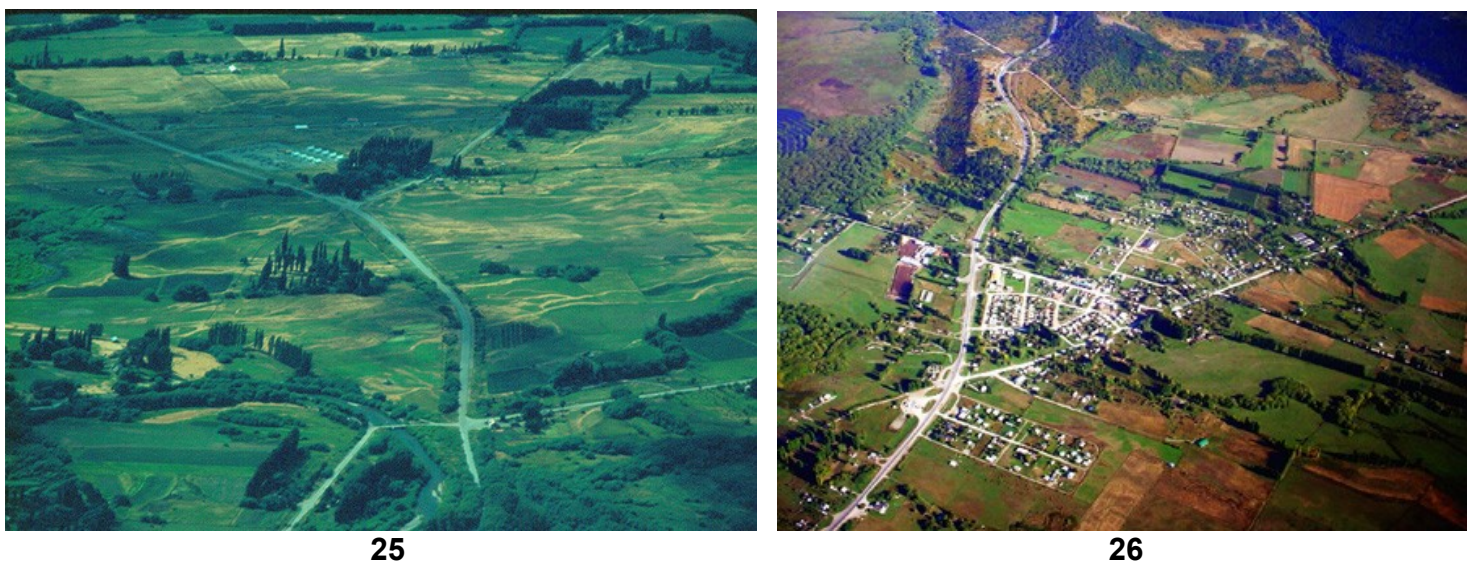

Fotos 25 y 26. Resultado espacial de 25 años de transformaciones en El Hoyo, 25: 1979 y 26: 2005. Nótese que son coincidentes la figura a modo de $Y$ sobre el centro en la foto 25 , con la misma figura ubicada hacia el ángulo inferior izquierdo de la 26. (Fotos: 25, Tato Álvarez y 26, F. Ottone).

Merece un comentario aparte el tema fronterizo. Resulta singular que la Comarca, con más de $100 \mathrm{~km}$. compartidos con Chile, prácticamente no tuviera más que una dinámica de intercambio apenas micro-doméstica. La falta de poblaciones trasandinas cercanas y lo quebrado del relieve, seguramente explican mucho de esta condición, pero, como se ha visto, en nuestro país hubo intencionalidad política en operar a favor de las fuerzas centrípetas en la periferia nacional. Es en los ' 80 y asociados también al surgimiento de los planteos dominantes neo-globalizadores, cuando se hizo manifiesto un cambio básico en el planteo fronterizo internacional. Con ello el reemplazo conceptual de la frontera-muro por la frontera de integración y cooperación, comenzó a estar presente en el discurso, claro que con resabios celosos a ambos lados. De cualquier modo, todo indica que es una dirección a mantenerse y con ello la Comarca deberá enfrentarse a una nueva posibilidad de cambios territoriales trascendentes.

\section{Estructura espacial $1985-1995$.}

- Se mantienen in crescendo las iniciativas oficiales y privadas en materia turística.

- Tendencia a la ruptura del aislamiento. Instalación de LRA57 Radio Nacional (A.M.) a principios de la década; obras de infraestructura vial, en telecomunicaciones y mayor oferta de transporte automotor concluyen en el desenclave sobre el final del corte con la pavimentación completa a San Carlos de Bariloche.

- Consolidación de la funcionalidad interna de la comarca a modo de eje (pavimentación de la Ruta Nacional 258 (actual 40) entre el extremo Norte de El Bolsón y Epuyén) y con El Bolsón como cabecera. 
- Importante movimiento inmigratorio de carácter 'anímico', sostenido en aspectos perceptivos y afectivos propios del paradigma de la 'vida natural'.

- Revalorización cultural de instancias productivas, tanto tradicionales como innovadoras. Ajustadas a patrones de vida neorrurales (granja, chacra, forestación, etc.).

- Importante retroceso para la producción agropecuaria en el mercado barilochense y a favor del Alto Valle del Río Negro y zonas mendocinas (nuevas instancias surgen a partir del completamiento del camino con asfalto Comarca-Bariloche en 1996).

- Urbanización de muy baja densidad y con amplias proyecciones en ámbitos rurales.

- Fortalecimiento de la tendencia regional del sobreparcelamiento rural asociado a procesos hereditarios y/o sustentabilidad productiva, al ahorro o a la especulación inmobiliaria propia de zonas turísticas.

- Surgimiento de compradores de campos, extranjeros y nacionales, con gran poder económico y de nuevas y variadas pautas respecto del uso de la tierra.

- Superposición funcional de dependencias y responsabilidades jurisdiccionales en relación a la condición comarcal de ser bi-provincial, estar en zona de frontera y tener un Parque Nacional.

\section{II.2.4. Perspectiva geoeconómica. Actividades y algunas cifras orientadoras.}

Presentada la funcionalidad territorial básica y las características sustanciales del medio natural y geohistórico, recurrimos nuevamente al planteo problematizador anunciado en el marco teórico y con el que es abordada la realidad local a modo de espacio abierto, en sintonía con el enfoque ya mencionado de Labasse.

Cabe recordar aquí que, atentos al planteo de una de las hipótesis cruciales de esta tesis, los asuntos económicos más atendidos serán aquellos con un sustancial contenido anímico-afectivo. Ejemplificando la orientación del análisis en este capítulo específico, puede valorarse el ejemplo que da la Feria Regional El Bolsón, fuerte ícono de actividad comarcal, donde según datos fidedignos, sólo un $14 \%$ de los feriantes tuvieron como motivación de la elección de autoempleo a la rentabilidad, mientras que la vocación y las circunstancias, agrupan un $70 \%$ de voluntades (Marchissio, Guido. 2007:45) ${ }^{147}$.

También es importante recordar que el tratamiento analítico se ocurre frente a transformaciones continuas, en ámbitos de cierta similitud con las modalidades pioneras tradicionales, pero donde, en principio, aquellas entidades socio-culturales de fuerte raigambre histórica en el país como familia (en su sentido amplio), iglesia, nacionalidad, corporación, etc., aparecen desdibujadas o, tal vez re-dibujadas, en un

\footnotetext{
${ }^{147}$ La Feria Regional El Bolsón es un seguro referente; ver sus características estructurales en materia de empleo y dinámica, consultar el importante e interesante análisis de base realizado por G. Marchissio (2007). De menor profundidad pero con resultados análogos, alcanzaron alumnos en trabajos prácticos del Seminario Geografía de la Patagonia, Facultad de Humanidades y Ciencias Sociales, UNPSJB. Octubre, 2006.
} 
contexto post moderno seguramente más personalista y con el marco natural como emblemático ${ }^{148}$.

En la Comarca, los modelos paradigmáticos del agricultor autosuficiente o figuras enaltecidas similares, aún cuando las más de las veces sean superadas por la realidad sociocultural concreta, llevan consigo instancias de vanguardia nada despreciables. La propia existencia de una Feria Regional (El Bolsón), que figura entre las más importantes del país con más de 400 puestos de venta (unidades económicas), así como poseer viveros forestales de neta orientación hacia las especies autóctonas o haber sido sede de una tecnicatura universitaria (la primera en el país) en agricultura orgánica intensiva ${ }^{149}$, pueden servir de muestra de una dirección reconocida ${ }^{150}$.

En términos de mercado este paradigma promueve una serie de comportamientos direccionados por la conjunción armónica, belleza natural - forma de vida y que se traduce primariamente en lo que Zingoni, Martínez y Quartucci identifican para el caso de San Martín de los Andes como, quienes están dispuestos a tener una menor rentabilidad de sus actividades a cambio de una vida más placentera (2006: 4) ${ }^{151}$. Por supuesto que nos referimos a ciertos 'estratos' sociales, aquellos que, en mayor o menor medida, están por encima de un piso de autonomía de capital y que básicamente motorizan la economía. En el resto del espectro social, las condiciones laborales y de proyección socio-económica, van atadas a situaciones de incertidumbre propias del sesgo pendular que conlleva el turismo y a la evolución propia de una economía que lleva décadas orientada hacia la flexibilización laboral y la consecuente precarización del empleo ${ }^{152}$.

En todo caso, el resultado espacial más visible es la validación de la dispersión territorial como modalidad de poblamiento pretendida; dispersión asociada estrechamente al paradigma anímico-afectivo de la vida natural y que sobrelleva problemas difíciles de resolver dado el carácter montañoso del paisaje comarcal. Al relativo confinamiento físico se suma aquí la heterogeneidad propia de valles, terrazas, faldeos y riberas; con ello, la dispersión y sus requerimientos en materia de servicios, implican un encarecimiento muchas veces extremo en términos económicos, así como

\footnotetext{
148 Salvando la complejidad propia de las regiones, hay similitudes ciertas con el paradigma que Ojeda Rivera denomina clorofílico cuando se refiere a la montaña europea, en particular ibérica (2004); sirva de ejemplo que entre los aspectos positivos que le significa a los feriantes trabajar en la Feria Regional, la autonomía es decididamente la cualidad más nombrada Marchissio, G. (50)

${ }^{149}$ Facultad de Agronomía, Universidad de Buenos Aires y Fundación Cooperar, El Bolsón, 2001-2005.

${ }^{150}$ Con todo, apenas algo más del $10 \%$ de los productores podría enmarcarse con un perfil de autoconsumo, mientras que la generalidad se sostendría en función de ingresos complementarios extra prediales (ver Chubut, PROSAP, 2001: Conclusiones).

${ }^{151}$ Ver también en Marchissio, Mariela. (2007)

${ }^{152} \mathrm{Si}$ bien se entra en un plano de discusión que nos aleja de nuestras temáticas centrales, todo indica que esta figura simplemente excluye de su estructura a los sectores de niveles socio-económicos menos favorecidos, dejándolos en el simple planteo de lo que se da por llamar efecto derrame y sus aciagos resultados. Las condiciones de pobreza y marginalidad, de un peso sustantivo en términos demográficos, no sólo no son novedosas en los centros turísticos andino-patagónicos, sino que se muestran crecientes, aún en instancias de bonanza turística. Carlos A. Abalerón avanza decididamente sobre el tema e incorpora importantes trabajos sectoriales sobre la temática (1995 y 2006).
} 
la merma de superficies con aptitudes productivas agrícolas y forestales; de allí inicialmente su consideración de muchas veces antisocial ${ }^{153}$. Ya Hernández y Mochkofsky lo anticipaban hace más de tres décadas cuando, tomando la expansión física de San Carlos de Bariloche como caso, destacaban cuatro puntos de fácil extrapolación en tiempo y espacio a nuestros días y a la Comarca: 1) el loteo especulativo, 2) el lote como inversión-ahorro, 3) la progresiva reducción a la accesibilidad del bien 'tierra' y 4) el creciente déficit comunal en función de la extensión de infraestructura y servicios (1974: ix y x)

Es indudable que falta recorrer un largo camino de indagación socio-cultural, pero, como se verá más adelante, lo que llamaríamos vectores o móviles en los procesos territoriales, se relacionarían más con conductas de sesgo individual de una débil afinidad grupal que con las estructuras familiares tradicionales. En cierta forma se insinúan, además, móviles más ocupados en lo que no se quiere que en lo que se busca obtener ${ }^{154}$. Asimismo, este marco referencial seguramente se ha enriquecido con la pérdida del significado simbólico del concepto 'progreso', aquel que perfiló el 'pionerismo' y que, en lo económico, encarnaba, principalmente el incremento del patrimonio material.

Como en lugares análogos del mundo, no parece haber una dirección indiscutida; el abanico de metas a seguir resulta indefinido, optando entonces por acomodar nuestra perspectiva desde la concepción de 'espacios de consumo' y los comportamientos de sesgo empírico, como las manifestaciones más evidentes desde una óptica geoeconómica ${ }^{155}$.

Retomando la secuenciación estructural de las lógicas territoriales vistas en la evolución temporal del capítulo anterior sobre la que avanza Claval en su análisis conceptual sobre el paisaje, ocurre que se ha fortalecido, hasta ser primaria, la lógica de la contemplación; esto, para la Comarca, en el contexto de la globalización, del desenclave físico y virtual, y la estructura de corredores turísticos. Destacando además del despegue turístico, una tendencia sostenida hacia la especialización sectorial, la marginalidad 'oculta' y la expansión físico-territorial (en tierras fiscales)

153

\footnotetext{
154 La resistencia hacia actividades o modalidades que sugieren un impacto importante sobre el medio natural es, desde hace ya varios lustros, unas de las características más reconocidas externamente sobre la Comarca (municipio no nuclear, no a las represas, no a la minería, a ciertas obras de infraestructura, y muchos etcéteras). Con ello, las explicaciones de los resultados económicos del devenir territorial, se alejan decididamente de la ortodoxia y su explicación sería más propensa a sostenerse en patrones culturales.

${ }^{155}$ Debe recordarse que espacios de consumo han existido largamente en la historia y las culturas; lugares recreativos, villas veraniegas, balnearios y demás, no son un producto post-moderno. Pero se diría que sí es primario en nuestros tiempos, de la mano de una realidad geopolítica homogeneizante, de las posibilidades tecnológicas y del rumbo de los gustos. Estos espacios ocupan un lugar central, desplazando a posiciones secundarias a la tradicional realidad económica moderna, basada en la producción industrial y agropecuaria y a las políticas territoriales sostenidas en cuestiones como la seguridad nacional en un marco de rivalidad hemisférica-ideológica. Dimitriu desarrolla el tema con énfasis en la Patagonia; su análisis arranca desde la grilla de prácticas espaciales de Harvey (2001).
} 
básicamente conflictiva, aunque no en exclusividad. Punto éste que con cierta moderación propia de realidades regionales distintas, puede adecuarse al concepto de geofagia (géophagique y géophagisme) desarrollado por Martine Droulers en referencia a procesos de acaparamiento de tierras 'vírgenes' en amplios sectores amazónicos (en de Sartre, 2005).

\section{II.2.4.1. Contexto económico general.}

Producción, intercambio y gestión económica-administrativa, con diferente entidad, acompañan transformaciones incesantes, donde los éxitos y fracasos son recurrentes en escaso tiempo. Valga de ejemplo, cómo, de una larga y variada lista de iniciativas, muchas simplemente quedan en tentativas. Esto ha valido tanto en materia agroganadera (yogurt, arándanos, ajos, forestaciones, especias, caprinos de razas refinadas, floricultura), de iniciativas en la administración pública (en materia política, educativa, ecológica, vial, aeronáutica, energética, etc..) y hasta en el turismo (deportes invernales, aperturas de restaurantes, campings y paradores, complejos cabañeros, aerosilla/s y parapentes, etc.). Con todo, la Comarca se estructura económicamente en una evidente tendencia creciente, como lo demostraría por ejemplo el hecho de sostener seis sucursales bancarias, que aunque de una complejidad propia para localidades pequeñas y medianas, se distribuyen entre El Bolsón (2 bancos) y el resto comarcal.

En materia de actividades son de destacar las 'explosiones' generadas a partir de la agricultura y el turismo en la temporada estival, con su contracara en una suerte de latencia económica invernal, cuyas mínimas expresiones se aminoran por el aporte de los salarios del sector público (Bondel, S. y de Almeida, A., 1996: 62-3) y, con altibajos propios de las sacudidas económicas nacionales, con el muy significativo aporte del sector de la construcción, poco sistematizado a la hora de la cuantificación, pero evidente en el desarrollo el crecimiento sostenido de los comercios del rubro. Al respecto sobresale la construcción de viviendas unifamiliares relacionadas a la migración interna de sectores medios y medios altos de la sociedad argentina, así como con la construcción cabañera y de servicios turísticos ${ }^{156}$.

\footnotetext{
${ }^{156}$ Aunque desarrollado en el devenir de una importante crisis, ver de M. Muscillo, artículo sobre la construcción, su importancia regional y comportamiento fluctuante. Suplemento Patagonia Economía, diario Piltriquitrón, El Bolsón. Nov. 1999.
} 
CRONOGRAMA OCUPACIONAL EN ALGUNAS ACTIVIDADES DE LA COMARCA ANDINA DEL PARALELO 42 (2005).

\begin{tabular}{|c|c|c|c|c|c|c|c|c|c|c|c|c|}
\hline Actividades / Meses & EN & FE & MR & AB & MA & JN & JL & AG & ST & OT & NO & DI \\
\hline turismo ${ }^{157}$ & & & & & & & & & & & & \\
\hline hortícola / cerealera & & & & & & & & & & & & \\
\hline lúpulo & & & & & & & & & & & & \\
\hline actividad forestal & & & & & & & & & & & & \\
\hline frutícola / fruta fina & & & & & & & & & & & & \\
\hline recolección-acopio hongos-nueces: & & & & & & & & & & & & \\
\hline turbera & & & & & & & & & & & & \\
\hline construcción & & & & & & & & & & & & \\
\hline ganadera & & & & & & & & & & & & \\
\hline
\end{tabular}

Referencias: 1: Períodos de actividad plena; 2: Actividad menos intensa pero sostenida 3. Períodos de menor actividad. 4: Actividad mínima.

Fig. 14. Cronograma ocupacional.

Fuente: elaboración propia en base a entrevistas de referentes sectoriales. Dada la heterogeneidad productiva y su dinámica de cambios, debe tomarse en términos generales.

El sector inmobiliario sobresale como un 'captador' importante de inversores extrazonales y extra-regionales presentándose así como un disparador de negocios locales, tanto en materia constructiva como de ahorro. Esta condición, por otra parte y como ya se planteara en el contexto problemático en la Primera Parte, provoca un alza en los precios relativos que prácticamente excluye del acceso a la tierra a los sectores locales menos acomodados y medios.

Por otra parte el sector productivo primario involucra a algo más de 300 explotaciones agropecuarias-silvícolas que son las que estructuran mayormente el espacio productivo comarcal ${ }^{158}$, toda vez que el bosque natural sin explotar, el desierto andino de alta montaña y los ámbitos urbanos, suburbanos y asentamientos poblacionales dispersos completan un mosaico propio de una Comarca de montaña con fuertes limitaciones naturales.

Respecto de las extensiones se afirmaba con cierto optimismo en un informe específico en materia de cultivos,.... "no es posible estimar con precisión la expansión de las superficies que se destinarán a los diferentes cultivos". Tentativamente se estimó una progresión para el lapso 1999-2005: un piso de 1200 has. para las frutas finas, otras 1200 ha. en horticultura y unas 600ha. para otras alternativas intensivas (aromáticas e industriales) (Fiorentino et al,1998).

\footnotetext{
${ }^{157}$ La temporada alta, en sentido estricto, ocupa sólo unos 45 días. (Fiorentino et al, 36).

${ }^{158}$ Las cifras difieren, pero según se puede constatar de diversas fuentes, podría afirmarse que en el sector rionegrino existen algo más de 150 explotaciones, mientras que en el chubutense rondarían las 170 . Censo Nacional Agropecuario. Dirección General de Estadística y Censos de Río Negro (2002). Chubut, PROSAP, 2001: 11
} 


\section{Sobre conectividad.}

Con la conectividad se recurre a una de las figuras geográficas explicativas clave a la hora de buscar instancias de síntesis en cuestiones del espacio. Esto cobra mayor valor si, atendiendo la condición comarcal de haber tenido en su posición geográfica uno de las principales, sino la principal, cualidades decisorias de su acaecer territorial. Cabe considerar que nos referiremos a la conectividad física. Si bien son evidentes múltiples efectos generados desde las nuevas conectividades virtuales, en especial a partir de la llegada de la fibra óptica y el uso de otras tecnologías de punta, también cabe entender que todavía son incipientes y requerirían de un planteo analítico que nos excede.

\section{La Comarca en el país y el mundo.}

Como se indicara al presentar a la Comarca en su funcionalidad territorial básica, el estar enclavada en los profundos y 'receptivos' valles cordilleranos, en la periferia de una estructura territorial nacional y en circunstancias históricas propias de no tener otra alternativa gravitatoria que aquella vinculada a la región pampeana con centralidad en Buenos Aires, marcaron ( $y$ aún mantienen un decisivo peso relativo) una configuración geográfica singular.

El aislamiento físico, en especial en materia de conectividad comercial, ha generado ciertas condiciones de sustentabilidad primaria, a modo de suplemento de los relativamente importantes recursos provenientes del aparato administrativo y político mantenido, tanto desde las respectivas capitales provinciales (Territoriales hasta 1955-56) como desde la gobierno nacional. Se ha visto en las estructuras espaciales de los cortes temporales, cómo a través del tiempo, el aislamiento relativo y sus consecuencias favorables y contrarias han sido una constante.

Pero, como se destacó en el capítulo anterior, en la actualidad persiste lo que dimos en denominar el $3^{\text {er }}$ arribo (hacia el desenclave). Situación que, desde la pavimentación del tramo restante de la Ruta Nacional 40 para unir la Comarca con San Carlos de Bariloche, concluye con su desenclave físico e integración a los sistemas de corredores turísticos, hecho potenciado con la culminación, también en la segunda mitad de los '90, del tramo El Bolsón-Esquel, con lo cual la Comarca se enlaza con la red caminera pavimentada nacional, tanto desde el Sur como desde el Norte, incluyendo además su vinculación internacional con la red vial troncal chilena. Sirvan de muestra los datos que siguen y que por su posición de registro resultan 
reveladores de una tendencia, así como de escala (incluso atendiendo el 'coletazo' de la crisis de fines del 2001).

Tabla: 5. Tránsito medio diario de automotores (2000-2007) ${ }^{159}$. Ruta Nacional $N^{\circ} 40$. Sector aeropuerto Esquel.

Fuente: Vialidad Nacional, 2008

Totales:

\begin{tabular}{|c|c|c|c|c|c|c|c|c|}
\hline Año & $\mathbf{2 0 0 0}$ & $\mathbf{2 0 0 1}$ & $\mathbf{2 0 0 2}$ & $\mathbf{2 0 0 3}$ & $\mathbf{2 0 0 4}$ & $\mathbf{2 0 0 5}$ & $\mathbf{2 0 0 6}$ & $\mathbf{2 0 0 7}$ \\
\hline TMDA & 639 & 613 & 550 & 506 & 690 & 901 & 1048 & 1227 \\
\hline
\end{tabular}

Tipos de vehículos:

\begin{tabular}{|c|c|c|c|c|c|}
\hline Año & Autos y Camionetas. & Bus & S/Acoplado & C/A & Semi \\
\hline 2007 & 79,6 & 3,7 & 9,2 & 1,3 & 6,2 \\
\hline
\end{tabular}

Debe tenerse presente que la denominación 'corredores turísticos', no es tan sólo una figura descriptiva, estamos ante sistemas de vinculación que lejos de concluir en los espacios regionales, se proyectan internacionalmente, provocando además de nuevas dinámicas fronterizas, un reacomodamiento en las redes de transporte terrestre y aéreo.

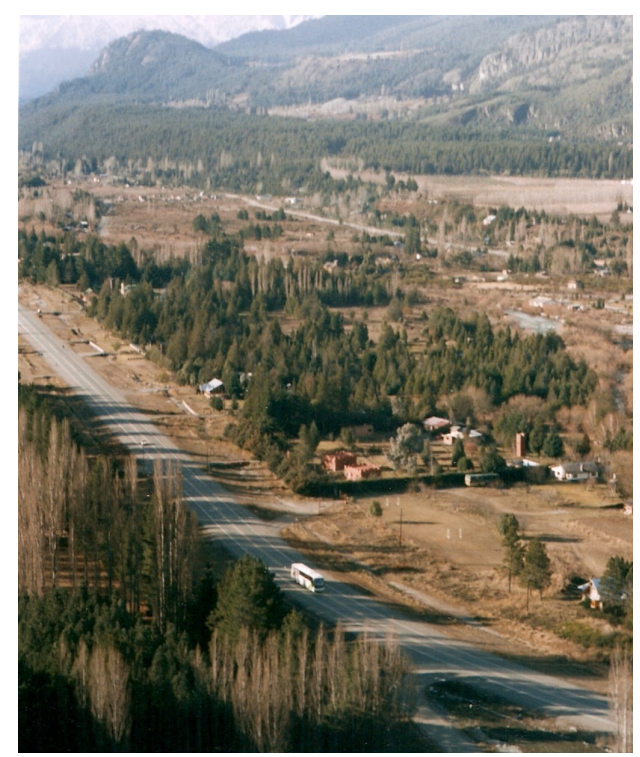

Foto 27: La Ruta Nacional 40 (ex 258); el completamiento del pavimento hasta Bariloche y Esquel implicó una instancia decisiva en materia de 'desenclave' y ordenamiento espacial. Tramo al Norte de El Bolsón. Foto del autor (2006).

En lo que a la Comarca compete, el transporte terrestre es el decisivo, pero no debe subestimarse la influencia del tráfico aéreo, que tiene en San Carlos de Bariloche uno de lo principales nudos turísticos de Latinoamérica y con ello sugiere una influencia local decisiva. Las 2 horas que separan al aeropuerto de Bariloche de la Comarca, la colocan en su directa área de influencia, si bien es cierto también que vivimos tiempos

\footnotetext{
${ }_{159}$ Valórese que para el 2007 en el tramo intermedio El Bolsón-San Carlos de Bariloche, es decir alejado de la influencia del tránsito local de cada localidad, el valor total de transporte automotor medio diario ha sido de 1400 unidades. Fuente: Vialidad Nacional, 2008.
} 
'globalizados' y las prioridades en materia de vínculos aéreos deben verse, casi con exclusividad, sujetos a la dinámica del turismo internacional en sus vínculos con Europa y Estados Unidos ${ }^{160}$.

En materia de líneas de transporte terrestre, el antes y el después, es manifiesto. Baste considerar que de contar con no más de 5 frecuencias diarias entre El Bolsón y Bariloche a comienzos de los ' 90 y una duración media de 4 hs. de viaje, se ha pasado a 15-20 trayectos regulares en al actualidad que no superan las $2 \mathrm{hs}$. de duración. Otro tanto ocurre con Esquel, cuando de sólo dos frecuencias diarias regulares y, al menos, 5 hs. de duración, se ha pasado a 7-9 con $2 \mathrm{hs}$. $30 \mathrm{~m}$. por trayecto promedio. Todo esto, además, con un cambio cualitativo importante y sin considerar las decenas de transporte de pasajeros de tipo chárter y 'especiales' que llegan y/o atraviesan la Comarca diariamente, en particular en alta temporada.

Pero, insistimos, en términos de conectividad es menester ponderar la condición de San Carlos de Bariloche como centro gravitatorio fundamental en la región; se diría que casi no hay ciudad de mediana jerarquía en adelante que no pueda vincularse con eficiencia importante por medio del transporte colectivo de pasajeros; incluso Ushuaia, San Salvador de Jujuy o Posadas, encuentran alternativas diarias en su terminal de ómnibus. Es cierto, también que las distancias imponen mayores costos, aunque debe destacarse que la relación costo-distancia, en muchos casos, suele ser relativamente 'inversa' cuando las frecuencias y el grado de competencia son altos; caso que, al menos en estos últimos dos lustros, es reconocida.

En definitiva, el estar netamente incluido en al área de influencia de San Carlos de Bariloche, ha puesto a la posición geográfica de la Comarca en una situación de privilegio, quitándole por un lado la condición de excentricidad que le diera una identidad reconocida y, por otra parte, potenciando el rol de 'corredor' que propone una multiplicidad de visiones que quedarán abiertos para el análisis. En términos turísticos el 'estar de paso' es advertida como una debilidad, y, en los hechos, el tema transporte público zonal y regional es ajeno a gestiones de orden comarcal; apenas si cada municipio puede tener alguna mínima influencia de gestión. Como recaudo y atendiendo las diferencias, se puede tomar la advertencia de Labasse, cuando observa que "...la aceleración (de los medios de transporte) tiende a espaciar los lugares de parada..." (171); complejo destino para varios puntos intermedios regionales.

\section{La conectividad comarcal interna}

\footnotetext{
${ }^{160}$ Tanto las tarifas diferenciadas como las condiciones de vinculación (¿desvinculación?) con destinos nacionales, demuestran a simple vista una sujeción casi extrema al condicionamiento externo en materia de tráfico aéreo argentino. La desproporción de vuelos entre Buenos Aires y Bariloche o El Calafate, respecto de otras plazas nacionales de 'Ileno' asegurado (Comodoro Rivadavia, Córdoba, Tucumán, etc.), proyectan un panorama en que las rutas demandadas internacionalmente por el turismo son prioritarias.
} 
La singular condición intramontana de la Comarca, lógicamente limita fuertemente la conectividad interna. Las cercanías aquí se expresan en tiempo más que en distancias, tanto por los obstáculos naturales como por el tipo de vía de comunicación. La red de caminos con asfalto es apenas incipiente, aunque en crecimiento estos últimos años y la ruta troncal Norte-Sur sólo presenta apéndices acotados que involucran a Lago Puelo y el Parque Nacional homónimo, Epuyén y recientemente El Maitén. El resto lo forman caminos consolidados y otros de menor calidad. En todos los casos estas dos formas resultan sumamente sensibles a las condiciones del tiempo y demandan tareas de mantenimiento costoso y de diferente respuesta según sea el municipio responsable. Se le agregan a las dificultades físicas de los terrenos, las bajas densidades de ocupación que tornan poco viables las iniciativas, justamente costosas, en materia de obras camineras.

El transporte público colectivo, sólo tiene frecuencias horarias o cercanas a ellas, entre El Bolsón y Lago Puelo (en horarios laborables) y en recorridos internos de El Bolsón y algunos de sus barrios; el resto de la Comarca, o no es atendido en absoluto o lo es con frecuencias que no superan las 4 diarias. Según sean las condiciones de los pobladores y en la mayor parte de la Comarca se utilizan automotores propios, así como todavía, el caballo, andar de a pié o a dedo, son una constante en los diferentes parajes. Aún así, existen sistemas públicos de transporte escolar y sanitario que tradicionalmente dan cobertura a amplios sectores rurales y rururbanos.

Inputs y outputs de una Comarca bi-provincial.

A este marco general desarrollado hasta ahora, le debería continuar la cuantificación, aunque fuera en términos aproximados de la pautas de intercambio territorial, es decir del movimiento económico-financiero que, a modo de sistema, sostiene los ritmos de inputs y outputs. Algo así, como el diseño económico sobre de qué apoya la Comarca $^{161}$.

Lamentablemente es un resultado que no pudo cuantificarse y aún cuando se ha intentado, han sido gestiones de sólo alcances parciales que dejan un vacío explicativo importante que se trata de mitigar con varios aportes sectoriales. Una razón fundamental a la hasta ahora inconclusa tarea de acercarnos a la verdadera dimensión económica de la Comarca como unidad territorial, está en la sencilla condición de ser éste un territorio bi-provincial con responsabilidades jurisdiccionales del más diverso tipo (nacional, provincial y municipal) donde conviven 6 municipios, un Parque Nacional, ser Zona de Frontera y contener a numerosos parajes rurales, que en sus 'distancias', gozan de cierta identidad a la hora de las gestiones. A esto se agrega la

\footnotetext{
${ }^{161}$ Ver en el Apéndice 7, 'Difícil de responder', un anticipo de varios años que llevaba esa dirección.
} 
condición de ser un lugar propio de la pluralidad en rubros económicos independientes, donde las representaciones tradicionales como las Cámaras y Asociaciones, apenas cubren un sector de relativa importancia del desenvolvimiento económico.

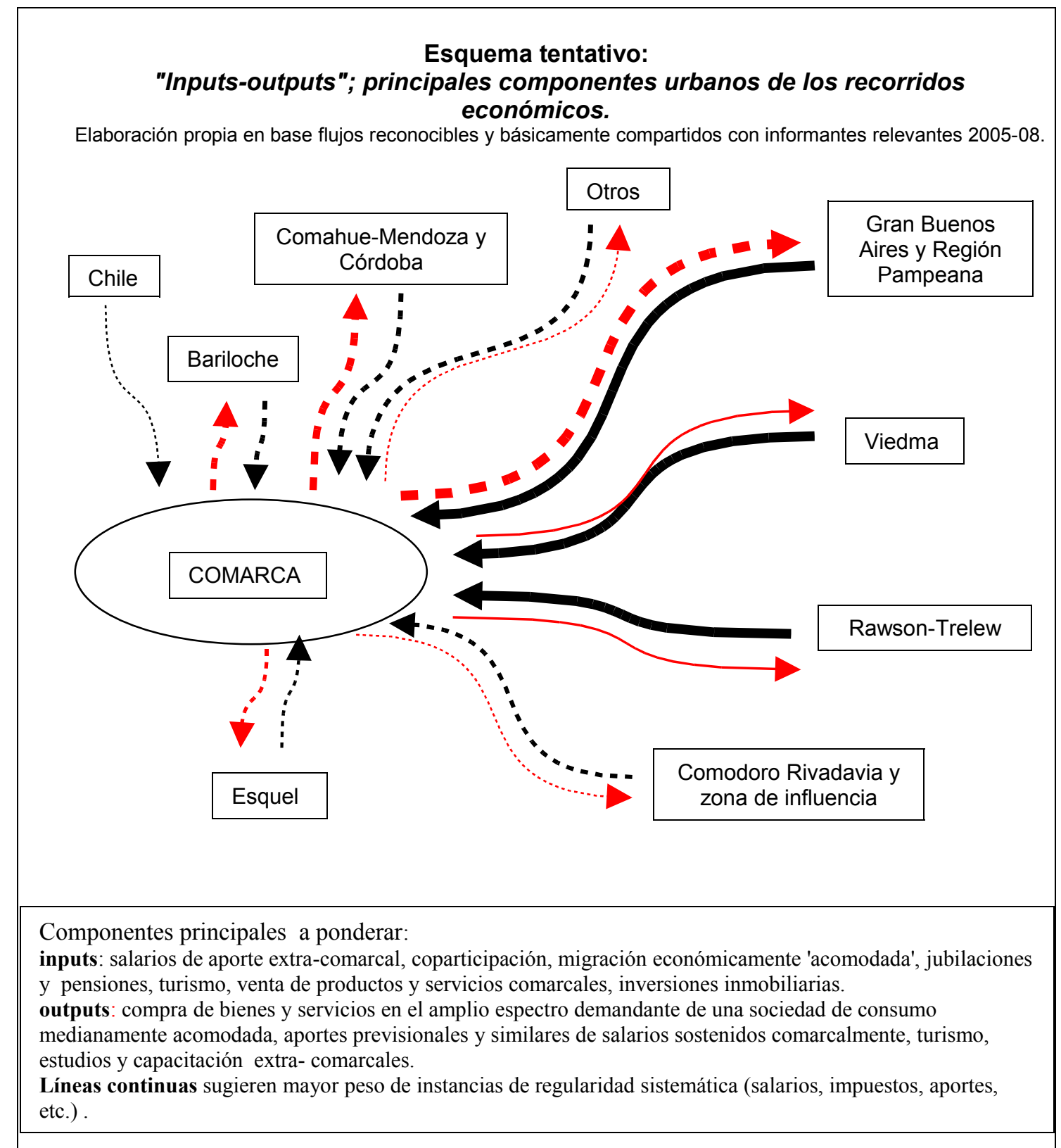

Figura 15: Flujos económicos. El esquema muestra tentativamente 'recorridos' o potenciales flujos monetarios, de un valor apenas ilustrativo, pero indicativo para una futura, y entendemos, sumamente necesaria indagación. Elaboración propia de base empírica sostenida en consultas a referentes locales (Gustavo Capece, Marcelo Muscillo, Abelardo de Almeida y Carlos Baroli).

Como dato indicativo, cabe destacar que El Bolsón reúne 900 actividades inscriptas impositivamente, es decir un $18 \%$ de las más de 4800 de total del Departamento 
Bariloche ${ }^{162}$. Proporción equilibrada en relación a los totales poblacionales aproximados (25.000 El Bolsón y alrededores rionegrinos ${ }^{163}$ y unos 125.000 en S. C. de Bariloche $\left.{ }^{164}\right)$.

Valiéndose de información comparativamente cercana (INDEC, 2001) y agrupados por Marchissio, G. (2007), se tomaron algunas cifras reveladoras de la escala comarcal ${ }^{165}$, para no perder de vista el orden de las magnitudes que pueden servir como contextualizadoras para el lector.

Tabla: 6. Empleo en la Comarca.

Población:

Datos generales del empleo comarcal (2001)

- Población total: 29.622

- Población activa: 11.396 (entre ocupados y desocupados) (58\%)

- Población inactiva: 8.341 (42\%)

Estructura básica de empleo:

- Empleados, sector privado: 2776 (34\%)

- Empleados, sector público: $2662(33 \%)^{166}$.

- Trabajadores por cuenta propia: 1855 (23\%)

- Trabajadores familiares: $455(6 \%)$

- Patrones: 352 (4\%)

En cuanto al empleo público, a título comparativo y pasados casi 15 años, resultan indicativos los siguientes valores en términos de ingresos (porcentuales en 1994; IIED-América Latina, 1994:32) ${ }^{167}$ :

- Empleo provincial: $\mathbf{5 6 \%}$.

- Empleo nacional: 14\%.

- Empleo municipal: $\mathbf{8 \%}$

- Jubilaciones: $22 \%$

Como datos más acotados y actualizados, cabe el punteo orientador que sigue, aún cuando los desagregados no siempre son estrictamente conducentes ya que existe

\footnotetext{
162 Cabe agregar la singularidad en la Comarca de la existencia de la Feria Regional El Bolsón, que, viéndola como organización unitaria, además de agrupar a casi 400 unidades de trabajo y algo más de 800 empleos directos y con ello reunir a la mayor cantidad de empleos. Sin embargo de sus componentes el $64 \%$ carece de cobertura social, lo que significa la no inscripción como actividad económica (Marchissio, 32 y 48)

${ }^{163}$ Estimación propia en base a los medidores domiciliarios de electricidad 2007. Fuente: EDERSA, 2007.

${ }^{164}$ Total ajustado censo del 2001: 101.248; total calculado 31/12/2005 124.703 personas. Fuente: Monasterio, 2006.

165 La condición de relatividad respecto de lo cercano de la fecha va asociado tanto a la gran crisis social, económica y política del país, con su situación explosiva de diciembre del 2001 y también a las circunstancias de la dinámica regional propia.

166 A título tan sólo informativo, según los datos de las respectivas páginas web de las estadísticas provinciales (2007-2008), llevan el total de empleados públicos provinciales a $\mathbf{3 5 3 2}$ agentes; 2251 en la parte chubutense y 1281 en la rionegrina. Curiosamente se trata de valores inversamente proporcionales al peso demográfico de cada sector, por lo que, prima facie, tomamos los datos con cautela, pues no tenemos forma de verificar la real situación dependiente para cada caso. De todas formas una desagregación interesante surge de los 1281 agentes rionegrinos ocupados en 16 organismos y municipios al año 2005 en El Bolsón; de ellos casi un $70 \%$ corresponden al Consejo Provincial de Educación, lo que le otorga un peso significativo a este sector público. Ver en http://www.spi.rionegro.gov.arl y http://www.estadistica.chubut.gov.ar/comarcas.html

${ }^{167}$ Resulta significativo la comparación que puede hacerse entre el porcentaje de empleados públicos que hubiera alcanzado sólo el 33\% (2001) con la estimación del peso de un 48\% que le cabe a los sueldos públicos que para 1999 a (Diarios Piltriquitrón y Diario El Cordillerano, Suplemento Patagonia Economía. Nov. 1999).
} 
cierta movilidad del empleado en virtud de adscripciones y demás posibilidades administrativas.

Tabla: 7. Empleados provinciales de El Bolsón (05/2007)

\begin{tabular}{|l|r|}
\hline Consejo Provincial de Educación & \\
\hline \hline Poder Judicial & 650 \\
\hline \hline Poder Legislativo & 6 \\
\hline Secretaria General de la Gobernación & 6 \\
\hline Secretaría de Estado Turismo & 23 \\
\hline \hline Ministerio de Gobierno & 2 \\
\hline \hline Ministerio de Familia (Salud y Desarrollo Social) & 9 \\
\hline \hline Ministerio de Producción & 58 \\
\hline \hline Departamento Provincial de Aguas & 87 \\
\hline \hline Dirección General De Rentas & 2 \\
\hline \hline I.PRO.S.S. (obra social) & 5 \\
\hline \hline I.P.P.V. (vivienda) & 10 \\
\hline \hline Consejo Prov. De Salud Pública 1844 y Func. & 2 \\
\hline \hline Consejo Prov. De Salud Pública 1904 - L 3117 & 130 \\
\hline \hline Agencia Rio Negro Cultura & 76 \\
\hline \hline Agencia Deporte y RE & 2 \\
\hline \hline Policía de Río Negro Escalafón 8 y 9 & 3 \\
\hline \hline TOTAL & 65 \\
\hline \hline
\end{tabular}

Cabe destacar que estos datos se los trae básicamente a título descriptivo ya que para arribar a conclusiones firmes, se debería seguir un análisis microeconómico más complejo. Valga por caso de esa necesidad, que los porcentuales, a la hora de precisiones, pueden variar enormemente por instancias políticas difíciles de rastrear. A título de ejemplo, hay experiencias notables en cuanto a desbalances económicos a uno y otro lado del límite provincial en materia presupuestaria, incluso con circunstancias en que las administraciones provinciales dejaron de pagar las correspondientes mensualidades en más de una oportunidad o en alguna otra, los sueldos alcanzaban a doblar su valor comparativo.

En la actualidad y en base a la información disponible, El Bolsón, agrupando un tercio de la población comarcal, apenas reúne un presupuesto similar al de los más pequeños municipios vecinos de Lago Puelo y El Hoyo (del orden de los \$15.000.000) y hasta resulta sensiblemente inferior al de El Maitén. 


\section{II.2.4.2. Principales actividades productivas a modo de inventario comentado.}

Este capítulo se ocupa de una descripción elemental de los diversos sectores productivos, con algunos detalles que pueden servir como orientadores en caso de necesitar una profundización del análisis.

Frutas finas y frutales en general:

La producción de diferentes frutales menores, como frambuesa y demás berries, frutilla, cassis, corinto, etc.) y otros mayores, como cereza, guinda, vid, nogal y manzanas, constituye una actividad distintiva respecto del contexto productivo regional. Como se señala en un informe técnico, estos frutos, denominados genéricamente como 'frutas finas' (están) íntimamente ligados al imaginario productivo de la comarca (Chubut, PROSAP, 2001: 11) e integran el paquete ofrecido por la producción a la agroindustria (dulces y conservas) y la producción fresca que se vende mayoritariamente en el mercado local y regional como producto especial proveniente de la Comarca Andina.

La buena, y algunas veces muy buena, adaptación edáfica, climática y sanitaria de varias especies de calidad reconocida, son determinantes para ello. Aún así, la visión especializada ${ }^{168}$, advierte dificultades que, además de la dependencia estructural hacia los vaivenes económicos (pautas cambiarias) y de las oscilaciones propias de sitios periféricos, podrían resumirse en: comercialización compleja, estacionalidad estricta y volúmenes de escala exigua ${ }^{169}$.

Todo ello, claro está, en consonancia con aspectos socio-culturales que manifiestan todavía un estado embrionario en cuanto al sostenimiento de una tradición frutícola. Aún así, en cuestiones de mercado se diría que a la condición de excentricidad que le cabe a la posición geográfica de la Comarca, su producción se ve forzada a responder también excéntricamente y esto es visto con optimismo. Como es sabido, las condiciones de competitividad se hacen enmarañadas cuando existen hoy ofertas relativamente análogas desde lugares más cercanos a los centros de consumo, y económicos en relación a costos de mano de obra; pero, aún así, es desde la economía que Krugman nos advierte, "... es absolutamente natural suponer una elevada elasticidad de la oferta de los factores hacia una región en particular, ya que los factores de producción se pueden atraer de otras regiones" (1995: 20-21), con lo cual quedan abiertas instancias de posibilidades alejadas de un determinismo espacial y mucho más cuando se trata, como es el caso de los berries y las cerezas, de producto de demanda insatisfecha ${ }^{170}$. En lo que a fruta fina se refiere (196 ha. y 90 productores, 2003) $)^{171}$, las distinciones parecieran

\footnotetext{
${ }^{168}$ Barría (2000); Martínez y Mariño (2006); Cobelo y Echagüe (2007); Melzner (2003);

${ }^{169}$ Ver también información detallada en Fiorentino (1998); específicamente en páginas 10, 13 y 20.

${ }^{170}$ Ver en Barría (2000) las instancias potenciales en relación a la producción-mercado frutícola (frutas finas) como oferente contra-estación en los mercados del Hemisferio Norte.

171 Datos de Melzner (2003). En Fiorentino et al se da cuenta que en 1992 se contaba con 122 productores con 184 ha. total; 112 de frambuesa, 59 de cereza y guinda, 13 de frutillas. Informe Fiorentino 1998).
} 
venir de la mano de las producciones orgánicas o semi-orgánicas, como cultivos especializados $^{172}$.

Según la información de base en la temporada 2005-6 la producción total anual de frutas finas en la Comarca (incluyendo principalmente frambuesas, boisenberries, cerezas, guindas, grosellas, frutillas) alcanzó a 650 toneladas, de modo que los rendimientos medios se sitúan en el orden de 3 a 5 toneladas de fruta fresca por hectárea.

Por otra parte, se toma de Melzner, "...La mayoría de los productores son propietarios (86\%). El $92 \%$ (...) realizan la gestión cotidiana de la explotación y solo el 37 \% se dedican exclusivamente a la actividad. Como puede observarse hay una gran dedicación del productor a la actividad. El sector genera 125 empleos permanentes y unos 42000 jornales transitorios, principalmente para cosecha...". Si se equiparan a empleos permanentes serían 143 para 12 meses o 430 para los 4 meses que dura la cosecha (Río Negro - CFI, 2007: 297).

\section{Actividades Forestales}

Las actividades forestales, vinculadas a los bosques nativos e implantados, comprenden tanto el aprovechamiento con fines maderables y no maderables, como a las estrategias de conservación de la masa boscosa.

En materia productora, existe una tendencia progresiva de tránsito hacia la explotación del bosque implantado por sobre el nativo (rollizos para aserrado) y promoviendo la figura de recurso renovable. Como señala un documento prospectivo de la gestión provincial rionegrina, "... . La base de sustentación de la foresto industria actual es el bosque nativo andino patagónico en sus especies ciprés, lenga y cohiue, un recurso natural que es cada día más valorado por su rol de productor de servicios (protección de cuencas, biodiversidad, captación de $\mathrm{CO}_{2}$ atmosférico, liberación de oxígeno, paisaje, etc.) que por su rol de proveedor de materia prima..." (Río Negro -CFI, 2007: 294). La misma fuente indica que en la Comarca, "... la participación de bosques de cultivo es del $40 \%$ del total, con tendencia creciente ya que año a año entran mayores superficies a turno de corta, lo cual indica que las industrias podrán trabajar con madera sin restricciones ambientales...". Esta última consideración seguramente se refiere en exclusividad al no aprovechamiento maderero de nativas, puesto que serán numerosos los condicionamientos ambientales que suponen las plantaciones forestales, máxime cuando son de carácter extensivo y monoproductor.

Sorprende en este último decenio la incorporación de grandes predios con nuevas plantaciones, en particular de $P$. Oregón, sobre los ámbitos esteparios de la Comarca, en particular en las estancias ganaderas. Aquí no sólo se observa un resultado importante en la

\footnotetext{
172 Un buen marco explicativo puede partir Cobelo y Echagüe cuando describen (2007): La producción de berries se distribuye en numerosos establecimientos con superficies reducidas (promedio de 0,5 ha), conducidas por productores que en muchos casos tienen una dedicación parcial (...).Aunque no se disponga de una cuantificación precisa de las oscilaciones en las superficies en producción de berries durante la década del '90, la información local de que se dispone (observaciones por parte de referentes técnicos, trayectoria de grupos de Cambio Rural) permite suponer que hubo una disminución de las mismas. Desde 2002 a la fecha esta tendencia se ha ido revirtiendo, aunque restringida por la estructura de tenencia de la tierra y los valores de la misma. El incremento de la producción de berries en la zona, asociado al mayor desarrollo turístico, viene acompañado por importantes modificaciones en el tipo de agentes productivos agrarios -un reemplazo de pobladores tradicionales, minifundistas, por pobladores de origen urbano, con niveles más elevados de instrucción e ingresos.
} 
generación del recurso, sino también una transformación en la fisonomía de los parajes con el literal reemplazo de la vegetación esteparia.

Para ponderar en escala alguna de las condiciones trascendentes de la actividad, nos valemos de un punteo provisto por la Delegación Forestal Lago Puelo (07/2007):

- el $90 \%$ del volumen de productos y subproductos forestales (entendemos que de la Comarca en general) corresponde a Pinus y $P$. Oregón; es decir bosque implantado.

- el $88 \%$ del volumen se destinó a 36 aserraderos de la zona.

- la recaudación bruta que generó el procesamiento de los rollizos en las industrias madereras de la región, el año pasado (2006) superó los 4 millones de pesos.

- el registro de obrajeros de esta Delegación cuenta con más de 50 trabajadores independientes (...) a los cuales hay que sumar uno o dos ayudantes por cada uno (conste que en este ítem no se incluyen las otras jurisdicciones comarcales).

- en la zona Oeste del Río Azul, se proyecta la erradicación de especies exóticas. Se han alambrado sectores para proteger y favorecer la regeneración natural de especies nativas.

En definitiva en la Comarca operan unos 40 aserraderos, de los cuales la cuarta parte son móviles, pudiendo, incluso ocuparse en oportunidades fuera de la Comarca. Un dato significativo que surge de las consultas sectoriales, es el hecho de que además de ser una actividad de fuerte ritmo a lo largo del año corrido, genera empleo continuo a unas 500 personas ${ }^{173}$.

Cabe por fin destacar que la actividad maderera en sí, se concentra en la elaboración primaria de machimbres y tableros, tirantería, vigas, estructuras para techos, portones y algunos muebles; se le agregan (sólo en madera nativa) la confección, tranqueras, varillas y revestimientos rústicos. El número de establecimientos madereros en la comarca oscila entre 20 y 30 aproximadamente.

\section{Ganadería}

Puede considerarse a la Ganadería como la actividad más tradicional de la Comarca, incluso, se puede afirmar que lo es de la Patagonia Andina en su conjunto. Tal vez, por ser el nuestro un país ganadero por excelencia, el carácter periférico, cuando no marginal que le cabe a la producción ganadera zonal respecto del conjunto nacional, llevan a un primer plano a otras actividades más singulares como la del turismo o las actividades maderera-forestal, lupulera o de las futas finas.

Como se ha visto, fue principalmente a través del ganado que se penetró en los bosques y se prepararon los valles para su ocupación moderna. Su valoración cultural, así como su efectividad o buen desempeño financiero a la hora de necesitar de recursos y alimentos, siguen colocando a la ganadería, especialmente bovina, en una posición trascendente en la economía doméstica.

Bovinos, ovinos, equinos y porcinos integran básicamente el espectro ganadero comarcal, aunque las diferencias en materia de escalas de producción y comercialización a la vez, son abismales en cuanto al carácter complementario o exclusivo de la actividad.

\footnotetext{
${ }^{173}$ Ver también en IIED-América Latina, 1994: 38)
} 
Ante la falta de información ganadera clasificada y agrupada comarcalmente y por los desfasajes que se producen dado el número de jurisdicciones administrativas, inicialmente nos valemos de las siguientes figuras total o parcialmente 'ganaderas' que permiten alcanzar una aproximación meramente formal, pero indicativa a nuestros propósitos ${ }^{174}$ :

- la estancia como unidad económica de escala empresarial; ocupante de grandes extensiones, mayormente en el Centro y Este de la Comarca, con campos de buena receptividad y posibilidades de manejo autónomo e interno de la dinámica veranadainvernada.

- la estancia minifundista, de sostén familiar sin capacidad de gestión empresarial; de tamaños considerables y distribución alternada en terrazas y faldeos de baja receptividad.

- la granja-chacra ${ }^{175}$ tradicional y / o exclusiva, con stocks ganaderos que apuntalan el autoconsumo e instancias de intercambio periódicos de acuerdo con la estacionalidad productiva

- La chacra moderna familiar-mixta (neorrural), de funcionalidad interdependiente con ingresos extra-chacra, con el sostenimiento de animales sólo como complemento menor.

Existe un importante desarrollo de la producción semi extensiva de carne bovina con aproximadamente 23.000 cabezas $^{176}$ que involucran tanto a extensos campos boscosos del Manso, Foyel y Turbio, como a las estancias o sectores de éstas, más extendidas y con mayor predominio de pastizales del Este comarcal (Cholila, El Maitén, Cuesta del Ternero, etc.). Como modalidad se distingue la cría, pero el engorde confinado sólo se realiza en 3 establecimientos, siendo el sistema de producción dominante el pastoreo del pastizal natural que torna al sistema en muy vulnerable a las alteraciones climáticas propios de ámbitos ecotonales. De todos modos la implantación de pasturas y producción de reservas es de volúmenes interesantes y destinados especialmente a la producción de heno ${ }^{177}$.

Entre las fortalezas de la actividad está la condición de ser zona considerada libre de aftosa sin vacunación, donde los problemas sanitarios son menores. Aún así, como señalan Fiorentino et al, "...sus debilidades o limitantes en la cría son la escala reducida de las explotaciones, la escasez de forraje en primavera avanzada y verano por falta de agua, y las dificultades de crecimiento de pasturas en invierno por falta de temperatura (47).

En cuanto a la producción ovina, se debe distinguir el esquema minifundista y/o complementario de muchos de los establecimientos intramontanos de aquella de las grandes estancias latifundistas, que para el caso se agrupan en sectores de las estancias del grupo Benetton.

En el primero de los casos puede alcanzar volúmenes relativamente importantes es extensiva con escasa producción relativa de corderos. La cuestión nutricional es gravitante en este análisis. (Fiorentino, 23 y 24).

Horticultura.

La producción básicamente está destinada al abastecimiento local y de San Carlos de Bariloche. Según el informe de Melzner, "... No existe una especialización marcada en alguna

\footnotetext{
${ }^{174}$ De gran valor analógico puede resultar la caracterización tipológica que hacen Mendía y Caputo (1992) para el Centro y Suroeste Oeste Neuquino; si bien las singularidades geoeconómicas y culturales propias del medio neuquino presentan diferencias importantes con la Comarca, en particular por la presencia decisiva de 'crianceros' en aquel medio, se valora su diferenciación de usos de fuerte sesgo ganadero.

175 Para el caso andino patagónico, parece razonable asimilar ambas figuras (granja-chacra) en su condición tradicional, si bien el concepto de chacra supone mayor tamaño y complejidad.

${ }^{176}$ En el censo agropecuario de 1988 se relevaron 26070 bovinos en 833 establecimientos de la Comarca.

${ }^{177}$ Entendiéndose que no hubo mayores cambios en las tendencias al respecto, considérese que hacia finales de la década de los años ' 80 , de 1020 ha. destinadas a la agricultura, casi la mitad estaba dirigida a cultivos forrajeros
} 
hortaliza en particular, siendo en general formada por producciones múltiples. De la superficie destinada a la horticultura, un tercio la forman productores hortícolas de producción variada, otro tercio por productores que se dedican a papa (la mayor especie plantada dentro de esta actividad) y el otro tercio lo forman productores de baja superficie y producción diversa. ..." (2003).

Con todo, resulta interesante la tendencia creciente hacia el consumo de producción local, tanto por parte del habitante comarcal como por las exigencias del turismo. Si bien no es competencia para con el flujo de mercaderías desde otros ámbitos del país (Mendoza, Buenos Aires y especialmente del Alto Valle del Río Negro), es una dirección de cierta pujanza, que, por un lado retoma alguna tradición hortelana de los 'paisanos', casi reducida a la huerta casera, y por la otra, incorpora innovaciones y adecuaciones tecnológica-productivas.

\section{Lúpulo}

Le cabe al lúpulo una condición distintiva en la economía local, aún en su escala micro para lo que significa el negocio cervecero. Ser reconocido este rincón del país como el más apto para su cultivo y, de hecho, constituirse como el área productiva por excelencia, le ha valido hasta para contar desde hace más de 30 años con una fiesta de carácter nacional ${ }^{178}$.

Hacia finales de la década pasada no se llegaba en todo el país a las 300 hectáreas cultivadas y casi 200 se desarrollaban en la Comarca, 180 ha. Aún así, esta exclusividad ecológica presenta vulnerabilidades importantes. Una de ellas es que la producción y comercialización posee un alto grado de concentración mundial, que lo hace sumamente vulnerable a las condiciones cambiarias; condición que casi significó la desaparición de la actividad con el esquema cambiario 1 a 1 y el devenir internacional en la materia. Se afirma, "... Fueron demasiados años de precios muy bajos que hicieron reducir las 400 ha. de lupulares que habia en la Comarca a sólo 160 ha. que existen en la actualidad...". (Leibretcht, A., entrevista en el diario Rio Negro. 28-01-2008, Suplemento Aniversario El Bolsón) ${ }^{179}$.

La otra condicionante, por cierto no excluyente para el lúpulo, son las progresivos avances en materia tecnológica que, según sea la dinámica del mercado y las ofertas ambientales, permiten explorar y especular con su producción en ámbitos de condiciones ecológicas más exigentes. Cabe agregar que este cultivo, además de una alta inversión en postes y alambres, requiere de galpones y maquinarias específicas (cosechadora, secaderos, prensa), condición de exigencia distintiva agravada por el hecho de ser equipamiento sin usos alternativos.

\section{Industria}

Atendiendo a diversos informes sectoriales, demasiado heterogéneos en sus consideraciones como para tener un panorama industrial claro, surgen como las más significativas de acuerdo

\footnotetext{
${ }^{178}$ Fiesta Nacional del Lúpulo. Es cierto que estas fiestas, en general, han sufrido una suerte de mutación turística, adecuándose en los últimos lustros más a esa actividad que a la convocante; por ejemplo, esta celebración se realiza antes y no a posteriori de la cosecha.

179 También deben valorarse situaciones inversas. Tomamos afirmaciones del mismo informante, "Los escasos productores (comarcales)- nueve entre Chubut y Río Negro según datos del INTA- han visto saltar el valor de u\$s 4,50 a u\$s 9 por kilo de flor (en bruto) y hatsa u\$s 10 en pellets". (Leibretcht, A., entrevista en el diario Rio Negro. 28-01-2008, Suplemento Aniversario El Bolsón).
} 
con el valor monetario de la producción, las madereras y dulcerías ${ }^{180}$. Conservas, licores y derivados de la rosa mosqueta, presentan un significativo peso relativo de la economía local (Fiorentino, 25), si bien al tratarse de actividades sostenidas a modo de Pymes, su estabilidad no se presenta clara como para definir estructuralmente el sector; incluso en muchos casos aún mantiene su origen artesanal que tiende a derivarse hacia el agro-turismo. Una actividad innovadora para la región le cabe a la producción de inoculantes, relacionada, además, aunque no en exclusividad, a otra actividad importante en términos de capital que es la extracción de turba (Mallín de los Pastos Comunes).

\section{Turismo}

Como se ha visto reiteradamente en este trabajo, el turismo resulta casi transversal a la historia cercana comarcal. De hecho a pasado a ser en los últimos años y en armonía con el desarrollo sectorial a nivel global y nacional, sino 'la' una de las actividades más relevante y dinámicas, sea ésta vista desde un enfoque exclusivamente económico, como desde su perspectiva sociocultural. También, por supuesto, la trascendencia territorial por no decir, su impacto, es decisivo y rector de los rumbos declarados de las gestiones políticas contemporáneas en el amplio espectro jurisdiccional nacional, provincial y municipal que se enlazan en figuras genéricas de envergadura como Corredores, Parques y Reservas, con todos sus significantes territoriales adosados (circuitos, escenarios especiales, equipamientos y servicios, infraestructura). El progresivo 'acomodamiento' del paisaje para la incorporación de la actividad turística ha cobrado suficiente entidad como para desplazar a las otras más tradicionales y de singular trascendencia espacial (ganadera y forestal) e insertarse plenamente en otras (fruticultura y agricultura).

Aún así, a la hora de cuantificar en términos monetarios, se regresa a un terreno de especulaciones más o menos verídicas y al que no aspiramos a penetrar.

Las modalidades turísticas más relevantes pueden resumirse en:

- turismo de descanso (familiar y estacional)

- turismo aventura, ecoturismo y otros (de familias, grupos e individuos) ${ }^{181}$

- turismo mochilero (de grupos e individuos)

- turismo de compras artesanales (en especial de adultos y adultos mayores).

En materia de estadías, se diferencia netamente el turismo:

- de paso (recorriendo el Sur). Una o dos noches.

- vacacional (de cabañas y camping). Varios días y/o semanas.

- de aventura, deporte y alta montaña ${ }^{182}$. Varios días, itinerando.

\footnotetext{
${ }^{180}$ Según los datos generales, los destinos de la producción son variados: “...el $65 \%$ de la producción de frutas finas se destina a confituras y conservas, el $17 \%$ a la venta de productos frescos y refrigerados, el $14 \%$ a la producción de congelados y el $4 \%$ a la producción de pulpa de fruta..." (Río Negro -CFI : 297).

${ }^{181}$ Ver una interesante desagregación en Marchissio donde además se analiza el origen geográfico y la composición etaria de los visitantes. (2007:25 y 26$)$,

182 Interesante ver la información desarrollada Zea (2007). También el informe muestra el estado de discusión, bastante agresivo y muchas veces falto de rigor, con el que se analizan cuestiones territoriales trascendentes del turismo en general y de la alta montaña en particular. Respecto del último tema, puede verse que desde la tenencia de la tierra hasta la identificación de geoformas clave (por ej.: circos glaciarios, crestas, o escorrentías), parecieran entrar sólo en un plano voluntarista y acotados en exclusividad a circunstancias de mercado.
} 
- diario, básicamente complementario del de S. C. de Bariloche y el propio proveniente de esta ciudad y en mucha menor medida desde Esquel.

En cuanto al perfil socio-económico de los turistas, se diría que es el propio de clase media, con aporte relativamente fugaz de segmentos más acomodados ${ }^{183}$

Tabla 8. Turismo, valores significativos.

\section{COMARCA}

1994: unidades de alojamiento: 57; plazas 2316 (IIED-América Latina, 1994:43)

\section{El Bolsón:}

1990: unidades de alojamiento: 32; plazas 1728 (IIED-América Latina, 1994:43)

2002: unidades de alojamiento 75 ; plazas 3462

2007: unidades de alojamiento 109; plazas 4345 y 17 campings con capacidad para 2.227 usuarios

Total turistas:

2006: 125.800 (150.000, según estimaciones de Marchissio, G.)

2007: 142.900

\section{II.2.4.3. En definitiva, 'un mosaico colorinche'.}

En términos de distribución de usos, la Comarca se presenta como un verdadero collage sobre el cual el dinamismo que muestran los distintos sectores productivos se muestran esquivos a la hora de hallar algún patrón guía. Aún así, siguiendo algunas pistas propias de la naturaleza física de los sitios y/o de la historia de la ocupación del espacio, se han podido desarrollar argumentos explicativos que, entendemos, contribuirán al desarrollo de una teoría sobre el orden territorial en la Patagonia Andina.

El mapa de usos del suelo del ejido de Lago Puelo, elaborado por la UATA, Esquel, y que requirió de la participación de un importante número de informantes ${ }^{184}$, es un buen ejemplo de lo enmarañado de la situación de usos. ¡Y, guay si se quiere entrar en detalles!. Es allí donde la lógica de producción, de la relación íntima con los recursos naturales y las actividades, entran en crisis, accediendo al terreno de lo anímicoafectivo, de los impulsos y la moda que, en todo caso, se respalda en la lógica de la contemplación y, que tiene también su talante económico, pero desarraigado de los circuitos productivos locales en materia de sustentabilidad ${ }^{185}$.

\footnotetext{
${ }^{183}$ Al respecto resulta muy interesante y sumamente ilustrativo un estudio de Marketing realizado por el denominado Grupo Estratégico de Negocios Alberto Wilensky (CFI, 2001), donde se trabaja a la Comarca desde una visión de mercado y desnuda su falta de acomodamiento para atender a los segmentos acomodados de la demanda turística (ABC1) y despliega una serie de estrategias más que elocuentes para subordinar la evolución territorial a sus necesidades.

${ }^{184}$ Convenio Municipalidad de Lago Puelo-UNPSJB, UATA, Esquel, 2006-7.

${ }^{185}$ Salvando las escalas de tiempo y espacio, resulta ilustrativo del análisis de Nogué i Font en referencia a la comarca catalana de La Garrotxa (op. cit.).
} 


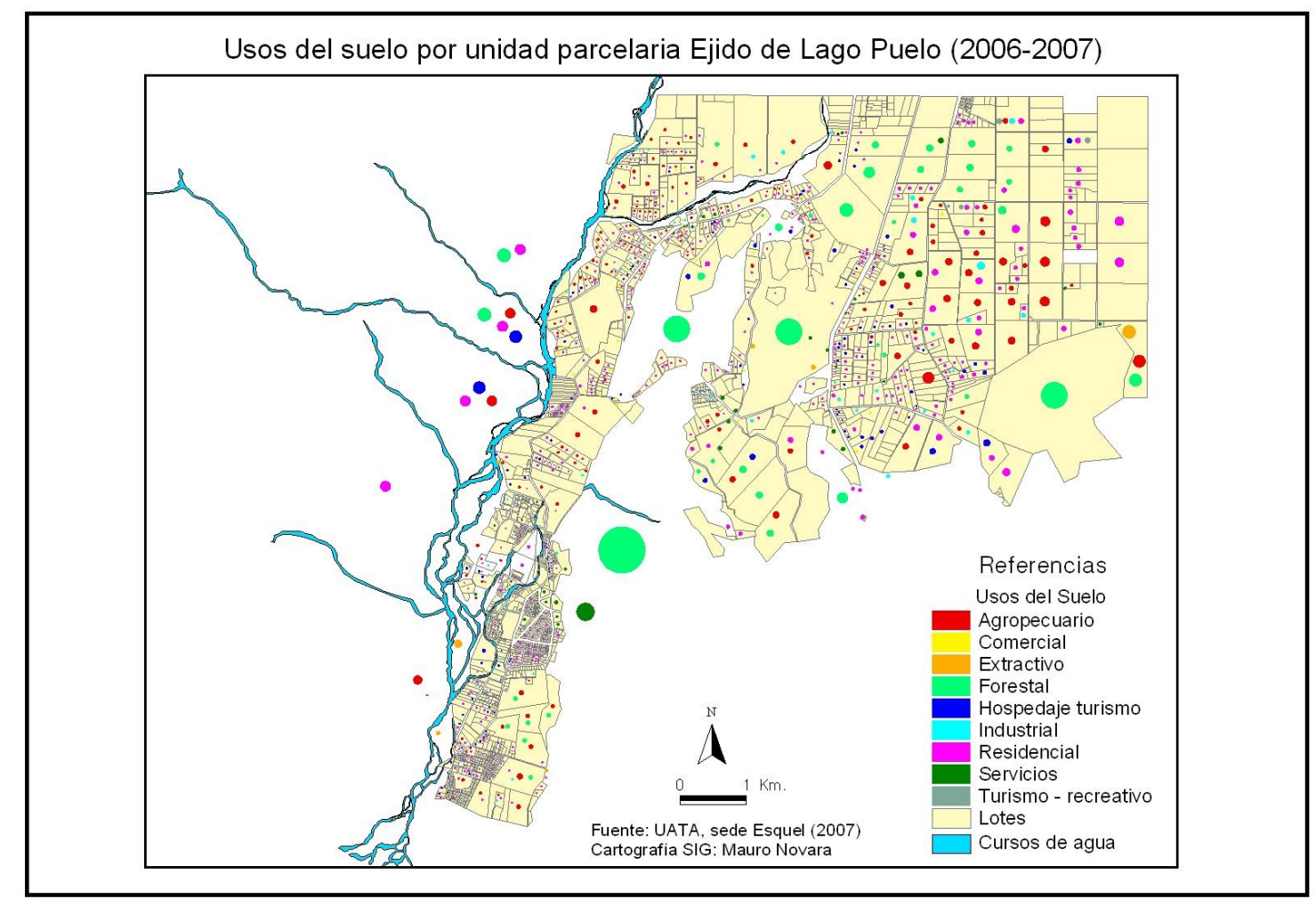

Mapa: 7. Usos del suelo en Lago Puelo.

Cantidad de usos del suelo por unidad parcelaria Ejido de Lago Puelo (2006-2007)

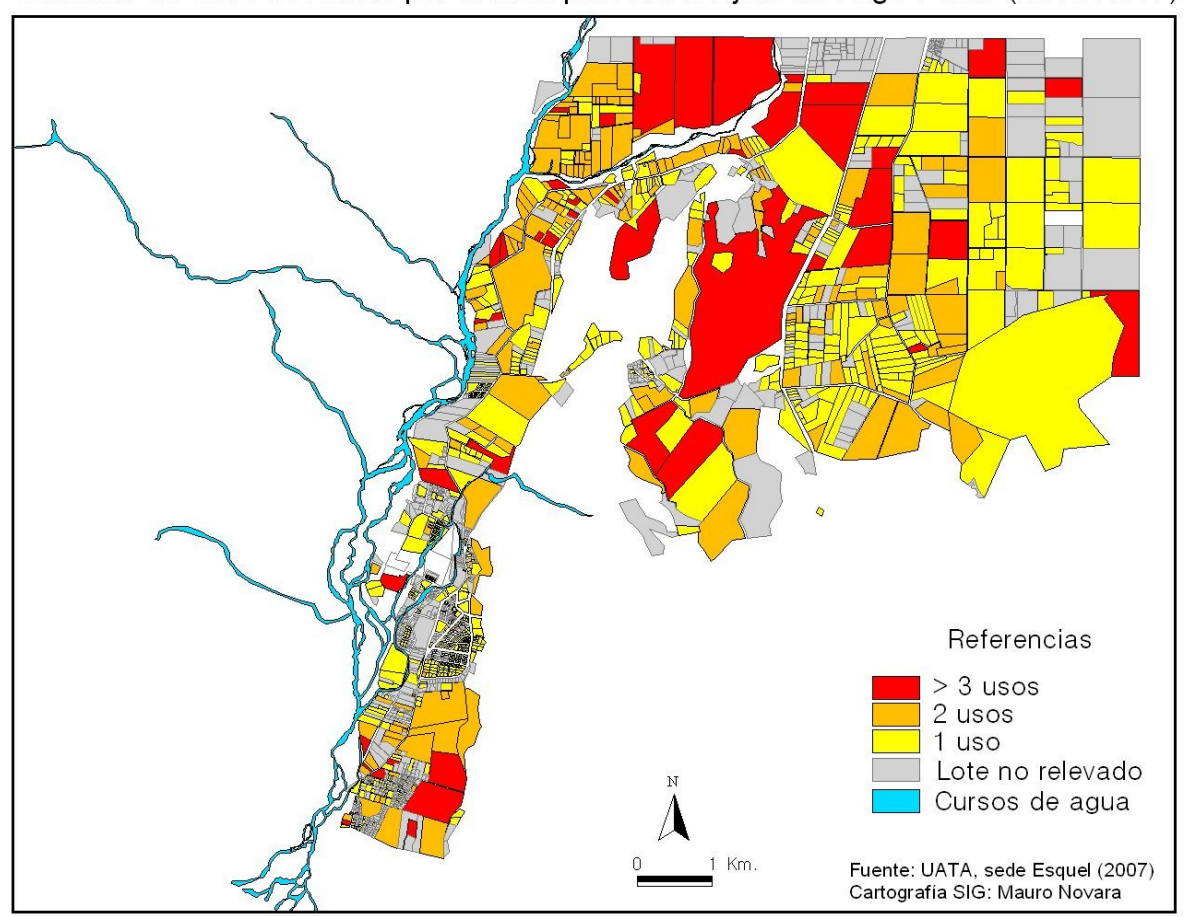

Mapa: 8. Usos del suelo por unidad parcelaria. 
En síntesis puede ser una estructura productiva de base complementaria la que ofrece la Comarca en conjunto, donde, siguiendo la tradicional clasificación de las actividades, se destacan:

Primarias:

- de sesgo agrícola: fruticultura, lúpulo, horticultura, floricultura, agricultura forrajera y apicultura.

- de sesgo ganadero: mixto bovino-ovino y acuicultura,

- de sesgo maderero: de forestaciones y nativas,

- de sesgo minero: extracción de turba y áridos y

- de recolección artesanal: hongos, rosa mosqueta, nueces, hipericum y helechos.

\section{Secundarias:}

- dulcería, apícola,

- madereras,

- elaboración de inoculantes,

- industrialización artesanal de algunos productos alimenticios (queso, leche, helados, chocolates, yogurt, cerveza, ahumados, textiles), alfarería, carpintería, herrería y otros,

- construcción (viviendas en especial)

Terciarias:

- servicios públicos,

- comercio,

- turismo,

- otros servicios privados (tradicionales)

- servicios privados alternativos (salud, recreación, etc.) y

- conservación de la Naturaleza.

Algunos de los usos económicos del espacio más extendidos.

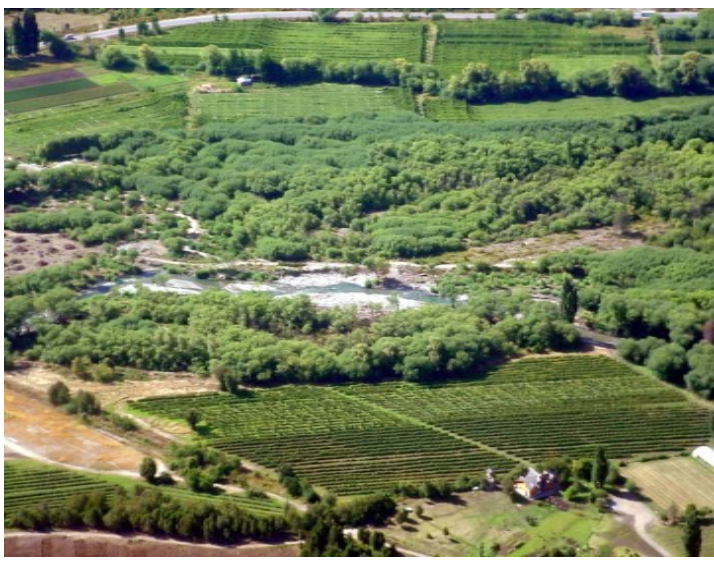

$$
28
$$

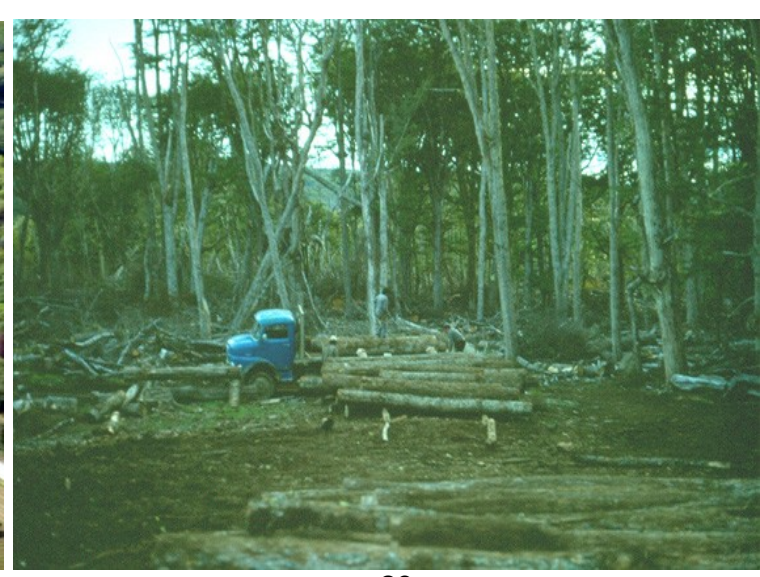

29

Foto 28: Frambuesales y otras plantaciones a la vera del río Quemquemtreu. Foto F. Ottone, 2004. Foto 29: Faena maderera, una cancha. Foto del autor. 


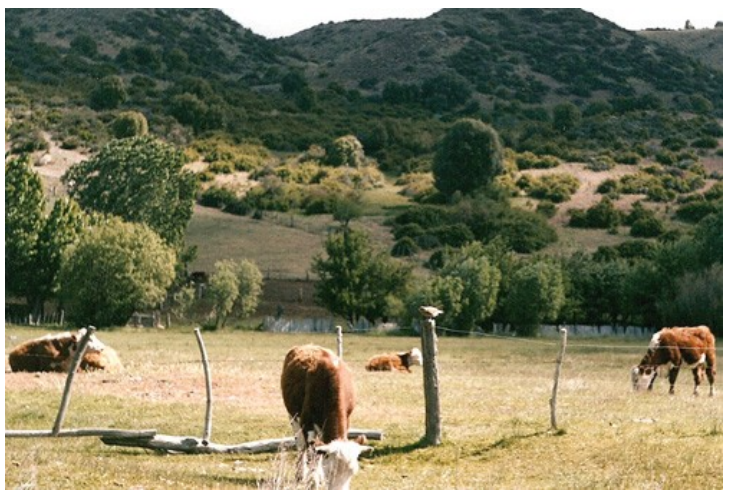

30

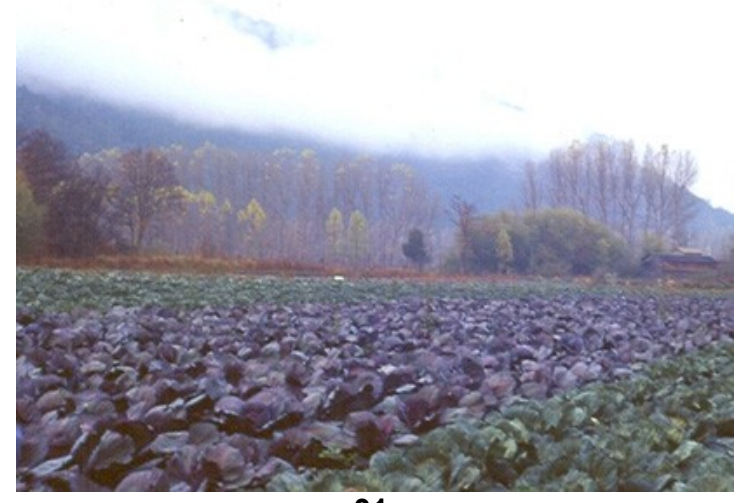

31

Fotos 30: Vacunos en ámbito netamente ecotonal bosque-estepa; cercanías de Cholila. Foto del autor. Foto 31: Hortalizas, un rubro activo con altibajos históricos. Foto del autor (Camino de los Nogales, 2005).

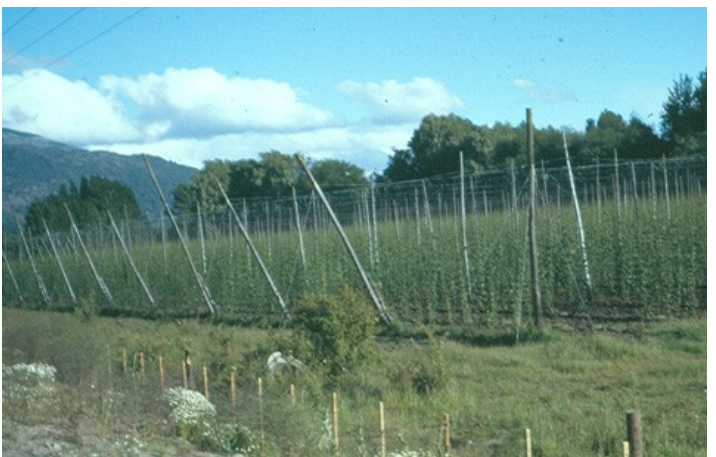

32

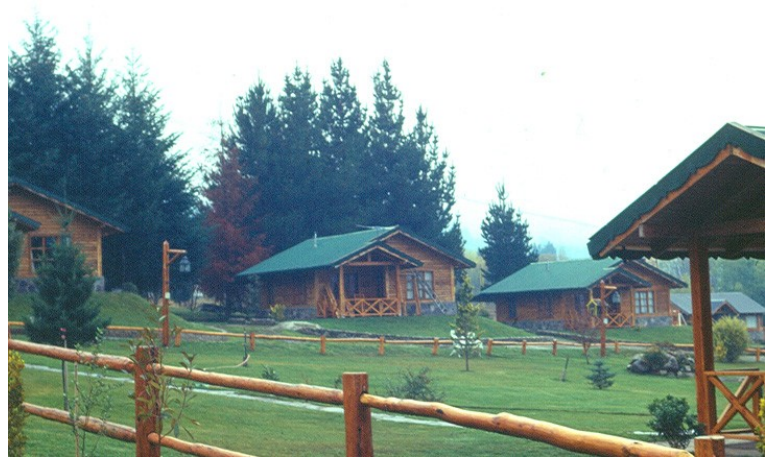

33

Foto 32: Lupular en Lago Puelo a mediados de febrero. Foto del autor. Foto 33: Turismo cabañero, de importante desarrollo y asociado con nuevas distribuciones espaciales en el medio rural. Villa Turismo. Foto del autor, 2005.

En todos los casos y a la hora de proyectar el espacio económico, convendrá ponderar la condición de un relieve sumamente quebrado, con ello, el siguiente punteo puede resultar ilustrativo a la hora de las proyecciones espaciales y el planeamiento:

\begin{tabular}{|c|c|c|}
\hline \multicolumn{3}{|c|}{ Demandas de superficie según actividades extra-urbanas } \\
\hline $\begin{array}{c}\text { Con posibilidades } \\
\text { de concentración } \\
\text { espacial (menos de } \\
\mathbf{2} \text { ha.).186 }\end{array}$ & $\begin{array}{c}\text { Necesariamente } \\
\text { extendidas en escala } \\
\text { valletanas (entre 2 ha. y } 10 \\
\text { coalescentes) }\end{array}$ & $\begin{array}{c}\text { Necesariamente } \\
\text { extendidas en escala } \\
\text { valletanas (más de 10 ha. } \\
\text { coalescentes) }\end{array}$ \\
\hline $\begin{array}{c}\text { industrial (incluye la } \\
\text { construcción) }\end{array}$ & de chacra & ganadería \\
\hline de granja ( $\geq 0.5$ ha.) ${ }^{187}$ & agricultura (forrajera) & de estancia \\
\hline turismo residencial & forestal & \\
\hline horticultura ( $\geq 0.5$ ha.) & turismo recreativo & \\
\hline fruticultura ( $\geq 0.5$ ha.) & lúpulo & \\
\hline floricultura $\geq 0.5$ ha.) & lechera comercial & \\
\hline minera & & \\
\hline artesanal comercial & & \\
\hline
\end{tabular}

Tabla 9. Actividades y demandas de superficie.

Fuente: elaboración propia en base a consultas sectoriales.

\footnotetext{
186 Valor que surge de la observación de tendencias en los últimos 15 años (datos propios)

${ }^{187}$ Criterio de unidad mínima de explotación agropecuaria (EAP) del Censo Nacional Agropecuario. Dirección General de Estadística y Censos de Río Negro (2002: 3)
} 
Se carece de los valores actualizados respecto del uso de la tierra en superficies netas, aún así y con seguros cambios significativos en aquellos parajes más poblados de los fondos de valle, tomamos los siguientes como orientadores importantes:

- Bosque natural de uso pastoril: $51 \%$

- Bosque natural de uso forestal: $29 \%$

- Superficie 'no apta' (pedreros, roca, etc.): $10 \%{ }^{188}$

- Bosque implantado: $7 \%$

- Agricultura y pasturas implantadas: $2 \%$

- Superficie con viviendas y caminos: $1 \%$

- Superficie apta no utilizada: $1 \%$

Fuente: Censo Nacional Agropecuario 1988 en IIED-América Latina (1994: 33).

\section{Unidades espaciales económicas}

Con esta base se identifican lo que dimos en llamar unidades espaciales económicas y que se agruparon en trece modalidades de uso, que, dada su movilidad intrínseca en materia evolutiva, ha sido imposible cartografiar ${ }^{189}$; toda vez que se presenta un recorrido representativo a modo de transecta descriptiva (mapa 9).

1. Usos urbanos, en la gama propia de localidades pequeñas, de centros comerciales difusos, con participación intra-urbana de las vías de comunicación regional y densidades bajas - muy bajas, según los patrones medios nacionales ${ }^{190}$. Tendencia espacial: plena expansión física sobre el medio rural y ámbitos boscosos periféricos.

\section{Usos rurales:}

2. De granja-chacra familiar tradicional ${ }^{191}$, sostenida en el autoconsumo e instancias de intercambio periódicos de acuerdo con la estacionalidad productiva. Tendencia espacial: en retroceso, casi exclusivo de personas mayores en que sus hijos (si los hubo), han optado por una residencia y/o actividad urbana.

3. De granja-chacra moderna familiar-exclusiva, de funcionalidad independiente de otras actividades, con excedentes productivos que en ciertos casos alcanzan dimensiones empresariales (fruta fina, lúpulo, agro-turismo). Tendencia espacial: en expansión apenas moderada.

4. De chacra moderna familiar-mixta (neorrural), de funcionalidad interdependiente con ingresos extra-chacra, sean en relación de renta o de miembros involucrados en empleos externos; en general de surgimiento relacionado con el autoconsumo (González, 2004, C. Cobelo y Echagüe, D. 2007) $)^{192}$. Tendencia espacial: en importante expansión.

5. De estancia ganadera tradicional; de acuerdo con el tamaño y capacidad productiva, desde la empresa familiar (individuales o asociadas) a sociedades anónimas; mayormente bovina en ámbitos ecotonales sub-húmedos y ovina en los esteparios (pastizal-arbustivo). De proyecciones crecientes en materia forestal y turística.

\footnotetext{
${ }^{188}$ Destáquese el fin agropecuario de la fuente de los datos. Otra sería la valoración en términos de la lógica contemplativa del espacio.

${ }^{189}$ Entendemos que su identificación cartográfica sería de una gran ayuda a la gestión territorial, para ello, y mientras persistan las condiciones dinámicas actuales, es menester contar con la voluntad institucional de sostener un relevamiento y monitoreo continuo de base SIG. El sólo relevamiento, como es nuestro caso de Lago Puelo, tan sólo responde a instancias coyunturales.

190 Por ejemplo, en El Bolsón, aún en los barrios de viviendas planificadas más populosos, los valores no llegan en ningún caso a los 100 h/ha. y el barrio Centro con 1570 habitantes sólo alcanza los 15 h/ha. (2001. Dirección G.de Estadística y Censos, Río Negro). Ver útiles analogías respecto del control de densidades en Randle (1985: 201-3).

${ }^{191}$ Como señalamos en el ítem Ganadería, en el caso andino patagónico es viable asimilar ambas figuras (granjachacra) en su condición tradicional.

192 Los modelos paradigmáticos del agricultor autosuficiente o figuras idealizadas similares, aún cuando sean superados por la realidad sociocultural concreta, llevan consigo instancias de vanguardia nada despreciables. La propia existencia de una Feria Artesanal que con más de 300 puestos de venta, figura entre las más importantes del país, así como poseer viveros forestales de neta orientación hacia las especies autóctonas o haber sido sede de una tecnicatura universitaria (la primer en el país) en agricultura orgánica intensiva (Facultad de Agronomía, UBA y Fundación Cooperar, El Bolsón, 2001-2005), pueden servir de muestra de una dirección reconocida. Con todo, apenas algo más del $10 \%$ de los productores podría enmarcarse con un perfil de autoconsumo, mientras que la generalidad se sostendría en función de ingresos complementarios extra prediales (ver Chubut, PROSAP, 2001: Conclusiones).
} 
Asentamiento central y puestos permanentes y/o semi-permanentes dispersos. En las mayores, con condición predominante de propietarios regionalmente 'ausentistas'.

6. De aserraderos y/o otros usos industriales. Localizaciones puntuales y dispersas. Tendencia espacial: en relativa expansión, condicionada por su trascendencia ambiental.

7. De las plantaciones (forestales), sin, o casi sin asentamientos estables (puestos). De cobertura continua en extensos polígonos en terrazas y faldeos. Tendencia espacial: regresiva en ámbitos húmedos y expansiva en la estepa graminosa-arbustiva (hasta isoyeta de $400 \mathrm{~mm}$.).

8. De minería, sobresale la turbera del El Hoyo (sitio de los ex-pastos Comunes); el resto responde a la extracción de áridos. Tendencia espacial: progresivos avances prospectivos, con fuertes condicionamiento social.

9. De residencia rural funcional, atendiendo modalidades de servicios (educación, salud, seguridad, comercio, etc.) y desvinculado de las actividades productivas primarias. Tendencia espacial: en sostenida expansión, aunque sólo en los corredores viales.

10. De residencia rural no funcional, exclusivamente residencial (temporal o permanente). Tendencia espacial: en expansión.

11. De turismo agreste, básicamente estacional (campings, refugios y senderos). Tendencia espacial: en sostenida expansión.

12. De turismo residencial, de infraestructura estable (hotelería, cabañas y paradoresrestaurantes). Tendencia espacial: en sostenida expansión.

13. De baldío rural; asociado, en general a la pérdida de interés por la actividad tradicional vinculado a instancias de fragmentaciones familiares y demás; incentiva la especulación inmobiliaria. Tendencia espacial: en sostenida expansión.

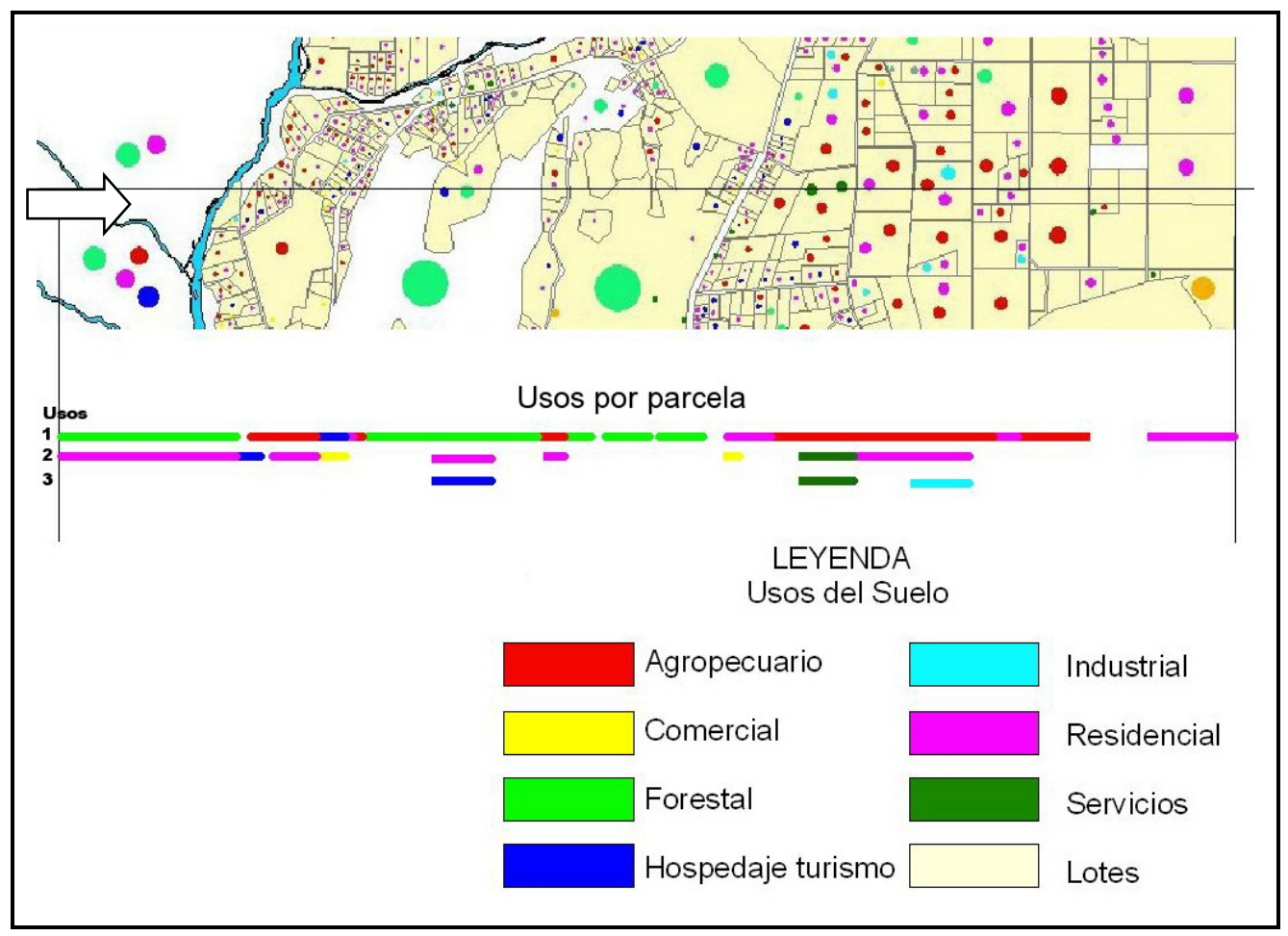

Mapa 9. Usos del suelo, transecta transversal en 'zona rural' de Lago Puelo. Heterogeneidad y sectorizaciones progresivas.

Fuente: elaboración propia en base a Mapa 7 (Martínez, O. et al. UATA, 2007). 


\section{II.2.5. Referencias bibliográficas.}

- Abalerón, Carlos Alberto. Tendencias de crecimiento poblacional y espacial en San Carlos de Bariloche con énfasis en el sector marginal. Informe Final; Consejo Federal de Inversiones. San Carlos de Bariloche. 1992. (61 p.)

- Abalerón, Carlos A.. Marginal urban space and unsatisfied basic needs: the case of San Carlos de Bariloche, Argentina, Environment and Urbanization, vol. 7 number 1, 1995. (pp. 97-116).

- Abalerón, Carlos A.. Los efectos de la caída del Plan de Convertibilidad sobre el turismo, la movilidad poblacional y las desigualdades en San Carlos de Bariloche, Argentina. IX Seminario Internacional de la Red de Investigadores en Globalización y Territorio. Universidad nacional del Sur, Bahía Blanca, 2006. Versión digital; 44 p..

- Albornoz, Ana, Adán Hajduk y Maximiliano Lezcano. 10.000 años de ocupación humana en el área del lago Nahuel Huapí. En revista Pueblos y Frontera de la Patagonia Andina. N `3. El Bolsón. 2002. (pp.4-11).

- Bandieri, Susana. (a) Historia de la Patagonia. Editorial Sudamericana. Buenos Aires 2005. (445 p.).

- Bandieri, Susana. (b) La cordillera de los Andes: de área de conflicto a espacio de interacción. En Revista Todo es Historia. , № 61. Buenos Aires. 2005.

- Barry, Roger $\left(2^{\circ}\right.$ ed. ) Mountain Weather \& Climate.. Ed. Routledge. London-New York. 1992. 402 p..

- Blanco, D., J. Méndes y G. Sánchez Reiche. Historia de una población de frontera entre Chile y Argentina: Segundo Corral 1930-1990. Informe inédito. El Bolsón, 1999.

- Bondel, C. Santiago y Abelardo de Almeida. "El Bolsón en la cuenca del lago Puelo. Descripción inicial de la relación hombre-medio ambiente". Anales XX, Sociedad Argentina de Estudios Geográficos. Buenos Aires, 1996. (pp.43-70).

- Bondel, C. Santiago y Abelardo de Almeida. El Bolsón en la cuenca del lago Puelo. Una introducción a la relación hombre-medio ambiente. Convenio INTA Bariloche- UNPSJB. Las Golondrinas. 1995. Mimeo.

- Bondel, C. S.; Novara, M.; Novella, M.M. y Raimondo, A. M.. Uso del espacio y transformaciones territoriales en la Patagonia Andina de Chubut y Río Negro. Proyecto de Investigación $\mathrm{N}^{\circ} 23$. Departamento de Geografía, Facultad de Ciencias Sociales, Sede Comodoro Rivadavia, Universidad Nacional de la Patagonia San Juan Bosco. 2006.

- Bondel, C. S.; Raimondo, A.M.; Novella, M.M; Novara, M. y Agustaci, C. Uso del espacio y transformaciones territoriales en la Patagonia Andina de Chubut y Río Negro, Proyecto de Investigación No 479. Departamento de Geografía, Facultad de Ciencias Sociales, Sede Comodoro Rivadavia, Universidad Nacional de la Patagonia San Juan Bosco. Informe final. 2002.

- Bran D., S. Rusak y J. Ayesa. Estructura de un matorral de ñire (nothofagus antarctica) y su regeneración inicial después de una tala, en el ecotono bosque - estepa. Instituto 
Nacional de Tecnología Agropecuaria (INTA), Centro Regional Patagonia Norte. Estación Experimental Agropecuaria Bariloche. San Carlos de Bariloche. 1998. 23p..

- Brazol, D.. Bosquejo bioclimático de la República Argentina. Meteoros, Año IV. Buenos Aires. 1954.

- Bruniard, Enrique. (1992). Climatología. Procesos y tipos climáticos. Ed. Ceyne, Buenos Aires.

- Burgos, J.. Clima del extremo austral de Sudamérica. En Boelcke, Burgos y Roig Transecta Botánica de la Patagonia Austral. CONICET, Buenos Aires. 1985.

- Capitanelli, Ricardo. Los ambientes naturales del territorio argentino. En, Juan Roccatagliata (coordinador) La Argentina. Geografía general y los marcos regionales. Ed. Planeta, Buenos Aires, 1988 (pp. 99-107).

- Capitanelli, Ricardo.: Patagonia: un medio duro, con focos pioneros y grandes posibilidades. En, Juan Roccatagliata (coordinador) La Argentina. Geografía general y los marcos regionales. Ed. Planeta, Buenos Aires, 1988 y ed. siguientes.

- Carabelli, F., S. Antequera, G. Martín y M. Gómez. Análisis ambiental y social de las cuencas hidrográficas cordilleranas de la provincia del Chubut. Serie técnica 5 . Centro de Investigación y Extensión Forestal Andino Patagónico - Agencia alemana de cooperación técnica. Dirección General de Bosques y Parques del Chubut. 2000 (60.p.).

- Casamiquela, Rodolfo. Los pueblos (etnias) indígenas del ámbito pampeano - patagónico. Fundación Peter Walas. Viedma. 2006. (100 p.).

- Catania, Oscar y Naco Sales. El Bolsón de Antes. Historia de Pioneros (de 1862 a 1916). El Bolsón. 2001. (292 p.).

- Cesari, Omar y J. M. Martínez. Carta Bosquejo Geomorfológico. Cátedra de Geomorfología. Facultad de Ciencias Naturales, UNPSJB. En: Bondel y de Almeida: El Bolsón en la Cuenca del Lago Puelo. Campo Forestal General San Martín (INTA). 1995. Mimeo.

- Chiozza, Elena y Cristina Carballo. Introducción a la Geografía. Bernal: Universidad Nacional de Quilmes Editorial. 2006. (160p.).

- Chubut, Programa de Servicios Agropecuarios Provinciales (PROSAP). Encuesta en Valles de Riego de la Comarca Andina: Lago Puelo, El Hoyo y Epuyén. Esquel, 2001.

- Civit, Estela y Matilde Velasco. Geografía Urbana de San Carlos de Bariloche. En Anales de la Sociedad Argentina de Estudios Geográficos. Tomo XIV. Buenos Aires. 1970.

- Claval, Paul. "La Geografía Cultural”. EUDEBA, Buenos Aires, 1999. (377p.).

- Clifton Goldney, Adalberto. Río Encuentro. Límite internacional de Argentina y Chile entre los Hitos 16 y 17 en el tramo comprendido entre la confluencia del río Encuentro con el Falso Engaño y el Cerro de la Virgen. Círculo Militar, Vol. 549. Buenos Aires. 1964. (334 p.).

- Cobelo, Claudia y Dolores Echagüe. Entre los planes y los empleos temporarios. Dificultades en el reclutamiento de trabajadores para la cosecha de berries en la Comarca Andina del Paralelo $42^{\circ}$ (resultados preliminares). Informe, AER El Bolsón, INTA- EEA Bariloche. 2007.

- Cobelo, Claudia. Informe sobre el relevamiento realizado en el $4^{\circ}$ trimestre de 2006. ANPRALE. INTA-EEA Bariloche-AER El Bolsón- Febrero de 2008. (Inédito; 16 p.). 
- CODECAP, "Proceso participativo para la formulación y gestión institucional y social de un proyecto de desarrollo sustentable, Consejo para el Desarrollo de la Comarca Andina del Paralelo 42", Informe final, documento del Consejo para el Desarrollo de la Comarca Andina del Paralelo 42 (CODECAP) y las Universidades Nacionales de La Plata, del Comahue y de la Patagonia S.J. Bosco, El Bolsón, diciembre de 1999.

- Conti, Hugo. Características climáticas de la Patagonia. Clima y Agua (CIRN), INTA Castelar, s/f..

- Cordon, Víctor H.; Juan Forquera. y Juliana Gastiazoro. Estudio microclimático del rea cordillerana del Sudoeste de la provincia de Río Negro. Cartas de precipitación. Universidad Nacional del Comahue, Facultad de Ciencias Agrarias. Cinco Saltos, 1993. Contiene mapas trimestrales de precipitaciones. Inédito.

- Correa, Maevia N.. Flora patagónica. Buenos Aires, INTA. 1969 (Colección Científica 8).

- Daus, Federico. El 'subdesarrollo' Latinoamericano. El Ateneo ( $2^{\circ}$ edición), Buenos Aires, 1976. (201 p.)

- Daus, Federico. La pendiente del Océano Pacifico. En Geografía de la República Argentina. Tomo VII, segunda parte, Hidrografía. Sociedad Argentina de Estudios Geográficos, GAEA. Buenos Aires. 1975, p g. 394-432).

- Daus, Federico A.. El Bolsón y el valle longitudinal. En Anales de la Sociedad Argentina de Estudios Geográficos. Tomo XIV. Buenos Aires. 1970. (pp. 37-54)

- De Fina, A. y J. Ravello. Climatología y Fenología agrícola. EUDEBA. Buenos Aires.1979.

- De Lasa, Luis. Historia ambiental. Sociedades humanas y transformaciones ambientales en la Patagonia (1500-1900). En Godoy Manríquez, Carlos (director) El Gran libro de la Patagonia Argentina. Ed. Planeta, Buenos Aires. (1998). (Cuarta Parte, pp. 595-676)

- Dentoni, María del Carmen y Silvia B. Cerne. La atmósfera y los incendios. Plan Nacional de Manejo del Fuego. Secretaría de Recursos Naturales y Desarrollo Sustentable. Gráfica San Lorenzo. Buenos Aires. 1999. (181p.).

- De Sartre, Xavier A.. Seminario de Posgrado. La Geografía Cultural y la Cuestión Ambiental. Hacia nuevas teorías para renovar el abordaje de un problema socio-científico. Universidad Nacional del Sur, Bahía Blanca. Octubre-Noviembre 2005.

- Dimitri, Milán J..La región de los bosques andino-patagónicos. Colección Científica del INTA, Tomo X. Buenos Aires, 1972. 381 p..

- Dimitri, Milán J.. Pequeña flora ilustrada de los Parques Nacionales Andino-Patagónicos. Publicación. № 46. Anales de Parque Nacionales, Tomo XIII. Servicio Nacional de Parques Nacionales. Buenos Aires, 1974.p.1-122.

- Dimitri, Milán. La región de los bosques andino-patagónico II. Flora dendrológica y cultivada. Colección Científica. INTA. Buenos Aires, 1982.

- Dimitriu, Andrés. Producir y consumir lugares: Reflexiones sobre la Patagonia como mercancía. Jornadas: Transformaciones Sociales y Reestructuración Capitalista del Siglo XX”. Universidad Nacional del Comahue. Revista de Economía Política de las Tecnologías de la Información y Comunicación. 2001. www.eptic.com.br, Vol. IV, n.3, Sep./Dic. 2002.

- Donoso Zegers., Claudio (a). Ecología Forestal. El bosque y su medio ambiente. Editorial Universitaria. Santiago de Chile, 1994 ( $1^{\circ}$ ed. 1981). 369 p.. 
- Donoso Zegers, Claudio (b). Bosques templados de Chile y Argentina. Variación, Estructura y Dinámica. Editorial Universitaria, Santiago de Chile. 1994. 484 p..

- Dumrauf, Clemente. Historia de Chubut. Ed. Plus Ultra. Buenos Aires, 1992. 535 p..

- Eriksen, Wolfgang. Kolonisation und Tourismus in Ostenpatagonien. Bonner geographische Abhandlungen. Ferd. Dummlers Verlag. Bonn, 1970. (289 p.).

- Eriksen, Wolfgang. Disruptions in the ecosystems of the steppe and forest regions of Patagonia by climate and man. Applied Science and Development 6: 127-142. 1975.

- Eriksen, Wolfgang. Aspectos de la colonización agraria en la Patagonia. GAEA, Sociedad Argentina de Estudios Geográficos, Buenos Aires. 1979. (21p.)

- Etchevehere, Pedro H..Los suelos de la región andino-patagónica", en Dimitri, M.J.. La región de los bosques andino-patagónicos. Buenos Aires, INTA, 1972. p.83-95.

- Ferruglio, Egidio. Los glaciares de la cordillera Argentina. En Geografía de la República Argentina. Tomo VII. Primera Parte. Sociedad Argentina de Estudios Geográficos, GAEA. Buenos Aires. 1957 (5-86).

- Finkelstein, Débora y María M. Novella. Poblamiento del Noroeste del Chubut. Aportes para su historia. Fundación Ameghino. Esquel, Chubut. 2005. (181 p.)

- Finkelstein, Débora, Gavirati, Marcelo y María M. Novella. Sociedad y economía del Noreste de Chubut (1880-1920). En Poblamiento del Noroeste del Chubut. Aportes para su historia. Fundación Ameghino. Esquel, Chubut. 2005. (pp. 11-32).

- Fiorentino, C., G. Peri y J. Pérez Pizarro. Programa de Servicios Agrícolas en la Comarca Andina y el Valle 16 de Octubre. Secretaría de Agricultura Ganadería, Pesca y Alimentación - Programa Nacional de Servicios Agrícolas Provinciales, Buenos Aires y Esquel, Informe, Diciembre 1998.

- Furlong, Guillermo. Nicolás Mascardi y su 'Carta-Relación' (1670). Ediciones Theoría. Buenos Aires, 1995. (137 p.).

- Gomis, Héctor. El problema hídrico de El Bolsón y su relación con el bosque. Río Negro, Dirección de Bosques. 1976, 14p..

- González, Myriam S..Una aproximación al paisaje vivencial de neorrurales y otros migrantes de una comarca cordillerana. El Caso de El Bolsón en la Patagonia Andina. Revista Geográfica, Instituto Panamericano de geografía e Historia. № 133. 2004.

- González, Myriam S. De neorrurales y otros migrantes. Paisaje vivencial y prácticas cotidianas de los habitantes de El Bolsón y su comarca. En revista Pueblos y Frontera de la Patagonia Andina. №7. El Bolsón. 2007. (pp.48-56)

- Grondona, Mario F.. Fitogeografía del Parque Nacional Nahuel Huapí. En Anales de la Sociedad Argentina de Estudios Geográficos. Tomo XIV. Buenos Aires. 1970. (pp. 71-88).

- Haggett, Peter. Geografía. Una síntesis moderna. Ediciones Omega. Barcelona. 1988. (668 p.)

- Hennessy, Alistair. The Frontier in Latin America. Edward Arnold (Publishers). London. 1978. (202 p.)

- Hoffmann, José y Núñez. Mapa bioclimático de la República Argentina. Servicio Meteorológico Nacional. Buenos Aires. 1981. 
- Instituto Internacional del Medio Ambiente y Desarrollo IIED-América Latina; Instituto Valle Nuevo. El Bolsón. Oportunidades para un desarrollo sustentable a nivel local. El Bolsón y municipios de la Cuenca del Río Puelo. Provincia de Río Negro, Argentina. Octubre, 1994 (58 p.)

- Instituto de Ordenación de Vertientes e Ingeniería Forestal (IOVIF). Ordenación de Cuencas de los ríos Quemquemtreu, Azul y Epuyén. Universidad Nacional de la Plata. 1971. Mimeo.

- Kaufmann, Bertha. La instalación humana en el Parque Nacional Nahuel Huapi. En Anales de la Sociedad Argentina de Estudios Geográficos. Tomo XIV. Buenos Aires. 1970. (pp. 97-119).

- Labasse, Jean. La organización del espacio. Ed. Ariel, Barcelona, 1973. (739p.).

- Lanciotti, María Luisa y María Victoria Cremona. Los suelos del área de influencia de la Agencia de Extensión rural de El Bolsón. INTA, EEA Bariloche (Prodesar). (27р.)

- Laría, Salvador C.. Introducción histórica al estudio de la geografía de la región del Nahuel Huapí. En Anales de la Sociedad Argentina de Estudios Geográficos. Tomo XIV. Buenos Aires. 1970. (pp. 89-96).

- Lemoine, Graciela y Leticia Sarabia. Instrumento para el Desarrollo Sustentable del Territorio Nacional. Revista Aportes. Microrregiones:, Asociación de administradores Gubernamentales. Buenos Aires. 2001

- Liberali, Ana M.. De la Geografía de los Límites a la Geografía de la Integración. Boletín del Centro Humboldt N 2. Buenos Aires. 1998.

- López Trigal, Lorenzo y François Guichard (Coord.). La frontera hispano-portuguesa: Nuevo espacio de atracción y cooperación. Fundación Rei Afonso Henriques. Salamanca. España. 2000. (313 p.).

- Luiz, María Teresa. Relaciones fronterizas en Patagonia. La convivencia hispano-indígena a fines del período colonial. Asociación Hanis y Universidad Nacional de la Patagonia San Juan Bosco. Ushuaia. (440 p.). 2006.

- Marchissio, Guido. La generación de empleo informal en el turismo a través de la producción y comercialización de productos regionales. Caracterización, problemáticas y posibles soluciones. Caso: Feria Regional El Bolsón. Tesina de Grado, Licenciatura en Turismo. Universidad Nacional del Comahue. Neuquén (2007). Inédita.

- Martínez, Adriana N.. Regionalidad y espacio político en Argentina: Base federalista para su construcción. Las relaciones intermunicipales como herramienta para la descentralización y el desarrollo local. Consejo Federal de Inversiones (CFI), 2006. www.cfired.org.ar/esp2/eventos/Region_C/pdfs/2-Adriana\%20Martinez.pdf

- Martínez, Marcelino. La Patagonia Central. Descripción física y política. Lajouane Editores. Buenos Aires. 1913.

- Martinic Beros, Mateo. En Transecta Botánica de la Patagonia Austral de Boelcke, Burgos y Roig. Cap. 6: La ocupación y el impacto del hombre sobre el territorio. CONICET. Buenos Aires, 1985.

- Melzner, Guillermo (2003).Diagnóstico productivo, sector fruta fina. Comarca Andina del Paralelo $42^{\circ}$. Fundación para el desarrollo Humano Sustentable de la Patagonia, Municipalidad de El Hoyo, Cooperativa del Paralelo 42. Informe final. 
- Mendes, José María y Blanco, Daniel. El Bolsón, sociedad y economía en las primeras décadas del Siglo XX. En revista Pueblos y Frontera de la Patagonia Andina. N5. El Bolsón. 2004. (pp.4-9)

- Mendía, Juan M., Irisarri, Jorge A.. Relevamiento de suelos con aptitud forestal en la región occidental de la provincia de Río Negro. Consejo Federal de Inversiones (CFI). Buenos Aires. 1986.

- Miatello, Roberto A.. Algunos aspectos de la población del Parque Nacional Nahuel Huapí. En Anales de la Sociedad Argentina de Estudios Geográficos. Tomo XIV. Buenos Aires. 1970. (pp. 121-231).

- Monasterio, Hugo J.. Medición de la economía formal de San Carlos de Bariloche, año 2006. Universidad F.A.S.T.A.. Sede San Carlos de Bariloche.

- Muscillo, Marcelo. Disímil comportamiento de la actividad de la construcción. Patagonia Economía. Suplemento de Economía Regional y Negocios de los Diarios Piltriquitrón (El Bolsón) y El Cordillerano (San Carlos de Bariloche). Año 1, № 9. Noviembre de 1999.

- Musters, George Ch.. Vida entre Ios Patagones. Ed. Solar-Hachete. Buenos Aires. 1964 (1 Ed. 1871). (437 p.)

- Navarro Floria, Pedro \& Gabriela Nacach. Un viaje al interior del sorprendente mundo fronterizo del área Nahuel Huapí. Estudio Preliminar de la Re-edición de: Cox, Guillermo E. 1863. Viaje en las regiones septentrionales de la Patagonia: 1862-1863. Santiago de Chile: CoLibris, 2006. (versión digital)

- Novella, María Marta y FinkesItein, Débora. La cordillera Sur: ¿Límite o espacio social?. En Revista Todo es Historia, № 461. Buenos Aires. 2005.

- Novella, María Marta. Análisis geohistórico del uso del espacio y las transformaciones territoriales en la Comarca Andina del paralelo 42 (1880-1920). En Informe final. Proyecto de Investigación Uso del espacio y transformaciones territoriales en la Patagonia Andina de Chubut y Río Negro. Departamento de Geografía, Facultad de Ciencias Sociales, Sede Comodoro Rivadavia, Universidad Nacional de la Patagonia San Juan Bosco. 2006.

- Ojeda Rivera, J. F.. El paisaje como patrimonio- factor de desarrollo de las áreas de montaña. Universidad Pablo de Olavide, Sevilla. Boletín de la AEG, 2004, nº 38.

- Ongaro, PROSAP-Chubut. Estudio de suelos de las áreas El Hoyo de Epuyén y Las Golondrinas en la provincia de Chubut. Informe Final. 1999.

- Pech, Pierre y Hervé Regnauld. Geografía Física. Fundación Hernandarias. Editorial Docencia. Buenos Aires. 1997. (403 p.).

- Pisano, Edmundo. Bosquejo fitogeográfico de Fuego-Patagonia. En Anales del Instituto de la Patagonia Vol. XII. . Punta Arenas-Santiago de Chile. 1981. (159-171).

- Prescott, J. R. V.. Boundaries and Frontiers. Croom Helm, London. 1978.

- Randle, Patricio. Atlas del desarrollo territorial de la República Argentina. Ed. Oikos, Buenos Aires. Tres tomos. 1981.

- Randle, Patricio. El Pensamiento urbanístico en los Siglos XIX y XX. OIKOS, Buenos Aires. 1985. 
- Rappoport, Eduardo. La primera guerra mundial de las especies. Entrevista Rev. Ciencia Hoy. Vol $1 \mathrm{~N}^{\circ} 6,1990$.

- Rey Balmaceda, Raúl. Geografía histórica de la Patagonia (1870.1960). Ediciones Cervantes. Buenos Aires 1976. (332p.)

- Rey Balmaceda, Raúl. La modificación del paisaje y su apreciación científica. En Transecta Botánica de la Patagonia Austral de Boelcke, Burgos y Roig (Coordinadores). CONICET. Buenos Aires, 1985. (pp. 95-104).

- Río Negro - Consejo Federal de Inversiones (CFI). Fortalecimiento Institucional y Promoción - Plan Estratégico Río Negro 2015. Informe Final. Viedma, 2007. (366p.).

- Río Negro. Censo Nacional Agropecuario. Dirección General de Estadística y Censos de Río Negro. Viedma, 2002.

- Roccatagliata, Juan. Regionalización. En Juan Roccatagliata (coordinador), La Argentina. Geografía general y los marcos regionales. Ed. Planeta, Buenos Aires, 1988 y ed. siguientes. (pp. 423-442).

- Roselli, Olga. La proclamación de El Bolsón como República Independiente. Revista Pueblos y Fronteras de la Patagonia Andina. Revista de Ciencias Sociales. Año 1, № 1. Comarca Andina del Paralelo 42. Octubre, 2000.

- Sarobe, José María. La Patagonia y sus problemas. Estudio geográfico, económico, político y social de los territorios nacionales del sur. Buenos Aires, A, López, 1935 (445p.).

- Seibert, P.. Carta de vegetación en El Bolsón y alrededores. F.E.C.I.C. (CONICET). Buenos Aires. 1981.

- Schlüter, Regina et al. Chubut, Turismo, Hábitat y Cultura. Facultad de Ciencias Económica, UNPSJB, Trelew, 1996.

- Urzúa Vergara, J. D.. Uso múltiple de los recursos naturales de la cuenca binacional del Puelo. CIEFAP, Publicación N 5. Esquel, 1992.

- Vapnarsky, César. Pueblos del Norte de la Patagonia 1779-1957. Editorial de la Patagonia. General Roca. 1982. (350 p.).

- Veblen, Thomas T. y Diane C. Lorenz. Recent vegetation changes along the forest/steppe ecotone of northern Patagonia. Annals of the Association of American Geographers, 78 (1), 1988.

- Vidoz, Félix. Parque Nacional Lago Puelo. Lago Puelo. 1998. (29 p.)

- Villalba, Ricardo. Influencia de las Variaciones Climáticas en el Decaimiento de los Bosques del Norte de la Patagonia. Documento inédito del Proyecto: Influencia de los cambios climáticos en el decaimiento y mortalidad de los bosques de Nothofagus en el norte de la Patagonia, Argentina. IANIGLIA-CONICET. 2003.

- Willis, Bailley. El Norte de la Patagonia. Naturaleza y riquezas Tomo I. Ministerio de Obras Públicas (Arg.). Buenos Aires., 1914. Reedición EUDEBA, 1988. (500р.).

- Zingoni, J. M., S. M. Martínez, y E. Quartucci. Causas y efectos de la valorización del suelo urbano en destinos turísticos de la cordillera andino patagónica; el caso de la localidad de San Martín de los Andes. Informe inédito. Bahía Blanca, 2006. 


\section{TERCERA PARTE}

\section{EL ENFOQUE GEO-CULTURAL. HACIA INSTANCIAS PROSPECTIVAS.}

Los capítulos de la Segunda Parte estuvieron dedicados a la presentación de la Comarca como área de estudio desde ópticas propias del análisis geográfico, diríase disciplinares, donde además de cierta información de base, se buscó rescatar el peso dado a lo condicionante en la instalación y organización territorial. Condicionante visto desde el amplio espectro proyectado en el territorio y que, como vimos y según los casos se acercan, ya sea a los estímulos, a la inducción o, por el contrario, a condiciones restrictivas para una u otra cuestión (ver cuadro 1 y apéndice 8). Cabe también recordar que se trata de un área comprendida en un conjunto regional aglutinante, el patagónico y, a la vez, formando parte de otro genérico, el andino patagónico ${ }^{193}$. Entendemos que en lo que se refiere a morfología y funcionalidad y visto desde su devenir temporal, la Comarca está presentada como un espacio social de condición unitaria y con complejidad territorial adecuada o suficiente. El hecho que una hipotética sumatoria: espacio + pertenencia comunitaria + ocupación (actividad) + trascendencia generacional, se desenvuelven con una razonable identidad, ratificaría la condición de unicidad territorial.

Será esta Tercera Parte, focalizada hacia lo prospectivo, donde se retorna a los planteos hipotéticos iniciales, atendiendo en especial a los aspectos considerados más críticos. Es aquí donde creemos que se sostiene una caracterización territorial inédita y que a la vez esperamos sirva de proyección para a la vez proyectarse transversalmente en los estudios locales.

Pues bien, para mantener el rumbo analítico de las transformaciones territoriales dentro de carriles básicamente geo-culturales, se reiteran sintéticamente y como orientadoras, las principales situaciones conflictivas de carácter geográfico detectadas y planteadas sobre el final del cuerpo metodológico:

1.- Excentricidad geográfica.

2.- Superposición funcional y jurisdiccional.

3.- Incumplimiento y/o incertidumbre en los comportamientos políticos, sociales y económicos hacia amplios sectores de trascendencia territorial.

4.- Expansión urbana espontánea, de muy baja densidad, 'confusa' y muchas veces antisocial.

5.- Parcelamiento y tenencias de la tierra condicionadas por procesos de inversión y especulación inmobiliaria (orgánica y voluntaria)

6.- Perfil cultural-socioeconómico heterogéneo de proyección territorial conflictiva.

7.- Crecimiento geo-demográfico y confinamiento físico.

\section{III.1. Percepciones y comportamientos espaciales.}

\footnotetext{
${ }^{193}$ Se profundiza en el tema en los apéndices 3 y 4.
} 
La sensación claustrofóbica argentina y la urgencia por salir, a menudo busca su solución en el Sur. Irse al Sur equivale a estar en otra parte, en otro país. El Sur alienta todavía los sueños de arraigo, la esperanza de encontrar el lugar. (Scheines, 1993, en Durán (1996:19).

La cita que toma Durán contiene aditamentos oportunos a la hora de enfrentarnos con una realidad en análisis, cargada de connotaciones anímico-afectivas (sensación, sueños, esperanzas) y vinculados a cabales entidades geográficas (irse al Sur, país, arraigo, lugar). Surgen de inmediato analogías para enfrentarse analíticamente ante la realidad contemporánea comarcal afirmados en la geografía cultural como camino interpretativo. Se presenta así, un recorrido aconsejable a la hora de resolver las tradicionales dificultades de acotar, de 'acordonarse' temáticamente en nuestro campo científico; es decir a esa característica tan propia del análisis geográfico, donde el interés crece proporcionalmente a la progresiva posibilidad de ver a sus objetos como unidades complejas cargadas de trascendencia en su unidad y no en su fragmentación.

Cuadros, punteos, fotografías, y una presentación visión matricial del conjunto, se suman entonces para generar con ello y a partir de los paisajes devenidos del medio bio-físico, del devenir histórico y de la expresión espacial de las actividades, un marco explicativo de las condiciones de transformación territorial ${ }^{194}$.

De acuerdo con el planteo teórico original, se trabajó sobre tres conceptos que aquí interactúan en una suerte de continuas idas y vueltas: paisaje-percepcionescomportamientos; entrelazados en cualquier sentido, con los comportamientos concluyendo en un 'resultado' paisaje, las percepciones implicando comportamientos, los paisajes sosteniendo comportamientos y así puede continuarse. De modo que el orden adecuado a la seguidilla estará en los móviles, en las motivaciones. Para el caso que nos ocupa, el de una comarca montana, el paisaje (jsus paisajes!), se muestra como el 'atractor', como el primer móvil para las consiguientes transformaciones y por ello como disparador del análisis ${ }^{195}$.

Las explicaciones a lo que sucede con el territorio en su condición integral se han buscado esencialmente en los resultados más trascendentes de la relación entre los actores (a modo de tipos sociales), en y con el espacio. Son actores involucrados (condicionados, contenidos y usufructuarios) y como tales, agentes directos y de vigor diferente, para cambios y permanencias ${ }^{196}$.

\footnotetext{
194 Cabría la similitud que indica Bailly cuando plantea el accionar del geógrafo sobre cuatro grandes preguntas: la naturaleza de nuestro sistema físico-socio-económico; su coherencia espacial (parcial y total); su inserción en el tiempo y el sentido de las prácticas y vivencias de los hombres. (1998:27)

195 Valdría este orden, paisaje-percepciones-comportamientos-paisajes, basándose en especial en la 'juventud' de los procesos históricos transformadores del espacio.

196 Involucrados problemáticamente, incluso identificando a aquellos que no sientan el compromiso pero la naturaleza de los problemas los abarca; es decir, más allá de los que resultan vitales para intervenir en las instancias participativas de desarrollo local. Tema ilustrado con precisión por Roberto Domeq en la Conferencia. Economía, sociedad y medio ambiente. Fundación Cooperar, El Bolsón, 2006.
} 
Aquella condición de inestabilidad de faldeos o las sucesivas inundaciones así como condiciones micro-topográficas o micro-climáticas, tendrán en la visión paisajística la orientación necesaria a la hora de explicar o intervenir. El aislamiento, las densidades o distribuciones y funcionalidad de tal o cual actividad, necesitará en sus planteos problemáticos espaciales de su paisaje como recurso integrador. Serán estos paisajes los que estarán cargados de connotaciones perceptivas y comportamentales y por ello su planteamiento se hace necesario y, creemos, enriquecedor del análisis.

Es con este contexto complejo en que se entendió que acudiendo a la sistematización de los impactos territoriales por tipo de poblador, pueden verse atravesadas casi todas, sino todas, las problemáticas territoriales más destacadas ${ }^{197}$.

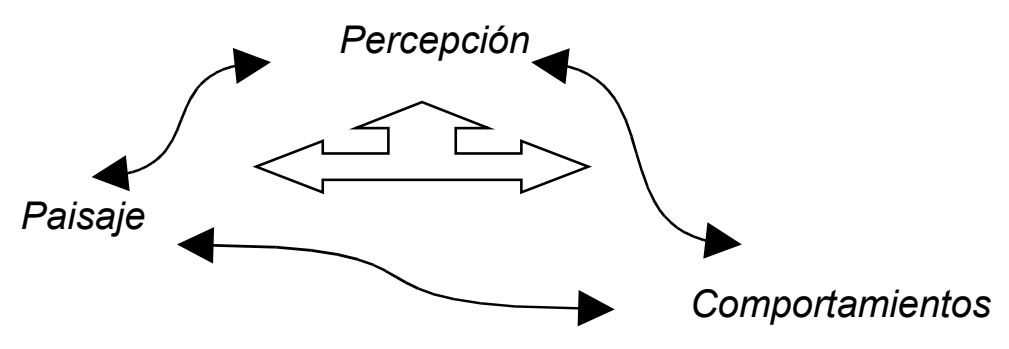

Fig. 16. Trilogía: Percepción-Paisaje-Comportamientos. En el esquema las relaciones interdependientes tripartitas sobresalen por su magnitud, si bien deben ponderarse aquellas bipartitas.

El cuadro que sigue, vinculado al capítulo antecedente en materia geohistórica, dispone a modo de síntesis un marco condicional para la comprensión de la complejidad perceptiva respecto de la geografía comarcal. En el apéndice 8 se encontrarán aportes complementarios.

197 Impactos más acuciantes en términos de gestión, como puede constarse en innumerables artículos periodísticos y análisis regionales. 
Cuadro 2. Antecedentes perceptivos y trascendencia básica territorial. Fuente: elaboración propia en base a Bondel et al 2002 y 2006.

\begin{tabular}{|c|c|}
\hline Percepción asociada con: & $\sqrt{l}$ \\
\hline $\begin{array}{l}\text { - Marginación indígena, despojo y } \\
\text { agresión. } \rightarrow\end{array}$ & $\begin{array}{l}\text { - marginal, asociados a un uso socialmente defensivo y } \\
\text { ambientalmente agresivo; importante movilidad al respecto en } \\
\text { los últimos años }{ }^{198} \text {. }\end{array}$ \\
\hline - $\quad$ Euforia, desafío y aventura. $\rightarrow$ & $\begin{array}{l}\text { - de características puntuales y muchas veces efímeras; } \\
\text { difíciles de identificar hasta no concretarse en un hecho; } \\
\text { inicialmente propios de los ámbitos pioneros }{ }^{199} \text {. }\end{array}$ \\
\hline $\begin{array}{l}\text { - Exploración, descubrimiento y } \\
\text { colonización. } \rightarrow\end{array}$ & $\begin{array}{l}\text { - de importante trascendencia; más sistemático que el anterior } \\
\text { y por ello más susceptible a la verificación comunitaria y su } \\
\text { accionar; hoy es una tendencia reavivada parcialmente y con } \\
\text { trascendencia aún incierta }{ }^{200} \text {. }\end{array}$ \\
\hline $\begin{array}{l}\text { - Pre-percepción confusa. Entre la } \\
\text { 'sobre e infra valoración' económica } \\
\text { y afectiva; 'malos entendidos'201. } \rightarrow\end{array}$ & $\begin{array}{l}\text { - ejecución de iniciativas sostenidas en el desconocimiento } \\
\text { previo, suelen ser las de mayor dificultad de reversión por } \\
\text { involucrar proyectos menores y más desprotegidos. }\end{array}$ \\
\hline $\begin{array}{l}\text { - Asociación por afinidad cultural } \\
\text { del migrante 'colono'202. } \rightarrow\end{array}$ & $\begin{array}{l}\text { - concreta y eficiente, lleva implícita la experiencia y con ello } \\
\text { una actitud más realista y mutual; se trata de quienes repiten } \\
\text { modalidades de uso adquiridas previamente. }\end{array}$ \\
\hline $\begin{array}{l}\text { - Individualismo innovador del } \\
\text { migrante 'moderno'. } \rightarrow\end{array}$ & $\begin{array}{l}\text { - creativo y ágil, por estar menos condicionado; a la vez } \\
\text { riesgoso en términos de sustentabilidad, por las dificultades } \\
\text { que suponen las instancias innovadoras en un marco de } \\
\text { aislamiento social }{ }^{203} \text {. }\end{array}$ \\
\hline $\begin{array}{l}\text { - Nostalgia afectiva; desarraigo- } \\
\text { desapego; desánimo (Bondel } 1992 \text { y } \\
\text { Eriksen, 1979). } \rightarrow\end{array}$ & $\begin{array}{l}\text { - de importante trascendencia por abandono de iniciativas o } \\
\text { desinterés por el desarrollo local. }\end{array}$ \\
\hline
\end{tabular}

\footnotetext{
${ }^{198}$ Baste ver que en los periódicos de mayor tirada de la región, las temáticas relacionadas con las condiciones críticas al respecto (migración expulsiva, sobrepastoreo minifundiario, sobreventa de derechos de ocupación, etc.), tienen una regularidad diaria (archivo personal de información regional contemporánea). Una señal novedosa se observa en algunos grupos andinos de raigambre mapuche afincados en la periferia de la ciudad de Neuquén y que estarían retornando a sus pagos rurales (Aluminé-Moquehue) desalentados con el contexto urbano y promoviendo un aggiornamiento tecnológico-cultural de resultados alentadores (Comunicación personal de Nicolás De Agostini y Christine Danklmaier, ambos profesionales de amplia participación en el medio neuquino).

${ }^{199}$ Anuncios políticos, consignas ciudadanas y hasta nombres de emprendimientos, entre muchas demostraciones, revelan esta tendencia de comportamiento; zona "no nuclear"; valles vírgenes e impolutos, travesías únicas, etc., son anuncios que, por ejemplo, sobresalen en las páginas web de la Comarca, en particular en las del rubro inmobiliario que justamente buscan captar esos sentires (entrevista agente inmobiliario local; 2004).

200 Grupos más o menos organizados de pobladores (jurídicamente orgánicos y ocupantes de hecho), grandes compradores, y hasta refugieros de alta montaña, ofrecen vectores expansivos de la más diversa índole, aunque difíciles de registrar a la hora de precisiones. Resulta sugerente el informe de Cobelo (2008) sobre el perfil de encuestados en el Área Protegida Río Azul-Lago Escondido (ANPRALE).

201 Ver por ejemplo en Abalerón (2007).

Esta condición informativa-perceptiva, ha sido una característica mantenida históricamente. Entre los malos entendidos geográficos más recurrentes y desde varias fuentes verificables en las guías turísticas locales, se tienen a:

- el origen ancestral homogéneo ('pueblos originarios'),

- la fertilidad extraordinaria de los suelos,

- la benignidad climática 'incondicional' (microclima sustantivo),

- las analogías directas con ámbitos naturales del Hemisferio Norte y su adecuación necesaria a las tipologías alpino-europeas. (Pozzo B., 2004).

${ }^{202}$ Nos referimos a la típica asociación por origen.

${ }^{203}$ Los intentos innovadores, más o menos exitosos (en general, menos), han ido de la mano con el arribo migratorio contemporáneo (ver en Myriam González, 2004).
} 


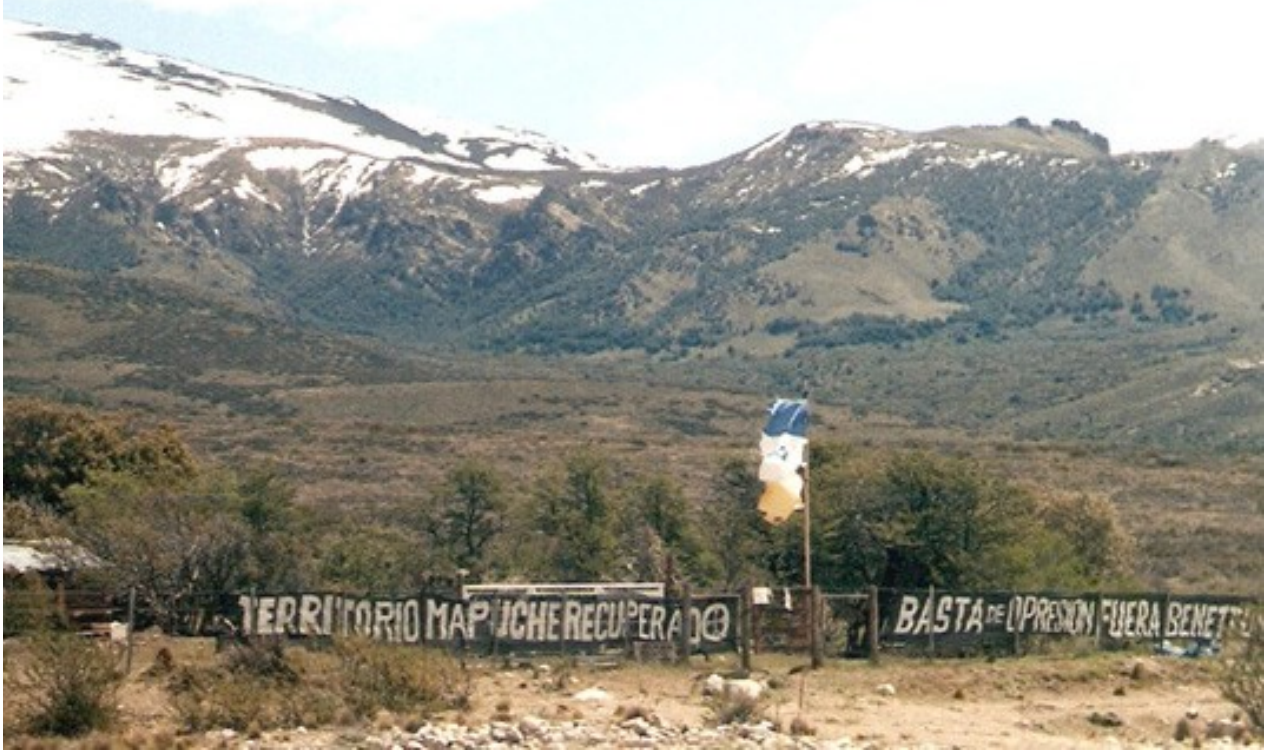

34

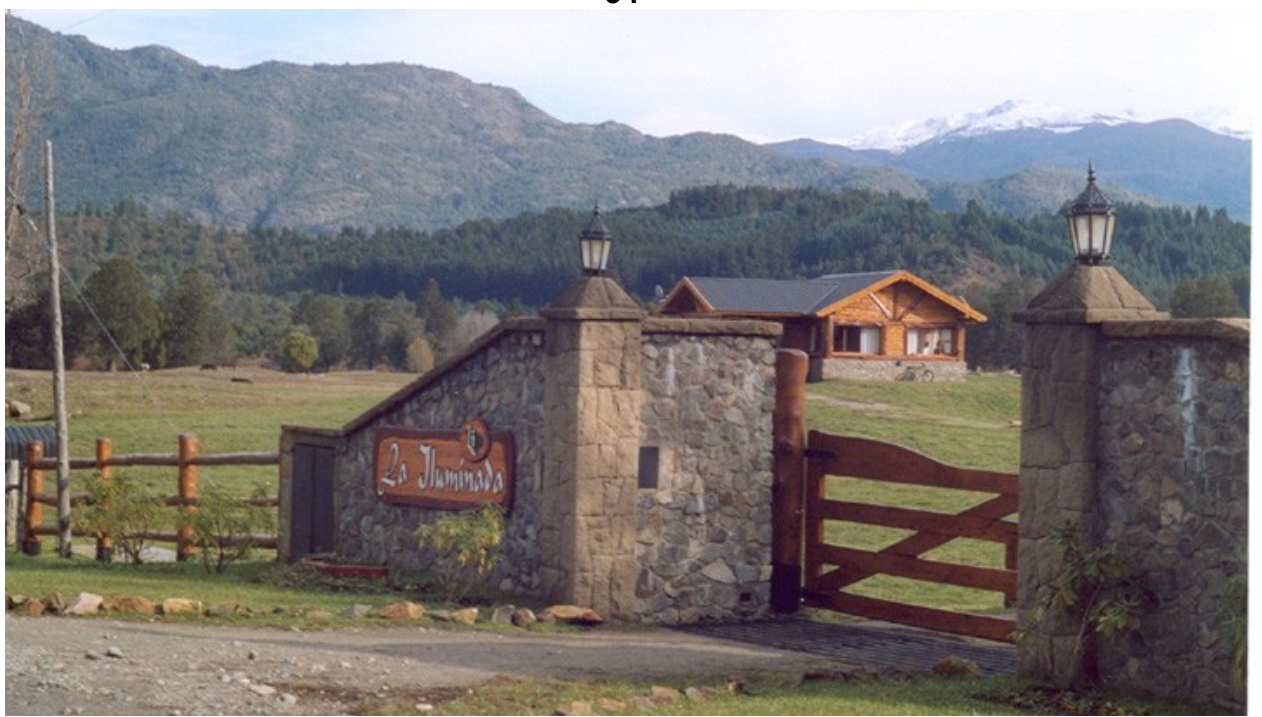

35

Fotos 34 y 35.

34: Reivindicaciones de los pobladores de origen mapuche. Campo ocupado y reclamado a la corporación Benetton sobre el cordón Leleque. 35: Reutilización espacial. Chacras tradicionales devenidas en ámbitos neorrurales. Valle del río Epuyén adyacente a la localidad de El Hoyo. Fotos del autor, 2007.

Con este background, los actuales tiempos posicionan a la Comarca entre los lugares altamente valorados; ya fuese para visitarlo o como destino de vida; son paisajes anhelados, codiciados, hacia donde se canalizan intenciones de trascendencia distinta para el lugar en sí. Los discursos (internos y externos) se caracterizan por cierta avidez ansiosa por aquello extraordinario, excéntrico, maravilloso, mágico y sorprendente y que, en especial, se hace plausible en las estrategias del marketing 
turístico y en las demandas mediáticas, muchas veces, en ambos casos, más cercanos a lo fabulesco que a la realidad compleja y dinámica ${ }^{204}$.

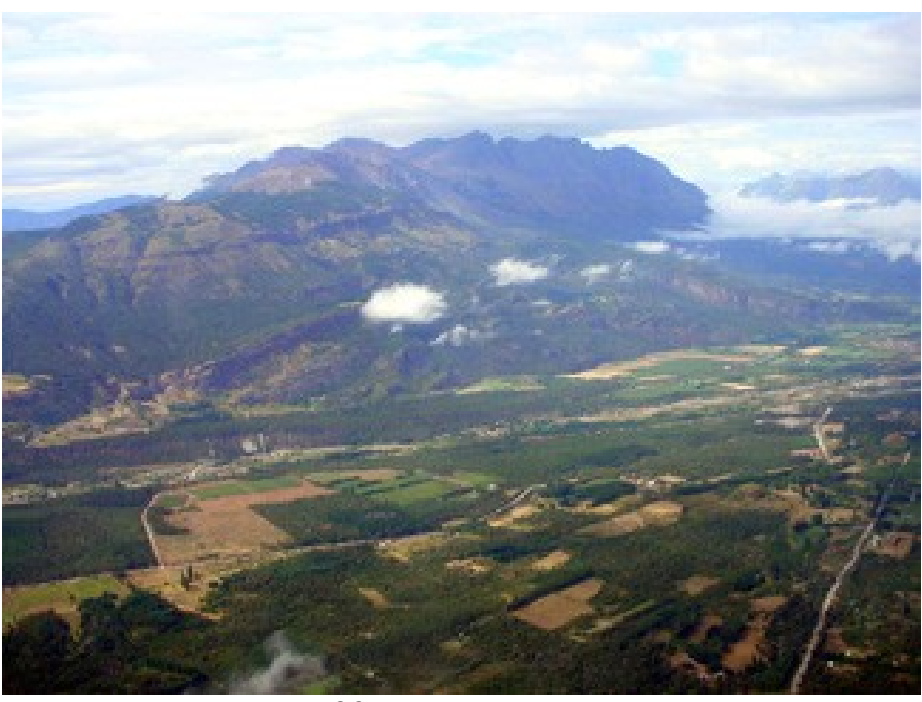

36

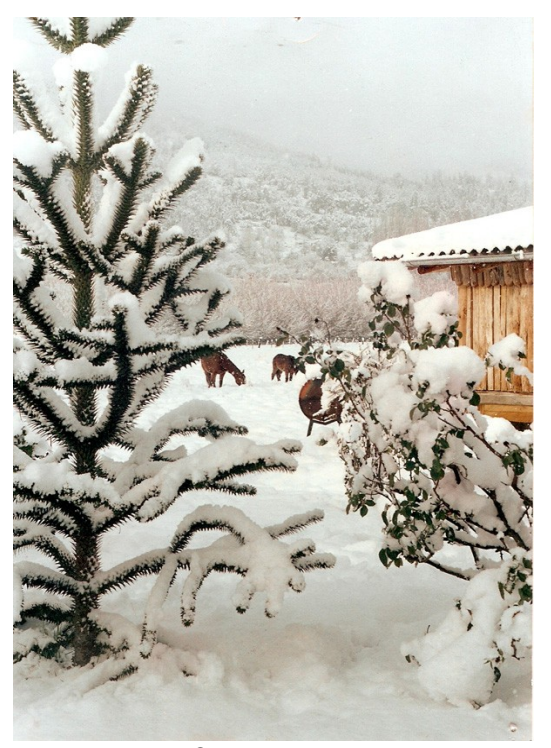

37

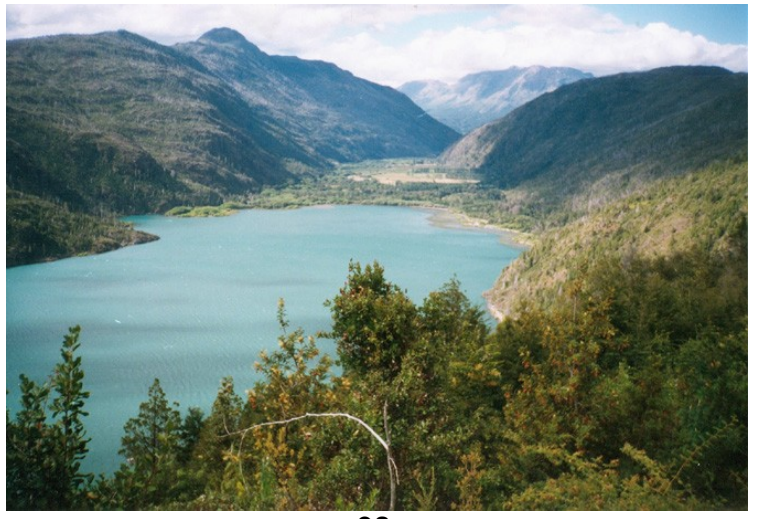

38

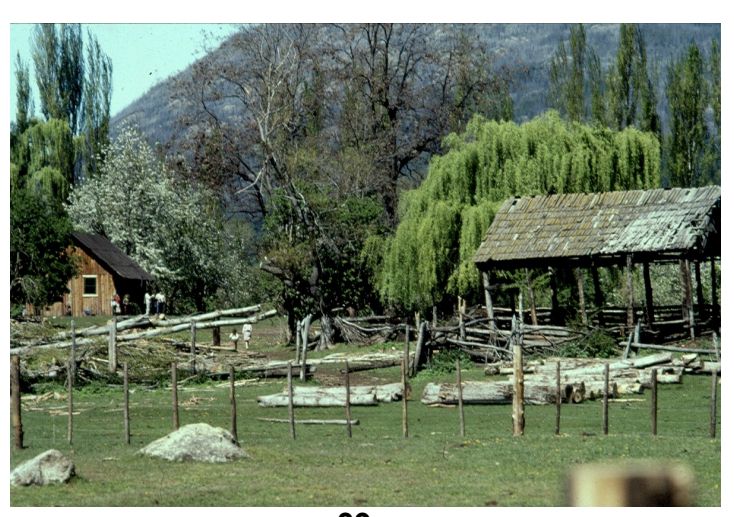

39

Fotos 36, 37, 38 y 39:. Las cuatro imágenes ofrecen una variedad importante de connotaciones más o menos inmediatas y de las que difícilmente se pueda evitar una percepción valorativa. Puede afirmarse que la 'lectura' del paisaje andino patagónico impulsa una valorización con abundantes representaciones y subjetividades provenientes del imaginario colectivo (la vida simple, natural y apacible en el bosque) ${ }^{205}$.

36: Zona Norte de El Bolsón y el Co. Piltriquitrón. Se observa el acceso Sur de Mallín Ahogado. Foto, F. Ottone, 2004.

37: Nevazón de invierno en la comarca. Foto del autor, 2003.

38: Sector del lago Puelo donde desemboca el río Epuyén, toma estival. Foto del autor, 1999.

39: Parte central de chacra tradicional, con indicios de pérdida de su capacidad económica-social. Las continuas subdivisiones (para el caso, por razones de sucesiones familiares), se alimentan tanto desde el re-planteo paradigmático de los descendientes de chacareros, como desde la visión enaltecida, por demandantes de propiedades desde los centros urbanos. Foto del autor, 1998.

\footnotetext{
${ }^{204}$ En Comarca abundan los ejemplos; se pueden ver desde las categóricas 'visiones' en un relativo reciente Estudio sobre el marketing (CFI-Grupo Wilensky, 2001.) hasta innumerables artículos periodísticos más o menos rigurosos.

${ }^{205}$ Ver por ejemplo en informe Martínez et al, UATA (2007); Interesantes resultados pueden obtenerse en Marchissio, M. E. (2007)
} 
Para no caer en simplificaciones apresuradas o en visiones unidireccionales a las que pareciera conducirnos el discurso mercantilista sobre este tipo de lugares, traemos un párrafo de Ortega con sentido inverso en cuanto a la admiración por este tipo de escenario, pero decididamente equivalente en cuanto a lo perceptivo-espacial. Refiriéndose a las alturas pirenaicas y en un contexto crítico hacia el paradigma romántico, escribía en El espectador "...Pronto advertimos que el paisaje no nos va. Es un paisaje vertical. Prisioneros en un valle angostísimo (...). El paisaje termina en punta (...). Mirar aquí es una virtual emigración al firmamento, una ascensión. Decididamente éste es un paisaje sublime, y lo sublime es una de las cosas más extemporáneas" (Ortega y Gassett, 172).

Pues bien, Ortega viene a auxiliarnos para enriquecer el marco conceptual. De hecho, se puede acordar o no con su mensaje, pero quedará claro el condicionamiento perceptivo que por entonces le sugería un ámbito como el de las altas montañas y profundos valles. Hoy en día y para muchos, su visión sería casi inaceptable, herética.

La amplitud de matices que supone atender la realidad perceptiva y la búsqueda de su comprensión, básicamente desde lo fenomenológico, inhiben una visión extendida y concluyente, pero, en todo caso resulta irrebatible la territorialidad de ciertos comportamientos, que por otra parte se sostienen en un gran número de entrevistas, encuestas e instancias académicas y de gestión.

Como puede constatarse, el énfasis estuvo puesto en descubrir parte del mundo cotidiano, el paisaje que los individuos viven, sienten y experimentan, con algunos de sus lazos afectivos significativos, que a menudo explican los comportamientos espaciales $^{206}$.

Se verá, entonces que los temas de este capítulo se empeñan en sintetizar la óptica y sensibilidad, tanto de los pobladores locales, como de quienes se vinculan 'desde afuera', los insiders y outsiders de Buttimer ${ }^{207}$, quedando abiertas, además, innumerables puertas de análisis, como es el ejemplo relevante del migrante y su 'recorrido' más o menos exitoso (fig. 19).

\footnotetext{
${ }^{206}$ Se ha tomado en especial el sustento conceptual en García Ballesteros, A.;1992 y 1998; A Nogué i Font, 1992 por lo analógico con nuestra área de estudio.

${ }^{207}$ Ver artículo sumamente ilustrativo sobre el Humanismo y la geografía. Buttimer, Anne en Ballesteros, Aurora (ed.) 1992: 19-52).
} 


\section{Percepciones 'desde adentro' y 'desde afuera'.}

Los dos ejemplos que siguen buscan tan sólo ilustrar recorridos que, como muchos otros, no pueden eludirse en el análisis. Ambas visiones conllevan comportamientos, si bien hoy la segunda domina las intervenciones.

1. "Para el hombre común, el pequeño productor de ganado que es lo que satisface sus necesidades inmediatas, el árbol se constituye en un estorbo más que en un aliado. (...). ... un viejo poblador (...), mirando por la ventana del refugio del Cerro Perito Moreno, me contaba que en su juventud, él podía recorrer los campos que veíamos, trabajando con las vacas, y que de ninguna manera existía esa 'tupición' de renovales que tanto ha 'achicado' el campo". En Andenmatten, E. Conferencia La Agro forestación y su impacto en la economía. "Taller para la red de bosques modelos en la República Argentina". La Cumbre, Córdoba. 1996.

2. Tomamos del CFI-Gupo Wilensky y su consultoría para un Plan de Marketing Turístico (2001): "... la idea-fuerza que entendemos debiera dominar la estrategia comunicacional de El Bolsón: La Naturaleza 'habla' desde su espíritu. Para desarrollar luego: el espíritu del agua (...), de la tierra (...), de la montaña (...) y del bosque con los duendes y su magia".
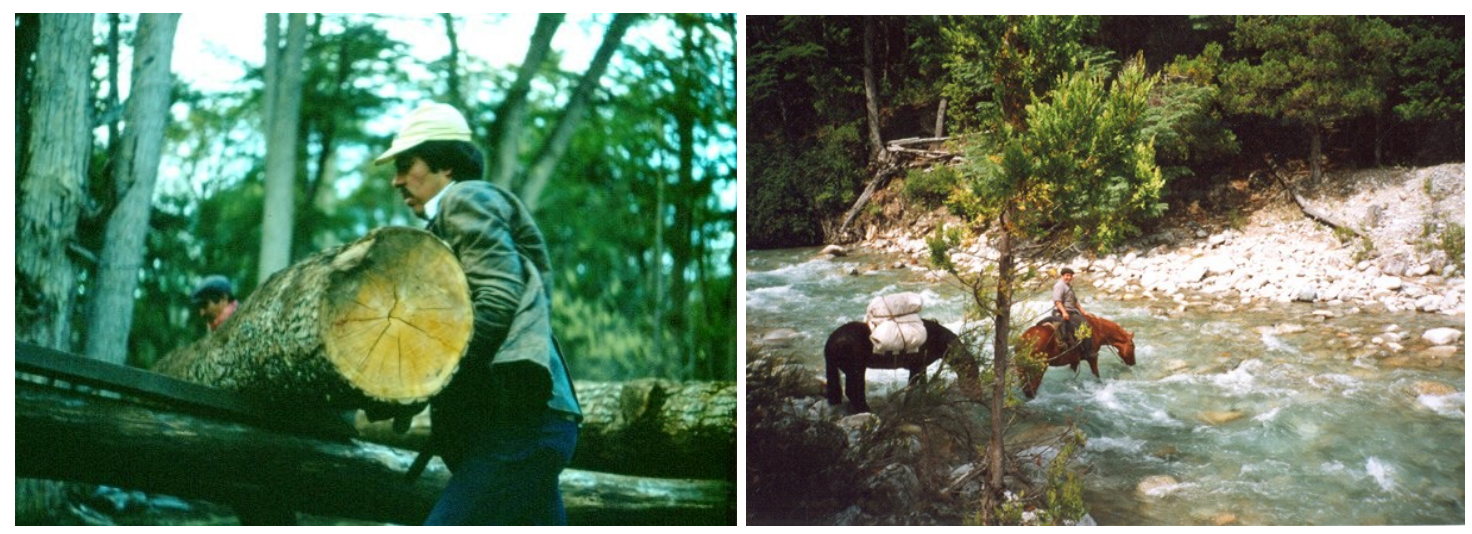

Fotos 40 y 41: Diferentes visiones. Para unos recursos, para otros obstáculos. Fotos del autor. 


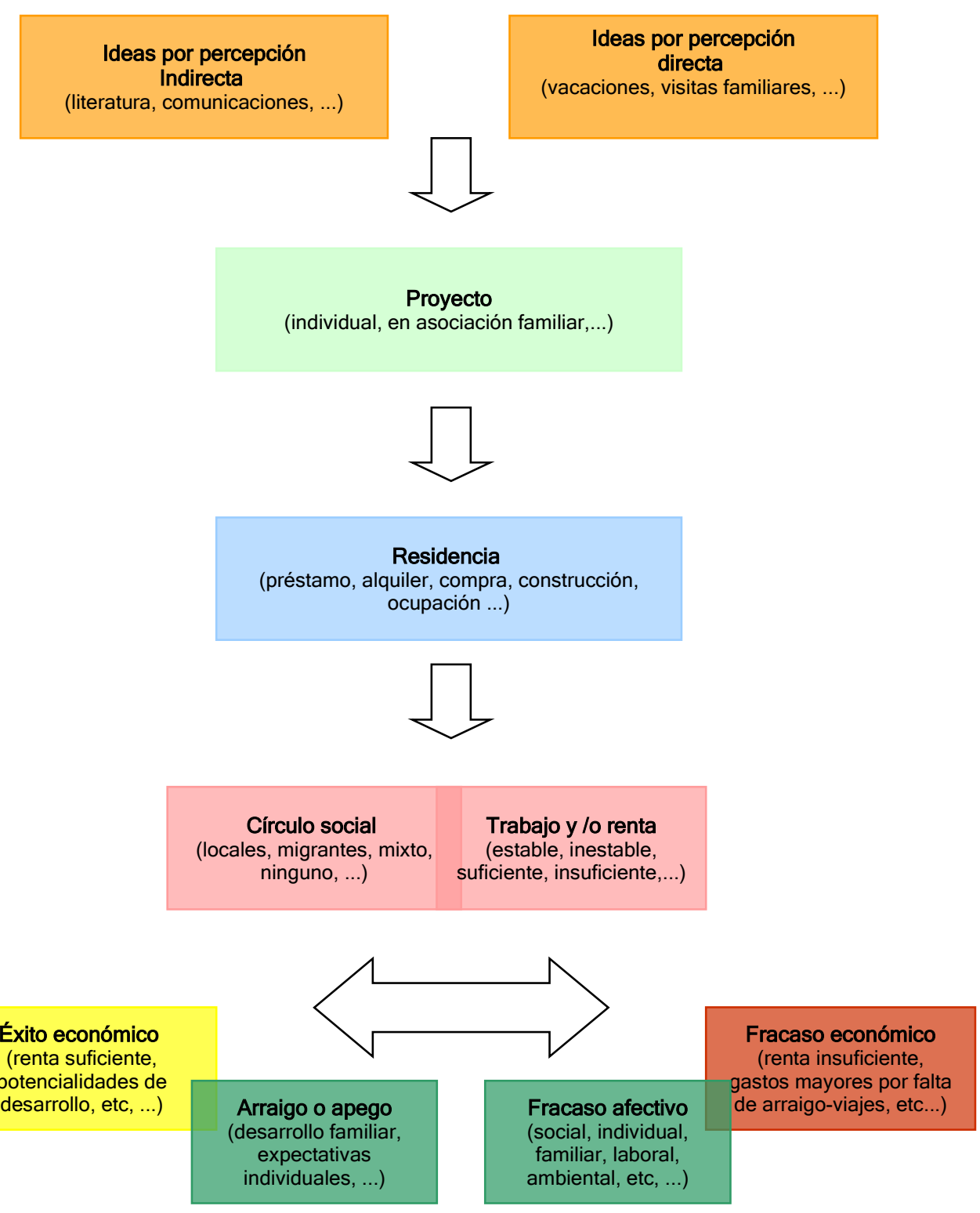

Fig. 17. Reconstrucción tentativa del camino perceptivo-concreto del migrante.

Fuente: Elaboración propia. Principalmente en base a Bondel et al, 2002 (entrevistas), a González, M.S.(2004) y a la participación en el equipo asesor para la Fundación Cooperar, El Bolsón, en el proyecto para la apertura de una carrera universitaria en la Comarca Andina del Paralelo 42. Unidad de Asistencia en Temas Ambientales Universidad Nacional de la Patagonia San Juan Bosco, Sede Esquel. Equipo técnico (UATA): Demarchi, G., Bondel, C. S., Arrieta, G., Danklmaier, C., Martínez, O y Carabelli, F.. 2006. 


\section{III.2. Sobre comportamientos y conflictos de esencia territorial}

Como ya lo hemos hecho en algún avance precedente ${ }^{208}$, tomamos la frase que sigue como pequeña muestra de un estado problemático de esencia territorial y que es abordado desde una geografía que enfatiza lo perceptivo y comportamental.

Sobre la vera de una lagunita de cerro Pirque, en tierras fiscales con derecho de pastaje y clavado en el tronco de un gran coihue, un cartel escrito 'a carbón' anunciaba:

"Proivido acampar y acer fuego y si no te gusta vení a berme".

Por supuesto que no hay ironías de por medio, ni del autor de esta tesis, ni de quien escribió el cartel. El aviso responde a la realidad, al sentir del que ocupa las tierras ${ }^{209}$ y que, sabemos, defendería a balazos si lo entendiera necesario ${ }^{210}$.

Ya de los capítulos precedentes se podrá colegir que desde el principio mismo de la colonización, el tema tierras se mantuvo en el tapete problemático. De las lecturas regionales clásicas como las de Bailley Willis o Pierre Denis y de los tantos proyectos 'patagónicos' asociados con la traza de ferrocarriles y desarrollo de Colonias agrícolas y pastoriles, se observa con facilidad que, aún con alguna advertencia especial, lo que predominó en materia de estrategia de poblamiento, fue la simple extrapolación a la Patagonia de pautas de uso del territorio desde otros ámbitos nacionales y mundiales. Con un tratamiento de 'tabla rasa', en un inicio para sostener la urgencia geopolítica vinculada a la actitud fronteriza chilena y, en la firme creencia de que 'el progreso' se expandiría a modo de efecto concatenado, se concretaron las mensuras iniciales y fijaron algunas condiciones de asentamiento inicial. El resto fue con 'cuentagotas' y la relación dominial de grandes extensiones de tierras obedeció más a complejas situaciones familiares y actitudes de los pobladores, que a una administración burocrática solvente. Lo curioso es que ha pasado una centuria y todavía son enormes los 'agujeros negros' en materia de tenencia y destino de las tierras.

En todo caso, se diría que hoy es perceptible cierta continuidad 'extrapoladora', incluso con el turismo contemporáneo, actividad económico-cultural de mayor dinamismo y agresividad que puja por acomodar el orden territorial a sus demandas ${ }^{211}$.

\footnotetext{
208 IV Encuentro Humboldt. Carlos Paz, Córdoba.. 2004.

${ }^{209}$ Corroborada en entrevista hecha tiempo después al ocupante de las tierras (dueño, es su decir); diciembre, 2005.

210 No se trata de exageraciones en cuanto a lo ríspido de las situaciones que por motivos como el de 'las tierras' ocurren con frecuencia. Se diría que sostienen un ambiente de incertidumbre poco saludable socialmente. Casos extremos como incendios intencionales, agresiones y hasta asesinatos, son bien tenidos en cuenta por los pobladores en general, a pesar que las comarcas andinas necesiten y brindan una imagen apacible y armoniosa (ver abundante información periodística en las páginas web de los periódicos locales y regionales: Piltriquitrón, El Ciudadano, Río Negro, El Cordillerano y El Oeste entre otros).

211 Sirva de ejemplo el desarrollo reciente de propuestas de Códigos de Planeamiento Urbano para las localidades comarcales de la provincia de Chubut y que obedecen a estrategias de gestión turística de nivel nacional para viabilizar instancias de crédito internacionales.
} 


\section{Conflictos socio-territoriales de la Comarca}

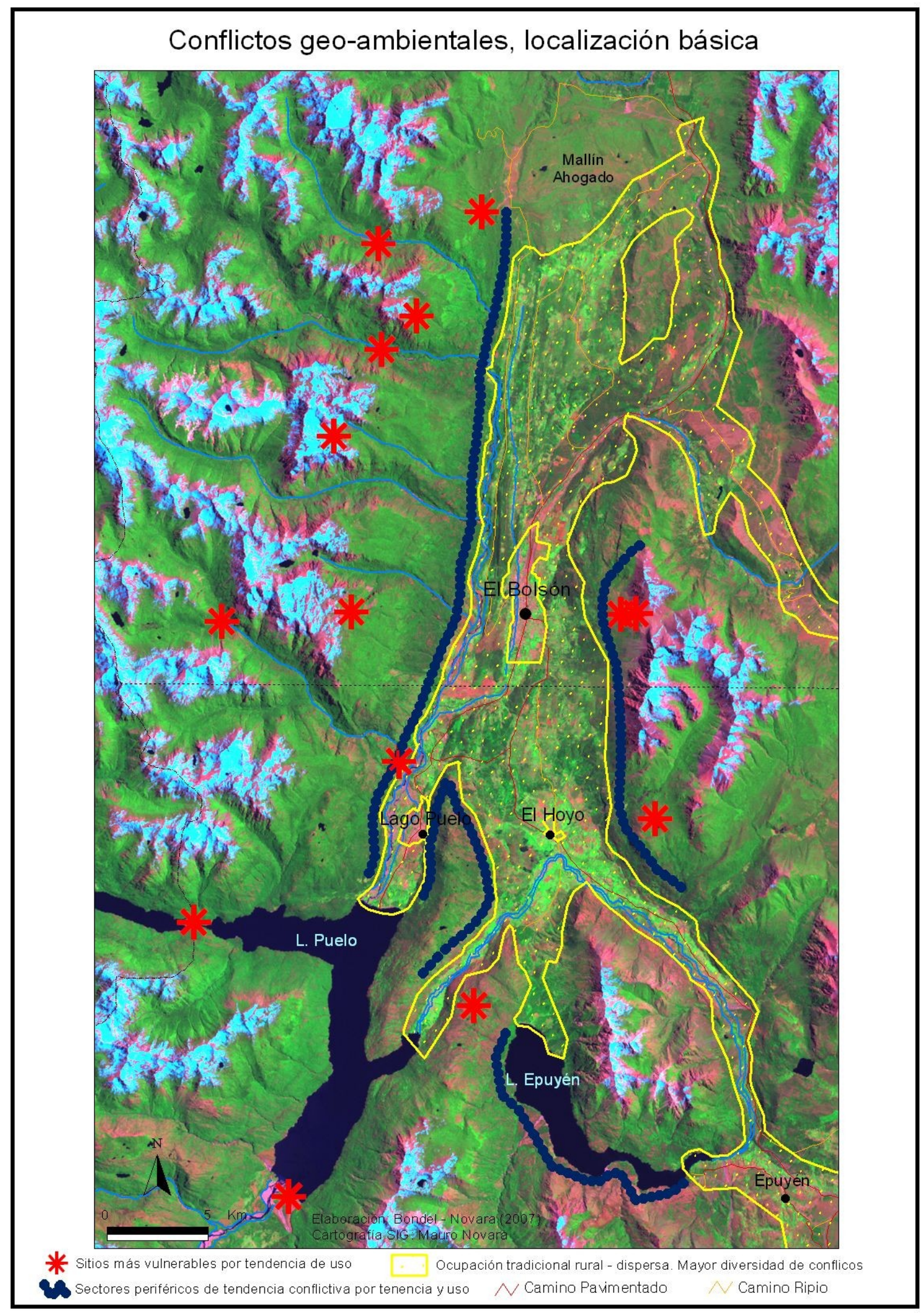

Mapa 10. Localización de los principales conflictos territoriales asociados con la expansión urbana Áreas, puntos y franjas sobre una imagen, permiten apreciar esquemáticamente las distribución conflictiva; ocupación de riberas y bosques, además de los accesos y usos en ámbitos de de alta montaña. Elaborado por Bondel-Novara (2007) con cartografía SIG de M. Novara. 
Indicios tipológicos de usos del espacio.

Antes de profundizar en cuanto de los pobladores en sí, respecto de sus comportamientos trascendentes territorialmente, se esquematizaron los usos actuales en ámbitos extra-urbanos basándonos en los planteos tipológicos genéricos de Lineau et al (1982) $)^{212}$ y con la orientación de la concepción de Claval (1999: 243-52) sobre lógicas en la estructuración del espacio humanizado, es decir 'territoriales'213.

Cuadro 3. Bases tipológica según formas. Elaboración propia en base a Bondel et al. 2002 y 2006

\begin{tabular}{|c|c|c|}
\hline \multirow{3}{*}{$\begin{array}{l}\text { SOBRE } \\
\text { LAS } \\
\text { FORMAS }\end{array}$} & Tipos resultantes & Formas \\
\hline & $\begin{array}{l}\rightarrow \text { de lógica de la producción } \\
\text { primaria agropecuaria en función } \\
\text { del tamaño (diversidad de recursos } \\
\text { básicos, agua, leña, suelos y } \\
\text { pasturas naturales). }\end{array}$ & $\begin{array}{l}\text { conformidad en las mensuras originales de los } \\
\text { conjuntos parcelarios de cada colonia y } \\
\text { extensiones con los principales cursos de agua } \\
\text { y fondos de valles. }\end{array}$ \\
\hline & $\begin{array}{l}\rightarrow \text { de lógica neorrural, de la } \\
\text { 'mixtura' escénica-residencial- } \\
\text { productiva; esencialmente anímica } \\
\text { (del gusto). }\end{array}$ & $\begin{array}{l}\text { re-parcelamientos anárquicos, en continua } \\
\text { situación de desborde orgánico-legal; se } \\
\text { sobrepasan los límites parcelarios de las } \\
\text { colonias y las condiciones del relieve o la } \\
\text { disponibilidad de agua no son determinantes. }\end{array}$ \\
\hline
\end{tabular}

Cuadro 4: Bases tipológica según génesis. Elaboración propia en base a Bondel et al. 2002 y 2006.

\begin{tabular}{|l|l|}
\hline \multirow{3}{*}{$\begin{array}{l}\text { SOBRE LA } \\
\text { GÉNESIS }\end{array}$} & $\begin{array}{l}\text { Tipos resultantes } \\
\text { ocupación inicial espontánea de origen chileno y que acompaña hasta nuestros días ya } \\
\text { con modalidades 'criollas' en formas complementarias en amplios sectores fiscales. }\end{array}$ \\
\cline { 2 - 3 } & $\begin{array}{l}\text { extensión de los colonos, ya como ocupación y explotación 'inorgánica' de pobladores sin } \\
\text { acceso a la propiedad. }\end{array}$ \\
\cline { 2 - 3 } & $\begin{array}{l}\rightarrow \text { ocupación moderna (1970-2007); confusa, espontánea, de prevalente carácter } \\
\text { afectivo y/o especulativo; acompañada con rasgos paradigmáticos diversos asociados } \\
\text { con temas 'vanguardistas': ecología, visión crítica cultural, económica y política. } \\
\text { La variedad de enfoques y sustentos barren un amplio espectro tanto formal (de raíz } \\
\text { burguesa -hippies, neorrurales, intelectuales-) como funcional-productiva (también de raíz } \\
\text { burguesa -fruta fina, producción orgánica, industrialización artesanal, turismo alternativo, } \\
\text { etc.). }\end{array}$ \\
\hline
\end{tabular}

\footnotetext{
${ }^{212}$ En su planteo, los autores incluyen además los aspectos prospectivos, hecho que también tomamos en la última Parte del trabajo

${ }^{213} \mathrm{Si}$ bien los usos urbanos nos desbordarían por su magnitud y diversidad, es interesante rescatar que, dado lo relativamente reducido del universo comarcal, en muchos casos lo rural se despliega intra-urbanamente (aserraderos con su 'cancha', parcelas frutihortícolas en medio de barrios, lugar de pastaje de hacienda familiar, lonjas y/o montecitos frutales, etc.).
} 
Cuadro 5. Bases tipológica según funcionalidad. Elaboración propia en base a Bondel et al. 2002 y 2006.

\begin{tabular}{|c|c|}
\hline \multirow{10}{*}{$\begin{array}{l}\text { SOBRE LA FUNCIONALIDAD (competitiva } \\
\text { - complementaria); es prevalente la múltiple } \\
\text { diversidad productiva, tanto en escalas } \\
\text { como en el tipo y formas de explotación. }\end{array}$} & Tipos resultantes \\
\hline & - $\quad$ silvícola-ganadera \\
\hline & - $\quad$ frutihortícola \\
\hline & - $\quad$ ganadera \\
\hline & - $\quad$ agrícola $^{214}$ \\
\hline & - $\quad$ silvícola \\
\hline & - $\quad$ turística y neorrural \\
\hline & - $\quad$ residencial rururbana \\
\hline & - $\quad$ institucional 'rural' \\
\hline & - urbana \\
\hline
\end{tabular}

\section{Tipos sociales.}

Es evidente que para poder adentrarse en materia de comportamientos de raíz espacial habrá que conocer las características de quienes ocupan y se ocupan en estas tierras, es decir sobre sus habitantes. Tema por demás ingente $\mathrm{y}$, si se quiere, tan complejo como en realidad lo sería cada uno de ellos si lo individual fuera una consigna a resolver. Las tipologías, entonces, se presentan como auxilio.

Como rescata Andrade, "...las tipologías (...) están orientadas por un fin, cuyo criterio fundamental es poner de relieve las anomalías de distribución de una población en relación con diversas variables consideradas simultáneamente y sobre un plano de igualdad" (de Hughes, Griffon y Bouveyron; 40).

En general, los valles cordilleranos patagónicos muestran patrones tipológicos tradicionales para los usos del territorio en áreas periféricas argentinas, con la ganadería extensiva como actividad económica dominante y la estancia como estructura formal y funcional característica. Pero es justamente en la Comarca, donde esta condición 'estanciera', de grandes extensiones se verifica mayormente en su periferia. De hecho, lo accidentado y variable del paisaje, lo singular de sus condiciones agroecológicas, así como los usos con destino de Parque Nacional, reflejan una significativa heterogeneidad en tamaños y formas que la posicionan excepcionalmente. De cualquier forma debe destacarse que en su esencia, es evidente una notable expansión de los 'tipos' comarcales frente a un retroceso de aquellos tradicionales. Si bien las estancias siguen existiendo, sus roles territoriales se entremezclan con pautas neorrurales que se suman a las demandas del turismo y hasta las surgidas de pobladores identificados como de los pueblos originarios.

A título de evitar el detalle extremo, se presentan identificaciones tipológicas de la relación dinámica, población-territorio, respaldadas en avances anteriores ya citados (Bondel, 2000 y 2006) Bondel, Novara y Carabelli (2006) y también en Danklmaier,

\footnotetext{
${ }^{214}$ De todas maneras, la diversidad contrasta con el predominio neto en superficie del uso ganadero-silvícola. Si tomamos por caso el sector chubutense de la Comarca de El Bolsón, sobre 3163 hectáreas en producción, apenas un $10 \%$ se ocupa para frutas, hortalizas, cereales, flores, aromáticas y lúpulo (ver Díaz, Arnoldo, 2001).
} 
2006; González, 2004; 'Plan de Desarrollo Territorial de Trevelín', Equipo Técnico Municipalidad de Trevelín y UATA, 2006. El cuadro que sigue presenta entonces una tipificación tentativa inicial, con los tipos sociales 'visibles' en la Comarca, agrupados a partir de reconocimientos sociales que se revelan a la hora de la indagación, donde cada uno reúne valores, intereses y actividades más o menos diferentes ${ }^{215}$.

Cuadro 6. Tipo sociales. elaboración propia (ver texto antecedente).

\begin{tabular}{|l|l|}
\hline & \multicolumn{1}{|c|}{ APROXIMACIÓN A LOS TIPOS SOCIALES CARACTERÍSTICOS } \\
\hline $\begin{array}{l}\text { POBLACIÓN } \\
\text { NATIVA (con 4 o } \\
\text { más generaciones } \\
\text { en la región); }\end{array}$ & $\begin{array}{l}\text { Mapuches, de raíces indígenas y entremezcladas con los paisanos; } \\
\text { tradicionalmente rurales, hoy muchos marginales urbanos. Resueltas señales de } \\
\text { reivindicaciones territoriales y re-construcción de lazos filiales. } \\
\text { mestizas tradicionales, de origen chileno y argentino, con raíces básicamente } \\
\text { asiática (sirio-libanés). Tradicionalmente de mayoría rural, hoy entre urbanos y y } \\
\text { rurales; de visible heterogeneidad socio-económica. } \\
\text { Urbanos tradicionales, de raíz criolla y criolla - europea, propios del poblamiento } \\
\text { nacional de zonas de frontera, responsables de servicios y comercio. }\end{array}$ \\
\hline $\begin{array}{l}\text { MIGRANTES } \\
\text { ARGETINOS } \\
\text { INTERNOS } \\
\text { (población nativa); }\end{array}$ & $\begin{array}{l}\text { Neorrurales, migrantes modernos de origen urbano, argentinos en mayoría y } \\
\text { extranjeros también; de los más diversos orígenes e incluye a quienes son } \\
\text { identificados como de modalidad hippies. } \\
\text { Migrantes de origen urbano instalados en el medio urbano. } \\
\text { Paisanos patagónicos provenientes de zonas rurales extraandinas, hoy muchos } \\
\text { de ellos marginales urbanos. } \\
\text { Militares y otros análogos, en mayoría urbanos, masculinos y de estabilidad } \\
\text { domiciliaria condicionada. }\end{array}$ \\
\hline $\begin{array}{l}\text { MIGRANTES } \\
\text { INTERNACIONALES } \\
\text { (población de } \\
\text { extranjeros); }\end{array}$ & $\begin{array}{l}\text { Colonos europeos, rurales y urbanos (muchos con intereses en el campo). } \\
\text { Importante participación de centroeuropeos. } \\
\text { Neorrurales, de origen urbano y de diversa procedencia, en especial europea } \\
\text { occidental. }\end{array}$ \\
\hline $\begin{array}{l}\text { AUSENTISTAS Y } \\
\text { TEMPORARIOS }\end{array}$ & $\begin{array}{l}\text { Grandes compradores "rurales". Reemplazantes de antiguos pobladores } \\
\text { rurales. Escasos en número. Responden -prima facie- a la moda ecológica, con un } \\
\text { efecto concatenado en compradores de gran poder económico. Inicialmente } \\
\text { extranjeros y actualmente también argentinos. } \\
\text { Militares, funcionarios y otros, de residencia temporaria, en su mayoría urbanos } \\
\text { yelativamente escasos en número (predomina el adulto-mayor). } \\
\text { Turistas, reconocidos, en especial, como de turismo familiar, de mochileros y de } \\
\text { 'nacionales' y extranjeros 'de paso'. }\end{array}$ \\
\hline
\end{tabular}

Con este orden tipológico, los dioramas de Hägerstrand mostrarían un atrayente recurso descriptivo-explicativo espacial. Si bien tan sólo se exhibe un caso específico y simplificado, resultan sugestivos los recorridos donde la relación tiempo-espacio diario se ve diferenciado entre distintos tipos sociales ${ }^{216}$.

\footnotetext{
215 Afirmar un más o menos tiene un significado cierto, dado que todo indica que los solapamientos, las mezclas, los intercambios predominan frente a tendencias grupalmente centrípetas también existentes. Lugares como la escuela pública, la feria regional, las riberas en verano y los senderos de montaña, por ejemplo, parecieran demostrar esa tendencia

${ }^{216}$ Cuando nos referimos a apenas insinuaciones, es porque una mirada rigurosa de una complejidad temática nos supera en la oportunidad; género, grupos etarios, condición social, momento histórico y hasta horarios, son condiciones ineludibles a la hora de un análisis profundo.
} 
Diorama espacio-tiempo(simplificado).

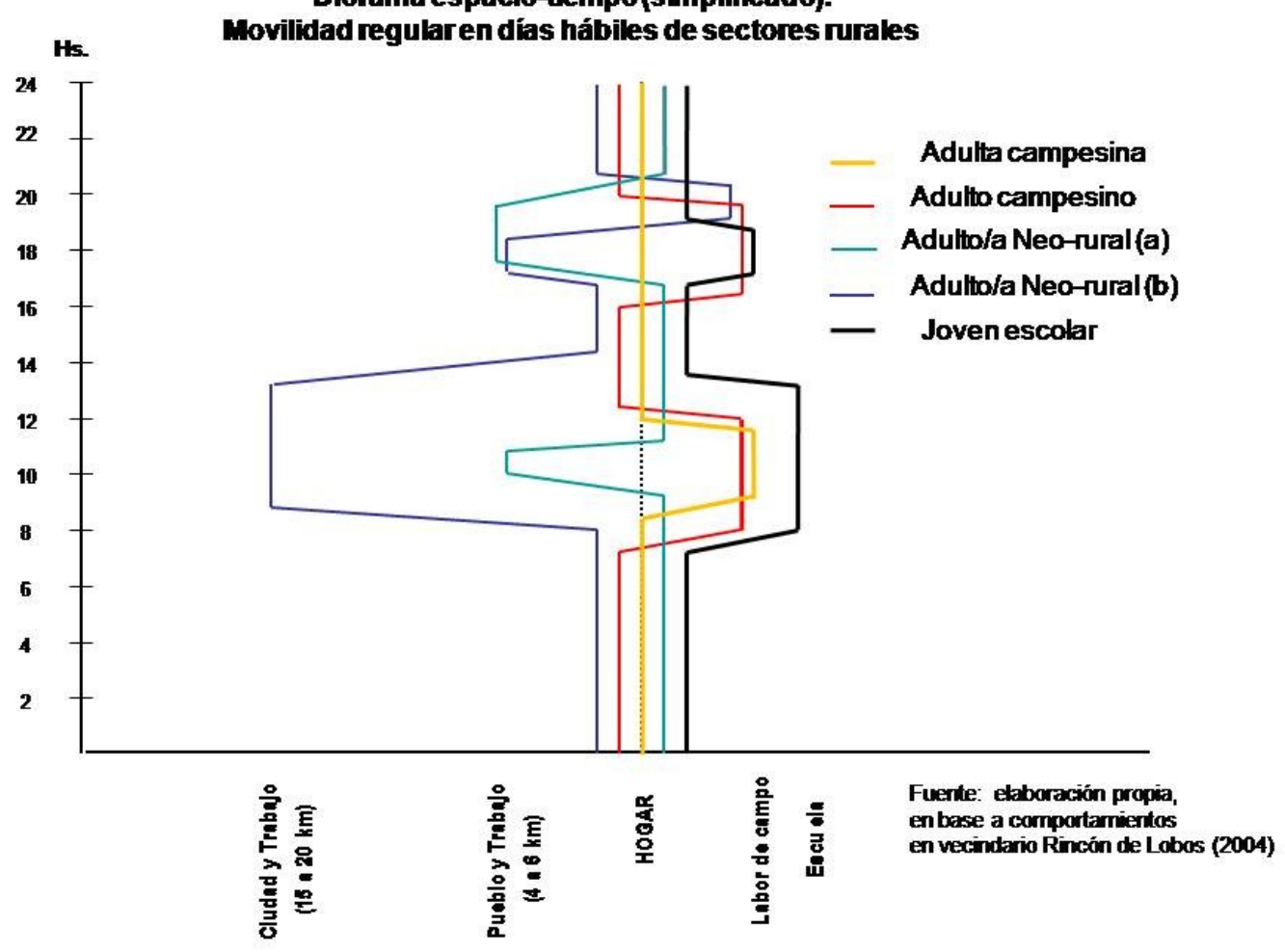

Fig. 18. Esquema espacio-tiempo rural.

El uso espacial, la reciprocidad estrecha con lo territorial, será el fin hacia donde se orienta esta esquematización de parte de la realidad, a sabiendas, claro está, que factores dinámicos de cambio pueden aparecer en cualquier momento. Sirva de ejemplo la posibilidad de acceso a la televisión satelital o el teléfono celular, que en menos de una década se instala y supera a la mayor parte de los obstáculos topográficos, implantándose resueltamente en 'las distancias'. Pocas dudas cabrán, entonces, para que los comportamientos sean otros y su resultado espacial deba resolverse de modos impensados unos años atrás. Por supuesto que hay muchas otras circunstancias menos identificables y más aciagas asociadas con la 'juventud' territorial de la Comarca. La actitud casi pasiva, se diría de resignación, respecto de las posibilidades de acceso a la tierra del poblador 'medio' local ${ }^{217}$, por ejemplo, es una cualidad socialmente instalada y que hoy, muestra un perfil opuesto a la euforia territorial ya mencionada. Por ello y evitando caer en un punteo interminable de circunstancias, se avanza en perspectivas de conjunto como para individualizar las situaciones territoriales más significativas a atender.

\footnotetext{
217 Como en otras zonas del país, también ocurren situaciones de ocupaciones de tierras fiscales y privadas sin consenso jurídico; sostenidas en reivindicaciones sectoriales (en especial vinculado a la población de raigambre mapuche) y en situaciones de marginalidad más ostensibles.
} 


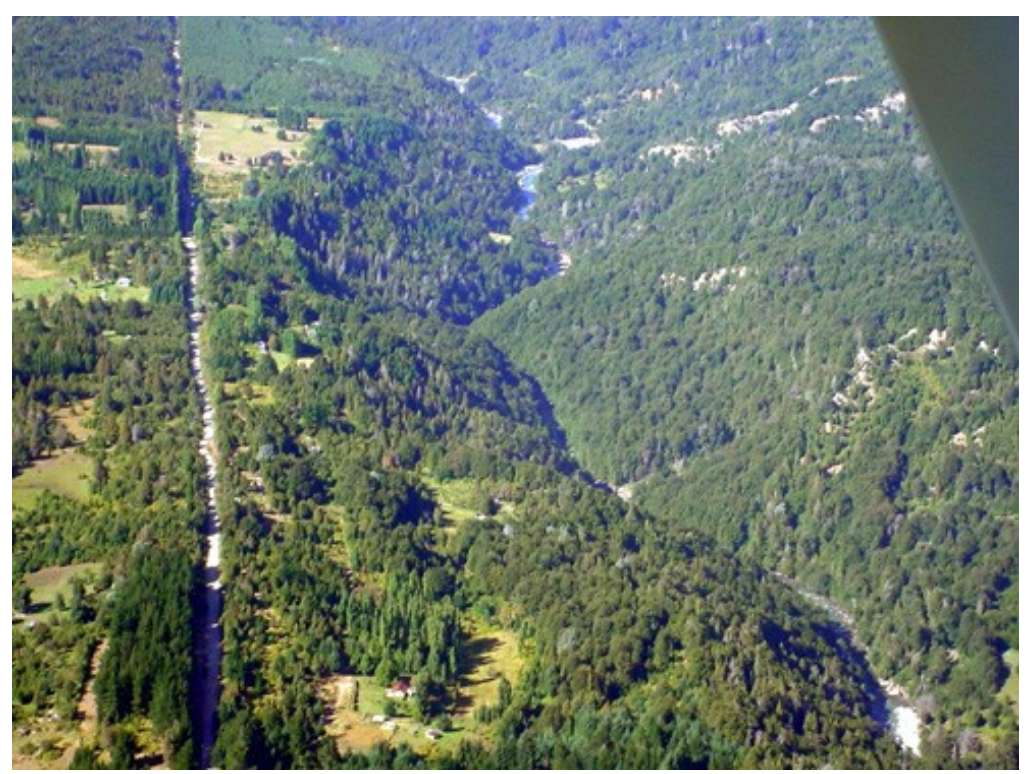

Foto 42: Tradicionales, neorrurales y ocupantes. Sector de Mallín Ahogado atravesado por el río Azul. En la margen izquierda se observa un ámbito intervenido a la usanza tradicional ganadera-silvícola, donde chacras, sembrados, electrificación, caminos, servicios y demás, confluyen iniciativas a modo del colono tradicional y del neorrural.; en la margen derecha del río se emplaza el Área Natural Protegida Río AzulLago Escondido que con unas 80.000 has se extiende hasta el límite internacional donde, con escasos habitantes permanentes se convive (y compite) con intervenciones apenas puntuales (sendas, refugios, corrales y cancheo silvícola); aquí ganaderos y prestadores turísticos con modalidades del ocupante, muestran matices a la acción paralela de la gestión territorial pública. Foto: F. Ottone 2004.

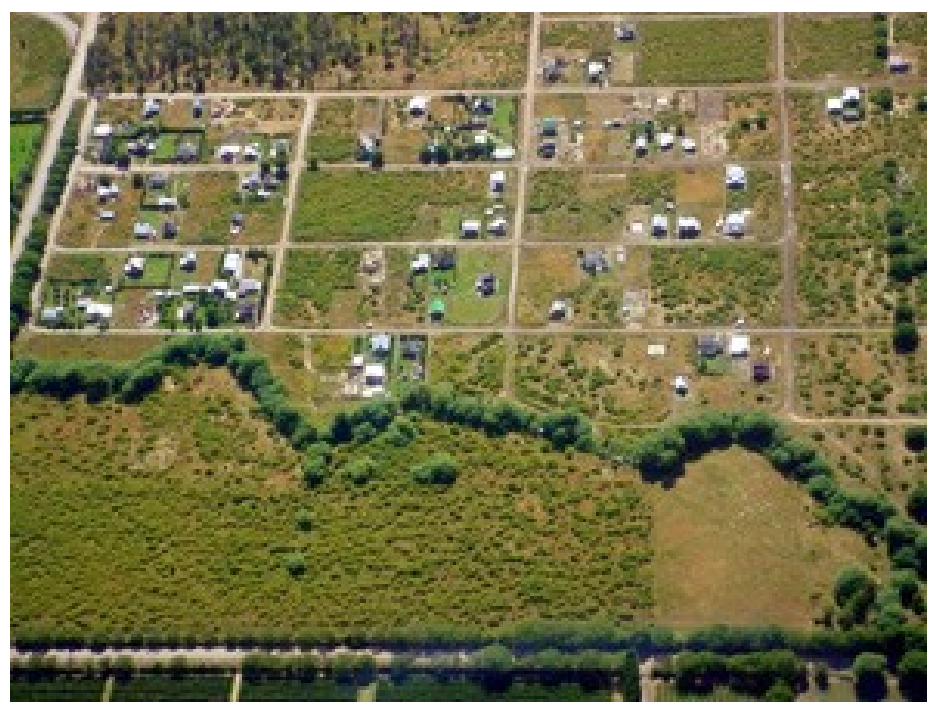

Foto 43: Reconversión chacra-barrio, una tendencia decidida. Barrio Arrayanes, por ahora no coalescente con la mancha urbana de El Bolsón distante 2 km.. Foto: F. Ottone, 2005

\section{El poblador rural y sus comportamientos; tipologías.}

El cuadro que sigue sostiene las tres tipologías dominantes (colono tradicional, ocupante y neorrural) en referencia a los resultados espaciales de conductas y sentires. Seguramente será controvertible, toda vez que la subjetividad es obvia; por otra parte, tampoco se trata de meras intuiciones, la experiencia, entrevistas e 
indicadores visibles orientan hacia estos resultados que necesariamente irán

acreciendo.

Cuadro 7. Aproximación a los comportamientos territoriales.

Elaboración propia en base a tareas de campo en el contexto de Bondel et al. 2002 y 2006 (a) y UATA, 2006

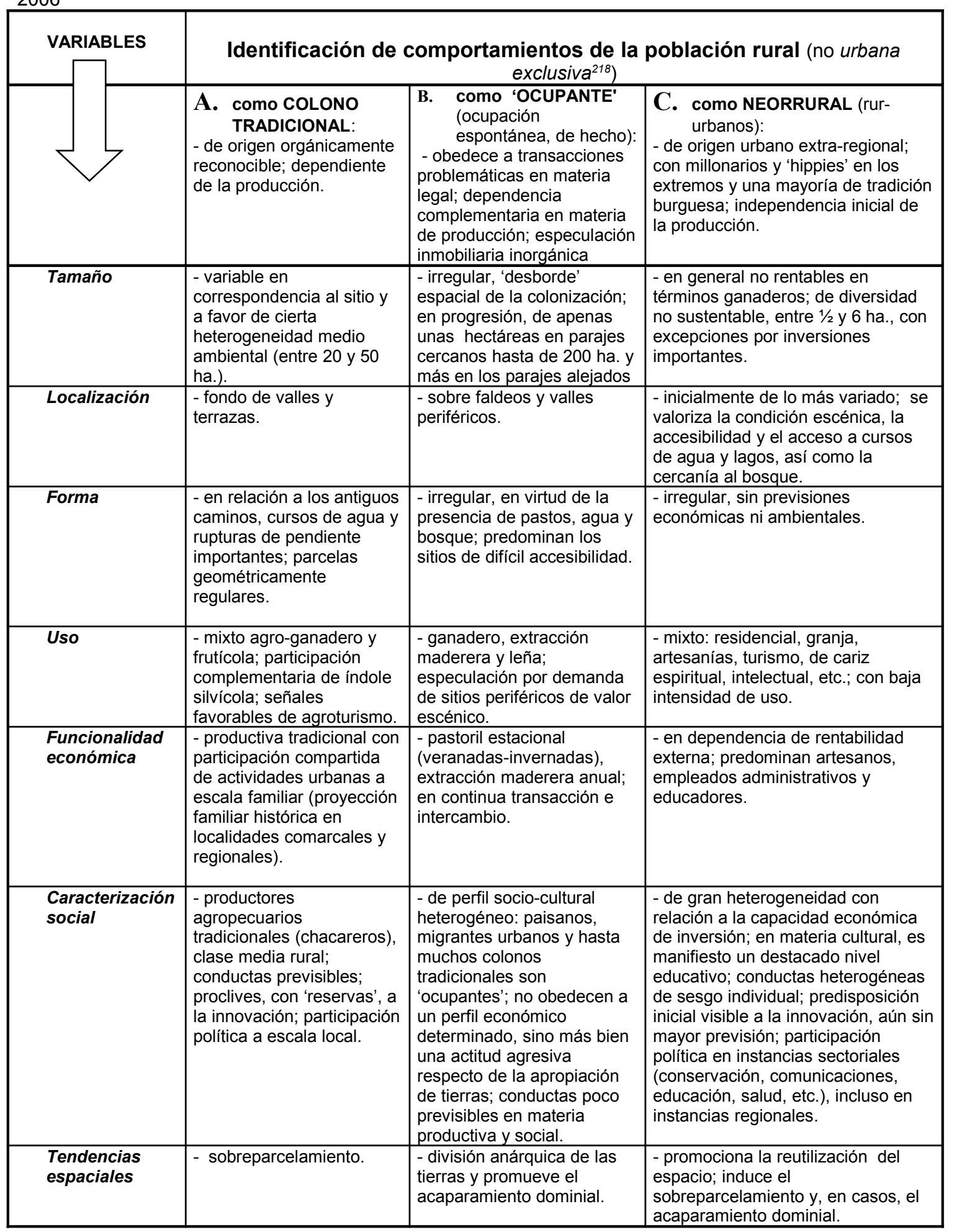

\footnotetext{
${ }^{218}$ Se entiende como urbana exclusiva a aquella que no guarda relación directa con el medio rural.
} 


\section{III.3. Valoración de los impactos territoriales críticos por tipo de poblador, una matriz tentativa con proyección planificadora.}

Visto desde la relación poblador-impacto y a la hora de mantener el conjunto territorial como condición intrínseca de esta tesis, se llega a una figura matricial, una figura 'síntesis' ocupada en la puesta en valor las relaciones entendidas como estructurales. Se ha buscado encontrar una representación que responda a instancias superadoras de la descripción estática; aquí, con similitud en el recorrido metodológico a la llamada técnica Delphi, se arriba a una figura que, así como explica aspectos del comportamiento social, permite la proyección de base a la investigación aplicada y la consideración prospectiva ${ }^{219}$. Su validación estaría en la posibilidad de encontrar con su uso, valorizaciones prudentes y orientadoras, en particular en el planeamiento y la gestión territorial.

La matriz, un recurso metodológico integrador, indica la tendencia a provocar impactos territoriales críticos, considerados como no deseados ${ }^{220}$, según los tipos de pobladores y relacionados con situaciones vinculadas directamente con las modalidades de uso. Por supuesto que la matriz no' acaba' con los comportamientos, ya que también existen quienes, sin ser pobladores, son generadores de impactos, en especial desde las gestiones de gobierno y empresarial. De cualquier modo, entendemos puede constituir una plataforma de análisis importante y que con su columna de síntesis propone una visión valorativa del conjunto.

El significado de impacto en esta matriz, responde a la noción de estabilidad, con un sentido más cercano al de armonía que al de equilibrio. Es decir a los efectos que resultan de la conjugación entre demandas por el uso del territorio con los ámbitos naturales en su rol de soporte y en torno a la disponibilidad tecnológica. Podría afirmarse que en ámbitos montanos como el de la Comarca, casi no hay asunto vinculado a la instalación humana que no suponga un impacto al menos visible. Topografía, hidrografía y flora, en especial, ofrecen un marco de alta vulnerabilidad, agravada por aquella condición ecotonal que imponen transiciones del medio natural que no siempre pueden ser homologadas con transiciones de las modalidades técnicas. Sirvan por caso, la roturación del suelo o el manejo silvo-pastoril que casi no ofrecen diferencias operativas en parajes que pueden tener precipitaciones anuales medias con diferencias del $50 \%$ o más.

\footnotetext{
${ }^{219}$ Aunque sin seguir sus fases, la técnica fue tomada como referente. Como se indicó en el cuerpo metodológico, han sido numerosas las entrevistas, muchas de ellas en profundidad, así como la participación activa en grupos de estudios y en temáticas locales y regionales. Ver en García Ballesteros, A. (1998: 110-126).

220 Se prefirió esta denominación a la de negativos, por dejar abiertas las posibilidades a circunstancias aún no comprendidas y/o aceptadas social y culturalmente..
} 
Matriz síntesis de la relación poblador-impacto territorial en la Comarca Andina del Paralelo 42. Cabe destacar que la valoración de la síntesis proviene del análisis sectorial de cada factor, contando además con la constatación de informantes clave.

\begin{tabular}{|c|c|c|c|c|c|c|c|}
\hline \multicolumn{8}{|c|}{$\begin{array}{l}\text { TENDENCIA DE IMPACTOS TERRITORIALES POR TIPO DE POBLADOR (ÁMBITOS EXTRA- } \\
\text { URBANOS) }\end{array}$} \\
\hline \multirow{2}{*}{$\begin{array}{l}\text { POR } \\
\text { MODALIDAD } \\
\text { DE USO }\end{array}$} & factores & $\Rightarrow$ & \multirow{2}{*}{$\begin{array}{l}\text { Presión } \\
\text { sobre } \\
\text { sectores } \\
\text { naturales } \\
\text { críticos } \\
\text { (Snc) }\end{array}$} & \multirow{2}{*}{$\begin{array}{l}\text { Presión } \\
\text { parcelaria } \\
\text { rural (Ppr) }\end{array}$} & \multirow{2}{*}{$\begin{array}{l}\text { Presión } \\
\text { inmobiliaria } \\
(\mathrm{Pi})\end{array}$} & \multirow{2}{*}{$\begin{array}{l}\text { Expansión } \\
\text { urbana } \\
\text { física (Euf) }\end{array}$} & \multirow{2}{*}{$\begin{array}{l}\text { SÍNTESIS } \\
\text { DE } \\
\text { IMPACTO }\end{array}$} \\
\hline & subtipos & & & & & & \\
\hline \multirow{3}{*}{$\begin{array}{l}\text { POBLADOR } \\
\text { TRADICIONAL }\end{array}$} & \multicolumn{2}{|c|}{ urbano nyc-vyq } & B & B & $M$ & $A$ & Mxb \\
\hline & \multirow[t]{2}{*}{ rural } & $\begin{array}{l}\text { residente } \\
\text { nyc-vyq }\end{array}$ & M & A & B & M & $\mathbf{M x}$ \\
\hline & & ausentista & B & B & A & B & Mxb \\
\hline \multirow{3}{*}{$\begin{array}{l}\text { POBLADOR } \\
\text { NEORRURAL }\end{array}$} & \multirow{2}{*}{$\begin{array}{l}\text { residente } \\
\text { vyq }\end{array}$} & $\begin{array}{l}\text { actividad } \\
\text { primaria }\end{array}$ & M & A & B & B & $\mathbf{M x b}$ \\
\hline & & $\begin{array}{l}\text { actividad } \\
\text { terciaria }\end{array}$ & A & A & A & A & A \\
\hline & \multicolumn{2}{|c|}{$\begin{array}{l}\text { invasivo-explorador } \\
\text { (ausentista) }\end{array}$} & M & B & A & B & Mxb \\
\hline \multirow{3}{*}{$\begin{array}{l}\text { POBLADOR } \\
\text { "OCUPANTE" }\end{array}$} & \multicolumn{2}{|c|}{ tradicional nyc } & A & M & A & B & Mxa \\
\hline & \multicolumn{2}{|c|}{ marginal nyc-vyq } & B & M & B & A & $M x b$ \\
\hline & \multicolumn{2}{|c|}{$\begin{array}{c}\text { invasivo-explorador } \\
\text { vyf }\end{array}$} & A & A & M & A & A \\
\hline \multicolumn{8}{|c|}{$\begin{array}{l}\text { REFERENCIAS: nyc, “nacido y criado"; vyq, "venido y quedado"; vyf, "venido y fluctuante”. } \\
\begin{array}{ll}\text { IMPACTO, generadores de condiciones de alteración a las condiciones: } \\
\text { en Snc: ecosistemas territoriales } & \text { en Ppr: sobre-parcelamiento territorial } \\
\text { en Pi: sobre-costos inmobiliarios } & \text { en Euf: en áreas rural, boscosa ylo ribereñas }\end{array}\end{array}$} \\
\hline \multicolumn{7}{|c|}{ Impacto, A: alto ; B: bajo impacto ; M: mediano } & \\
\hline
\end{tabular}

Matriz: aclaraciones por subtipos:

Con el fin de profundizar los alcances matriciales y despejando solapamientos en los comportamientos, se acude también a un agregado tipológico de la población, considerando en especial su condición relativa al espacio comarcal:

- Tradicional urbano con injerencias en ámbitos extra-urbanos

- Tradicional rural residente

- Tradicional rural ausentista

- Neorrural residente y de actividad primaria (agro-silvo-pastoril)

○ Neorrural residente y de actividad terciaria (incluye artesanías)

- Neorrural ausentista

- 'Ocupante' tradicional, baqueano y de arraigo ganadero.

○ 'Ocupante' marginal, migrante de ámbitos patagónicos rurales expulsores de población.

○ 'Ocupante' invasivo-explorador, en general de origen urbano.

A todo esto, con fines todavía descriptivos, se les ha agregado la condición $\mathrm{de}^{221}$ :

o nyc (nacido y criado): la condición local de origen y crianza.

○ vyq (venido y quedado): la condición de migrante establecido.

${ }^{221}$ Las dos primeras denominaciones (nyc y $v$ yyq) son de uso popular en la Comarca y en la Patagonia en general; Ciccolella, por ejemplo, lo destaca al asignarle un significativo rol en su análisis sobre las transformaciones territoriales en Tierra del Fuego. (1994:146-150) Estas 'categorías' ciudadanas, muchas veces anteceden, a modo de señorío, las presentaciones personales. Con ello, será fácil ver lo socialmente trascendente que pueden resultar. Ver comentarios al respecto en el apéndice 9. 
○ vyf (venido y fluctuante): la condición de migrante, aleatorio, indeciso.

Si bien los factores generadores de impacto ya han sido vistos a lo largo del trabajo, tal vez convenga recordar que los mismos obedecen a circunstancias de gran complejidad analítica. Por dar un caso ilustrativo de las problemáticas comarcales, rescatamos en Labasse un párrafo respecto de las pautas que condicionan el establecimiento del tamaño mínimo de las explotaciones agrícolas, cuando dice “... Son precisos una colonización homogénea y un espacio recíprocamente homogéneos y nuevos, una asistencia técnica, coherente y resuelta, que ponga a la par la orientación de los cultivos y su comercialización, para que la fijación de una dimensión standard de las explotaciones tenga posibilidad de ser eficaz, ...”.(1973: 124)

La figura propone entonces a las instancias planificadoras posibilidades de contar con un antecedente para comprender, en la heterogeneidad dominante, e intervenir, en especial en instancias anteriores a aquellas zonificaciones determinantes de estructuras espaciales de mediano y largo plazo, como son en nuestro medio los Códigos de Planeamiento.

De las siete principales situaciones conflictivas contextuales de carácter geográfico enunciadas al comienzo de esta Tercera Parte, se han tomado aquellas tres que se vinculan fuertemente con el poblador y su desenvolvimiento al respecto:

1.- Identificación y delimitación incierta de amplios sectores de trascendencia territorial. 2.- Parcelamiento y tenencias de la tierra condicionadas por procesos de inversión y especulación inmobiliaria.

3.- Expansión urbana espontánea, confusa y muchas veces antisocial.

Es decir, aquellas donde los comportamientos no pueden evadirse en materia de resultados en el espacio; donde el hecho de identificarse con modalidades de uso distintivas hace vital su visión sistemática a la hora de la explicación.

Aquí, entonces, se cruzan modalidades con problemáticas y el comportamiento espacial de la población en correspondencia con su involucramiento con el espacio extra-urbano ${ }^{222}$.

Serán situaciones con visiones parciales y/o conjuntas las que podrán atenderse desde esta matriz de impactos por modalidad de uso y se concibe que pueda contribuir tanto para comprender determinadas situaciones socio-territoriales, como para llevar adelante iniciativas que involucren a espacio y sus actores. Su carácter cualitativo impone una lectura contextual, siendo sus valoraciones un telón de fondo del desenvolvimiento territorial. Así, por ejemplo, prestar especial atención a la

\footnotetext{
${ }^{222}$ El espacio urbano propiamente dicho, su interior, no forma parte del análisis dada la escala espacial del trabajo. No obstante son sí considerados aquellos habitantes urbanos ocupados en cuestiones extra-urbanas.
} 
población neorrural con actividades terciarias y desvinculadas de la producción primaria, será vital si se quieren entender determinados resultados espaciales o, directamente plantear proyectos concretos a seguir adelante.

\section{Grandes impactos:}

- de raíz natural: inundaciones, sequías, retroceso del bosque, incendios de campo y bosque, estabilidad de los faldeos, retrocesos de flora y fauna autóctona, expansión de flora y fauna 'introducida', pérdida de suelos y contaminación: del agua (cursos, lagos-lagunas y subterránea), del aire, sonora y visual.

- de raíz social: deterioro escénico, manejo conflictivo del agua (riego y recreación), déficit energético, accesibilidad, sobre-parcelamientos, acaparamiento de tierras, sub-urbanización progresiva, ocupación de áreas ecológica y socialmente 'clave' (cabeceras de cuencas, relictos de flora y fauna, desembocaduras, etc.) y disputas jurisdiccionales. 


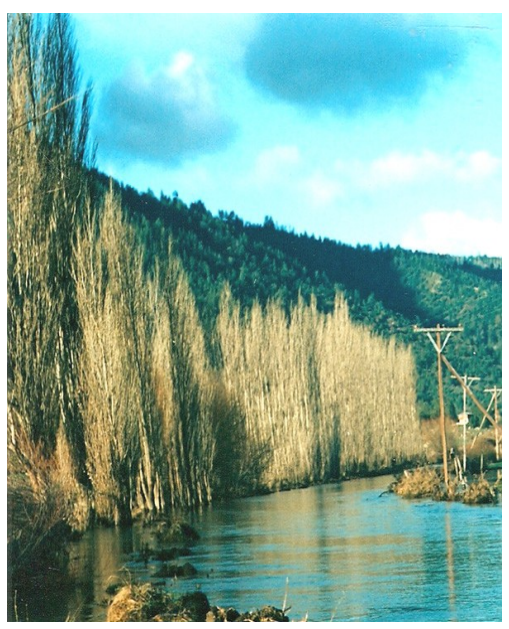

44

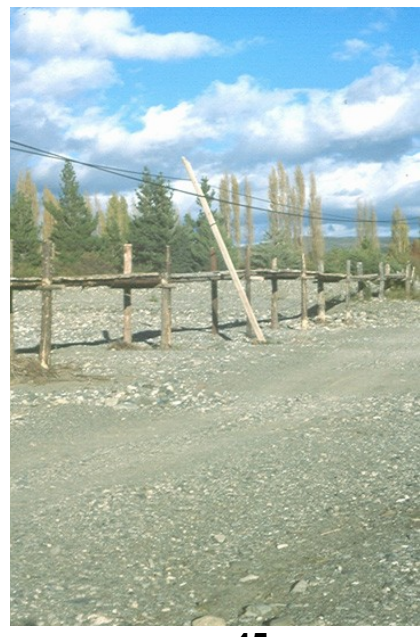

45

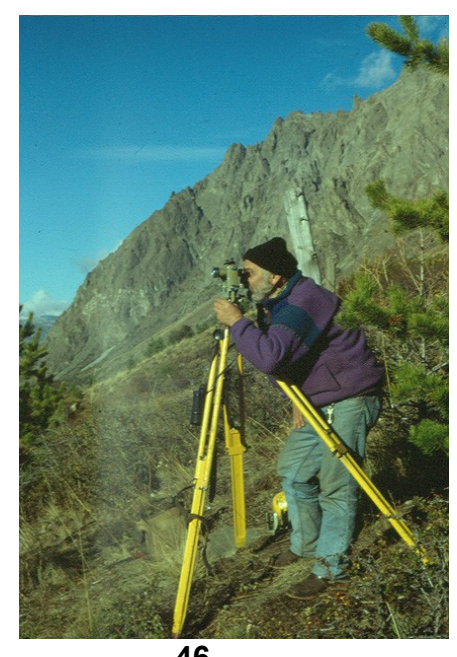

46

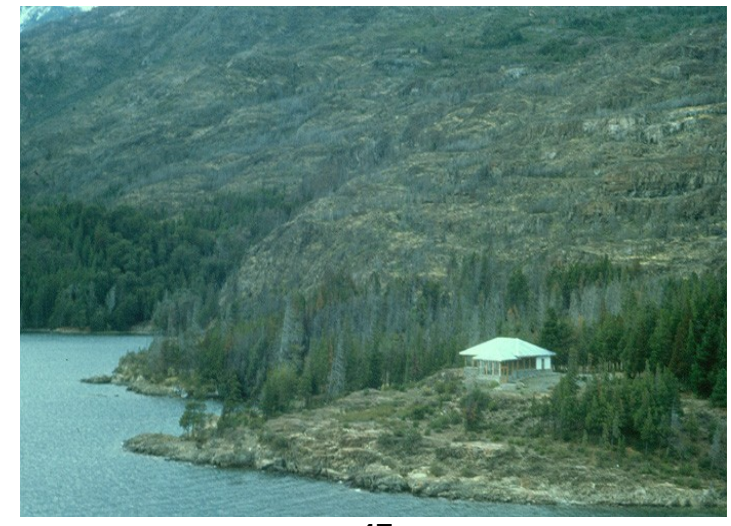

47

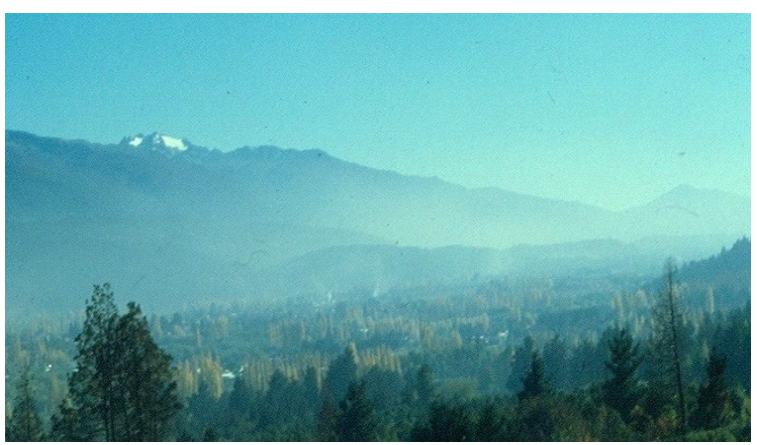

49

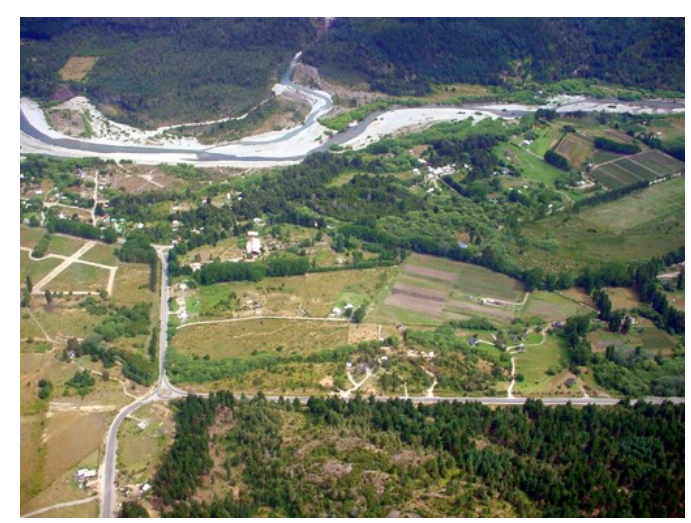

48

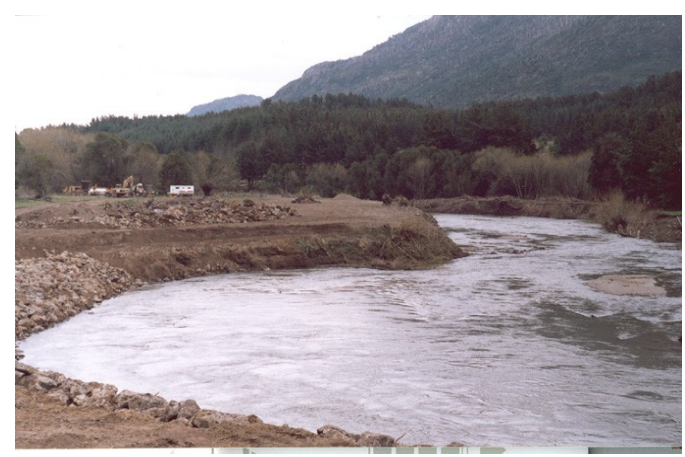

50

Fotos 42 a 48: Algunos de los impactos territoriales más destacados.

44: Inundaciones; frecuentes y de importante trascendencia. Camino vecinal en El Hoyo (foto del autor). 45: Sequías también recurrentes y de gran trascendencia ambiental; arroyo Blanco en Epuyén. Foto del autor, 2003.

46: Ocupación progresiva de ámbitos bio-físicos de fragilidad e importancia ecológico-social; altos faldeos del cerro Piltriquitrón. Foto del autor, 1998.

47: Incendios forestales, una amenaza permanente; Puerto Bonito en Epuyén con sus cipresales calcinados. Foto: F. Ottone, 2005.

48: Sub-urbanización progresiva; nótese la variedad de usos en un sector rural en proceso de transformación continua; sector Maderera en Lago Puelo. Foto: F. Ottone, 2004.

49: Contaminación del aire en complemento con un proceso de inversión térmica; El Bolsón. Foto del autor.

50: Manejo sectorial y conflictivo del agua (riego y recreación). Tratamiento de riberas y fondo del río Epuyén. Foto del autor, 2005. 


\section{III.4. Referencias bibliográficas.}

- Abalerón, Carlos A.. No ha sido el barilochense el que ha dirigido el destino de la ciudad. Entrevista por Susana Yappert. Suplemento Debates, Diario El Cordillerano, 2/12/2007, páginas 4 y 5 .

- Andenmatten, Ernesto. La Agro forestación y su impacto en la economía. Conferencia en el Taller para la Red de bosques modelos en la república Argentina. La Cumbre, Córdoba. Mayo de 1996.).

- Andrade, Larry. Sociología de la desertificación. Los productores ovino extensivos de la Patagonia Austral. Miño y Dávila editores.; Universidad Nacional de la Patagonia Austral. Buenos Aires. 2005. (287 p.).

- Bailly, Antoines. La geografía, imagen del mundo. En Ballesteros, Aurora (Coord.) Métodos y técnicas cualitativas en geografía social. Oikos-tau. Barcelona. 1998.

- Blanco, D., J. Méndes y G. Sánchez Reiche. Historia de una población de frontera entre Chile y Argentina: Segundo Corral 1930-1990. Informe inédito. El Bolsón, 1999

- Bondel, C. S.. Planeamiento urbano, medio ambiente y nomadismo en Patagonia. Exposición en el II Encuentro sobre temáticas regionales patagónicas, las ciencias sociales y el medio. Facultad de Humanidades y Ciencias Sociales, UNPSJB. Comodoro Rivadavia, 1992. Ponencia inédita.

- Bondel, C. S.. Tipologías de uso y 'lectura ambiental' en la explicación de situaciones territoriales comprometidas. La Patagonia Andina como caso paradigmático. Ponencia en el 50 Congreso internacional de Americanistas. Warszawa, Polonia. Julio, 2000. (21p.).

- Bondel, C. Santiago. El medio natural y la formación profesional en geografía. Reparos. En Revista Virtual del Centro de Estudios Alexander Von Humboldt: Posición Internacional. Buenos Aires, Año 2, № 2. Marzo de 2002.

- Bondel, C. Santiago (Director) et al. Proyecto de investigación: Uso del espacio y transformaciones territoriales en la Patagonia Andina de Chubut y Río Negro. Facultad de Humanidades y Ciencias Sociales, UNPSJB. Informe Final, 2006.

- Bondel, C. Santiago, Francisco Carabelli y Mauro Novara. "Problemáticas socioterritoriales en comarcas andino patagónicas de argentina". Fundación Cooperar, Serie de Divulgación Científica №1. El Bolsón 2006 (18p.).

- Ciccolella, Pablo. Transformaciones recientes del territorio fueguino argentino. En Territorios en transformación (Análisis y Propuestas). Editores: Curbelo, José L., Francisco Alburquerque, Carlos A. De Mattos y Juan Ramón Cuadrado. Fondo europeo de Desarrollo Regional (FEDER). C.S.I.C.. Madrid. 1994. (pp. 135-153).

- Consejo Federal de Inversiones (CFI). Grupo Estratégico de Negocios Alberto Wilensky. Plan de Marketing turístico de El Bolsón. Informe Final. Buenos Aires, 2001.

- Claval, Paul. La Geografía Cultural. EUDEBA, Buenos Aires, 1999. (377p.).

- DankImaier, Christine. Modelos de desarrollo forestal para la diversificación de los sistemas agrarios del Noroeste del Chubut. Diagnóstico social. Proyectos Federales de Innovación Productiva PFIP 2004-1. 2006 (mimeo).

- Díaz, Arnoldo. Encuestas en Valles de riego de la Comarca Andina: Lago Puelo- El HoyoEpuyén. EPDA- PROSAP. Informe Final, Esquel, Chubut. 2001.

- Eriksen, Wolfgang. Aspectos de la colonización agraria en la Patagonia. GAEA, Sociedad Argentina de Estudios Geográficos, Buenos Aires. 1979. (21p.). 
- García Ballesteros, A. Las aportaciones de la Geografía Humanística. En García Ballesteros, A.(Ed.). Geografía y Humanismo, Barcelona, Oikos-tau, 1992 (114 p.).

- García Ballesteros, A..(Coord.). Métodos y técnicas cualitativas en Geografía Social. Barcelona, Oikos-tau. 1998. (239 p.).

- González, Myriam Susana. Una aproximación al paisaje vivencial de los habitantes de una comarca cordillerana. El caso de El Bolsón en la Patagonia Andina. Revista Geográfica. Instituto Panamericano de Geografía e Historia, N N 133. México. 2004.

- Labasse, Jean. La organización del espacio. Ed. Ariel, Barcelona, 1973. (739p.).

- Lago Puelo, El Hoyo, El Maitén, Cholila. Formulación de planes de ordenamiento urbano. Presidencia de la Nación. Secretaría de Turismo, Préstamo BID 1648 /oc-ar. Programa de mejora de la competitividad del sector turismo en áreas piloto Provincia de Chubut. Teckno Mak S. A.. Buenos Aires, 2007.

- Lineau, Cay et al (1982). Rural settlements. Lenz-Verlag-Giessen. Ed. Harald Uhlig. Giessen, 1982.

- Marchissio, Mariela E.. Migrantes de anemidad. Nuevos emprendedores del sector turístico. Estudio de caso: El Bolsón y Lago Puelo. Tesina de Grado. Facultad de Turismo. Universidad nacional del Comahue. 2007.

- Martínez, Oscar A., Bondel, C. Santiago, Demarchi, Gabriela. y Danklmaier, Christine. Directrices de ordenación para el desarrollo territorial de Lago Puelo. Municipalidad de Lago Puelo - Unidad de asistencia en temas ambientales (UATA) de la Universidad Nacional de la Patagonia San Juan Bosco, sede Esquel. 2007.

- Nogué i Font, Joan. El paisaje existencial de cinco grupos de experiencia ambiental. Ensayo metodológico en García Ballesteros, A. (Ed.). Geografía y Humanismo, Barcelona, Oikos-tau. 1992. (pp. 87-96).

- Ortega y Gassett. El espectador. Textos escogidos. Ed. Salvat. Buenos Aires 1970.

- Pozzo B., Mario. Ciudad Patagónica: clima y vida cotidiana. Revista Pueblos y Fronteras de la Patagonia Andina. Revista de Ciencias Sociales. Año 5, № 5 . Comarca Andina del Paralelo 42. Octubre, 2004.

- Scheines, (1993); en Diana Durán. Geografía y transformación curricular. Lugar Editorial. Buenos Aires, 1996. (96 p.) Bailly, Antoines. La geografía, imagen del mundo. En Ballesteros, Aurora (Coord.) Métodos y técnicas cualitativas en geografía social. Oikos-tau. Barcelona. 1998.

- UATA, Unidad de Asistencia Técnica en Temáticas Ambientales, Universidad Nacional de la Patagonia San Juan Bosco. Equipo Técnico Municipalidad de Trevelín y UATA, 2006. Plan de Desarrollo de Trevelin. 2006. 


\section{CUARTA PARTE}

\section{APORTES AL PLANEAMIENTO TERRITORIAL, HACIA LAS CONCLUSIONES.}

En esta última Parte se atienden los planteos originados en las hipótesis iniciales y las comprobaciones alcanzadas a lo largo del trabajo. Para ello y dada la intención inicial de contribuir en instancias del Planeamiento territorial, se presentarán como marco de las conclusiones dos situaciones contextuales que entendemos como de las más trascendentes, la competencia territorial y alternativas para replanteos en el espacio comarcal, en particular respecto de los patrones de ocupación del espacio. Su tratamiento propone, además, alcances de índole metodológico para el primer caso y de índole operativa en el otro.

\section{IV.1. Aportes de índole regional-metodológica: la condición de competencia territorial, entre capacidades y expectativas.}

Desenvolvimiento espontáneo versus desenvolvimiento consciente.

El carácter dicotómico del subtítulo requiere de algunas valoraciones primarias a fin de no caer en el desatino que supondría un planteo entre lo malo y lo bueno. Si bien en el terreno territorial se tiende a asociar lo espontáneo con el desorden, esto no es más que una simplificación que no debe generalizarse.

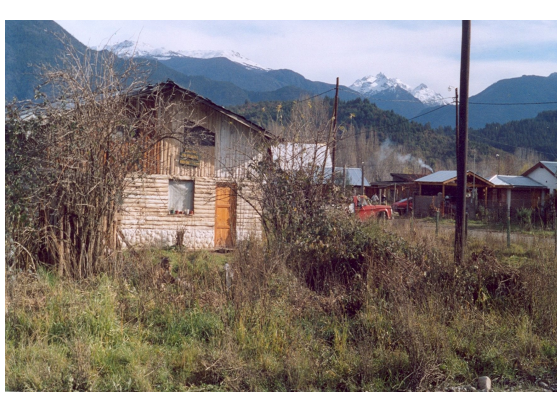

51

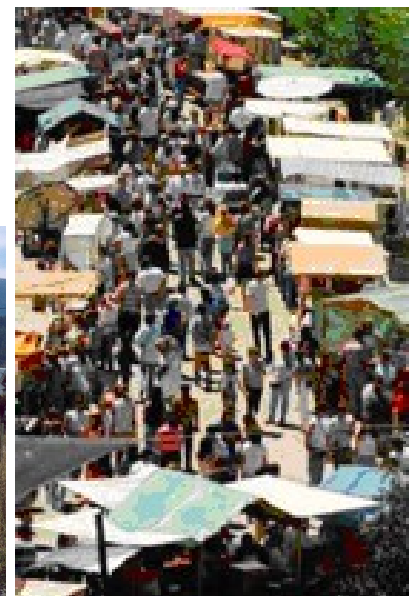

52

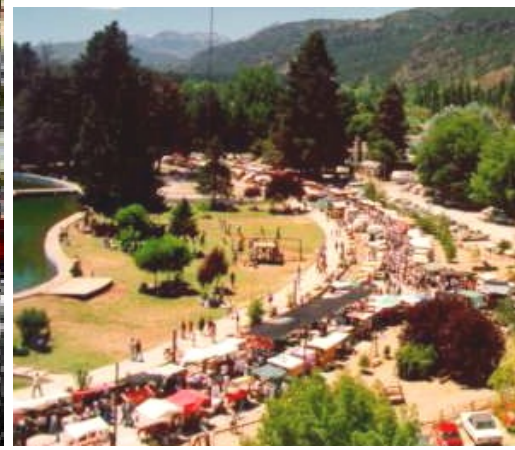

53

Lo espontáneo y sus efectos territoriales vacilantes; Foto 51: Como en todas las localidades, expansión residencial sobre tierras de buena aptitud agrícola (El Hoyo); foto del autor. 52 y 53: Feria Regional, un recorrido inicialmente espontáneo en demanda de coherencia de usos (fotos: G. Marchissio).

Para el caso, bastará ver la evolución muchas veces enriquecedora de iniciativas individuales o de algunos vecinos de mejorar la calidad y funcionalidad de sus 
viviendas, sistemas de producción o incluso de comercialización, para ver la riqueza de opciones que pueden llegar a plantearse y que sería muy difícil que ocurriera en instancias planificadas donde la flexibilidad necesaria para corregir un error de cálculo o pronóstico puede faltar. La Feria Regional de El Bolsón, hoy demandada de estrategias concertadas, nació y se fortaleció en la espontaneidad.

Justamente se prefirió utilizar el término consciente frente al de planificado, para adaptarse más a una realidad como la estudiada, donde las condiciones básicas para el planeamiento territorial chocan con la complejidad de un medio como el ya descripto, y donde, en especial, se destaca la superposición funcional de dependencias y responsabilidades jurisdiccionales (nacionales, provinciales, municipales) ${ }^{223}$.

También merece subrayarse el término desenvolvimiento que así como no significa crecimiento, tampoco excluye esa posibilidad. De hecho, el crecimiento en sentido demográfico, económico y espacial, con algún altibajo, se presenta como destacado a la hora de los análisis y comentarios (y temores por 'falta' de espacio) relacionados con la realidad de la zona.

En el marco teórico ${ }^{224}$, se llamó la atención sobre la necesidad de abordar los conceptos de aptitudes, expectativas, capacidades, umbrales, límites, tolerancia, sustentabilidad y otros. La demanda social en tal sentido es, tal vez, la más destacada $\mathrm{y}$, si se quiere, polémica y contradictoria ${ }^{225}$.

Es en ese contexto, donde queda de manifiesto con toda intensidad lo alejado del paisaje de ser un componente neutral en la sociedad ${ }^{226}$, es que tomamos al concepto de competencia como guía orientadora hacia un devenir territorial adecuado. Competencia, nos repetimos, en su sentido de competente, de ser capaz, de estar preparado para desenvolverse en determinada dirección de desarrollo.

Ante el planteo, la reunión de expectativas y capacidades se mostraron como vías de observación oportunas en favor de alcanzar una visión integral de un lugar en una circunstancia histórica particular y proclive a transformarse. Con ello y desde el

\footnotetext{
${ }^{223}$ Uno de los tantos ejemplos ocurre con las situaciones que se reiteran en aspectos relacionados con el turismo, en especial el de alta montaña, donde las gestiones de refugios, seguridad, pasarelas, sendas, impactos y demás, carece de responsables específicos. Sus resultados, en definitiva, responden a cuestiones netamente voluntaristas de las entidades que en más o en menos responden al perfil de gestión necesitada. Ver también en Madariaga (2007: 12).

${ }^{224}$ Ver Ítem: Competencia territorial y territorios complementarios.

225 Los vaivenes o pérdida de vigencia de Códigos de Planeamiento (El Hoyo, Lago Puelo), Planes Estratégicos (El Bolsón) y similares (CODECAP), así como las dificultades para alcanzar resultados socialmente aceptados y geográficamente estructurados, muestran un escenario aún vago a la hora de reflejar una cultura de convivencia con el medio natural. Consta, también, que casi no hay artículo periodístico o episodio de participación social referido al desarrollo regional, donde el tema no sea recurrente. Incluso, en el 'apuro', llega a reducirse a un rígido determinismo sostenido en la figura de capacidad de carga.

226 En realidad y aunque no hayamos podido dedicarnos en particular, creemos que sería oportuno avanzar en la verificación de ciertos 'cabos perdidos' del determinismo geográfico ratzeliano, excluidos tempranamente por sus factores ideológicos generalizadores sin una válida o, al menos, profunda discusión científica (cf: Silverol, Aline, 2000 y ver también en Capel 1981: 284-85).
} 
análisis, se valora la posibilidad de acompañar procesos, que, como se puede ver en nuestro medio, son fuertemente traumáticos.

Las expectativas serán las que traducen esperanzas e intereses personales y sociales; una 'categoría' plenamente subjetiva, con un grado de fidelidad directamente proporcional a la calidad y profundidad del análisis. Está visto que entrevistas, encuestas, censos y muestreos, dejan hendijas sin atender o se muestran con claroscuros, pero también su existencia es concluyente a la hora del funcionamiento socio-económico y político de nuestros pueblos; de hecho sería inconcebible su no existencia.

La capacidad territorial, por otra parte, agrupa en si misma aptitudes e impactos; unos como producto de las ventajas y desventajas existentes para las actividades y otros, como resultado de la convivencia del medio con las tecnologías de uso. Así pues, esa capacidad surge con sencillez relativa de cruzar las aptitudes del lugar con los impactos potenciales de las intervenciones ${ }^{227}$.

Tan sólo como una analogía simplificada se muestran las dos fotografías que siguen y que representan distintos resultados, producto histórico-tecnológico, para condiciones físicas similares.

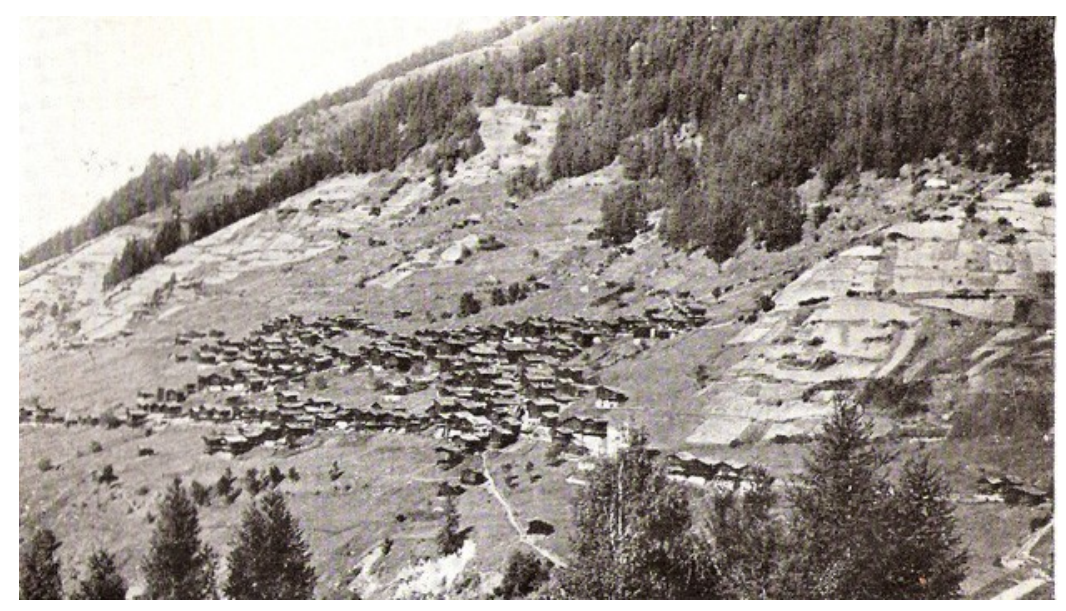

Foto 54: Fotografía del la villa de Val en Suiza, extractada de la Geographie Humaine de Jean Brunhes (1943). Valórese que tanto la localidad como las parcelas de cultivo se sitúan en pendientes desconocidas para nuestro medio.

227 Como se afirma en Martínez et al (UATA) 2007 (Lago Puelo), 'La mayor capacidad territorial se dará allí donde el impacto sea el menor y la aptitud la mayor'. 


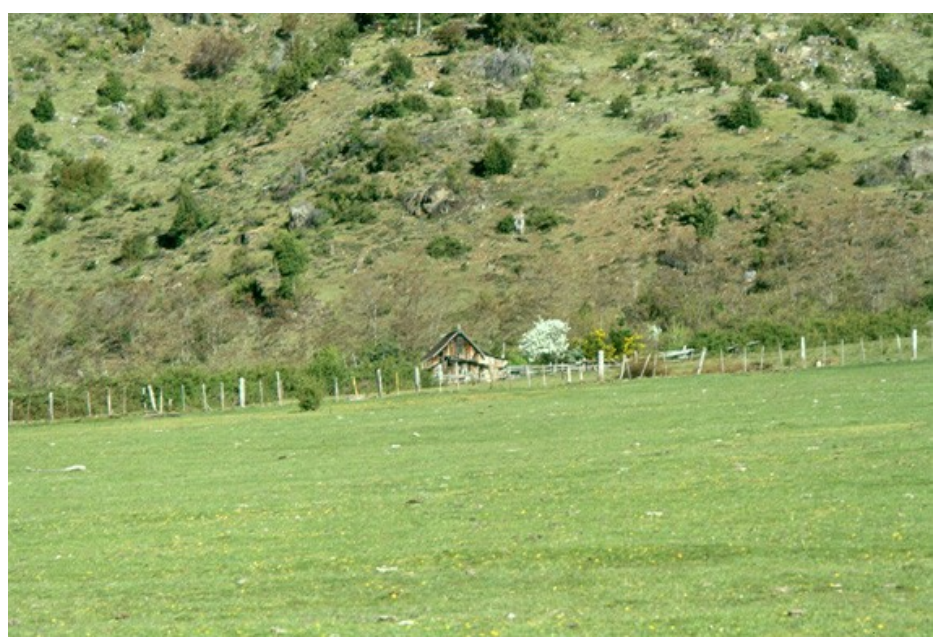

Foto 55: En nuestro medio, las pendientes excesivas son eludidas toda vez que sea posible. Lo habitual es, al menos asentarse al pié de los faldeos. Vivienda campesina tradicional, El Hoyo. Foto del autor. Ya apuntaba Labasse en ese sentido, “... La originalidad de la actitud de cada pueblo con respecto a su territorio no proviene directamente de las 'condiciones de vida e interacción entre los seres vivos y el medio'. Viene del compromiso establecido o.

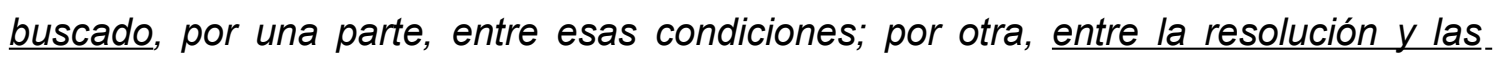
aspiraciones de la comunidad... (1973: 600); el subrayado es propio.

En la convergencia de capacidades y expectativas, entonces, se verá reflejada la condición de competencia territorial y con ello, finalmente, una valoración operativamente diagnóstica. Será pues al señalar los grados de compatibilidad o incompatibilidad de las distintas actividades en diferentes medios, en que el análisis podrá contribuir con el planeamiento. El esquema que sigue refleja el recorrido propuesto y será fundamental el objetivo que se persiga para llegar a una ponderación.

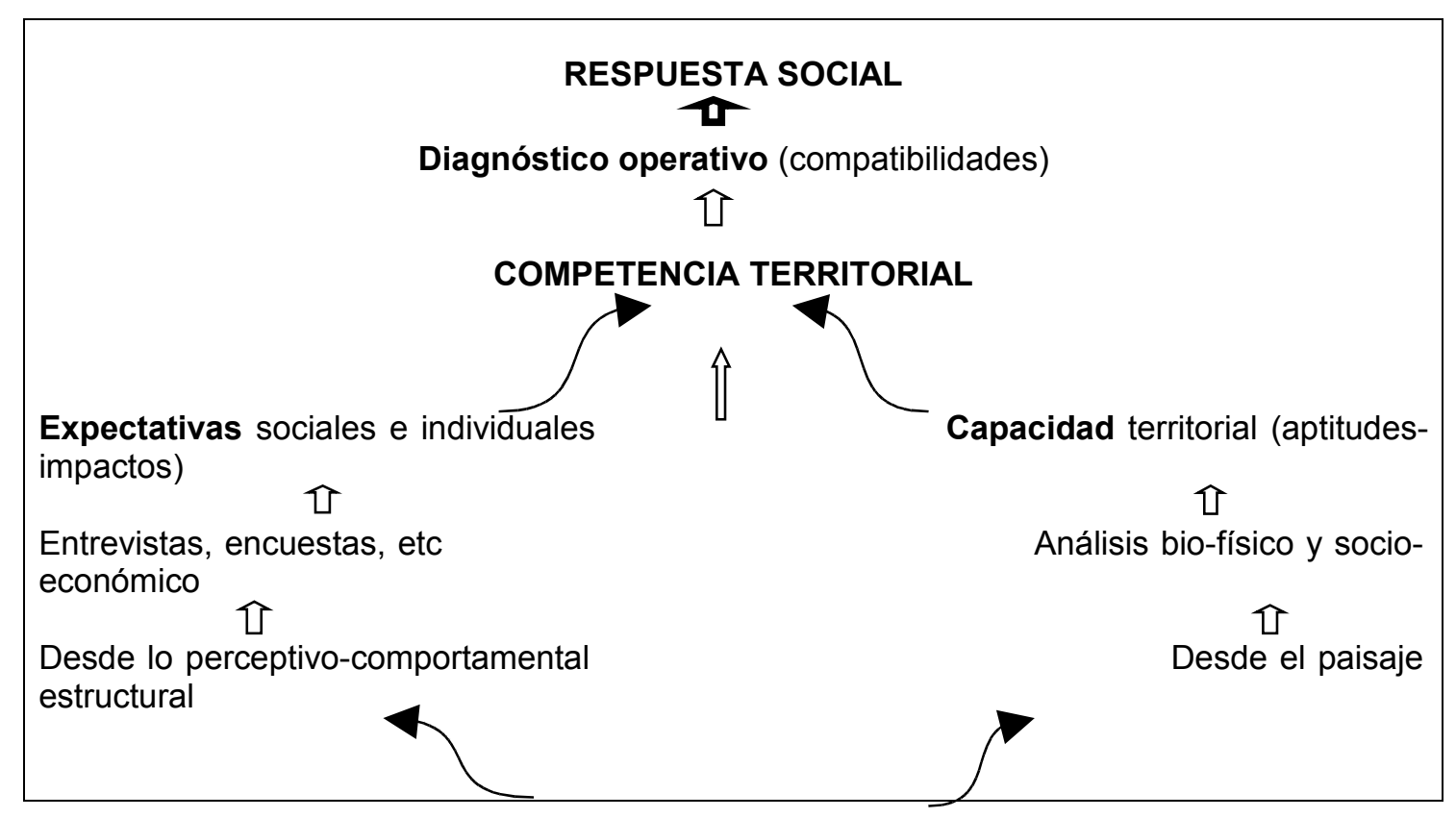




\section{Territorio a considerar \\ T \\ Presentación territorial problemática}

Fig. 19. La competencia territorial, esquema metodológico para su valoración.

Se concluye entonces, que para establecer categorías de competencia territorial se hace necesario indagar con rigor a través del encadenamiento de los factores: capacidad - expectativas. Ese rigor podría provocar como contrapartida una suerte de atascamiento operativo en vista del universo problemático a contemplar, de modo que, nuevamente se torna fundamental la claridad en la dirección a tomar.

Tomamos por caso el de la localidad de Lago Puelo, cuyas autoridades municipales (2007) recurren a la Universidad Nacional de la Patagonia San Juan Bosco (demanda social) requiriendo asesoramiento en materia de ordenamiento territorial dada una importante crisis en materia de conflictos de usos y desactualización de su Código de Planeamiento.

Lago Puelo y la búsqueda de su perfil territorial como caso analítico.

El ejemplo, sólo abordado desde algunos de sus aspectos más ilustrativos, entendemos que destaca el rol activo que le cabe al análisis geográfico en los procesos de transformación territorial; rol que lleva implícito conservar cierta sincronía con los mismos y por lo tanto una actitud profesional acorde a la hora de enfrentarse a la demanda social.

Como demostración se ha tomado una de las etapas de la "Elaboración de directrices de ordenación territorial y zonificación general de Lago Puelo" (Martínez, et al. UATA, 2007); experiencia de neto corte multidisciplinario, que ha reunido a profesionales y

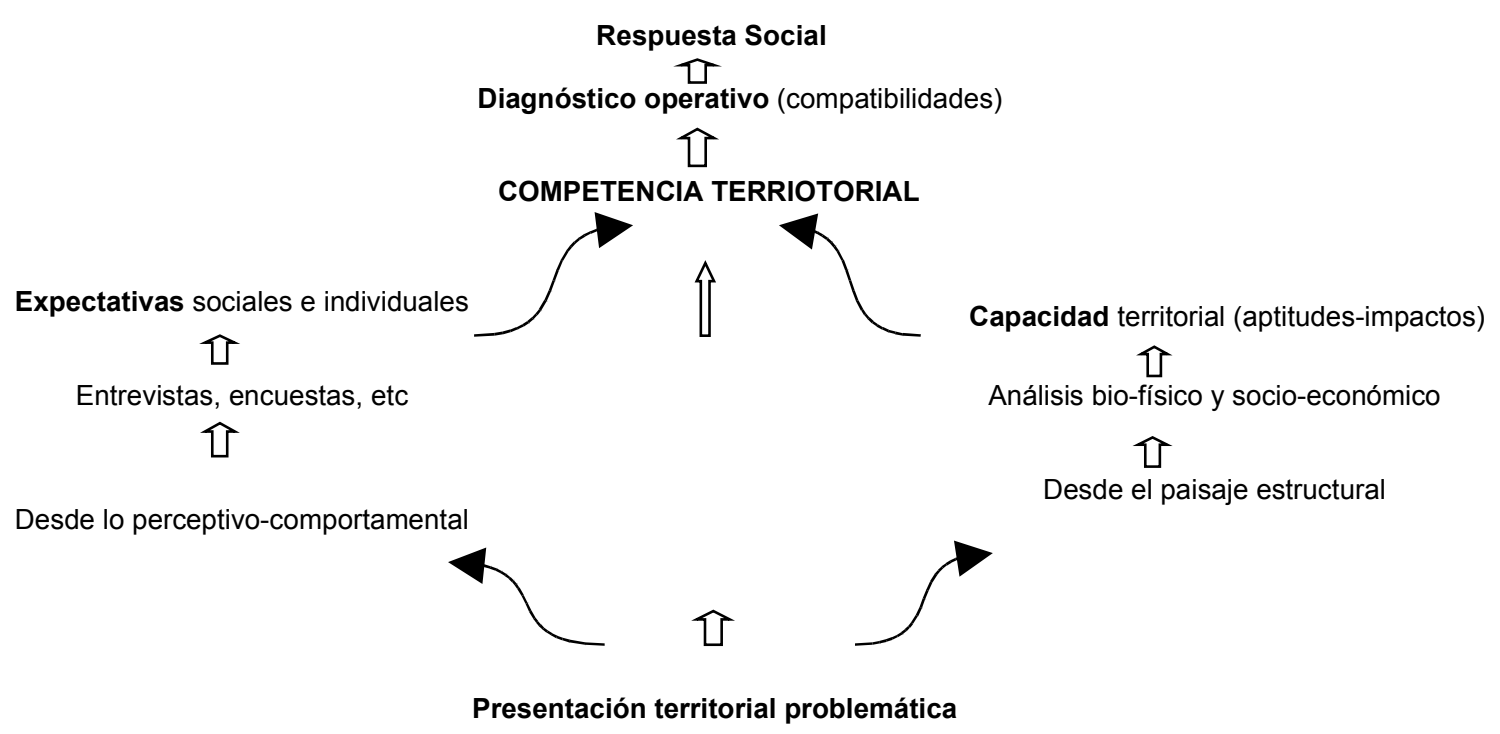


técnicos de diversa formación para un producto unitario ${ }^{228}$. Se trata de un documento elaborado como herramienta de gestión territorial cuyo objetivo principal fue el de contribuir con un desenvolvimiento que tienda hacia su sustentabilidad y en armonía con las actividades humanas. Un conjunto de enunciados denominados "Directrices de Ordenación", proponen líneas de acción o recomendaciones de uso que deberían orientar tanto el diseño e implementación de las políticas públicas, como la radicación y desarrollo de actividades económicas y productivas promovidas por el sector privado. De esta manera, se obtuvo un marco orientador para la elaboración de las futuras normativas del uso del suelo y en particular, la necesaria reformulación del Código de Planeamiento vigente. El valor y pertinencia de las Directrices de Ordenación desarrolladas radica, esencialmente, en el enfoque participativo de la metodología utilizada para su formulación. Más de 300 pobladores fueron encuestados y más de 250 participaron de los talleres abiertos realizados en los distintos parajes desde el inicio del proceso, en octubre de 2006.

Cabe destacar que el ejido de Lago Puelo (unas 11.000 ha), con aproximadamente, 6.000 habitantes permanentes y en franca expansión, inmerso en un proceso de gestación territorial de permanente cambio, abierto y sensible a circunstancias extraregionales, repite en su esencia patrones problemáticos andino patagónicos.

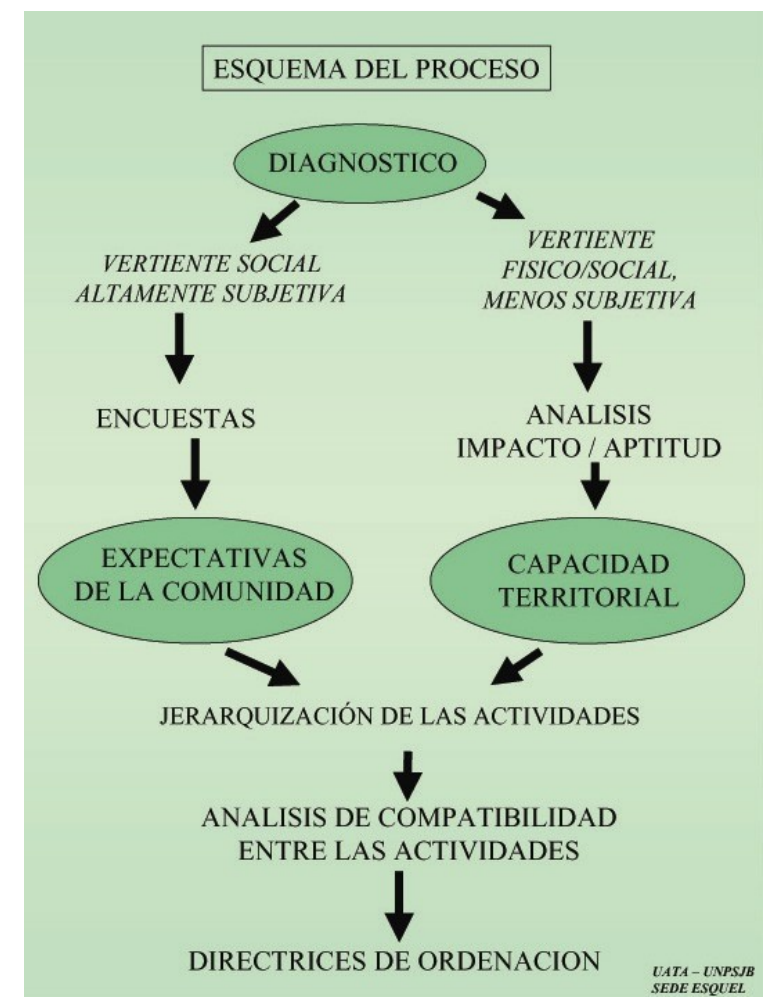

Fig. 20. Esquema del proceso (Martínez, et al. UATA, 2007)

Capacidades y expectativas territoriales de pobladores de Lago Puelo.

\footnotetext{
${ }^{228}$ Esta necesidad de una accionar multidisciplinar surge casi como una respuesta profesional espontánea en ciertos ámbitos regionales; surge aquello de, como rescata Bozzano de Santos y Souza, tal vez el espacio sea, "...el más interdisciplinar de los objetos concretos..." (2004: 24).
} 
La etapa metodológica elegida giró en torno a la identificación de las capacidades y expectativas territoriales existentes y si bien no alcanzaron aún instancias operativas concretas, consta su utilización en el discurso de los re-planteos de los Códigos de Planeamiento locales (Lago Puelo, 2008 y El Hoyo, 2008).

Se han escogido las figuras que siguen como modelo del recorrido del análisis, toda vez que cabe destacar que se trata tan sólo de algunas de formas diagnósticas y su verdadera potencialidad está tanto en el trabajo en su conjunto, como así también en su eventual aceptación social de las mismas.

Los criterios metodológicos intervinientes presentan dos vertientes analíticas distintivas:

1) La determinación de las capacidades territoriales obtenidas a partir del análisis sistemático de sesgo ecológico, económico y socio-cultural; se trata de la relación de aptitudes con impactos con la valoración de todos los 'analistas' intervinientes (en la oportunidad cuantificada de $0-10)^{229}$.

Aquí, la necesidad diagnóstica inicial se vuelve, en todo caso, imprescindible a la hora de identificar y valorar a los impactos o efectos negativos generados por el desarrollo de las diferentes actividades y así alcanzar una ponderación de la capacidad territorial. Hay un retorno continuo a las cualidades geográficas del lugar analizado; así fuera por condiciones microclimáticas, escurrimientos, tipo de sustrato o por modalidades productivas o de asentamiento, entre el inagotable universo de la complejidad de los lugares, la visión sistemática confluye en la interpretación geográfica. Nos cabe retomar aquello que planteáramos en otra oportunidad, de validar a la geografía 'profesional', a la operativa, aquella de la acción, de la prevención y participación responsable, abarcativa y abierta a la multidisciplina (Bondel, 2002).

\footnotetext{
229 Merece valorarse el sesgo multidisciplinario del ejercicio ya que los resultados se obtuvieron cruzando ponderaciones de un geólogo, un geógrafo, una antropóloga y una filósofa especializada en desarrollo local, con participación más específica además, de un economista, una historiadora y un ingeniero forestal, todos con importantes antecedentes en actividades académicas y/ profesionales en la región.
} 


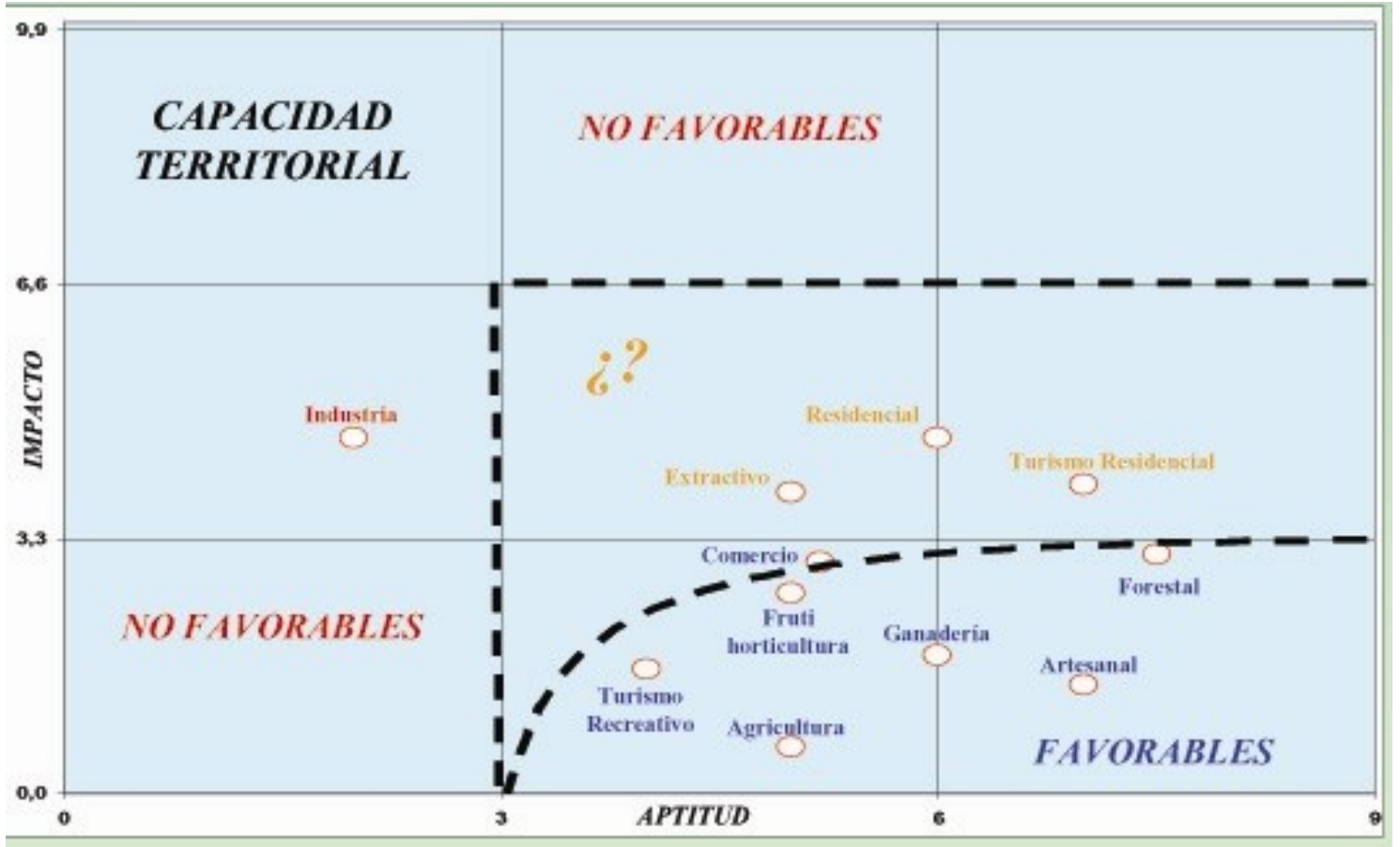

Fig.: 21 Capacidad territorial. Resultados en el Paraje (sector) Las Golondrinas en (2007); distribuciones aptitud-impacto de las actividades. En esencia, de base analítica profesional.

2) La determinación de las expectativas y jerarquización de las actividades para cada paraje o sector, éstas obtenidas a través de una sistematización perceptivacomportamental que, para el caso considerado, surgió de la participación de los pobladores intervinientes en talleres y encuestas (uno por unidad habitacional). A modo de ejemplos, véase en las figuras que siguen cómo de los resultados de encuestas, el paisaje y la tranquilidad sobresalen en la serie de visiones, todas altamente comprometidas con el entorno geográfico (Martínez et al. UATA, 2007) ${ }^{230}$. Cabe reiterar que ha sido luego del diagnóstico, es decir de la caracterización del territorio y tipificación de usos, cuando fueron consultadas las expectativas de la comunidad, reuniendo intereses, deseos y proyectos de los ciudadanos.

\footnotetext{
230 Las encuestas (316) fueron posteriores a talleres y reuniones conducentes. Incluye preguntas y repuestas ilustrativas de fuerte connotación para con los comportamientos, como: ¿qué actividades quieren los residentes de Villa del lago que se desarrollen en el Paraje Entre Ríos? y ¿Por qué elige como primera y segunda actividad las siguientes?.
} 

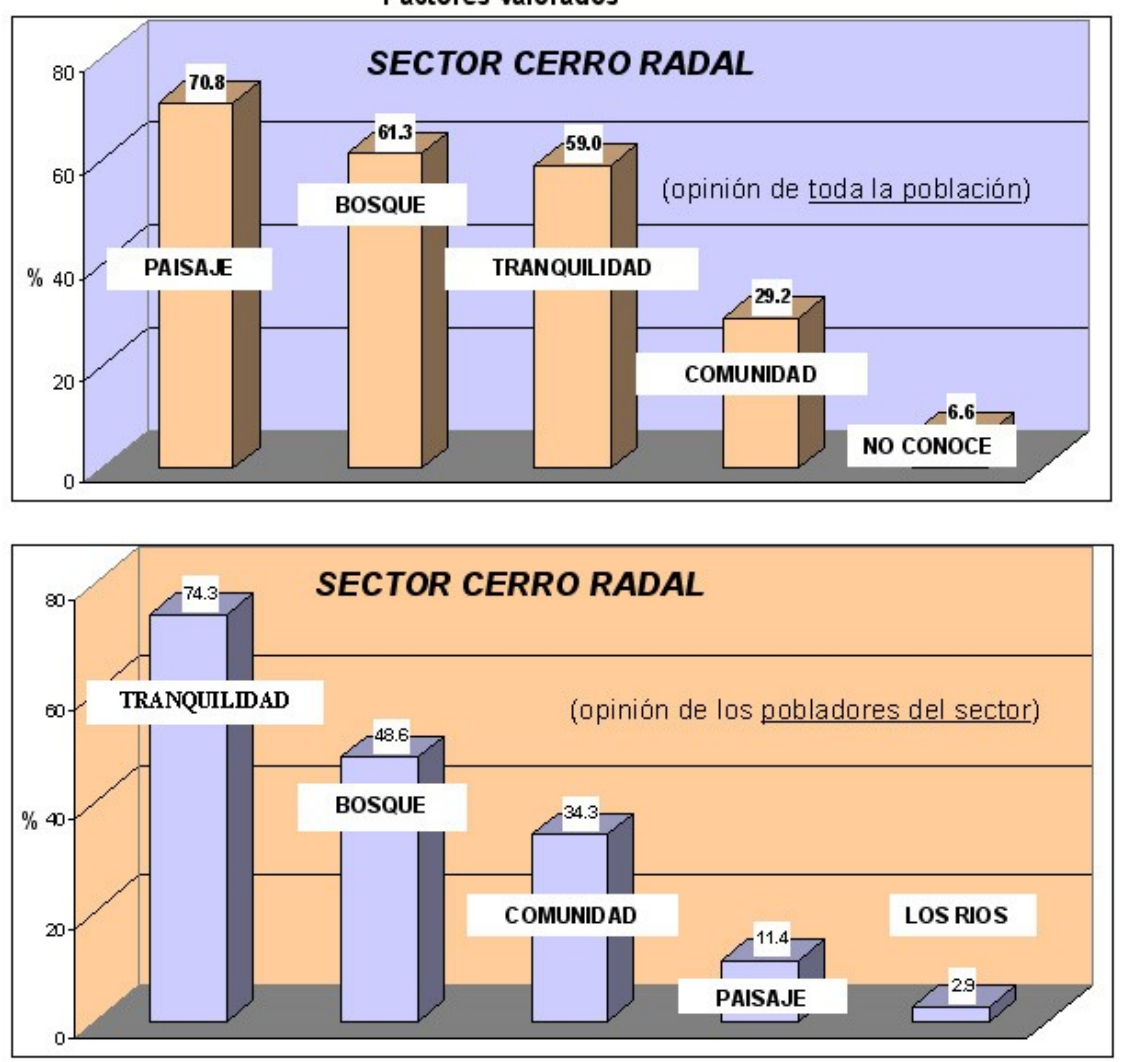

Fig.: 22. Valoración de los pobladores. Resultados en el Paraje Cerro Radal (2007). Los 5 primeros factores socio-territoriales valorados en las expectativas a conservar y/o desarrollar. Al referirse a toda la población es referido a aquellos habitantes de ejido Lago Puelo.

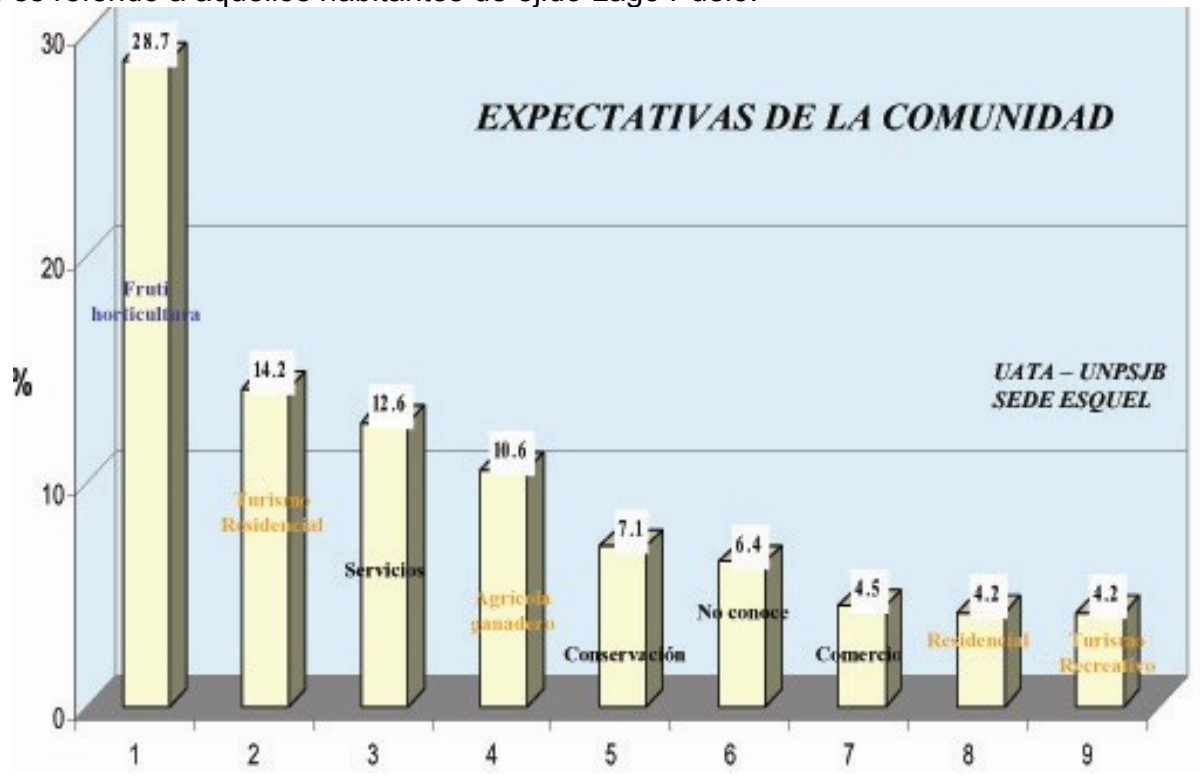

Fig.: 23. Expectativas de los pobladores. Paraje Las Golondrinas (2007); expectativas sobre las actividades deseables para el paraje; en base a consultas sociales y vistas con relación a valoraciones territoriales.

En honor a no extendernos en demasía ya que requeriría analizar los detalles por paraje, cabe añadir el texto de la directriz general de ordenación territorial y la 
zonificación propuesta (mapa 7), ambos instrumentos políticos clave a la hora del Planeamiento.

Propuesta de directriz de ordenación general para Lago Puelo (Martínez, O. et al UATA, 2007):

Lago Puelo se entiende como una unidad de territorio que pretende proyectarse en el marco de la conservación de la Naturaleza y un estilo de vida aldeano ${ }^{231}$ adaptado a altos patrones de calidad de vida ${ }^{232}$, con el turismo y la actividad frutihortícola como líneas principales de desarrollo estratégico.

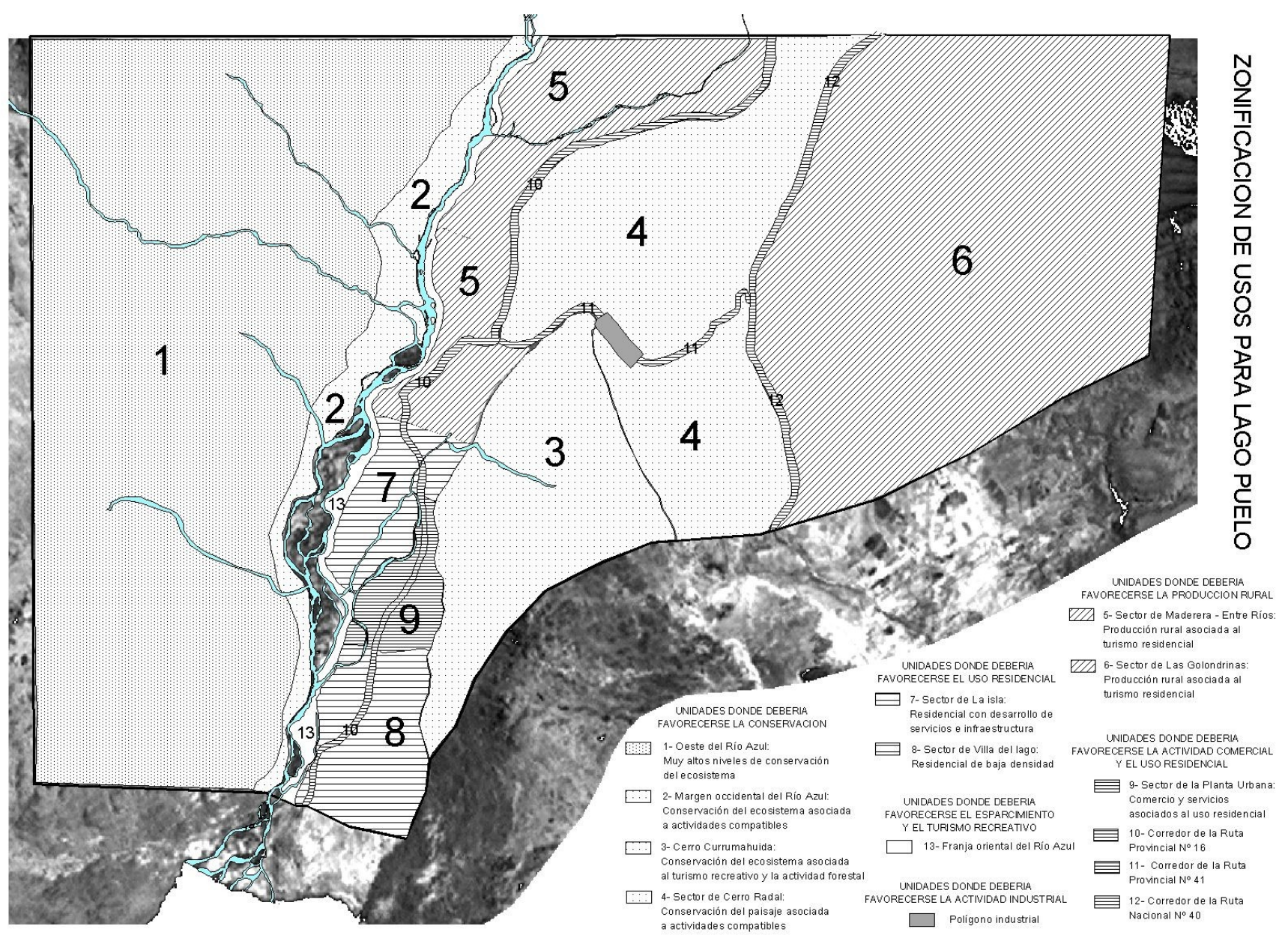

Mapa 11: Zonificación para las directrices del ordenamiento territorial; ejido de Lago Puelo. El mapa tan sólo se inserta para ejemplificar, de un modo apenas visual, con uno de los resultados más trascendentes a la hora del Planeamiento producto de una tarea multidisciplinaria y socialmente participativa. (Martínez et al. UATA, 2007).

Finalmente, cabe agregar que será recién cuando se atiendan instancias precisas, es decir acomodada a alguna problemática específica, que se podrá recurrir a aquella

\footnotetext{
${ }^{231}$ Estilo de vida aldeano: implica un ritmo diario distendido y seguro, con predominio de las relaciones personalizadas, en espacios abiertos, con una vida comunitaria activa.

${ }^{232}$ Altos patrones de calidad de vida: implica la satisfacción de las necesidades básicas (vivienda, capacidad de subsistencia, condiciones sanitarias, educación) y culturales, de seguridad, de la calidad medioambiental, de tranquilidad, con accesibilidad a la información, manteniendo el contacto directo e inmediato con la naturaleza.
} 
figura de competencia territorial, ya en instancia más políticas más académicas (ver esquema de la figura 19).

\section{IV.2. Aportes de índole regional-operativa: densificación urbana y territorios complementarios, alternativas para replanteos en el espacio comarcal.}

Dado el grado de análisis alcanzado hasta ahora, en esencia explicativa del contexto problemático socio-territorial planteado desde los inicios, se presentan dos perspectivas analíticas potencialmente paliativas de desarmonías territoriales vinculadas inexorablemente con la expansión urbana espontánea de muy baja densidad manifiestas en todas las localidades de la Comarca y el confinamiento físico impuesto por el medio físico y el devenir geohistórico. A modo de una instancia propositiva, refiriéndonos a tendencias emergentes de relaciones probables, al decir de Bozzano (2004: 35), se tratará, por un lado la posible promoción a la densificación urbana y por el otro a la valorización de territorios complementarios ${ }^{233}$.

Ambos escenarios responden a alcances territoriales en esencia deseables (urbanísticos y productivos) y, seguramente, estarán más cercanos al bien común que la proyección espacial presente ${ }^{234}$.

Algunas consideraciones generales vistas como un anticipo sugerente:

a. Densificación urbana con estándares coherentes; revisión de criterios arquitectónicos-tecnológicos e impositivos para el re-direccionamiento de las tendencias espacialmente dispersivas. Ciudad, pueblo y aldea de montaña 'compactos'.

La densificación urbana se muestra como un ejemplo cabal respecto de las atenuaciones a la expansión espacial desproporcionada de los vecindarios. Por supuesto que deberá tratarse de una densificación con altos estándares urbanísticos, que, entre otras cosas, debe promover tanto la calidad edilicia como los resultados escénicos y vivenciales (Pozzo B., 2004). De alguna manera es la recuperación de las bondades que significa la ciudad como lugar de encuentro, protección, producción e

\footnotetext{
${ }^{233}$ No es que se excluyan las otras problemáticas, pero la elección de estas dos va de la mano con el consenso político-mediático que existe en cuanto a la 'falta de lugar' y a los límites físicos que se imponen al crecimiento demográfico y económico.

${ }^{234}$ Entendemos que ya se han mostrado bastantes ejemplos que ratifican estos conceptos (Hernández y Mochkofsky, 1974), pero, en todo caso sirvan estas apreciaciones de neto corte mercantilista vigentes en discursos políticos regionales: "pero si se crece en orden, cuando se alcancen los límites del crecimiento sustentable, el mercado a través del precio de la tierra puede ser un factor que regule el asentamiento de la población. Esto quiere decir, que naturalmente, si existe menos tierra o espacio disponible, tenderá a aumentar el valor inmobiliario, (...) como un mecanismo de regulación que tiende a mantener la población estable, o sea que cada habitante que vende sale del sistema, u ocupa otro nicho, para que haya lugar para el nuevo habitante que entra, y se mantenga en su punto óptimo, una población estable en equilibrio con el ambiente (cf.: Refundación de El Bolsón. Merino. Mimeo, 2005).
} 
intercambio, despegándose de aquellas otras tan desarrolladas desde hace ya varias décadas, donde hacinamientos, congestión y contaminación se retroalimentan en una suerte de violencia desproporcionada ${ }^{235}$.

Nos ha tocado vivir en tiempos en que la ciudad en sí, en particular la latinoamericana, parece hallarse en una suerte de crisis paradigmática, donde tanto la escala como la diversidad de problemas han 'borroneado' las virtudes tradicionales del hecho urbano en sí y acentuado sus conflictos. Es así que aquí se confirma de la mano con el proceso de globalización y con modalidades de las más disímiles, una suerte de 'huída urbana', real o deseada, de grupos sociales, incluso 'acomodados', arrastrando con ello nuevas pautas territoriales (desde una exorbitante demanda de lugar físico y una suerte de desaparición de espacios públicos, hasta la atomización intra-urbana con sus consecuencias).

Fuera de los términos regionales de la discusión se confrontan diversas interpretaciones con diferente valorización de prioridades (cf: Claval, Paul; 1999, Cap. 11. Di Pace, M., S. Federovisky y J. Hardoy; 1991. Haggett, Peter; 1988. Cap. 14. Randle, P., 1985. Cap.1 y 3; Morello, J., en Rev. Fronteras. GEPAMA, UBA, 1, 2002. Hernández y Mochkofsky, 1974: Introd.), la pérdida de tierras de buena potencialidad agroecológica y el sostenimiento de servicios públicos para pobladores dispersos no incorporados a instancias productivas rurales, afirman en nuestros días una dirección poco sustentable.

Pero tal vez, sea importante no perder de vista que cuando se descalifica a la expansión urbana indiscriminada por su carácter antisocial, se lo hace frente a circunstancias actuales. Sea por la extensión de servicios comunitarios o por pérdida de tierras de labrantío, por ejemplo, la realidad nos muestra un escenario que no da descanso al ingenio político de atender demandas de todo tipo. Sin embargo resulta innegable también la trascendencia de la capacidad tecnológica y las formas de vida predominantes, de modo que cabe la necesidad de una revisión progresiva que pueda atender aquellas innovaciones con posibilidades espacialmente armónicas.

\footnotetext{
${ }^{235}$ Cabe destacar que en el área bajo estudio, especialmente entre los migrantes modernos, prevalece el rechazo a la figura de ciudad, lo cual refuerza la tendencia a la dispersión asociada con las motivaciones neorrurales. Se ratifica este comentario anti-urbano, por ejemplo en los antecedentes de Martínez et al, UATA, 2007; en Marchissio, M. 2007: 32-34), en Las Bases para el Plan Estratégico de El Bolsón, 1998).
} 


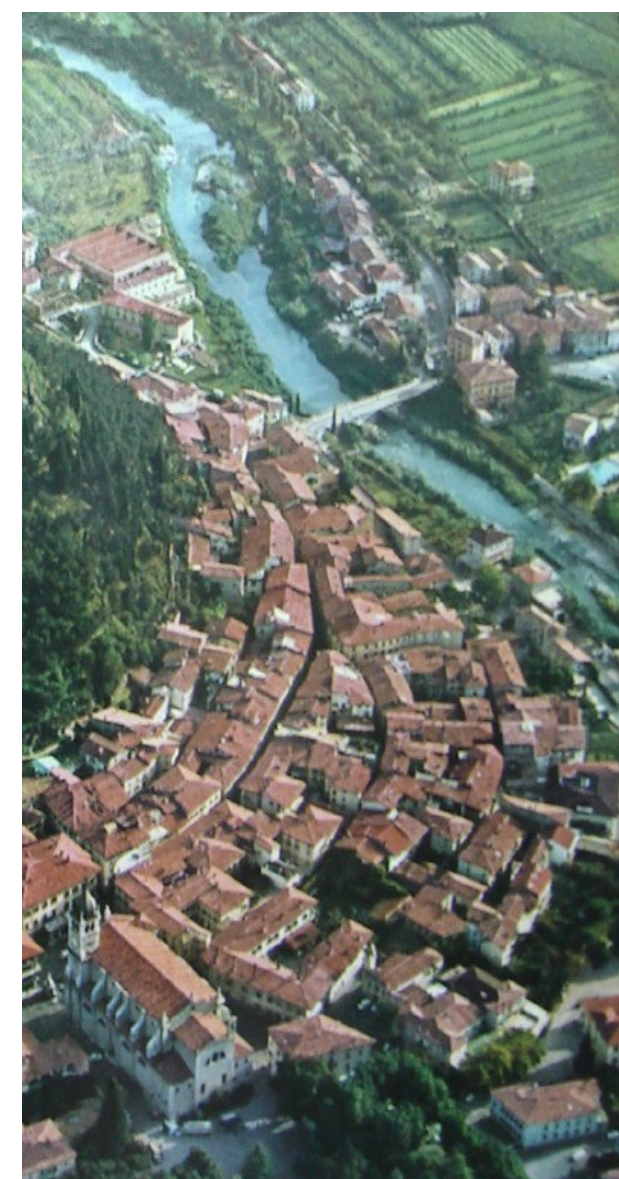

56

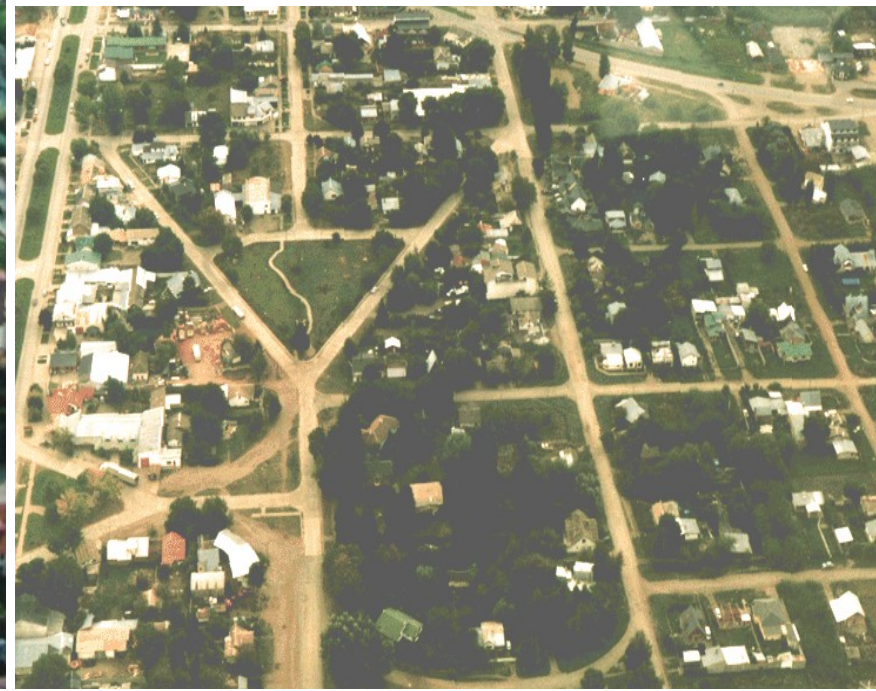

57

Fotos: Densidades urbanas en pueblos y ciudades de montaña. Dos realidades contrastantes (foto. 56: núcleo central de Arco en el Trentino italiano (véase la cercanía de las plantaciones). Foto de poster turístico s/d; 57: parte del casco central de El Bolsón. Foto del autor.

b. Incorporación de territorios complementarios en las estrategias de ordenamiento territorial.

Ante las condiciones de 'estrechez' que impone el confinamiento físico de las montañas, los territorios complementarios, cuyo significado no va más allá que lo que indica ese calificativo, se visualizan como una alternativa categórica en términos socioterritoriales.

La idea principalmente se sostiene en que:

- el confinamiento espacial impone límites forzosos, tanto ecológicos como tecnológicos a la expansión física; con ello hasta el mismo crecimiento vegetativo encontraría una valla difícil de vencer, suponiendo una progresiva pérdida del potencial ecológico-productivo.

- son territorios en estado embrionario, donde prevalece la fragmentación espacialjurídica de tipo antecedente y sobrepuesta a condiciones ecológicas heterogéneas; 
- donde ambientalmente se está frente a previsibles umbrales críticos propios de períodos de crecimiento socio-económico-demográfico ${ }^{236}$;

- donde conviven tecnologías de uso del espacio imprecisas o de escaso arraigo (cultura de la extrapolación migratoria), apenas incorporado a la tradición argentina ${ }^{237}$.

En la historia se encuentran las causas básicas que explican los conflictos entre la capacidad territorial deseada y la configuración de los ejidos legales; sostenemos aquí, que desde una lectura contemporánea y básicamente geográfica, podrán alimentarse nuevos direccionamientos en la organización de los espacios.

El caso sugiere inicialmente la valoración de una complementariedad 'natural' que puede observarse respecto de los ámbitos bio-físicos y sociales. Nuevos espacios proclives de satisfacer una demanda diversificada por el uso del territorio y la tecnología disponible. Es fundamental, de todas formas, comprender que la reflexión tendrá validez en tanto y en cuanto sea ésta una dirección a tomar, es decir exista voluntad social de direccionarse hacia la complementariedad territorial.

Los ejemplos más evidentes, aunque no los únicos en este sentido, los tendremos con las grandes terrazas pedemontanas que forman el oriente comarcal. Superficies extensas de la estepa-arbustiva inmediatamente adyacente a los bosques de nothofagus y austrocedrus. Se trata de las extensas terrazas fluvioglaciarias que conforman los entornos de El Maitén, Epuyén y Cholila y en un marco condicionante ecotonal, valoramos algunos aspectos interesantes que, profundizados en su análisis podrán ser indicadores sugerentes en un terreno exploratorio.

Condicionantes complementarias favorables de estos ámbitos:

- topografía de relativo bajo condicionamiento (véase mapa 12);

- disponibilidad razonable de agua por captación de cursos;

- condiciones de heliofanía más favorables que los valles centrales;

- relativa escasa complejidad jurídica por predominio de grandes estancias ${ }^{238}, y$

- relativa buena conectividad

Entre las limitantes:

- temperaturas relativamente bajas con veranos frescos e inviernos rigurosos (en función de la altura - del orden de los 600-800 m.s.n.m.)

- posibilidades ciertas de heladas tardías y tempranas;

- semiaridez generalizada e importante frecuencia e intensidad de los vientos del Oeste.

- falta y/o pérdida de tradición campesina como para promover actividades rurales.

- estructura jurídica antecedente

- falta de proyectos jurisdiccionales conjuntos que promuevan la expansión hacia el Este.

\footnotetext{
${ }^{236}$ Presentamos a la Patagonia Andina como territorios adolescentes y con ello cierta connotación soñadora, irritable, "bajonera", desafiante y encaradora (Bondel en Concepto Forestal, 2006).

${ }^{237}$ Como ya se anticipó, en términos comarcales y con un enfoque fenomenológico, Nogué i Font presenta el caso montañés de La Garrotxa, donde prima la diversidad en el paisaje (1992: 89)

${ }^{238}$ Sería una ingenuidad confundir complejidad jurídica con capacidad jurídica; en todo caso la revisión del origen poblador de las colonias agro-pastoriles de fines del Siglo XIX y comienzos del S XX, seguramente propongan líneas de adecuación a los tiempos que corren.
} 


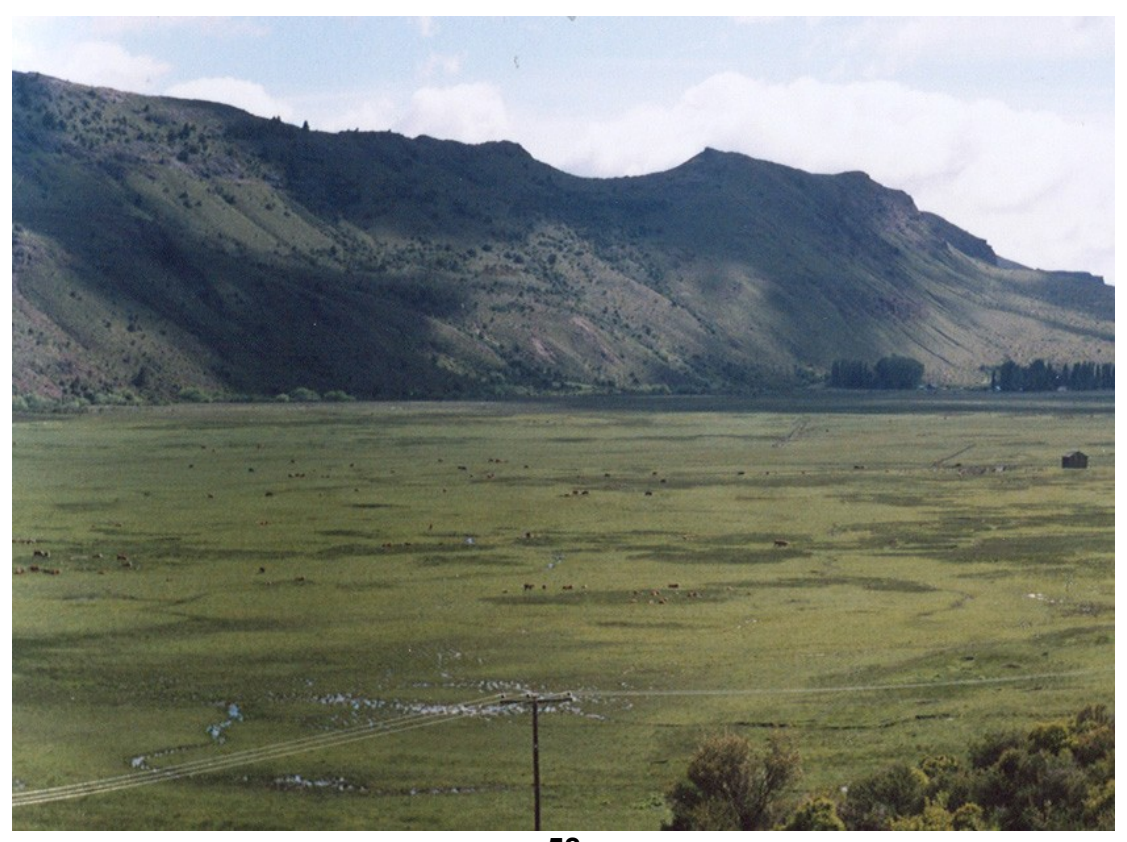

58

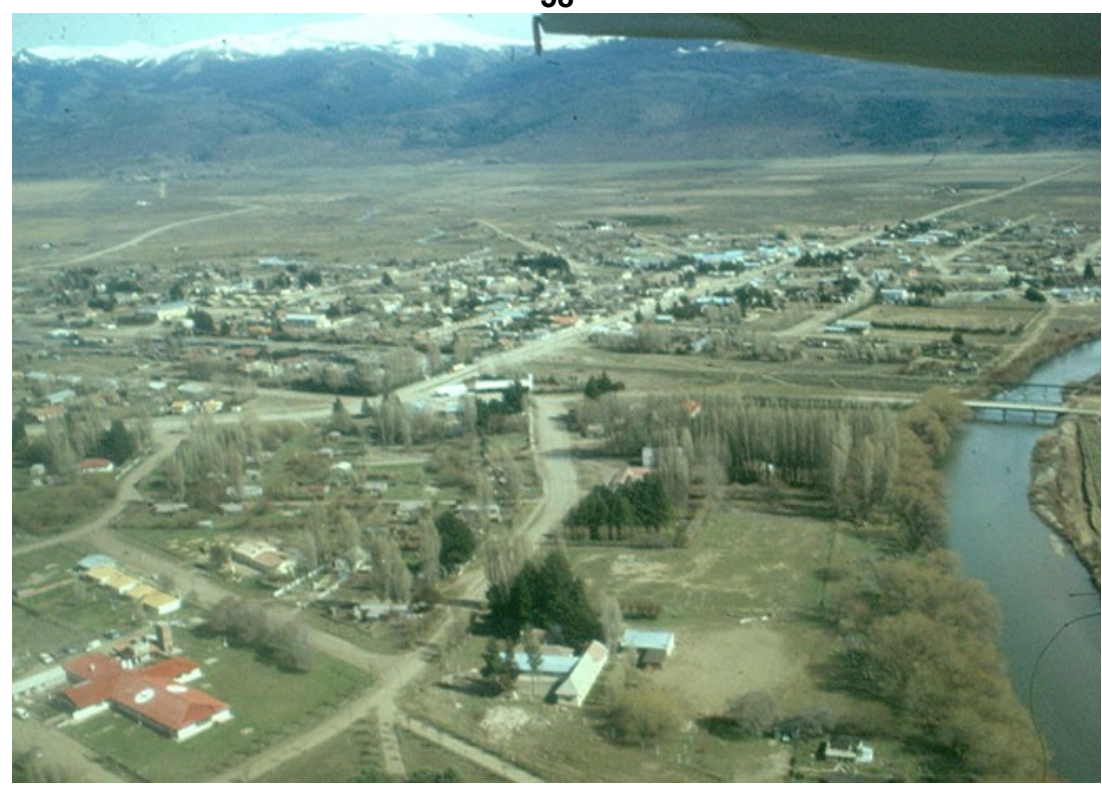

59

El Este de la Comarca, posibilidades de expansión y sustentabilidad ante el crecimiento demográfico y económico zonal. Foto del autor, 2006. Foto 58: Campos de reconocida aptitud ganadera en el entorno de Cholila. Foto 59: El Maitén, confinada entre grandes estancias; un destino que no parece posible de sostener. Foto del autor, 1999.

A todo esto, puede observarse que en pequeña escala es una tendencia posible, como lo demuestran instancias de gestión en este sentido con resultados auspiciosos en El Maitén y otros más conflictivos pero que indican una dirección interesante (Ocupación Santa Rosa en Leleque; foto: 36). En todo caso y aún cuando por su distinta y menor complejidad no sean directamente comparables, resultan sugestivos los diagnósticos y experiencias favorables en materia de plantaciones de coníferas, donde varias de las limitantes se ven mitigadas por estrategias relativamente sencillas. 


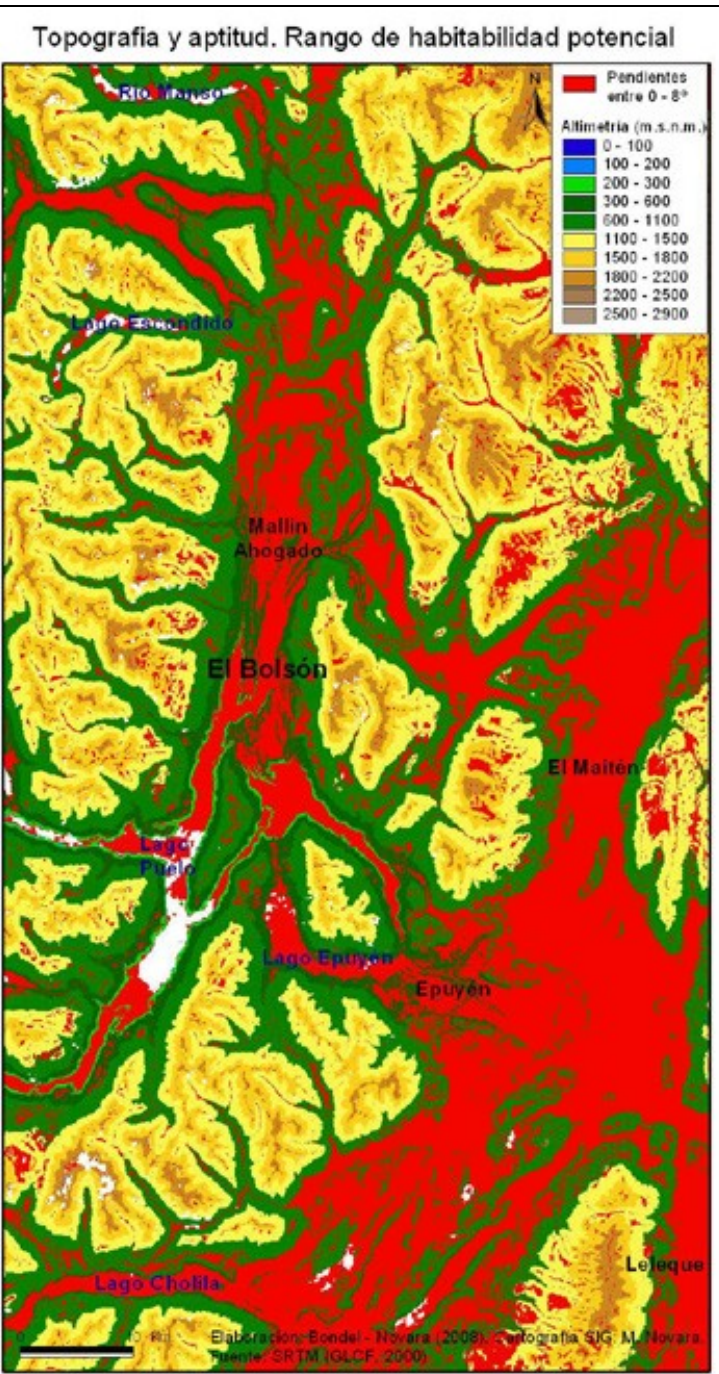

Mapa 12 Pendientes y asentamientos. En rojo las superficies con pendientes reconocibles entre las tipologías contemporáneas en la Comarca. Mapa en proceso de verificación y 'filtrado' de información, en particular por asimilación de superficies lacustres a las pendientes consideradas.

El mapa muestra diferentes pisos altitudinales; se destacan las pendientes entre los $0^{\circ}$ y $8^{\circ}$ en rojo, consideradas potencialmente habitables según un primer muestre ${ }^{239}$. Nótese el desarrollo de las mismas en el Este y Sur-Sureste comarcal.

El rango se ha tomado a partir de los asentamientos actuales, es decir según el interés y su respuesta tecnológica, toda vez que día a día se observan adaptaciones que podrían elevarlo y habilitar pendientes mayores ${ }^{240}$. Cabe rescatar, de todos modos y especialmente para reiterar la condición dinámica de los procesos territoriales, que las montañas ofrecen posibilidades interesantes por su simple esencia de topografía quebrada (veranadas-invernadas, panoramas, recreación, deportes, energía, escurrimiento, etc.), pero en general para los usos tradicionales del espacio, los faldeos sugieren más un obstáculo, un desafío, que una invitación cómoda y competitiva.

\section{Resultará claro que las instancias de expansión física no se agotan en estas terrazas y}

valles, la ocupación de valles más profundos alejados de los pueblos, así como la incorporación de la alta montaña a nuevas instancias de uso, muestran rumbos importantes y, en general, de gran conflictividad.

\footnotetext{
${ }^{239}$ Valga la aclaración que las pendientes fueron valoradas en escalas aproximadas a la hectárea, de modo que en menores superficies se podrían encontrar adaptaciones a mayores pendientes. Avances inéditos en Bondel, S. y M. Novara. Nuevas modalidades territoriales en la 'alta montaña' de la Patagonia Andina. Proyecto de investigación (PI 021/08 FHCS-UNPSJB).

${ }^{240}$ Ver en Miorrelli et al (2004), el caso de las adaptaciones progresivas en el caso de los Alpes italianos.
} 


\section{3. CONCLUSIONES Y REFLEXIÓN FINAL}

En concordancia con el objetivo general de esta tesis y proyectando una realidad geográfica que en muchos aspectos de peso involucra a la montaña patagónica en su generalidad, hemos arribado a esta instancia detrás de la preocupación de poder generar líneas analíticas que incorporen con plenitud a los comportamientos de trascendencia territorial. Siguiendo, si se quiere, el sentido profundo de los dichos de Claval cuando destaca, "Un análisis superficial de los paisajes humanizados no permite descubrir los objetivos de los grupos y la afirmación de los valores que los animan. La multiplicidad de los proyectos y de los intereses que se entrecruzan, y la diversidad de las motivaciones de los decisores que dividen las tierras, las cultivan, construyen edificios, los habitan y los modifican, hacen de ellas un elemento complejo, cuya organización sólo puede comprenderse procediendo mediante un análisis minucioso (1999: 244).

\section{Alcances}

Se presenta como el primer alcance y tal vez el de mayor trascendencia en materia geográfica regional a:

- el haber desarrollado un análisis interpretativo de la organización territorial en ámbitos donde sobresalen procesos de transformación y que están sometidos a una constante puja de intereses sociales propios de paradigmas socioculturales post modernos.

Será entonces un alcance que atiende a dos vertientes de acción, la operacional (el análisis de esencia geográfica) y la instancia regional (el 'contenido').

De proyección más acotada, pero también trascendentes fueron los alcances orientados a satisfacer los objetivos más específicos:

- Desarrollo de tipologías de usos a partir de las relaciones 'poblador-uso', con lo cual se espera aportar al análisis problemático regional conceptos y situaciones algunas veces inéditas.

- Desarrollo, desde enfoques de la geografía regional con la valoración de singularidades y generalidades que hacen al conjunto geográfico de la Comarca, de las bases explicativas para planteos locales siguiendo el esquema espacio-tiempo-comportamientos.

- Desarrollo explicativo de la configuración geográfica, donde varias temáticas sectoriales aún requieren de 'ajustes' informativos (en especial en materia geoeconómica). De cualquier modo y netamente asociado al resultado del 
análisis de los conflictos socioterritoriales más importantes, proyectamos la figura de territorios complementarios en el terreno prospectivo comarcal.

- Fortalecimiento de enfoques integrales (básicamente fisiogeográfico, geohistórico y socioeconómico) desde instancias disciplinares de la geografía (unidad conceptual sociedad-territorio).

- Generación de un marco teórico relacionado con la instalación humana en áreas montañosas, en particular de la Patagonia Andina, para que principalmente, sirva de insumo ante las evidentes situaciones de expansión, ocupación y transformación espacial ocurrentes.

Conclusiones, a modo de enunciados de tesis

Se relacionan con los planteos hipotéticos.

1) En la Patagonia Andina contemporánea, las intervenciones territoriales de mayor trascendencia se orientan decididamente por aspectos afectivos emocionales, obedeciendo así a la lógica territorial de la contemplación por sobre la productiva.

Esta conclusión se respalda en haber desarrollado un análisis interpretativo de la organización territorial en ámbitos donde sobresalen procesos de transformación sometidos a una constante puja de intereses sociales propios de paradigmas socioculturales post modernos, donde la valoración escénica del paisaje de montaña patagónica y su apropiación cultural actúa como el principal motivador. Aquí, sin perder de vista a los componentes tradicionales del espacio geográfico y su diversidad de matices, es el dominio de lo geo-cultural que estructura lo regional.

Serán fundamentales, tanto para la explicación de sus problemáticas como para el Planeamiento y la Gestión territorial, la primordial atención que se le de a los comportamientos junto con el rol de complemento necesario que le caben, con distinto peso relativo según las circunstancias de análisis, a los condicionamientos naturales, históricos y económicos.

2) Frente a las sucesivas transformaciones territoriales andino patagónicas, el análisis geográfico encuentra dos principales vertientes de acción, la de la geografía regional, desde cuyos enfoques surgen las bases explicativas para planteos locales-zonales, y la operacional, es decir la del análisis de esencia multidisciplinar básicamente orientado por el carácter propio de las problemáticas a tratar. 
Es así que corresponde atender la instancia regional en sí, donde priva una necesaria fortaleza en la comprensión geográfica y desde cuyos enfoques surgen las bases explicativas locales-zonales (mayormente micro-geográficos), de acuerdo con la trilogía espacio-tiempo-comportamientos. También es cierto que las transformaciones territoriales, aún cuando posean evidentes matices geográficos, tendrán en otros campos de estudio la esencia de sus motivaciones y cualidades; con ello, el análisis geográfico entra en un terreno operativo necesariamente multidisciplinar, aquel que impone atender una demanda social, y que estará en esencia, encaminado en concordancia con el tono o sesgo de los problemas a tratar (socio-culturales, económicos, políticos, etc.).

3) Las identificaciones tipológicas en materia de usos territoriales se muestran como un recurso necesario y apropiado para la explicación geográfica en el medio andino patagónico.

El desarrollo de tipologías de usos a partir de las relaciones 'poblador-uso' se muestran aquí como camino explicativo. Entendemos que, aún cuando caben continuas revisiones, su identificación muestra una vía ventajosa frente al análisis problemático regional atravesado por transformaciones continuas. Un ejemplo tratado en esta tesis, ha sido el de las directrices territoriales en Lago Puelo, donde fue necesario acordar una tipología de usos que resultó operativamente útil.

Además, la tipificación de trece modalidades de uso del espacio con el que se concluye la Segunda Parte, ha mostrado un replanteo importante en la materia y propone la identificación de unidades espaciales económicas. A su vez, el haber sistematizado las singularidades de los comportamientos espaciales de los pobladores, en particular los tradicionales, neorrurales u 'ocupantes', permite priorizar el análisis de las conductas en base al planteo geo-cultural de las lógicas territoriales.

Por otra parte, frente al análisis de las problemáticas recurrentes, las tipologías han demostrado ser operativamente viables, atendiendo, en particular con punteos, tablas y una matriz, las partes sustantivas del complejo territorial (la Comarca).

4) Frente a la expansión geo-demográfica sostenida ocurrente en la Patagonia Andina y donde el paisaje montañés actúa como el principal motor de las transformaciones, el condicionamiento del medio natural a la instalación humana por las restricciones que imponen los territorios montanos, tienen en la complementariedad territorial, valles boscosos - valles esteparios, una alternativa vigorosa en favor de la sustentabilidad. 
Es ésta una conclusión que prácticamente en un todo ha surgido del desarrollo de la tesis. Si bien su enunciado se ocupa de las restricciones de la naturaleza física del territorio a su vez, se espera estimule la necesidad de entrelazar aspectos naturales, históricos y socio-económicos para llevarlos a la noción de paisaje y con ello motorizar una revisión profunda en materia del direccionamiento de la ocupación de los espacios, tanto urbanos como rurales. Creemos que, justamente, será a partir de la comprensión de esa figura integral desde donde podrán orientarse políticas territoriales asociadas a la sustentablidad. El Este semi-árido barilochence, el entorno del alto Limay y sectores periféricos de San Martín de los Andes y Junín de los Andes, muestran una dirección espontánea y de adaptación tecnológica que respondería a la demanda paisajística y que merece ser analizada en profundidad para responder así a otros condicionantes, en particular los históricos y socio-económicos que hacen a las formas de ocupación, tenencia de la tierra y actividades económicas en sectores singulares de las grandes estancias. Los entornos de Epuyén, El Maitén, Cholila y Leleque, por sus aptitudes geográficas, muestran direccionamientos compatibles con el desarrollo armónico y la descompresión de los conflictos territoriales más dilemáticos de la Comarca.

\section{5) El diagnóstico territorial de la Comarca tiene sus indicadores de base en siete} principales situaciones conflictivas de carácter geográfico ${ }^{241}$.

Como se puede ver a lo largo de la tesis, casi no se trató tema donde alguna/s de estas situaciones tuviera un papel destacado y ya desde la presentación de los antecedentes y contexto problemático estas características fueron recurrentes. Se diría que resultan imprescindibles a la hora de comprender la geografía comarcal y, como se dijo desde un principio, la fragmentación de las problemáticas se ha tomado como recurso metodológico ya que cada una de las situaciones presenta una importante gama de condiciones territoriales conflictivas identificables.

Cabe valorar también que ha sido distinto el alcance del análisis para cada situación, ya fuera por la complejidad de las temáticas, en especial aquellas de sesgo cultural, o por la dificultad en la obtención de datos precisos, en particular de indicadores económicos. De todos modos, entendemos haber alcanzado una visión problemática unitaria y de profundidad suficiente para su proyección analítica.

6) Las modalidades neorrurales son en materia paisajística el resultado más

\footnotetext{
${ }^{241}$ En resumen, se recuerda que son:

1.- Excentricidad geográfica.

2.- Superposición funcional.

3.- Incumplimiento y/o incertidumbre en los comportamientos.

4- Expansión urbana espontánea.

5.- Parcelamientos y tenencias.

6.- Perfil cultural-socioeconómico heterogéneo.

7.- Crecimiento geo-demográfico y confinamiento físico.
} 


\section{visible del devenir territorial andino patagónico.}

Esta conclusión, proveniente de un análisis importante de la dinámica territorial de los últimos lustros, revela una situación que aunque propia del devenir cultural post moderno occidental y por lo tanto no exclusiva, tiene aquí una trascendencia geográfica crucial. Las condiciones geo-demográficas y sus tendencias expansivas demostradas, revelan la necesidad de ser cuidadosos a la hora de la intervención. Es a través de la conceptualización de la competencia territorial, que entrecruza el ámbito de las expectativas con las capacidades y que reúne un fuerte perfil multidisciplinario, desde donde esta tesis propone una dirección operativa para el Planeamiento y la Gestión Territorial.

\section{REFLEXIÓN FINAL}

Aún cuando la figura regional andino patagónica ha sido ineludible a lo largo del desarrollo de esta tesis, con lo cual pudiera esperarse una reflexión de 'cierre' respecto a sus características y porvenir, a la hora de valorar al conjunto, he sentido como más oportuno reflexionar sobre la índole metodológica-profesional en la que estuvo envuelto el trabajo. Es que, como geógrafo, el hecho de abocarme a esta actividad académica se conjugó con una necesaria implicación como partícipe activo en un territorio problemático y sugerente.

Hace ya más de una década, un amigo y ecólogo ${ }^{242}$, tratando una cuestión bastante desesperada relacionada con las inundaciones, me comentó, éste es el valle de las pasiones desencontradas. Fue entonces cuando, sorprendido, reconsideré el profundo significado geográfico de lo comportamental en la región, un significado que no sólo describía una generalización más o menos intuitiva y punzante, sino que ofrecía un campo de investigación concreto y problemático y que hasta entonces, sin dejar de percibirlo, cumplía un papel periférico para el análisis.

Es que de por sí, los valles y las pasiones entrelazados, constituyeron (y constituyen) un conjunto geográfico, diríase, monumental; y fueron los recorridos seguidos para la apropiación científica de la compleja realidad territorial, más áspera y encubierta de lo que supone a primera vista (¡qué bello!), los que estructuraron la tesis. Ojalá que su lectura pueda contribuir en favor de las formas de apropiación del conocimiento geográfico regional en general y del desenvolvimiento andino patagónico en particular.

\section{IV.4. Referencias bibliográficas}

\footnotetext{
${ }^{242}$ Ricardo Guerra, profesional de Parques Nacionales.
} 
- Bondel, S. y M. Novara. Nuevas Modalidades territoriales en la alta montaña de la Patagonia Argentina. Proyecto de Investigación (PI/021/08 Facultad de Humanidades y Ciencias Sociales; UNPSJB. Comodoro Rivadavia. 2007.

- Bondel, C. Santiago. Artículo del Boletín Electrónico Concepto Forestal; Newsletter CF 11-06. Tema: "Ordenamiento territorial en la Patagonia Andina, ¿en un territorio 'adolescente'?" Secretaría de Agricultura, Ganadería, Pesca y Alimentos, Buenos Aires conceptoforestal@oncca.gov.ar . 2006.

- Bondel, C. Santiago. El medio natural y la formación profesional en geografía. Reparos. En Revista Virtual del Centro de Estudios Alexander Von Humboldt: Posición Internacional. Buenos Aires, Año 2, № 2. Marzo de 2002.

- Bondel, C. S.; A. M. Raimondo; M. M. Novella; M. Novara y C. Augustaci. Uso del espacio y transformaciones territoriales en la Patagonia Andina de Chubut y Río Negro. Proyecto de Investigación № 479. Departamento de Geografía, Facultad de Ciencias Sociales, Sede Comodoro Rivadavia, Universidad Nacional de la Patagonia San Juan Bosco. Informe final. 2002.

- Bondel C. S.., Coordinador académico y participación con un seminario en el Curso Introductorio en Gestión Ambiental. Capacitación en temáticas de la Comarca Andina del Paralelo 42. Octubre-noviembre 2006. Facultad de Humanidades y C. S. de la UNPSJB y Fundación Cooperar, El Bolsón

- Bozzano, Horacio. Territorios reales, pensados y posibles. Aportes para una Teoría Territorial del Ambiente. Editorial Espacio, $1^{\circ}$ reimpresión; Buenos Aires, 2004. (263)

- Brunhes, La Géographie Humaine. Édition Abrégée, Presses Universitaires de France. Paris, (1947), $355 \mathrm{p}$.

- Capel, Horacio. Filosofía y ciencia en la Geografía contemporánea. Una introducción a la Geografía. Barcanova, Barcelona 1981.

- Claval, Paul. La Geografía Cultural. EUDEBA, Buenos Aires, 1999. (377p.).

- CODECAP, "Proceso participativo para la formulación y gestión institucional y social de un proyecto de desarrollo sustentable, Consejo para el Desarrollo de la Comarca Andina del Paralelo 42", Informe final, documento del Consejo para el Desarrollo de la Comarca Andina del Paralelo 42 (CODECAP) y las Universidades Nacionales de La Plata, del Comahue y de la Patagonia S. J. Bosco, El Bolsón, diciembre de 1999.

- Di Pace, M., S.. Federovisky y J. Hardoy. Problemas ambientales en ciudades argentinas. En: -IIED-América Latina. "Medio ambiente y urbanización". Año 9. №37; Buenos Aires. 1991.

- Foglia, María Elena, Mónica E. Sánchez, Carlos A. Gómez y Liliana Argüello. El Bolsón. Provincia de Río Negro. República Argentina. Bases para la elaboración de un plan estratégico. Facultad de Arquitectura, Urbanismo y Diseño. Universidad Nacional de Córdoba. Córdoba. 1998. (57p.).

- Haggett, Peter. Geografía. Una síntesis moderna. Ed. Omega, Barcelona, 1988.

- Hernández, Raúl Augusto y Mochkofsky. Notas sobre un ejercicio de simulación del uso del Medio Ambiente. El caso de Bariloche. Departamento de Sociología. Fundación Bariloche. San Carlos de Bariloche. 1974. (123 p).

- Labasse, Jean. La organización del espacio. Ed. Ariel, Barcelona, 1973. (739p.) 
- Madariaga, Marta. Interacción entre ambiente y población en San Carlos de Bariloche, INTA, Bariloche. 2007. Versión digital.

- Marchissio, Mariela E.. Migrantes de anemidad. Nuevos emprendedores del sector turístico. Estudio de caso: El Bolsón y Lago Puelo. Tesina de Grado. Facultad de Turismo. Universidad nacional del Comahue. 2007.

- Martínez, Oscar A., Bondel, C. Santiago, Demarchi, Gabriela y Danklmaier, Christine. Directrices de ordenación para el desarrollo territorial de Lago Puelo. Municipalidad de Lago Puelo - Unidad de asistencia en temas ambientales (UATA) de la Universidad Nacional de la Patagonia San Juan Bosco, sede Esquel. 2007.

- Merino, José A. La Refundación de El Bolsón. Mimeo. 2005.

- Miorelli, E., G. Rea y P. Zattelli. Caratterizzazione delle relazioni tra dinamiche demografiche e fattori fisici: un'applicazione in ambiente montano. Dipartimento di Ingegneria Civile e Ambientale, Università degle Studi di Trento. (2004).

- Morello, Jorge. ¿Cuáles Fronteras? Revista Fronteras (GEPAMA). Facultad de Arquitectura y Urbanismo. Universidad de Buenos Aires. Año 1, № 1. Buenos Aiores. 2002.

- Nogué i Font, Joan. El paisaje existencial de cinco grupos de experiencia ambiental. Ensayo metodológico en García Ballesteros, A. (Ed.). Geografía y Humanismo, Barcelona, Oikos-tau. 1992. (pp. 87-96).

- Pozzo B., Mario. Ciudad Patagónica: clima y vida cotidiana. Revista Pueblos y Fronteras de la Patagonia Andina. Revista de Ciencias Sociales. Año 5, № 5. Comarca Andina del Paralelo 42. Octubre, 2004.

- Randle, Patricio. El Pensamiento urbanístico en los Siglos XIX y XX. OIKOS, Buenos Aires. 1985.

- Silverol, Aline. Ratzel. Administradora do Grupo Universidade Federal do Espírito Santo. Versión digital difundido por el Centro de Estudios A. Von Humboldt, Buenos Aires. 2000.

El Hoyo, Chubut. 5 de noviembre de 2008 


\section{V. ÍNDICE DE MAPAS, FIGURAS, TABLAS, CUADROS Y FOTOGRAFÍAS.}

V. 1. Mapas.

Página

1: La Comarca en la Patagonia Andina.

2: Áreas de influencia comarcal.

3: Densidad de población rural.

4: Imagen de la Comarca en su contexto topográfico. $\quad 64$

5:. Estructura básica de las tenencias de la tierra. $\quad 94$

6: Extracto de mapa del Automóvil Club Argentino editado en 1967.

7: Usos del suelo en Lago Puelo. 123

8: Usos del suelo por unidad parcelaria en Lago Puelo. 124

9: Transecta de usos del suelo en 'zona rural' de Lago Puelo 127

10: Principales conflictos territoriales asociados con la expansión urbana. 145

11: Directrices del ordenamiento territorial, zonificación; ejido de Lago Puelo. 168

12: Pendientes y asentamientos.

174

V.2. Figuras.

Página

1: La investigación aplicada en el conjunto de actividades científicas. 13

2: Esquema conceptuales de referencia (1). 38

3: Esquema conceptuales de referencia (2). 38

4. Perfiles topográficos. 65

\begin{tabular}{ll} 
5: La condición ecotonal, & 66 \\
\hline 6. & 63
\end{tabular}

$\begin{array}{ll}\text { 6. Temperaturas, valores extremos medios y absolutos } & 73\end{array}$

\begin{tabular}{ll} 
7. Temperaturas, curvas comparativas & 73 \\
\hline
\end{tabular}

$\begin{array}{ll}\text { 8. Vientos. Velocidades medias mensuales comparativas.. } & 75\end{array}$

$\begin{array}{ll}\text { 9: Precipitaciones medias mensuales. } & 77\end{array}$

10: Irregularidad en los totales pluviométricos $c 78$

11: Balance hídrico. $\quad 78$

12. Secuenciación temporo-espacial. $\quad 89$

\begin{tabular}{lc} 
13. Esquema de los flujos poblacionales dominantes & 102 \\
\hline
\end{tabular}

14. Cronograma ocupacional. 108

15: Flujos económicos. 113

16.Trilogía: Percepción-Paisaje-Comportamientos. 137

17. Reconstrucción tentativa del camino perceptivo-concreto del migrante. 143

$\begin{array}{lc}\text { 18. Esquema espacio-tiempo rural. } & 149\end{array}$

19. La competencia territorial, esquema metodológico para su valoración. 163

20. Lago Puelo, elaboración de directrices; esquema del proceso. 164

21. Lago Puelo, capacidad territorial. Paraje Las Golondrinas. 166

22. Lago Puelo. Valoración de los pobladores. Resultados en Paraje Cerro Radal. 167

23. Lago Puelo. Expectativas de los pobladores. Paraje Las Golondrinas 167

V.3. Tablas.

Página

\begin{tabular}{|lr}
\hline 1. Población & 58 \\
\hline
\end{tabular}

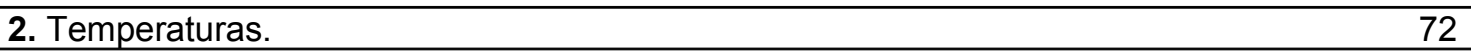

\begin{tabular}{ll} 
3. Precipitaciones. & 77 \\
\hline 4. & 81
\end{tabular}

4. Hidrografía, Algunos datos ilustrativos.

5. Tránsito medio diario de automotores (2000-2007). 110

\begin{tabular}{ll} 
6. Empleo en la Comarca. & 114 \\
\hline
\end{tabular}

7. Empleados provinciales de El Bolsón (05/2007). 115

$\begin{array}{lc}\text { 8. Turismo, valores significativos. } & 122\end{array}$ 
V.4. Cuadros.

Página

\begin{tabular}{|lc} 
1. El medio natural en su rol de condicionante, aproximaciones. & 82
\end{tabular}

$\begin{array}{ll}\text { 2. Antecedentes perceptivos y trascendencia básica territorial. } & 138\end{array}$

\begin{tabular}{ll}
\hline 3. Bases tipológica según formas & 146
\end{tabular}

$\begin{array}{ll}\text { 4. Bases tipológica según génesis. } & 146\end{array}$

\begin{tabular}{ll} 
5. Bases tipológica según funcionalidad. & 147 \\
\hline 6. & 148
\end{tabular}

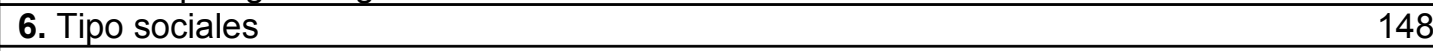

\begin{tabular}{ll}
\hline 7. Aproximación a los comportamientos territoriales. & 151
\end{tabular}

\section{V.5. Fotografías.}

1. Altos del Turbio. 28

2. Pampas de Mallín Ahogado y Cerro Perito Moreno. 28

3. Lago Epuyén 28

4. Casco urbano central de Lago Puelo. 29

5: Barrio Alto (S. C. de Bariloche). 29

6. Laguna Alerce (sobre 'umbral' Lagos Epuyén y Puelo). 29

7 y $8 . \quad$ Escenario panorámico vs. espacio vivido 29

$\begin{array}{ll}9,10 \text { y 11. Fondo de valle del Río Epuyén. } & 30\end{array}$

12. Fronteras jóvenes; hito fronterizo.

13. Aeropuerto de Esquel. 53

14 y 15. Ciudad y pueblos en la organización espacial. El Bolsón-Lago Puelo. 54

16 y 17.La diversidad de usos (Parajes Cerro Radal y Entre Ríos). 59

18. Toma en altura del ámbito cordillerano a la latitud del Monte Tronador. 63

$\begin{array}{ll}\text { 19. Cordón Serrucho Norte. } & 63\end{array}$

$\begin{array}{ll}\text { 20. Cipresal en terraza de la margen derecha del río Quemquemtreu. } & 70\end{array}$

21 y 22. Las inversiones térmicas, situaciones recurrentes. 76

23. Desembocadura del río Turbio en el lago Puelo. $\quad 81$

$\begin{array}{lc}\text { 24. Chacra andina tradicional. } & 96\end{array}$

25 y 26. 25 años de transformaciones en El Hoyo. 103

27. Ruta Nacional 40 (ex 258). Tramo Norte en El Bolsón. 110

28. Frambuesales y otras plantaciones a la vera del río Quemquemtreu. 124

29. Faena maderera, una cancha. 124

30. Vacunos en ámbito ecotonal bosque-estepa; cercanías de Cholila. 125

31. Hortalizas, un rubro activo con altibajos históricos. Camino de los Nogales. 125

$\begin{array}{ll}\text { 32. Lupular en Lago Puelo. } & 125\end{array}$

33 Turismo cabañero. Villa Turismo. 125

$\begin{array}{ll}\text { 34. Reivindicaciones de los pobladores de origen mapuche. } & 139\end{array}$

35. Reutilización espacial. Chacras tradicionales devenidas en ámbitos neorrurales. 139

36. Zona Norte de El Bolsón y el Co. Piltriquitrón. 140

$\begin{array}{ll}\text { 37. Nevazón de invierno en la comarca. } & 140\end{array}$

38. Sector del lago Puelo donde desemboca el río Epuyén. 140

39. Chacra tradicional, con pérdida de su capacidad económica-social. 140

40 y 41: Diferentes visiones. Para unos recursos, para otros obstáculos. 142

$\begin{array}{ll}\text { 42. Sector de Mallín Ahogado atravesado por el río Azul. } & 150\end{array}$

43. Reconversión chacra-barrio, una tendencia decidida. Barrio Arrayanes. 150

44 a 50. Algunos de los impactos territoriales más destacados. 156

51. Expansión residencial sobre tierras de buena aptitud agrícola (El Hoyo). 160

52 y 53. La Feria Regional. 
54 y 55 . Pendientes y los asentamientos. Villa de Val en Suiza y chacra en El Hoyo.

56 y 57 . Densidades urbanas en ciudades de montaña. Dos realidades contrastantes. 171

58 y 59 . El Este de la Comarca, posibilidades de expansión y sustentabilidad.

173

\section{APÉNDICES.}

1: ¿Vértigo territorial?

2: Reflexiones complementarias sobre la Patagonia Andina y sus límites.

3: Patagonia Andina de los lagos.

4: La franja andina, entre lo general y lo singular.

5: Inundaciones.

6: Datos hidrográficos sugerentes.

7: Difícil de responder.

8: Condicionamientos históricos y económicos.

9: Nacidos y criados.

\section{Apéndice 1:}

\section{¿Vértigo territorial?}

La investigación regional condicionada.

Un componente aditivo a este trabajo y que creímos conveniente advertir es que, como sucede en buena parte del mundo y seguramente alentado por una creciente e invasiva influencia mediática, la región toda, y en particular la franja andino patagónica, se contextualiza política y socialmente en situaciones consideradas geográficamente apremiantes. Una urgencia generadora de condicionamientos adicionales y de peso para con el análisis, al punto que podríamos referirnos a la generación de cierto vértigo territorial. La seguidilla de cambios o sus proclamas y el fuerte requerimiento de atención hacia los mismos (obras o su falta, emprendimientos, concesiones y/o usurpaciones prediales, accesos o inhibiciones, códigos y excepciones, etc.), han generado un contrapunto político-académico casi incompatible en términos temporales, siendo una constante en el análisis enfrentarse con argumentos sobreinformados de difícil discernimiento.

Albet (2001), nos orienta un tanto cuando puntualiza que la crítica epistemológica postmoderna cuestiona a las tradicionales relaciones entre poder y saber demandados desde la visión hegemónica del mundo occidental. Y así como la crítica postmoderna se encarga de poner en cuestión esta supuesta universalidad (la del discurso occidental), también impulsa la introducción del discurso del 'otro ${ }^{243}$. Con ello se explicaría la complejidad creciente de un nuevo universo de análisis por ahora incipiente. Cabe, sin embargo, valorar la potencial y creemos frecuente inexistencia de 'compatibilidad conceptual' para un buen número de $\operatorname{casos}^{244}$. Y, si bien no hemos aún podido profundizar sobre el tema, al menos dejamos planteado una recurrente devaluación del alcance conceptual de aquello 'científicamente comprobado', y esto, al menos en términos regionales (de los lugares), pareciera estar aportando más confusión que claridad. Por cierto, estas afirmaciones no evaden la carga histórica negativa que le cupo a la modernidad en la sobrevaloración de la perspectiva científica. Adherimos con aquella afirmación de Octavio Paz en su Posdata, "...la ciencia no tiene por objeto juzgar sino comprender..." (1970:128).

Podemos concluir al respecto y tratando de no alejarnos de lo netamente geográfico, que nos ha tocado dedicarnos y preocuparnos en tiempos embebidos en circunstancias de urgencia territorial y con ello correr el riesgo de que esta superposición científica-política en lugar de confrontar en el campo de las decisiones, han consensuado en fundirse y actuar en

\footnotetext{
243 Pueblos colonizados, minorías étnicas, mujeres, homosexuales, etc..

${ }^{244}$ En especial cuando se quieren utilizar parámetros comparativos entre estas otras visiones y el abordaje científico geográfico tradicional (jerarquías, propiedades, responsabilidades, derechos, ritmos de intercambio y producción, etc.)
} 
conformidad. Se suma a esto algún reconocimiento social para con esta actitud, lo que coloca a quienes no acuerdan en su 'urgencia' en un plano de casi herejía intelectual.

Debe tomarse al párrafo anterior en su sentido cabal, puesto que esta tesis ha buscado estar ligada al desenvolvimiento regional contribuyendo a la superación de situaciones geográficas críticas de fuerte y negativo impacto social que, curiosamente y con las diferencias obvias, son visibles en la generalidad del cuerpo social y no tan sólo en los sectores más desposeídos. Es más, se puede intuir que ante una revalorización racional y genuina del contexto regional, se potenciará más positiva y armoniosamente la notable sucesión de iniciativas de todo tipo que confluyen en territorios de vanguardia como el andino patagónico.

Recogemos el encabezamiento con el que presentamos el proyecto de tesis y que fue sugerente a modo de contexto motivador, "Tenemos la oportunidad de organizarnos en nuestro espacio montañés; la historia enseña que la ocupación positiva del territorio implica superar instancias de mero asentamiento; ocupar supone el estar y el quehacer" y, en verdad, su enunciado se condice con la dirección a la que se orienta este trabajo en conjunto. Actitud, acción y lugar, forman una trilogía estructural que acompaña, casi a modo de escolta, el desarrollo del análisis. Análisis que básicamente ha buscado fortalecerse en el cuerpo teórico de la geografía, en particular de la geografía regional, pero que también aspira a proyectarse como potencial insumo en intervenciones de orden territorial ${ }^{245}$.

\section{Referencias bibliográficas}

- Albet i Mas, Abel. ¿Regiones singulares y regiones sin lugares?. Reconsiderando el estudio de lo regional y lo local en el contexto de la Geografía Postmoderna. Boletín de la A. G. E. N ${ }^{\circ}$ 32. 2001. (pp. 35-52).

- Labasse, Jean. La organización del espacio. Ed. Ariel. Barcelona. 1973.

- Paz, Octavio. Posdata. Siglo Veintiuno Editores. México D.F.. 1984 (decimoctava edición).

\section{Apéndice 2:}

\section{Reflexiones complementarias sobre la Patagonia Andina y sus límites}

En verdad, nos asisten dudas, dado que la Patagonia misma, a pesar de ser un referente regional consolidado ${ }^{246}$, todavía ofrece resistencias a la hora de ser exigente en materia de definiciones limítrofes, especialmente en su sector Norte.

Cabe destacar que nos preocupamos por el límite geográfico en su complejidad, no en aquellos sectoriales que obedecen a tal o cual característica, mayormente bio-física. No obsta que recurriremos a isoyetas, geoformas, biomas o subtipos, etc., es decir, a concluyentes y menos 'espinosos' demarcadores de situaciones espacialmente definitorias (húmedo-semiárido, bosque-estepa, andino-subandino, etc. $)^{247}$.

\footnotetext{
245 Seguramente ha sido Jean Labasse (1973) quien con su Organización del Espacio, pudo encontrar caminos de enlace sólidos para aquella trilogía y su discurso se vuelca sucesivamente hacia el terreno de la toma de decisiones. Así, con la dominante hidráulica, por ejemplo, se anticipaba en varias décadas a la visión estructurada en problemáticas territoriales políticamente descollantes.

${ }^{246}$ Hasta existe un Parlamento Patagónico como entidad política con representantes de las legislaturas respectivas y del Congreso de la Nación..

${ }^{247}$ Interesantes y útiles muestras de delimitaciones sectoriales en la Patagonia pueden verse en Ecología Austral, Ecosistemas Patagónicos (1998); en particular los trabajos sobre el clima regional de Paruelo, et al; sobre el sistema regional en suelos de $\mathrm{H}$. del Valle; también sobre biozonas de J. Paruelo, E. Jobbágy y O. Sala y sobre el ecotono bosque-estepa en relación a las plantaciones forestales de T. Schlichter y $P$. Laclau. También ver importantes desarrollos sectoriales y demarcaciones en Bercovich et al (1998:225-312). Propuestas más integradoras y también de
} 
Pero nuestro caso, fundamentalmente por el peso relativo de sus componentes socio-culturales y económicos contemporáneos, requiere de una ponderación de multiplicidades espaciales todavía no desarrolladas para el Oeste patagónico. Incluso la importante revisión de la evolución histórica regional moderna en relación con los pueblos Mapuches, la Araucanía en general y los resultados de las políticas nacionales, particularmente en materia territorial, muestran todavía un largo camino a recorrer ${ }^{248}$.

Por cierto que hay numerosos y destacados antecedentes respecto de planteos 'regionalizadores' de la Argentina y que muestran esfuerzos fundamentales en la 'lectura' regional del país ${ }^{249}$; de ellos partimos, y, desde ya, habrá que incorporarles las condiciones geográficas 'pos-noventa', donde todavía pareciera que las incertidumbres superan a las certezas en la materia. Respecto de esta última consideración en cuanto a lo incierto de las representaciones territoriales, resulta oportuna la reflexión de Cóccaro, "...La reconstrucción de las sucesivas secuencias espacio-temporales es esencial para determinar el espesor del hoy territorial y dilucidar 'el peso de las herencias' que presenta la configuración actual. Desde esta perspectiva se advierte la 'imprecisión' de los límites del presente en el territorio, tanto hacia adelante como hacia atrás, y supone una selección significativa de ciertas secuencias de su historia abrevada en una construcción ideológica, teórica-conceptual y política" (2002: 194).

Pero no es intención alejarnos de nuestro propio espacio de análisis, el de la Patagonia Andina, como parte, justamente, de la Patagonia.

En otras oportunidades hemos ahondado un tanto en cuestiones identificatorias de la Patagonia y afirmamos "... Es cierto que la Patagonia, por su heterogeneidad paisajística y pobre cohesión socio-económica, se nos presenta como un caso típico en que el 'objeto geográfico' de estudio necesitará definirse más por su 'esencia territorial' que por sus contornos o límites físicos. Y entonces, la excentricidad de su localización, su carga histórica (singular) y la originalidad del medio natural, serán determinantes en la definición del espacio regional". (Bondel 2000: 8-9).

Si a esta afirmación, un tanto vacilante, y la anterior de Cóccaro, le sumamos ciertas condiciones de volatilidad o metamorfosis continua en el devenir del concepto región que ya destacamos en el Marco Teórico, nos queda la sensación que es más conveniente poner el énfasis sobre los problemas territoriales y llevar la cuestión de los límites a una condición más complementaria que esencial ${ }^{250}$. Incluso, para añadir indecisiones, resultará significativo que mientras la Patagonia Andina sugiere una integración progresiva con el resto de la región y el país, actividades de punta, como el turismo y la conservación de la Naturaleza, imponen desde el paradigma ecológico, una visión espacial cohesionada con figuras como El corredor de los Lagos, la Reserva de la Biósfera o los Patrimonios de la Humanidad. Figuras que relativizan a la frontera internacional y que, además, se posicionan firmemente en el acaecer de la gestión territorial y sobresalen en las agendas políticas, incluyendo las locales.

Hace apenas quince-veinte años no titubeábamos en valorar el hecho de estar tratando con territorios en plena formación, en analogía a los frentes pioneros, donde las fuerzas creativas y los acomodamientos obedecen a factores dinámicos heterogéneos, muchas veces cargados de dramatismo, pero que en definitiva se asociaba a estereotipos previsibles respecto de las estructuras espaciales (colonización) ${ }^{251}$. Hubiéramos apuntado a recuperar aquella idea de que la existencia de una región tiene como condición primaria el estar descripta, pintada y cantada, enfrentándonos así con un proceso aún incompleto, pero de rumbo inequívoco para que el análisis geográfico penetrara en ese molde.

Hoy, como sugiere con énfasis Albet, tanto lo tangible como lo virtual sugieren tantas dudas como prudencia a la hora de asegurar identidades territoriales (2001). Apenas podemos hacernos cargo de atender las que entendemos como las problemáticas territoriales sobresalientes en los Andes Patagónicos. Optamos por, permítaseme la analogía, no

utilidad cierta a la hora de presentar espacios definidos se encuentran en de Jong et al (1978) y en Capitanelli (1988: 687:734).

${ }^{248}$ Ver, por ejemplo en, de Lasa (1998), Bandieri (a) (2005); Finkelstein y Novella (2005). O incluso fuentes primarias como Cox (1863, red. en 1999); Willis (1914, red. 1988); Musters (1865 y red. siguientes)

249 Al respecto ver una instructiva síntesis en Roccatagliata (1988: 423-442). También en Rey Balmaceda (1977: 85-118); además un valioso aporte metodológico aplicado a la Patagonia y ajustado a su tiempo e información disponible, puede verse en Gurevitz y Álvarez (1978).

${ }^{250}$ Al respecto y sumado a otros puntos tratados, resulta revelador y 'actual' el artículo Problemas de la Geografía de William Kirk (1963).

${ }^{251}$ Decíamos a comienzos de los años '90, "Por ahora el territorio ofrece un panorama que no supera en mucho al de una estructura desencajada que no puede disimular su tipología colonial", Bondel (1994). 
anteponer el carro al caballo; aquí el caballo es sinónimo del análisis de las problemáticas específicas y el carro la explicación territorial o si se quiere, regional, que en una proporción acorde con los problemas, demandará criterios veraces a la hora de delimitar.

Entonces, antes de decidirnos por tal y cual línea divisoria, se hacen necesarias algunas aclaraciones descriptivas importantes y que se relacionan con la visión dual, formal y funcional (no dicotómica) del análisis regional, a la cual adherimos para un caso como el nuestro, donde las circunstancias de cohesión interna y autonomía económica son históricamente débiles (cf.: Daus 1982: 10-12).

Patagonia Andina Argentina, a modo de definición geográfica: territorio argentino con modalidades de poblamiento propias de los sistemas montañosos andino patagónico.

Montañas, hidrografía, clima montano y gradación ecotonal W-E (bosques templados-húmedos y estepa graminosa-arbustiva), participan de un contexto socioeconómico turístico, silvo-pastoril con veranadas-invernadas y focos agro-frutihortícolas, de los Parques Nacionales, la frontera y los servicios. Aquí el comercio, la gestión política (periférica) y hasta cierta arquitectura incipiente, revelan un continuo que convive con la heterogeneidad ecológica propia del 'sotavento' andino patagónico ${ }^{252}$.

\section{Referencias bibliográficas}

- Albet i Mas, Abel. ¿Regiones singulares y regiones sin lugares?. Reconsiderando el estudio de lo regional y lo local en el contexto de la Geografía Postmoderna. Boletín de la A. G. E. N 32. 2001. (pp. 35-52).

- Bandieri, Susana. (a) Historia de la Patagonia. Editorial Sudamericana. Buenos Aires 2005. (445 p.).

- Bercovich, Patricia y Luis Irrisarri. Geografía General de la Patagonia. Situación Ambiental. En Godoy Manriquez, Carlos (director) El Gran libro de la Patagonia Argentina. Ed. Planeta, Buenos Aires. (1998). (pp. 221-404, Segunda Parte).

- Bondel, C. Santiago. El extremo Sur de la Patagonia. Su ámbito natural. Editorial Universitaria de la Patagonia. Comodoro Rivadavia, 2000. (50 p.)

- Bondel, Santiago. Geografías en la Patagonia. Diario El Patagónico. Suplemento: Regionales. Comodoro Rivadavia. 27/08/1994.

- Capitanelli, Ricardo.: Patagonia: un medio duro, con focos pioneros y grandes posibilidades. En, Juan Roccatagliata (coordinador) La Argentina. Geografía general y los marcos regionales. Ed. Planeta, Buenos Aires, 1988 y ed. siguientes.

- Cóccaro, José M. La voz del territorio: el desafío de escucharla. En Reflexiones Geográficas. Agrupación de Docentes Interuniversitarios de Geografía. Río Cuarto, Argentina. 2002. (pp. 193-198).

- Cox, Guillermo. Viaje en las Rejiones (sic) septentrionales de la Patagonia (1862-1863). Ed. Elefante Blanco. Santiago de Chile y Buenos Aires. 1999. (293p.).

- Daus, Federico. Fundamentos para una división regional de la Argentina. Sociedad Argentina de Estudios Geográficos. Serie: Aportes al pensamiento geográfico №1. Buenos Aires 1982. (pp. 7-26).

- De Jong, Gerardo (coord.), A. Kahanowikz, A. Dick y S. Gigante). En Chiozza, Elena. El país de los argentinos. (Patagonia). Centro Editor de América Latina, Buenos Aires. 1978. (pp. 73-120). Fascículos: La configuración espacial y Los paisajes.

- De Lasa, Luis. Historia ambiental. Sociedades humanas y transformaciones ambientales en la Patagonia (1500-1900). En Godoy Manríquez, Carlos (director) El Gran libro de la Patagonia Argentina. Ed. Planeta, Buenos Aires. 1998. (Cuarta Parte, pp. 595-676)

- Ecología Austral. Ecosistemas Patagónicos. Publicación de la Asociación Argentina de ecología. Volumen 8, № 2. Buenos Aires. 1998.

\footnotetext{
${ }^{252}$ La disposición en sentido Noroeste-Sudeste de los Andes fueguinos y el ser un meridiano el demarcatorio del límite internacional con Chile, dejan al Departamento Ushuaia como excepción de sotavento. Como se sabe, para los argentinos, la capital fueguina es su única ciudad trasandina.
} 
- Finkelstein, Débora y María M. Novella. Poblamiento del Noroeste del Chubut. Aportes para su historia. Fundación Ameghino. Esquel, Chubut. 2005. (181 p.)

- Gurevitz, Nélida y Héctor Álvarez. Territorio patagónico: enfoque para una metodología regional. En Geografía del Chubut. Sociedad Argentina de Estudios Geográficos. Serie especial $\mathrm{N}^{\circ}$ 6. Buenos Aires, 1978. (pp. 155-183).

- Del Valle, Héctor. Patagonian Soils: a regional synthesis. En la Rev. de la Asociación Argentina de Ecología: Rev. Ecología Austral 8: 103-123. Buenos Aires, 1998. (pp. 103-123)

- Kirk, William. Problemas de la Geografía (1963). En Randle, P. (editor), Teoría de la Geografía.. Oikos-GAEA. Buenos Aires. 1984. (pp.306-328).

- Labasse, Jean. La organización del espacio. Ed. Ariel. Barcelona. 1973 (739 p.)

- Musters, George Ch.. Vida entre los Patagones. Ed. Solar-Hachete. Buenos Aires. 1964 ( $1^{\circ}$ Ed. 1871). (437 p.).

- Paruelo, José, Esteban Jobbágy y Osvaldo Sala. The climate of Patagonia: general patterns and controls on biotic processes. En la Rev. de la Asociación Argentina de Ecología: Rev. Ecología Austral 8:85-101. Buenos Aires. 1998.

- Rey Balmaceda, Raúl. Geografía Regional. Teoría y aplicación. Editorial Estrada. Buenos Aires. 1977 ( $2^{\circ}$ ed.). (190p.).

- Roccatagliata, Juan. Regionalización. En Juan Roccatagliata (coordinador), "La Argentina. Geografía general y los marcos regionales". Ed. Planeta, Buenos Aires, 1988 y ed. siguientes. (pp. 423-442) Referencias bibliográficas.

- Schlichter, Tomás y Pablo Laclau. Ecotono estepa-bosque y plantaciones forestales en la Patagonia norte. Rev. Ecología Austral 8: 285-296. Buenos Aires. 1998.

- Willis, Bailley. El Norte de la Patagonia. Tomo I. Ministerio de Obras Públicas (Arg.). Bs.As., 1914. Reedición EUDEBA, 1988.

\section{Apéndice 3:}

\section{Patagonia Andina de los lagos.}

Limites adoptados, algún detalle.

Hacia el Oeste, se presenta el único límite que no admite discusión para este planteo; es el internacional con Chile, donde huelga reiterar sobre la existencia de aspectos unitarios a uno y otro lado fronterizo, incluso con modalidades novedosas derivadas de un contexto de distención geopolítica latinoamericana.

Hacia el Norte, se reconoce como límite a la cuenca del Aluminé y su entorno. Es decir con el ámbito llamado de los Andes de Transición. Del Moquehue hacia el Norte nos encontramos con la Patagonia de la trashumancia, de los Andes más elevados, semiáridos, con una red hidrográfica más 'austera' que hacia el Sur; con bosques de araucarias pero sin encadenamientos lacustres. Aún así, el límite no es por contraste y se diría que una amplia faja del Norte departamental de Aluminé forma parte de un límite por transfiguración.

Hacia el Sur, justamente se ha considerado al reborde Sur del Departamento Languineo en Chubut. Coincide aquí que, en territorio argentino desde el lago Vintter hacia el Sur, tanto las condiciones fisiográficas como las modalidades de la instalación humana cambian sustancialmente. Ya sin el ciprés (Austrocedrus chilensis), especie emblemática de la

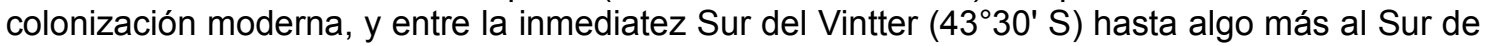
Los Antiguos (46 $30^{\prime} \mathrm{S}$ ), con la excepción de la cuenca Fontana-La Plata, la cordillera propiamente dicha, se desarrolla casi con exclusividad en territorio chileno, predominando en nuestro sector de altas pampas, pequeñas localidades sumamente dispersas y apenas articuladas con el resto de la región patagónica.

Hacia el Este, adoptamos para la ocasión y a sabiendas de su temporalidad relativa: - en Neuquén, los rebordes departamentales, donde la clásica fisonomía andina boscosa desaparece, reemplazada por la estepa graminosa-arbustiva instalada en antiguos remanentes montañosos y volcánicos. - en Río Negro y Chubut, el límite Este de la Zona de Frontera en Río 
Negro (Decreto 887/94) entre Paso Flores sobre el río Limay y la intersección con el límite del Departamento Languineo; involucra a las pequeñas localidades esteparias de Pilcaniyeu y Ñorquinco, en coincidencia con la ex Ruta Nacional 40 y es hasta donde se mantienen varias modalidades andinas.

\section{Apéndice 4:}

\section{La franja andina, entre lo general y lo singular.}

Con extremos Sur y Norte en los lagos Vintter en Chubut y Aluminé-Moquehue respectivamente, y en un contexto ecuménico periférico de escasa población, la geografía física zonal rescata condiciones naturales que han sido concluyentes en cuanto del verdadero potencial respecto de las formas de ocupación del espacio, al menos en términos socioeconómicos. Sucede que a pesar de cierta sobrevaloración positiva generalizada para con las condiciones geo-ambientales existentes desde el mismo arranque de la colonización moderna, estas condiciones han sido menos 'amigables' que las sospechadas para las formas de asentamiento establecidos. A un clima regional y un soporte geomorfológico bastante desfavorables a los modos tradicionales de colonización agro-pastoril y sus instancias productivas, en particular en lo agrícola, se agregó, en el país de pampas fértiles, una posición geográfica excéntrica con sus consecuentes resultados económicos. Es fácil comprobar que ya desde un principio, sólo el turismo y alguna actividad excepcional tendieron a alterar esta situación (cf. Eriksen, W., 1979).

Aún así, Daus en su cruda, y en general resistida reflexión sobre el conjunto de la Patagonia como región atrasada ${ }^{253}$, jerarquiza a los valles andinos como excepciones (1976: 169-75); pero a la vez remarca la condición de tratarse de comarcas muy precisamente delimitadas. Circunstancia clave para no caer a engaño ya que, basta apartarse un poco de ciertos parámetros naturales propicios, para encontrarnos con ambientes 'hostiles' al asentamiento tradicional.

Pues bien, desde el inicio es fundamental valorar la posición hemisférica de la franja andino patagónica en la que está inserta la Comarca. La misma, se extiende linealmente y en sentido meridiano, por más de $550 \mathrm{~km}$ (entre los $39^{\circ}$ y $44^{\circ}$ Sur). Por otra parte y si mantenemos la unidad fisiográfica por sobre la frontera internacional, el borde Occidental se corresponde con el piedemonte cordillerano Oeste con lagos cerrados por colosales arcos morénicos en el Gran Valle Central-Austral chileno y su continuidad hacia el Sur en el litoral marítimo de los grandes Golfos de Ancud y Corcovado; hacia el Este, en cambio, es en la transición desde el ambiente subandino donde se aprecia un borde, también contrastante, asociado con los sistemas orientales más áridos de los Andes ${ }^{254}$. Estos 'limites' revelan las condiciones propias de la componente climática de latitudes medias hemisféricas, donde a la circulación de los Vientos Permanentes del Oeste (Westerlies), se le añade el despliegue de la cordillera andina.

Cordillera de morfología fuertemente quebrada (joven), con alturas regulares del orden de los 2000-2300 m.s.n.m.; cada tanto atravesada transversalmente por profundos valles, con un sistema hídrico complejo de ríos y lagos, con la presencia progresiva hacia el Sur de glaciares de circo y remanentes y, además, un importante número de volcanes con cimas entre los 2500 y 3500m.s.n.m.. Se trata de sistemas montañosos abruptos con un modelado glaciario retrabajado por la actual red de avenamiento y donde, desde el punto de vista de la instalación humana se destacan las planicies glacifluviales, fluvioglaciarias y terrazas aluviales pedregosas como sitios preferenciales. Tal es el caso de San Carlos de Bariloche, San Martín de los Andes, Esquel o El Bolsón.

Circunscribiéndonos nuevamente al sector argentino, de Norte a Sur se manifiestan progresivos cambios florísticos propios del efecto latitudinal, en especial la gradual disminución del treeline (de los $1800 \mathrm{msnm}$ al Norte hasta aproximadamente los $1300 \mathrm{msnm}$ en el entorno del Vintter $)^{255}$ y de la transición hacia ámbitos subhúmedos hacia el Norte.

\footnotetext{
${ }^{253}$ La condición de atraso y postergación patagónica, ha sido una temática instalada en el debate territorial nacional a lo largo de todo el siglo XX

${ }^{254}$ Dada su coincidencia con las últimas estribaciones cordilleranas, goza de aceptación considerar a las isoyetas entre 400 y $500 \mathrm{~mm}$ como límite oriental del ámbito natural andino (Eriksen, 1975:130). Aún así, ya desde los $41^{\circ} 30^{\prime} \mathrm{S}$. cabe especular que resulta importante el incremento de la influencia marítima producto de las profundas entradas de las aguas pacíficas al Este de la gran isla de Chiloé y que se traduciría, por un lado en el desarrollo pleno de la Selva Valdiviana, a la vez que en un destacado incremento de superficies englazadas por encima de los $1700 \mathrm{msnm}$.
} 
De Oeste a Este, como ya se indicó en varias oportunidades, se transita del ámbito netamente cordillerano, híper-húmedo y boscoso, hasta la estepa graminosa-arbustiva y arbustiva, desarrollada sobre los Patagónides y las altas y ventosas planicies del Oeste Extra-andino. Transición análoga a la que Pisano llama degeneración esteparia para los ámbitos magallánicos (1981: 166-67) y que confirma Villalba, "... Las precipitaciones disminuyen desde los 4000 - 6000 en el sector occidental hasta menos de $200 \mathrm{~mm}$, tan sólo a $100 \mathrm{~km}$ al este de la cima de los Andes" (2003) ${ }^{256}$. En definitiva, en apenas decenas de kilómetros, se pasa del bosque a la estepa; del ambiente húmedo a la aridez y de los sistemas de lagos a unos pocos ríos alóctonos y arroyos intermitentes ${ }^{257}$.

A todas estas 'coordenadas' iniciales, le cabe la consideración geográfica especial de constituir un conjunto donde desde el punto de vista de la relación hombre-naturaleza, lo riguroso, desapacible o duro, como diría Capitanelli (1988: 687), se conjuga en un escenario de valorada belleza. Se agrupan aquí, aquella fama de inhóspita y hostil que cupo a la Patagonia desde su inscripción en la historia, con esta otra propia de lo majestuoso, bello, indómito y recóndito, resaltado ya desde las perspectivas románticas decimonónicas para los paisajes montanos y con recobrados bríos post modernos, muy en especial, desde la consolidación de los paradigmas contemplativos de la actividad turística, ...Look at the view!.

\section{Referencias bibliográficas:}

- Bran D., S. Rusak y J. Ayesa. Estructura de un matorral de ñire (nothofagus antarctica) y su regeneración inicial después de una tala, en el ecotono bosque - estepa. Instituto Nacional de Tecnología Agropecuaria (INTA), Centro Regional Patagonia Norte. Estación Experimental Agropecuaria Bariloche. San Carlos de Bariloche. 1998. 23p..

- Capitanelli, Ricardo.: Patagonia: un medio duro, con focos pioneros y grandes posibilidades. En, Juan Roccatagliata (coordinador) La Argentina. Geografía general y los marcos regionales. Ed. Planeta, Buenos Aires, 1988 y ed. siguientes.

- Daus, Federico. El 'subdesarrollo' Latinoamericano. El Ateneo ( $2^{\circ}$ edición), Buenos Aires, 1976. (201 p.).

- Eriksen, Wolfgang. Aspectos de la colonización agraria en la Patagonia. GAEA, Sociedad Argentina de Estudios Geográficos, Buenos Aires. 1979. (21p.).

- García, Celestina. El clima de Bariloche y sus alrededores. En Anales de la Sociedad Argentina de Estudios Geográficos (GAEA). Tomo XIV. Buenos Aires. 1970 (55-69).

- Mendía, Juan M., Irisarri, Jorge A. .Relevamiento de suelos con aptitud forestal en la región occidental de la provincia de Río Negro. Consejo federal de Inversiones (CFI). Buenos Aires. 1986.

- Pisano, Edmundo. Bosquejo fitogeográfico de Fuego-Patagonia. En Anales del Instituto de la Patagonia Vol. XII. . Punta Arenas-Santiago de Chile. 1981. (159-171).

- Veblen, Thomas T. y Diane C. Lorenz. Recent vegetation changes along the forest/steppe ecotone of northern Patagonia. Annals of the Association of American Geographers, 78 (1), 1988.

\footnotetext{
255 Villalba (2003) nos aclara respecto de la lenga (Nothofagus pumulio) y la franja altitudinal que ocupa: "... es bastante variable, dependiendo de la latitud considerada. Varía desde los 1000 a los $1700 \mathrm{~m}$ de altitud en la parte norte de su distribución, y desde el nivel del mar hasta los 700 - $800 \mathrm{~m}$ en su límite austral. En este espacio el fenotipo de la lenga es bastante variable, presentando características arbóreas en las partes más bajas, y disminuye gradualmente su altura hasta llegar a individuos enanos o achaparrados en el timberline o treeline. ... ".

${ }^{256}$ Ejemplos: con sólo 11' de diferencia de longitud $(\lambda)$ entre $S$. C. de Bariloche (ciudad) y su aeropuerto, la diferencia de la frecuencia media anual de heladas es de 81,5 a 103,1 respectivamente; en las precipitaciones de $1035 \mathrm{~mm}$. a $742 \mathrm{~mm}$. (García, 1970: 60). Al respecto y desde un abordaje más amplio de variables, resulta ilustrativo el índice de continentalidad que desarrollan Mendía e Irisarri para la faja andina nordpatagónica. Se aprecian, para el caso, valores crecientes de continentalidad (bajos por cierto), entre Bariloche, El Bolsón y Esquel (1986).

257 Si bien se trata de ámbitos contrastantes por la existencia o no de masa boscosa, el límite bosque-estepa en sí mismo es temporalmente dinámico y plantea un interés científico singular. Bran et al señalan, "... Existen evidencias que en diversos sectores ha habido un avance de la estepa sobre el bosque (Eriksen, 1975). Este fenómeno ha sido interpretado por Kalela (en Veblen y Lorenz, 1988), como consecuencia de una aridización general debido a cambios climáticos. Otros autores, entre ellos Veblen y Lorenz (1988), encuentran la causa de este "retroceso" de los bosques, en el accionar del hombre (principalmente incendios e introducción de ganado doméstico y fauna exótica). (...). Se resalta también la importancia de los ecotonos, considerados como las partes más sensibles de las interacciones en el paisaje debidas al accionar humano".
} 
- Villalba, Ricardo. Influencia de las Variaciones Climáticas en el Decaimiento de los Bosques del Norte de la Patagonia. Documento inédito del Proyecto: Influencia de los cambios climáticos en el decaimiento y mortalidad de los bosques de Nothofagus en el norte de la Patagonia, Argentina. INTA, Bariloche. 2003.

\section{Apéndice 5:}

\section{Inundaciones}

Diario La Nación. 16/10/2002

Pcias. Río Negro y Chubut

Al cierre de esta edición, 2093 personas permanecían evacuadas en Río Negro y Chubut. En la rionegrina Bariloche había 63 evacuados. A ellos se suman los 1880 que quedan fuera de su casa en El Bolsón, donde muchos barrios permanecen con servicios interrumpidos (gas, agua, electricidad). En Lago Puelo y El Hoyo, Chubut, donde los evacuados todavía sumaban 150, evaluaban ayer los daños a las producciones fruti-hortícolas, que se estiman cuantiosos. En las otras localidades más afectadas -Esquel, Trevelin y El Maitén- la situación estaba controlada.

El Bolsón. Octubre 2002.

Si bien en un principio se restringió el acceso desde la ciudad de Bariloche por derrumbes, éstos fueron removidos y en menos de 48 horas se encontraban transitables.

Afectaciones

Conforme a los relevamientos efectuados provisoriamente, se estima que el número de evacuados en el momento más crítico superó los 1.100 evacuados, más una proyección de aproximadamente 400 personas auto evacuadas. Este número de redujo en forma gradual, con lo que se efectuó la reagrupación estratégica de los evacuados a fin de optimizar la utilización de los recursos y facilitar su atención. En uno de los casos se efectuó la reubicación del centro de evacuados por advertirse presencia de roedores (alto riesgo de patologías asociadas en función de la época).

En el casco urbano se relevó un total de 289 viviendas afectadas seriamente en su estructura y algunas desaparecidas; no obstante se tiene conocimiento que la creciente aisló y llegó a un número de viviendas ampliamente superior. Asimismo, el desborde de letrinas (abundantes en los sectores mas afectados) y la rotura de desagües cloacales, generaron un cuadro sanitario adverso y de alto riesgo en extensos lugares de ambas riberas. Las autoridades sanitarias locales realizaron un a difusión extensiva de recomendaciones de higiene y salubridad orientadas a la crisis presente dirigida a los centros de evacuados y población en general. No se registraron brotes masivos de patologías asociadas a esta eventualidad.

Fuente:

http://aplicaciones.medioambiente.gov.ar/archivos/web/UCC/File/comunicaciones nacionales/Vulnerabil idad_Patagonia.pdf

\section{Apéndice 6:}

\section{Datos hidrográficos sugerentes.}

Un aporte importante donde se profundiza en el análisis de las cuencas hidrográficas andinas de Chubut cruzando aspectos naturales y sociales se puede encontrar en Carabelli et al (2000). A título demostrativo se señalan algunos valores trascendentes para el ámbito más representativo de la Comarca, esto es la cuenca del río Puelo. 


\begin{tabular}{lr} 
Parámetro & Valor \\
1. Superficie de la Cuenca en km2 & 3040 \\
2. Coeficiente de compacidad & 1,93 \\
3. Densidad de drenaje $\mathrm{km} / \mathrm{km} 2$ & 0,47 \\
4. Flujo no encauzado km & 0,24 \\
5. Pendiente media de laderas (\%) & 24,2 \\
6. Erosión hídrica potencial & 322 \\
(t/ha/año) & $(\mathrm{MA})$ \\
7. Erosión hídrica actual (t/ha/año) & $42(\mathrm{~m})$ \\
\multicolumn{2}{c}{ m: moderada; MA: muy alta } \\
Caracterización hídrica de la cuenca del río Puelo.
\end{tabular}

Fuente: Carabelli, et al. (2000:11)

Aclaraciones ilustrativas (ver en Carabelli et al 2000:9-11):

1. En el sector argentino la superficie es de $3040 \mathrm{~km} 2$

2. $C C=0,28 \mathrm{P} / \sqrt{ } \mathrm{A}$; relación entre el perímetro de la cuenca y el perímetro de un círculo de área equivalente. El valor 1 es de máximo riesgo de desbordamiento.

3. $\mathrm{DD}=\mathrm{L} / \mathrm{A}$; relación entre la longitud total de los cauces y el área de las cuencas. Valores por debajo de $4 \mathrm{~km} / \mathrm{km} 2$ revelan litologías más resistentes y una protección adicional de la vegetación.

4. $F N E=1 / 2 D D$, donde $\mathrm{DD}$ es densidad de drenaje. Es la distancia que debe recorrer el flujo antes de encausarse (las más activas en materia erosiva); lo normal es que el valor se aproxime a la $1 / 2$ de la distancia promedio de los cauces.

5. Rug = DD.RT; donde RT es el relieve total.

6. Para su cálculo intervienen los factores climático, edáfico y topográfico.

7. Se introduce el factor uso de la tierra.

\section{Referencia bibliográfica:}

- Carabelli, F., S. Antequera, G. Martí y M. Gómez. Análisis Ambiental y Social de las Cuencas Hidrográficas Cordilleranas de la Provincia del Chubut. CIEFAP, GTZ y Dirección General de Bosques y Parques. Documento Técnico N5., Esquel, Marzo,2000. 56p..

\section{Apéndice 7:}

\section{"Difícil de responder"}

Artículo en el Diario Piltriquitrón. Santiago Bondel, agosto del 2001

\section{El modo de vida de estos valles es un interrogante habitual y muy difícil de contestar con claridad} sin que en la explicación se pierdan cuestiones importantes.

Seguramente muchas veces los cordilleranos nos hemos visto en un aprieto ante las preguntas lisas y llanas sobre ¿de qué? y ¿cómo se vive por aquí?. De hecho y también más de una vez, la respuesta habrá empezado con comentarios sobre, '... el turismo familiar, cabañero, de la feria, la fruticultura, la 
madera, los artesanos, el comercio tradicional, el empleo público provincial, nacional o municipal, el 'cóctel' agrícola-ganadero, la venta de tierras, los trashumantes laborales, etc., etc.. En verdad, si queremos ser razonablemente precisos con el tema, no va a ser nada fácil.

Algunos indicadores pueden ser ilustrativos, por ejemplo ingresos directos por salarios desde los diferentes ámbitos externos (provincia y Nación) o las transferencias bancarias en general, pero se sabe también que hay en los modos de vida zonales una especie de 'underground' informal, una ensalada de vínculos y lazos, ricos en matices y de una trascendencia con 'aroma' saludable.

Los límites entre las actividades, es decir de lo específico, sea por ejemplo del comerciante, docente, agricultor o policía, tan claros en otras zonas del país, aquí son difusas, hasta se diría que más bien se acoplan unas con otras y que, además, no son fáciles de cuantificar. En un hogar pueden tener chanchos o abejas, con un miembro de la familia trabajando en un supermercado, otro docente y cada tanto el conjunto recolecta hongos, tranza con madera, dulces o algún servicio de la más diversa índole. Un 'urbano' de El Bolsón, así como puede dedicarse al comercio o a las artesanías, es posible que maneje una parcela para la saca de madera o viaje periódicamente a vender a otras ciudades de la región o el país. Y así la pluralidad.

Pero como se suele decir, depende con la lupa con que se mire. Así tenemos informes seriamente confeccionados que llegan a ser poco menos que hostiles en sus diagnósticos, como el reciente sobre turismo (VIP) encargado al CFI. Ante ello se nos ocurre que estos valles ofrecen más que un maquillaje como el que parecería que se recomendara para contentar la demanda. Es más, que la comarca sea una anomalía a la imagen 'deseada' del Sur, con sus lagos, bosques, montañas y "gente como uno", tendrá seguramente impacto negativo en la renta sectorial más o menos inmediata. Pero, como es tan visible en los Altos de Bariloche, la falta de diversidad, la mono dependencia (casi minera) del turismo exclusivo y lo cosmético en materia productiva, pueden resultar insalubre, por no decir letal, para ámbitos pequeños y alejados. Después de todo, con la crisis general de nuestra economía nacional, pareciera que con Villa La Angostura y San Martín de los Andes alcanza y sobra si es cosa de contentar a los más desahogados.

Habría mucha tela que cortar y estas no son más que consideraciones incompletas, pero para no aburrir al lector, le propongo que tome la revista "Clic" y sus clasificados, y verá que con unas pocas de sus 90 páginas van a encontrar argumentos atractivos ante aquellas preguntas iniciales, ¿de qué? y ¿cómo se vive aquí?

Apartando muchos rubros y a modo de pequeña muestra se tomaron los siguientes 20 avisos con sus asuntos que, vale decir, 'suenan' bien; por lo menos sugieren una comarca viva, problemática, pero de 'carne, hueso y sentires' ¿no le parece?

Ofrezco $1 \frac{1}{2}$ hectáreas en Golondrinas para pasturas o a talaje

$>$ Compro nueces limpias.

$>$ Permuto 3 hectáreas en Mallín Ahogado por auto.

$>$ Permuto bicicleta por salamandra.

> Permuto camioneta por tierra en la zona.

$>$ Permuto leña por computadora.

> Permuto tres gansas y un ganso por patos o pavos.

$>$ Permuto motosierra por montura.

> Permuto tractor con desmalezadora por cuatriciclo o 1 o 2 hectáreas.

> Cooperadora ofrece a la venta plantines de araucaria, roble pellín, pinos europeos, ...

$>\quad$ Vendo 25 ha. en Cochamó (Chile).

- Permuto casa en Capital por propiedad en El Bolsón.

> Vendo chacra 2 ha. en Golondrinas.

- Permuto lancha por casa prefabricada o tierra en la zona.

$>$ Fabrico muebles artesanales.

Dxcelente lechigada de shar-pei, 6 machos, padre campeón, abuelos campeones.

- Vendo casa en Trelew o permuto por tierra o casa en la zona.

$>$ Cambio toro Hereford por vaca lechera con ternero.

Se busca vocalista y bajista.

$>$ Centro naturista ofrece....

\section{Apéndice 8}

\section{Condicionamientos históricos y económicos.}

El cuadro que sigue reúne de modo esquemático los principales alcances de los desarrollos históricos y económicos de la Segunda Parte con la certeza de tener resuelto sólo algunos componentes mientras que otros todavía necesitarán de su profundización.

\section{Principales condicionamientos históricos y económicos en los usos del territorio} comarcal. Indicios a considerar. 


\begin{tabular}{|c|c|}
\hline CONDICIONAMIENTO & POSIBLE TRASCENDENCIA EN LOS USOS \\
\hline $\begin{array}{l}\text { Nomadismo ancestral y heterogeneidad } \\
\text { indígena } \rightarrow\end{array}$ & $\begin{array}{l}\text { - sin mayores 'resistencias' en materia de competencia } \\
\text { con la colonización; paradigmas diferentes. }\end{array}$ \\
\hline Ocupación violenta $\rightarrow$ & $\begin{array}{l}\text { - marginación de la población original (condiciones eco- } \\
\text { ambientales periféricas y de legalidad condicionada). }\end{array}$ \\
\hline $\begin{array}{l}\text { Frontera 'antecedente' y potencialmente } \\
\text { conflictiva } \rightarrow\end{array}$ & $\begin{array}{l}\text { - control político extra-regional; aporte económico; } \\
\text { generador de enclaves. }\end{array}$ \\
\hline Mosaico migratorio pos-conquista $\rightarrow$ & - 'mosaico' en los usos del espacio. \\
\hline Aislamiento geográfico $\rightarrow$ & $\begin{array}{l}\text { - a favor del autoabastecimiento y la consolidación de la } \\
\text { trama social; } \\
\text { - en contra de la integración regional-nacional y de la } \\
\text { expansión económica y cultural. }\end{array}$ \\
\hline Escaso peso demográfico $\rightarrow$ & $\begin{array}{l}\text { - a favor de una tendencia innovadora creciente; } \\
\text { - en contra de los beneficios de la economía de } \\
\text { aglomeración. }\end{array}$ \\
\hline $\begin{array}{l}\text { Excedentes agropecuarios y forestales de } \\
\text { escala zonal } \rightarrow\end{array}$ & $\begin{array}{l}\text { - posibilidades, aunque de escasa envergadura, de } \\
\text { acompañar situaciones de crisis (ambientales y políticas). }\end{array}$ \\
\hline Recursos económicos 'ausentistas' $\rightarrow$ & $\begin{array}{l}\text { - a favor, generación de inputs al sistema económico. } \\
\text { - en contra, dependencia estructural. }\end{array}$ \\
\hline $\begin{array}{l}\text { Valoración económica de la tierra fiscal de } \\
\text { base casi exclusivamente física } \rightarrow\end{array}$ & $\begin{array}{l}\text { - exclusión de los aspectos culturales y socioeconómicos } \\
\text { internos de proyección política voluntarista. }\end{array}$ \\
\hline Sobrevalorización predial por moda $\rightarrow$ & $\begin{array}{l}\text { - exclusión del acceso a la propiedad de una amplia } \\
\text { franja de población local. }\end{array}$ \\
\hline Rururbanización creciente $\rightarrow$ & $\begin{array}{l}\text { - a favor: potencial mejoramiento en indicadores clásicos } \\
\text { de calidad de vida. } \\
\text { - en contra: sobreparcelamiento; encarecimiento del } \\
\text { gasto público por dispersión. }\end{array}$ \\
\hline Especulación inmobiliaria. $\rightarrow$ & $\begin{array}{l}\text { - a favor: generación de inputs al sistema económico; } \\
\text { potenciación del ahorro. } \\
\text { - en contra: debilitamiento de capacidad de 'soporte } \\
\text { ambiental'; sobreparcelamiento y acaparamiento. }\end{array}$ \\
\hline Excentricidad económica $\rightarrow$ & $\begin{array}{l}\text { - a favor: destino turístico buscado. } \\
\text { - en contra: marginación económica y de gestión. }\end{array}$ \\
\hline
\end{tabular}

Fuente: elaboración propia como síntesis del desarrollo de la Segunda Parte de esta tesis.

\section{Apéndice 9.}

\section{Nacidos y criados.}

\section{Nyc y Vyq.}

El perfil social y cultural patagónico presenta una figura de relación comunitaria propia de los lugares con una dinámica demográfica altamente activa y que se refiere a aquella que ocurre entre los nacidos y criados (receptivos) con los venidos y quedados (arribados). Aquí 
interesan las modalidades propias del contacto, modos variados con distintos resultados, dependiendo tanto del tipo de migrante (espontáneo, transferido, momentáneo, permanente, etc.) como del tipo y magnitudes relativas a la población receptiva.

La figura de pioneer patagónico y su legitimación social frente a otras modalidades descalificadas sotto voce -, incluso janteriores o coetáneas!, es un buen antecedente relativamente moderno que ofrece distinciones inmediatas en los llamados frentes pioneros. Hoy sin un actual 'prototipo' reconocido, las distinciones son más ambiguas y con ello el panorama menos claro para la reconstrucción sistemática.

La condición de nacidos y criados y venidos y quedados, sin alcanzar a manifestar tensiones de alta conflictividad social, surgen a modo de complemento identitario y muchas veces es valorizada en situaciones comunitarias puntuales. Se diría que estas cualidades, son utilizadas como rasgo garante de mayor genuinidad.

Cabe agregar que en distintos sectores de la Patagonia Andina, la tirantez "nyc-vyq" se verifica históricamente con los diferentes pulsos migratorios, pero circunscripta a circunstancias localmente especiales. Se rescata del Plan de Desarrollo de Trevelin (2006), "La tensión "nyc" y "vyq" (...) a pesar de que se ha manifestado históricamente en diversos espacios sociales de la localidad, tiende a diluirse y a equilibrarse en la representatividad de "nycs" y "vyqs" en espacios públicos, sociales, culturales, etc. Sin embargo, en una proyección al futuro, la tensión puede profundizarse ante el crecimiento no vegetativo de la población, sobre todo en el caso de explosiones demográficas tales como las que se verificaron en comunidades patagónicas eminentemente turísticas.

Se toma del mismo informe por su validez regional y con adaptaciones para cada comarca, "... ni el grupo "nyc" ni el grupo "vyq" son enteramente homogéneos. Dentro del grupo "vyq" existen personas que se radicaron en la localidad en distintas épocas, con las características respectivas de cada migración. A su vez la inserción de los "vyqs" en el tejido social (...) depende de su integración en núcleos laborales, su participación en actividades culturales y sociales, etc.".

Cabría agregar en estas diferenciaciones poblacionales y a los fines de hacer más abarcativas a las matrices ( 1 y 2 ) y también por su fuerte impacto territorial, más que por su número, a aquellos pobladores de carácter diríase, circunstancial y que actúan mayormente como exploradores, sin mayores expectativas iniciales de arraigo. Siguiendo las simbología, los llamamos "venidos y fluctuantes, vyf" y el rasgo distintivo uniría la exploración (de espacios y de modos de vida) con una manifiesta inestabilidad operativa en materia jurídica y económica. 